Pacific Northwest

National Laboratory

Operated by Battelle for the

US. Deparment of Energy

\section{Theoretical, Methodological, and Empirical Approaches to Costs Savings: A Compendium}

Edited by:

M.R. Weimar

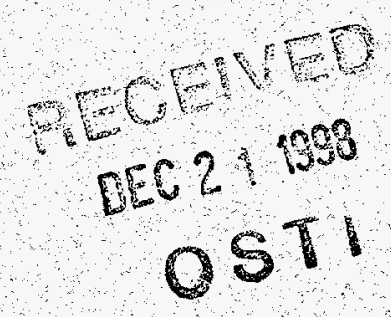

December 1998

Prepared for the U.S. Department of Energy under Contract DE-ACO6-76RLO 1830 


\title{
DISCLAIMER
}

This report was prepared as an account of work sponsored by an agency of the United States Government. Neither the United States Government nor any agency thereof, nor Battelle Memorial Institute, nor any of their employees, makes any warranty, express or implied, or assumes any legal liability or responsibility for the accuracy, completeness, or usefulness of any information, apparatus, product, or process disclosed, or represents that its use would not infringe privately owned rights. Reference herein to any specific commercial product; process, or service by trade name, trademark, manufacturer, or otherwise does not necessarily constitute or imply its endorsement, recommendation, or favoring by the United States Government or any agency thereof, or Battelle Memorial Institute. The views and opinions of authors expressed herein do not necessarily state or reflect those of the United States Government or any agency thereof.

\author{
PACIFIC NORTHWEST NATIONAL LABORATORY \\ operated by \\ BATTELLE \\ for the \\ UNITED STATES DEPARTMENT OF ENERGY \\ under Contract DE-AC06-76RLO 1830
}

\author{
Printed in the United States of America \\ Ayailable to DOE and DOE contractors from the \\ Office of Scientific and Technical Information, P.O. Box 62, Oak Ridge, TN 37831; \\ prices available from (615) $576-8401$.
}

Available to the public from the National Technical Information Service, U.S. Department of Commerce, 5285 Port Royal Rd., Springfield, VA 22161

This document was printed on recycled paper. 


\section{DISCLAIMER}

Portions of this document may be illegible in electronic image products. Images are produced from the best available original document. 


\section{Theoretical, Methodological, and Empirical Approaches to Costs Savings: A Compendium}

Edited by:

M.R. Weimar

December 1998

Prepared for

the U.S. Department of Energy

Under Contract DE-AC06-76RLO 1830

Pacific Northwest National Laboratory

Richland, Washington 99352 



\section{Contents}

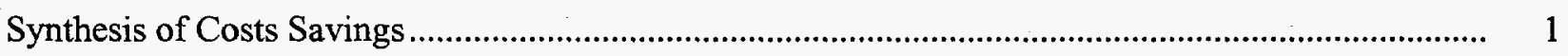

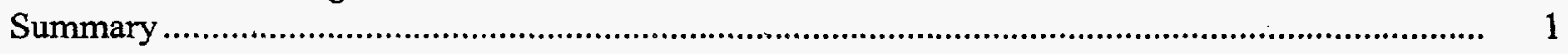

Cost Comparisons with Alternative M\&O Approaches ............................................................................. 3

Comparing the Privatized Approach with the $\mathrm{M} \& \mathrm{O}$.................................................................... 3

DOE-RL M\&O Estimate .................................................................................................... 5

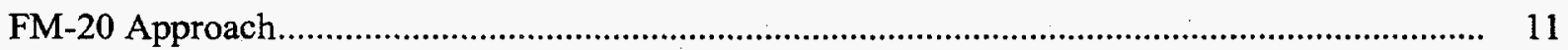

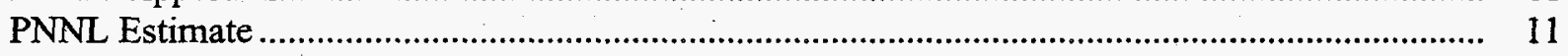

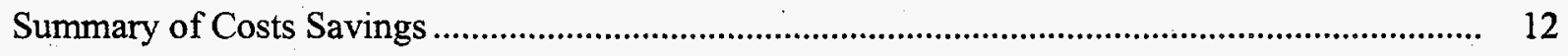

Comparison of Other Historical Costs .......................................................................................... 14

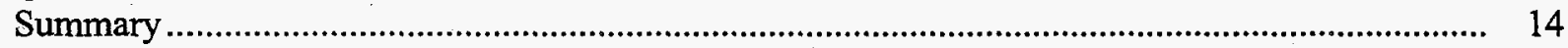

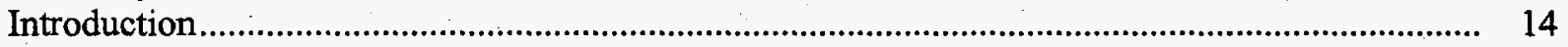

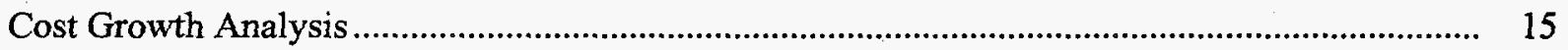

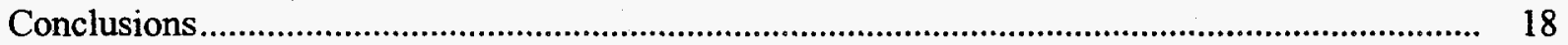

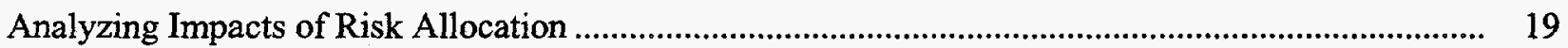

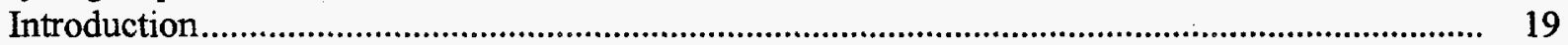

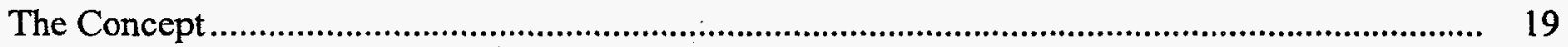

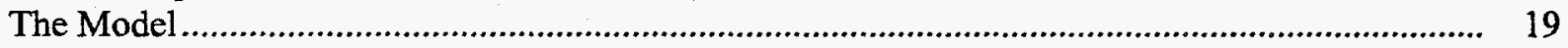

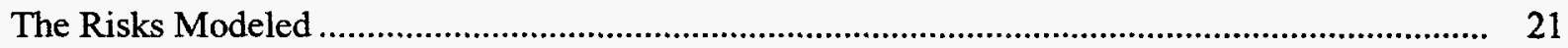

Analysis Results............................................................................................................. 22

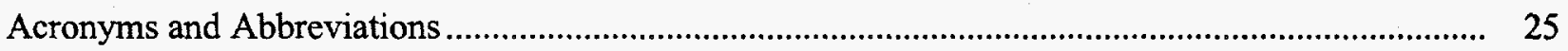

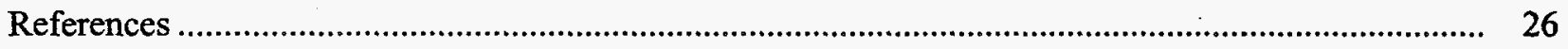

Appendix A DOE Cost-Savings From Private Contracting? ……..................................................... A-1

Appendix B Methodology for Assessment of Cost Savings Under TWRS Privatization ........................ B-1

Appendix C The TWRS Economic Assessment Model ................................................................... C-1

Appendix D Development of the DOE Cost Estimate that Compares Cost Reimbursable to Fixed Price Workscope for the Tank Waste Remediation System Privatization ............................. D-1

Appendix E Comparison of Cost Growth and Waste Remediation Costs

at Savannah River and West Valley .......................................................................................... E-1

Appendix F Price Reasonableness and Cost Savings Risk Allocation Modeling and Analysis............... F-1 


\section{Figures}

1 "Theoretical" Total Risk Allocation Curve-Complex Technical Activity.................................... 20

2 Government Costs as Risks Are Allocated Between the M\&O and Private Contractor.................. 23

3 Total Cost Increase Uncertainty ............................................................................................. 24

\section{Tables}

1 Estimated Costs for a Cost-Reimbursable Contractor to Perform Phase I of TWRS Privatization.. 10

2 Summary of Estimated Cost Savings from the Phase I Contract..................................................... 13

3 Analytical Results for the Defense Waste Processing Facility and the West Valley Demonstration Project ................................................................................ 16

4 Normalized HLW Vitrification Program Costs ...................................................................... 17

5 BNFL Risk-Allocation Modeling: Preferred Risk Allocation for the BNFL Enhanced Case ......... 23 


\section{Synthesis of Cost Savings}

\section{Summary}

This publication summarizes and contains the original documentation for understanding why the U.S. Department of Energy's (DOE's) privatization approach provides cost savings and the different approaches that could be used in calculating cost savings for the Tank Waste Remediation System (TWRS) Phase I contract. The initial section summarizes the approaches in the different papers. The appendices are the individual source papers which have been reviewed by individuals outside of the Pacific Northwest National Laboratory and the TWRS Program. Appendix A provides a theoretical basis for and estimate of the level of savings that can be obtained from a fixed-priced contract with performance risk maintained by the contractor. Appendix B provides the methodology for determining cost savings when comparing a fixed-priced contractor with a Management and Operations (M\&O) contractor (cost-plus contractor). Appendix $\mathrm{C}$ summarizes the economic model used to calculate cost savings and provides hypothetical output from preliminary calculations. Appendix $D$ provides the summary of the approach for the DOE-Richland Operations Office (RL) estimate of the M\&O contractor to perform the same work as BNFL Inc. Appendix E contains information on cost growth and per metric ton of glass costs for high-level waste at two other DOE sites, West Valley and Savannah River. Appendix $\mathrm{F}$ addresses a risk allocation analysis of the BNFL proposal that indicates that the current approach is still better than the alternative.

\section{Theoretical Implications}

A theoretical approach as discussed in Appendix A was undertaken to analyze the difference and establish a theoretical basis between fixed-price contracting and cost-plus contracting. A cost-benefit analysis implies that the gains from recontracting will depend positively on competitive pressures to reduce cost overruns and sole-source profit margins, and depend negatively on the potential risk premiums required by contractors for risk-bearing under an incentives contracting regime. A conservative cost-savings projection is made using a sample of 13 of DOE's Environmental Management (DOE-EM) cost-plus projects completed between 1980 and 1996, and 49 World Bank fixed-price projects completed between 1971 and 1990 . The theoretical study projects cost savings of between 10 to $30 \%$ relative to using costplus $\mathrm{M} \& \mathrm{O}$ contracting. The absence of sufficient risk premium and risk-sharing information precludes making more accurate quantitative projections.

The absence of competition in DOE's nuclear cleanup program resulted in M\&O contractors failing to minimize project costs. Project costs could be reduced by allowing private contractors to compete for the right to perform cleanup projects under incentive contracts. The effort to determine cost savings for the study concerns the use of these contracting instruments in DOE-EM activities, which are currently carried out by $\mathrm{M} \& \mathrm{O}$ contractors on a cost-plus basis. As envisioned, DOE's "privatization" effort calls for recontracting its nuclear cleanup projects with fixed-price terms based on competitive bidding among private contractors.

Awarding cleanup contracts through competitive bidding increases economic efficiency by imposing incentives to reduce abnormally high profit margins and minimize schedule delays and cost overruns. Conversely, the current bureaucratic cost-plus contracts stimulate higher profit margins while offering no meaningful incentives for sole source contractors to select cost-minimizing production and management approaches. Comparing the two extremes, the present study argues that private contractors are unlikely to agree to fixed-pricing because of the significant cost and managerial uncertainties involved in the privatization of DOE's large-scale, pioneer cleanup projects. More likely, successful privatization 
contracting under cost-uncertainty will include both fixed-price and cost-plus elements. Ultimately however, the limitations of noisy data should not detract attention from the real issue at hand-that DOE's cost-plus M\&O contracts leave much to be desired by way of meeting scheduled deadlines and minimizing project costs. Given the extent of DOE's cost-plus overruns, there is ample room for costsavings from private contracting. The mere fact that incentive contracting can help discipline bureaucratic errors makes for a chance worth taking. 


\section{Cost Comparisons with Alternative M\&O Approaches}

Two approaches were taken to determine cost savings under the performance-based (privatization) contract contemplated for the TWRS tank waste vitrification project because no official Management and Operations (M\&O) estimate for a phased approach existed. The two approaches included 1) three alternatives to estimating the costs under an $\mathrm{M} \& \mathrm{O}$ approach, and 2) cost analysis using a risk-allocation approach.

At the outset, it should be clearly stated that, for any specific large project, it is very difficult to confidently predict the exact or actual level of savings that would stem from the choice of a privatization approach against a traditional M\&O. As one report prepared for this study concluded, "the only way to determine the true difference between an $\mathrm{M} \& \mathrm{O}$ cost and a privatized cost would be to perform the TWRS project both as $\mathrm{M} \& \mathrm{O}$ project and as privatization project, which is obviously not feasible" (Burns and Roe 1998).

\section{Approaches for Estimating M\&O Costs}

Three general approaches were pursued to estimate the cost of the program under an M\&O-type contractor. The first approach is to employ a cost estimate as prepared by an actual M\&O contractor seeking to perform the work. For TWRS, Westinghouse Hanford Company (WHC) prepared such an estimate in 1994 that is called the TWRS FY 1995 Baseline (WHC 1994). This estimate was modified to match the scope in BNFL's Contract as discussed in Appendix D. The second and third approaches are more conceptual in nature, but better conform to the technical specifications of the private contractor bid. In this approach as discussed in Appendices A, B, and C, the private contractor's engineering costs ("hard costs") are transformed to provide an estimate of what an M\&O might cost. Two groups developed estimates based on this approach: 1) DOE's Office of Field Management (FM-20), and 2) Pacific Northwest National Laboratory (PNNL). The last approach, as discussed in Appendix F, compares costs of completing work through a risk analysis framework. The privatized approach allocates performance risk to the contractor and most other risks to the government. With the M\&O approach, generally all risks are allocated to the government.

\section{Comparing the Privatized Approach with the M\&O}

As discussed in Appendixes B and C, to make a valid economic comparison using the first three approaches, the government's cost evaluation between the privatization approach and an M\&O approach must consider three major elements: 1) government cost of finance, 2) incentives and the tendency for cost growth, and 3 ) federal taxes. This section discusses the adjustments that must be completed to make a valid comparison.

\section{Government Cost of Finance and Discounting}

Under TWRS privatization, the private contractor will acquire its own financing (e.g., debt or equity) to construct the vitrification plant. This mechanism ensures that the government will pay for waste processing only as it is delivered. Under an M\&O approach, the government will pay for construction of the vitrification plant and waste processing on a pay-as-you-go basis. These alternative approaches thus produce quite different time profiles of expenditures by the federal government. The financing costs associated with the privatization are clearly embodied in the per-unit prices the contractor must charge to recover the cost of the vitrification plant as well as annual operating expenses. The financing cost under the $\mathrm{M} \& \mathrm{O}$ approach is not inherent, because no explicit interest charges must be budgeted by DOE. 
The Office of Management and Budget (OMB), however, recognizes the implicit governmental cost of funds in its guidance on how to perform a cost-effectiveness analysis of alternative programs. By discounting projected expenditure streams of alternative projects to a present value, one can effectively incorporate the government's cost of funds. This is accomplished by simply using the government cost of funds as the discount rate. In its January 1998 guidance, OMB prescribed a discount rate of 3.8\% (real) for the evaluation of long-term projects.

Although the computation of present value represents one means of comparing the privatization and $\mathrm{M} \& \mathrm{O}$ costs, it is not the only means. Given that the $\mathrm{M} \& \mathrm{O}$ and private contractor would perform waste processing over the same time period, one can also compare the total (constant-dollar) costs over that period. To perform the comparison in this manner, one assumes that under the M\&O approach, the government finances the construction cost of the plant and then retires the accumulated debt (via tax revenues) over the operating period of the plant. In this case, the cost of the plant is amortized over its operating period using the OMB interest rate of $3.8 \%$ per year. Either method, present value or simple summation of constant-dollar costs, produces the same relative measure of cost savings between the two approaches. Because the sum of constant-dollar costs relates more easily to the budgeting process, this metric will be used.

\section{Cost Growth: M\&O Versus Privatized Approach}

Based on historical experience, private contracting, through fixed-price contracting arrangements will generally lead to lower project costs to the government in comparison to the traditional cost-reimbursable contracts used by $M \& O$ contractors. In simplest terms, $M \& O$ contractors behave as "cost-plus monopolies"- -their revenues reflect cost reimbursements plus predetermined profit margins proportional to project budgets. Consequently, M\&O profit margins, though low in percentage terms, are protected from competition by bureaucratic insularity. This also has the effect of offering no incentives for M\&O contractors to select cost-minimizing production and management approaches. On the other hand, the use of fixed pricing promotes a maximal incentive to minimize schedule delays and cost overruns.

The cost savings from a privatization approach ultimately depend on two key factors. The first is the predicted extent to which the $\mathrm{M} \& \mathrm{O}$ will overrun the initial cost estimate, given the lack of incentives just discussed. It should be recognized, however, that the initial cost estimate from the M\&O would generally be lower than that supplied by the privatization contractor. As discussed in Appendix A, the privatization contractor must incorporate this second factor, the required premium associated with absorbing the project's cost and technical risk, into its fixed-price bid. These risk premiums would be reflected in the competitive bidding process. Although premiums may be large in light of normal contingency factors, as shown in initial M\&O project cost estimates, the extent of DOE's previous cost-plus overruns and schedule deviations suggest opportunity for cost savings from private contracting even with these premiums.

The previous discussion suggests that one key factor to be considered in defining an M\&O project cost would be to apply cost-growth factors-developed on the basis of prior experience in comparable projects - to the initial cost estimates as developed by an M\&O. For a scope and technical approach comparable to Phase I, Part B of TWRS, no independent M\&O estimate is available. As an approximation, however, the engineering and construction costs ("hard costs") provided by the privatization contractor can be employed. The cost-growth factors are applied to these estimates to arrive at a total estimated cost for an M\&O. This cost can then be compared to the total price bid by the privatization contractor. The extent of the cost savings will thus depend on the two countervailing

\footnotetext{
${ }^{1}$ A fixed percentage fee of about $3 \%$ is added to these costs to reflect the fee pool available to an M\&O.
} 
factors: 1) magnitude of the cost-growth factors assigned to the $\mathrm{M} \& \mathrm{O}$ versus 2) financing and risk premium costs that are built into the private contractor's price.

\section{Federal Taxes}

In comparison to an $\mathrm{M} \& \mathrm{O}$ contractor, a contractor operating under a fixed-price contract will generally generate a higher level of profits. As mentioned earlier, the greater level of profits compensates for the higher level of risk assumed by the private contractor. However, the higher level of expected profits will likely generate more tax payments.

An appropriate economic comparison of public costs for the tank cleanup should take account of these tax revenues and compute the program cost net of federal taxes. Like the governmental financing cost, this adjustment does not affect the level of DOE budgets.

\section{DOE-RL M\&O Estimate}

DOE's traditional contracting approach for the type of work to be performed in Phase I, Part B would be the use of a cost-reimbursement contract. In this section, DOE's estimate of the cost of having the Phase I, Part B scope performed under a cost-reimbursement type contract (e.g., the Hanford Site $\mathrm{M} \& \mathrm{O} / \mathrm{M} \& \mathrm{I}$ [Management and Integration] contract) is presented.

\section{Basis for the Cost-Reimbursable Contractor}

The cost estimate discussed in this section is intended to provide an indication of the estimate that DOE would receive from a cost-reimbursable contractor for the performance of the Phase I Scope of Work. This estimate is not intended to reflect data that would be submitted in a construction project data sheets (PDSs). If the cost-reimbursable contractor were to proceed with the Phase I Scope of Work, DOE would request and fund the Hanford Site M\&I Contractor to develop a cost estimate and prepare a construction PDS.

\section{Comparability}

In developing the cost estimate for a cost-reimbursable contractor, DOE attempted to ensure comparability with the scope of the privatization contractors by basing the scope on the privatization contracts approach when feasible.

Technical descriptions of the processes that would be used by a cost-reimbursable contractor to accomplish this scope were prepared, and the summary of this approach is discussed in Appendix D. In a number of instances, the technical approach was based on a study entitled Tank Waste Remediation System Facility Configuration Study (WHC 1994), also referred to as the Facility Configuration Study (FCS). This study, which was performed by the Hanford Site M\&O contractor in 1994, examined the size, physical layout, and technology employed in a number of potential waste treatment and immobilization facility configurations. This study provides a reasonable indication of how a costreimbursable contractor might approach the work scope contained in the privatization contracts. In other cases, the technical approach was the same as the approach that would have been used by the Initial Pretreatment Module (IPM) had this facility been constructed. The description of the IPM is documented in the Initial Pretreatment Module Conceptual Design Report 30\% Review Package, WHC E/B-SDW236B-RTP-031 Rev. 0A, (WHC 1995a). 
Brief descriptions of the major divisions of this scope of work are provided below.

- Solid/Liquid Separations: involves the removal of particulate material from the waste feed. It is assumed that the contractor would use a process comparable to the processes proposed by the M\&O in the FCS or proposed as part of the IPM.

- Transuranics (TRU)/Strontium-90 Removal: requires decomplexation of organics in the feed to force precipitation of TRU and strontium-90, which are then removed by filtration.

- Cesium-137 Removal: would be accomplished by the use of an elutable ion exchange resin. This process requires the use of multiple ion-exchanger columns in series and parallel and installation of support systems that allow the installation, removal, and storage of resins. This process is comparable to the processes proposed in the FCS and proposed as part of the IPM.

- Technetium Removal: is accomplished via the use of an elutable ion exchange resin. This process requires the use of multiple ion-exchangers in series and parallel and installation of support systems that allow the installation, removal, and storage of resins. This is not the same resin that is used for cesium-137 removal. The means of accomplishing technetium-99 removal is based on an approach proposed by the privatization contractors.

- Low-Activity Waste (LAW) Immobilization: will be accomplished via vitrification. This process requires the use of multiple melters. Vitrified LAW is placed in packages, comparable to those specified in the privatization contracts. The immobilization process is comparable to that proposed in the FCS, except that the FCS proposed a waste form consisting of glass cullet (fractured glass) in a sulphur polymer cement.

- High-Level Waste (HLW) Immobilization: will be accomplished via vitrification. This process requires the use of a single melter. Immobilized HLW is placed in canisters, comparable to those specified in the privatization contracts. The immobilization process is comparable to that proposed in the FCS.

In addition to ensuring scope comparability, DOE was also careful to ensure comparability with respect to facility type, operational philosophy, etc. Key elements of these considerations included the following:

- Facility Type: Both privatization contractors proposed construction of large concrete structures. These large structures allow for better radiation shielding and ensure that seismic qualification requirements can be met. Construction of larger facilities provides DOE with the capability to continue operation of the facilities for an extended period of time.

- Facility Operating Life: Because of needs related to facility type, both privatization contractors recommended that the facilities be designed and built to operate for periods of time on the order of $20+$ years.

- Facility Maintenance: Both privatization contractors described construction and operations of facilities commonly referred to as "hot cells" that would allow maintenance to be performed continuously. Continuous maintenance would require the installation of shielding internal to the facility for personnel and equipment protection purposes.

- Level of Occupancy During Maintenance: The privatization contractors recommended the construction of facilities that allowed personnel to perform work, such as maintenance, continuously. 
As a result, walkways, cut-up facilities, ventilation, etc., were required. This feature allows facilities to operate while routine maintenance is being performed, thereby increasing the efficiency of the facility.

\section{Type of Estimate}

DOE determined that preparing a parametric cost estimate was the most reasonable process for developing the estimate for cost-reimbursable contractor costs. The decision to use parametric costestimating methods was based on

- the amount of information available to prepare an estimate

- the number of estimates that would be required to be performed

- the fact that the estimate was designed to be used as a tool to compare costs and not to request capital funds

- cost

- the limited funding available to support the preparation of a cost estimate.

The parametric estimate that was prepared represents a rough order of magnitude estimate, that is, one with a high level of uncertainty (i.e., $\pm 40 \%$ ). DOE recognized that for such estimates, which are typically prepared for engineering studies and portions of conceptual designs, the use of analogies and extrapolations was appropriate. Before implementing the cost-estimating process, DOE performed research to determine the level of technical and cost data available from Hanford sources to support the estimating process. The FCS provided various cost estimates for facilities of different configurations (integrated or separate facilities), different sizes (multiple small facilities or large facilities), and different technologies (preparation of glass monoliths or glass cullet). These estimates provided DOE with a reasonable database of costs associated with having a cost-reimbursement contractor provide treatment and immobilization services.

In addition to Hanford Site information, DOE obtained information from the Defense Waste Processing Facility (DWPF) at the Savannah River Site. This information, which represents costs that DOE is actually incurring for the production of borosilicate glass, was used to validate portions of the costreimbursement estimate.

\section{Assumptions Used in Preparing the Cost Estimate}

Information contained in the FCS was used to calculate a number of major cost elements. These assumptions are included in the following list.

- Engineering, Title I, and Title II Design: These costs were assumed to be $40 \%$ of the costs attributable to equipment and structures.

- Construction Management Costs: These costs were assumed to be $10 \%$ of the costs attributable to equipment and structures. 
- Project Management Costs: These costs were assumed to be $10 \%$ of the cost attributable to equipment and structures, Engineering, and Construction Management.

In addition to the costs listed above, other costs that DOE should expect to pay for capital projects are described in the following list.

- Conceptual Design Costs: These costs were assumed to be 3\% of the capital cost of the project, which includes equipment, structures, and engineering.

- Development Costs: These costs were attributable to the technology development program that accompanies the capital project. The FCS provided an estimate for the technology development program that would be necessary for accomplishing the TWRS work scope.

- Startup Costs: These costs were associated with bringing a new construction project on-line for the operational staff. A variety of time frames could be used for estimating costs; however, DOE assumed that it would take approximately 16 months to bring the facility on-line. Because the operational staff would be necessary during facility startup, DOE assumed that the costs associated with 16 months of facility operations could be used as an estimate for startup costs.

- Initial Inventory of Maintenance Parts: This is not a large cost driver for the facility but represents a cost that DOE must take into account. Using an industry standard of $5 \%$ of capital equipment costs, an estimate for the initial load of spare parts could be established.

A number of additional assumptions were necessary to develop the estimate. Those assumptions are discussed below.

- The cost-reimbursable contractor proposal for the treatment and immobilization of tank waste meets the requirements of the contract. The technical requirements for the privatization contract are neither different nor more difficult than the technical requirements that DOE would have imposed on the cost-reimbursement work scope.

- With respect to technology development/technology selection, it is assumed that the costreimbursable contractor would not have benefited from preparation of the privatization contractor proposals or from all DOE relevant studies. As a result, lessons learned about technology as a result of Phase I Part A of TWRS privatization would not be available for application to the costreimbursable contractor approach.

- Technology development occurs in a just-in-time basis. There are no construction or design delays that result from delays in the development of technology.

- A critical decision process, comparable to DOE Order 430.1, Life-Cycle Asset Management, is implemented (DOE 1995). The critical decision process requires that DOE prepare specific deliverables and submit these deliverables to DOE-Headquarters (HQ) prior to DOE-RL receiving permission/funding to proceed to the next phase of work. DOE uses this process to judge the viability of proceeding with the next phase of a project. All critical decisions require 6 months to obtain. Because of the size and complexity of the project, DOE-HQ would not delegate to DOE-RL the approval of critical decisions. 
- DOE oversight of the facility is consistent with that applied to the existing Hanford Site contractor. TWRS privatization proposes changes to the way DOE oversees its contractors. This new philosophy was not assumed in implementing the cost-reimbursable scope of work.

- Funding is available to support construction of the facility. Funding changes can affect the progress made by DOE and the cost-reimbursable contractor. In order to avoid developing estimates for the impact of funding changes, both increases and decreases, DOE assumed no funding changes after Conceptual Design.

- The schedule for the design, construction, permitting, startup, and operation of the facility is met. There are no delays in meeting the schedule of the project. This assumption requires that the costreimbursement contractor will complete the desired work scope in the stated time frame, and DOE will perform its reviews in a timely manner to support that work scope.

- There are no delays in providing critical site services for the support of facility construction.

- The stakeholders and regulators agree with the processes chosen by the cost-reimbursement contractor for treatment and immobilization of the waste.

- The cost-reimbursement contractor staffs and operates the TWRS facilities in a manner comparable to other Hanford Site contractor facilities. There is no assumed efficiency/deficiency in management processes used by the cost-reimbursement contractor.

\section{Comparison to BNFL "Hard" Costs}

Comparison of BNFL costs to the estimated costs for the cost reimbursable contractor is a twofold process. The first is a comparison of the "hard costs," those specifically related to the design, construction, permitting, and operation of the facility. The second part of the process is to analyze the total cost to the government for pursuing each of the two contracting approaches. The latter step is completed in the cost savings summary.

Table 1 provides a comparison between the hard costs from the cost-reimbursable contractor estimate and the BNFL proposal. Comparison of the costs is difficult. Because the constraints of Phase I, Part A did not permit the sharing of cost information (even knowledge of the work breakdown structure [WBS] was limited), both DOE and BNFL prepared cost estimates using different WBSs. Differences in the work scope assigned to each WBS element are critical to understanding the comparison. The different approaches do not prevent making a comparison between the two cost estimates; it simply highlights the importance of the analyst and reader understanding the limitations of making line item comparisons.

Several areas of comparison are important. These areas are equipment costs, facility costs, project management, construction management, design, and operation of the facility. Table 1 provides an estimate for each of these cost elements consistent with the DOE WBS that has necessitated some reclassification of the BNFL costs.

Design, project management, and construction management costs for the cost-reimbursable contractor and BNFL differ significantly. The estimate for the cost-reimbursable contractor individual cost elements is based on a traditional $M \& O$ estimate basis where these elements are a percentage of the cost associated with the facility construction. BNFL was able to prepare a bottoms-up estimate of the costs required to perform the design, project management, and construction management functions. 
Operation cost is the area that has the greatest degree of difference between the two cost estimates. The two factors that appear to drive the cost differences in the two estimates are the operating philosophy that each contractor employs and the availability of cost information that can be used as a basis of the estimate. BNFL, both in past Hanford studies and as a private corporation, brings a different commercial operating philosophy to bear on completing work. The cost-reimbursable contractor is not similarly restricted in its efficiency and is normally compensated for every dollar spent. The need for a high level of operational efficiency is not as paramount with the cost-reimbursable contractor as it is with BNFL. The magnitude of difference quantified does raise concern about the reliability of this comparison. Because of the lack of detailed cost information for the M\&O to perform the work scope being estimated, DOE was required to use very high-level cost data and make reasonable assumptions regarding the operating costs. This cost-reimbursable contractor's yearly operating costs (approximately $\$ 400 \mathrm{million} / \mathrm{yr}$ ) appear reasonable, based on the DWPF costs (approximately $\$ 200 \mathrm{million} / \mathrm{yr}$ which is limited by funding and prevents full utilization of the plant) for about one-third the work scope. BNFL was able to prepare a detailed operating plan for their facility and used that data for estimating the operating costs.

Table 1. Estimated Costs for a Cost-Reimbursable Contractor to Perform Phase I of TWRS Privatization

\begin{tabular}{|c|c|c|c|c|}
\hline $\begin{array}{l}\text { DOE } \\
\text { WBS }\end{array}$ & $\begin{array}{c}\text { DOE } \\
\text { Nomenclature }\end{array}$ & $\begin{array}{c}\text { DOE Estimated } \\
\text { Cost }(\$)^{1,2}\end{array}$ & $\begin{array}{c}\text { BNFL Proposed } \\
\text { Cost (\$) }\end{array}$ & $\begin{array}{c}\text { BNFL } \\
\text { Nomenclature }\end{array}$ \\
\hline 1.01 & Design & $615,508,208$ & $1,723,500,000$ & Facility Construction \\
\hline 1.02 & $\begin{array}{l}\text { Project } \\
\text { Management }\end{array}$ & $277,192,259$ & & \\
\hline 1.03 & $\begin{array}{l}\text { Construction } \\
\text { Management }\end{array}$ & $148,477,931$ & & \\
\hline 1.04 & Pretreatment & $177,270,540$ & & \\
\hline 1.05 & HLW Facility & $725,434,398$ & & \\
\hline 1.06 & LLW Facility & $293,615,588$ & & \\
\hline 1.07 & Tank and Pipeline & $29,700,000$ & & \\
\hline 1.08 & Support Facilities & $283,215,744$ & & \\
\hline 1.09 & $\begin{array}{l}\text { Development } \\
\text { Costs }\end{array}$ & $242,978,118$ & & \\
\hline 1.10 & Start-Up & $755,301,459$ & $1,026,500,000$ & Operations \\
\hline 1.11 & Operations & $2,197,292,751$ & & \\
\hline \multirow[t]{6}{*}{1.12} & Deactivation & $116,255,278$ & $107,000,000$ & Deactivation \\
\hline & Contingency & $2,337,986,310$ & $413,000,000$ & Contingency \\
\hline & & & $259,785,000$ & $\begin{array}{l}\text { Insurance, General and } \\
\text { Administration, B\&O Tax }\end{array}$ \\
\hline & & & $204,586,000$ & Property Tax \\
\hline & & & $128,720,000$ & Fee \\
\hline & Total & $8,200,139,183$ & $3,863,091,000$ & Total \\
\hline
\end{tabular}

Note: Values are in constant $1997 \$$.

${ }^{1}$ This reflects "hard costs" and excludes such elements as property tax, financing, and fee/profit

${ }^{2}$ Some reclassification was necessary to provide a comparable breakdown. 


\section{FM-20 Approach}

In contrast to the estimate based on adjusting the 1995 Westinghouse Hanford estimate, a division of DOE's Office of Field Management, FM-20, used BNFL engineering costs as a starting point for the M\&O cost estimate. The approach has the advantage of ensuring identical scope and technical approach. The issue is that the relative lack of incentives under the traditional M\&O contracting approach is very likely to increase cost growth, perhaps sufficiently to outweigh the perceived financing cost advantages that accrue to the government.

FM-20 employed Burns and Roe Enterprises, Inc., an engineering and construction firm, to perform an independent estimate of the likely cost for an M\&O to complete the TWRS waste vitrification during Phase I, Part B. The Burns and Roe team performed this work in several stages. The first stage involved a review of available information on a government contract performance and documented evidence of cost overruns. The FM-20 requested that the team consider a number of factors that would lead to cost differences between an $\mathrm{M} \& \mathrm{O}$ and privatization approach: 1) project duration, 2) management oversight (e.g., fewer reporting requirements with fixed-price contracts), 3) cost risk, 4) competition, and 5) differences in applicable DOE orders.

In the second stage of the work, another Burns and Roe team was convened to perform a Management Review. The outcome of this review was to quantitatively estimate the differences between the costs of an M\&O contractor and a privatization approach. The differences were developed as factors to multiply the summary level cost estimates (e.g., project management, design, construction, etc.) from the privatization approach to yield a comparable estimate for an M\&O approach. Developing the factors was based on integrating the information collected during the first stage with their own extensive experience in cost estimating and procurement for government and commercial contracts.

In the final stage, Burns and Roe applied the adjustment factors discussed above to the prevailing fair-cost estimate of the BNFL proposal. In this report, however, the factors are applied to the reconciled hard costs associated with the final BNFL "enhanced" proposal. The FM-20/Burns and Roe methodology could not be rigorously followed, because two of their cost elements, program management and deactivation, are not separately identified in the BNFL cost proposal. An overall adjustment factor of 1.60 was derived by taking a weighted average of the remaining four components-the weights are based on the cumulative (escalated) costs of these elements. Given that FM-20 estimate of the cost-adjustment factor for project management is much greater than for the remaining elements, the procedure here would understate slightly an exact duplication of the FM-20 methodology.

(Based on discussions with Department of Energy Headquarters, the full $68 \%$ increase was applied to the BNFL direct costs. The concern from headquarters was that the PNNL approach was too conservative.)

\section{PNNL Estimate}

A small group of economists at PNNL recently undertook a general examination of the potential DOE cost savings from private contracting as discussed in Appendix A. Using their results, an approach similar to the one used by FM-20 can be used to estimate the cost savings for the Phase I, Part B work scope. The PNNL group examined historical evidence of cost overruns for both fixed-price and cost-plus contracts and provided general guidance from which to derive factors that can be applied to the hard construction and operating costs supplied by BNFL. (Also refer to the discussion on cost growth associated with DWPF and West Valley HLW vitrification in the section, "Comparison to Other Historical Costs.") 
Prior to examining empirical evidence, the PNNL team reviewed and extended the theoretical economic framework of how these differing contractual mechanisms should be evaluated. Their study provides a rigorous explanation for the reasons that DOE traditional contracting is economically inefficient by comparing the bounding extremes of cost-plus and fixed-price contracting mechanisms.

The empirical work by PNNL reflects an awareness of sample selection bias in awarding either costestimate contracts (in which a prospective M\&O makes an initial cost estimate of the work) or fixed-price contracts. This bias leads to the consistent observation that average realized costs of projects tend to be greater than initial cost estimates. Clearly, this is often the case in government contracting, in which projects with low estimated costs are more likely to be funded. This bias also shows up in fixed-price contracts. A study of the 49 World Bank-funded hydroelectric projects completed between 1971 and 1990 - primarily undertaken with fixed-price contracts - showed an average cost overrun of about $24 \%$.

PNNL used this information, together with historical estimates of DOE cost overruns ( $40 \%$ to $65 \%$ ), to suggest the level of possible savings from privatization. Under a conservative scenario, their report indicated the cost savings from privatization would range between $10 \%$ and $30 \%$ of the initial M\&O estimate. Although PNNL used some of the same sources detailing DOE's historical cost overruns with M\&O contracts (as did the FM-20 study), they adjusted the magnitude of the average overrun for the sample selection bias discussed above.

In this analysis, the higher end of the range-30\%-is taken as best representing the cost differential that may be most appropriate for the TWRS Phase I Part B situation. Several considerations prompt this choice. First, the sample selection bias adjustment based on the World Bank data may be too high for this application. Those projects likely had greater competition, which would have tended to keep their initial bid prices relatively lower than the bid made by BNFL competing against a single other firm. Moreover, the hydroelectric projects likely did not incorporate the degree of risk premium that is reflected in the BNFL bid. ${ }^{2}$ The second reason stems from the fact that the PNNL study only compared the historical cost growth of fixed-price and cost-plus contracts. The additional reporting and regulatory requirements would tend to increase even the initial cost estimate for an M\&O as compared to BNFL hard-cost estimate. Thus, to finally arrive at a single point value, a cost-increase factor of 1.3 is used in the cost savings estimates summary shown below. (Because DOE-HQ believed this number was too conservative, the factor was increased to 1.38 to maintain a $30 \%$ differential between the fixed-price and cost-plus approaches. This occurred during the final stages of writing the Congressional Report based on the difference between the Burns and Roe Report and a 30\% increase in the fixed-price contract. In the last stage of writing the Congressional Report [DOE 1998], DOE-HQ believed this cost differential approach was too conservative and the approach was dropped.)

\section{Summary of Cost Savings}

Table 2 summarizes the range of expected savings associated with the privatization approach. The first row provides the initial cost estimates associated with each approach. The second, third, and fourth rows add the major adjustments that were described above. The last two rows roll up the expected net costs to the government and the expected savings from the privatized approach.

\footnotetext{
${ }^{2}$ In other terms, the degree of risk premium inherent in the BNFL bid is likely to prevent future overruns from being as high as those experienced by the World Bank contractors.
} 
Table 2. Summary of Estimated Cost Savings from the Phase I Contract

(Constant 1997 Dollars, Billions)

\begin{tabular}{|l|c|c|c|c|}
\hline \multicolumn{1}{|c|}{ A } & B & C & D & E \\
\hline & BNFL & DOE-RL M\&O & \multicolumn{2}{c|}{$\begin{array}{c}\text { M\&O Estimates Derived } \\
\text { from BNFL's Costs }\end{array}$} \\
\cline { 4 - 5 } & Contract & Estimate & FM-20 & PNNL \\
\hline Base Cost Estimate & 6.9 & 8.2 & 3.9 & 3.9 \\
\hline Potential Cost Growth & 0.0 & 0.0 & 2.6 & 1.5 \\
\hline $\begin{array}{l}\text { Opportunity Cost of Government } \\
\text { Financing }\end{array}$ & 0.0 & 1.6 & 2.0 & 1.6 \\
\hline Credit for Federal Taxes & $(0.7)$ & $(0.07)$ & $(0.06)$ & $(0.06)$ \\
\hline Net Cost to the Government & 6.2 & 9.7 & 8.4 & 6.9 \\
\hline $\begin{array}{l}\text { Expected Cost Savings for } \\
\text { Phase I Contract }\end{array}$ & -- & $3.5(36 \%)$ & $2.1(26 \%)$ & $0.7(10 \%)$ \\
\hline
\end{tabular}

The fourth row shows the single adjustment applied to the BNFL enhanced cost estimate (i.e., the predicted level of taxes that will be returned to the federal government). The estimate of tax revenues is based on BNFL's estimated taxes. However, it is not possible to accurately estimate M\&O contractor income tax impacts. The federal tax impacts shown above do not materially affect this comparison.

The first M\&O estimate shown in the table is the one developed by DOE-RL and is based on a scaling of the 1995 cost estimate made by WHC. The principal adjustment is the imputed amount of interest that would be paid by the federal government to yield the same cost profile as the privatized contractor. Total interest payments, assuming a 3.8\% real borrowing rate, sum to $\$ 1.6$ billion (1997 dollars). With the addition of imputed interest, this approach suggests that an $M \& O$ would cost about $\$ 3.5$ billion more than the privatized approach.

The second M\&O estimate is based on the factored hard cost methodology employed by FM-20. It uses the magnitude and profile of construction and operating costs as presently projected by BNFL. The imputed interest cost of the privatized approach (again assuming a $3.8 \%$ real rate) is $\$ 2.0$ billion. $^{3}$ The expected cost increase from the $M \& O$ contracting approach is estimated at $\$ 2.6$ billion, based on the weighted-average factor of 1.68 as discussed above. With no cost increases, the M\&O would pay approximately $\$ 40$ million in federal taxes. These adjustments yield net government cost of $\$ 8.4$ billion. Compared to the BNFL enhanced proposal, the M\&O would cost the government an additional $\$ 2.1$ billion.

The third M\&O estimate is also based on a factored hard cost methodology, but employs a somewhat more conservative estimate of the cost increase associated with an M\&O. As discussed above, PNNL's estimate is more conservative because it recognizes that there is propensity for cost growth, even in fixedprice contracts. Assuming a 38\% difference between a fixed-price and a cost-reimbursable contract, the PNNL approach yields a cost savings of roughly $\$ 700$ million.

3 One may reasonably question why the imputed interest for this case is not much lower than the DOE-RL M\&O estimate, given the large disparity in the base costs. A larger proportion of the DOE-RL M\&O estimate stems from operating costs, which do not affect the imputed interest. The spending profile for construction for the two cases is also different; the DOE case incurs the greatest costs in the last few years of the design and construction period (thus, minimizing cumulative interest charges), whereas the BNFL profile (as presently modeled) has a more even spending pattern over the period. 


\section{Comparison to Other Historical Costs}

\section{Summary}

The Defense Waste Processing Facility (DWPF) at the Savannah River Site and the West Valley Demonstration Project (WVDP) provide cost comparisons to BNFL's price per metric ton for HLW vitrification. These comparisons are discussed in Appendix $\mathrm{E}$. These costs are not readily comparable to TWRS HLW vitrification costs. DWPF has other functions, such as the salt stone facility, but the facility only produces HLW glass. The WVDP is a demonstration plant with a short operating period of approximately 3 years, not a production plant. Thus, its costs would be higher.

BNFL's price per metric ton of waste is $\$ 1.225$ million. Assuming a $25 \%$ waste loading, glass costs approximately $\$ 300$ per metric ton of glass. BNFL currently prices all waste treatment and immobilization services the same for either metric tons of sodium waste or waste oxide. PNNL provided a rough calculation of the glass cost per metric ton for BNFL based on an allocation of BNFL's capital and operating costs. Based on the immediate cost of the contract, the initial costs of glass are approximately $\$ 900,000$ per metric ton. Based on a 25 -year useful life, these costs decline to $\$ 340,000$ per metric ton. This compares to DWPF costs of $\$ 670,000$ at 25 years and West Valley costs of $\$ 1.228$ million for 2.5 years. If the plant life is extended to 5 years for West Valley's operation, their costs decline to $\$ 621,000$ per metric ton. The costs for West Valley are high because of its pilot plant nature. The costs for DWPF and West Valley do not include an adjustment for the government cost of capital nor does the BNFL costs reflect the federal tax benefit.

\section{Introduction}

Analysis of the costs for the DWPF and the WVDP helped gauge the reasonableness of the estimated prices for the wastes treated by BNFL. The actual costs were obtained for the two projects and the costs per metric ton of treated waste were determined. Westinghouse is the M\&O contractor for the two projects at Savannah River, South Carolina, and West Valley, New York. Beyond the narrow interpretation of how much it costs to produce a metric ton of HLW glass, any comparisons should be made with caution. The missions and the wastes being glassified are different.

DWPF will solidify defense HLW at the Savannah River Site for temporary onsite storage and eventual transportation to and disposal in a federal repository. The facilities will immobilize the HLW in borosilicate glass in steel canisters. Construction at the DWPF started in approximately 1981 and was completed in 1996.

The Western New York Nuclear Service Center near West Valley, New York, reprocessed nuclear fuel from 1966 to 1972 . During that time, the fuel reprocessing generated approximately 560,000 gallons of alkaline HLW and it was stored in a CS tank located in an underground vault. The alkaline waste is similar to that stored at the DOE's Savannah River and Hanford Sites. The WVDP facility mission is to demonstrate high-level liquid nuclear waste management. Construction on the WVDP started in the late 1980 s and was completed in approximately 1996.

The major system acquisition (MSA) estimates help answer the following four questions.

- How do the actual costs of completing the construction of a MSA and operating it under an M\&O contractor compare with the estimated cost with TWRS privatization? 
- What is the growth in constant dollars between the MSA's initial projected cost (before construction actually begins and at the time of the first initial Congressional request for funding) and the actual project construction costs?

- What is the growth (in constant dollars) that is attributable to project delays and schedule slippage?

- What are the costs to produce one metric ton of treated, vitrified wastes at each facility?

\section{Cost Growth Analysis}

PDSs provided the most important source of data for each project. The PDSs, prepared annually for the project's Congressional budget request, represent a past, present, and future funding profile. The PDSs contain a substantive amount of high-level data, including the following information:

- $\quad$ project title and location

- initiation date for project architecture and engineering work

- dates of start of physical construction and of estimated project completion

- project funding profile, past, present, and future. The funding profile is divided between construction costs and other project costs (e.g., R\&D, other related project costs, etc.). The costs are expressed in nominal or year-of-expenditure dollars.

- brief description of the project and a section on project purpose, justification, and scope

- estimated project life and annual operating costs.

The PDSs were the primary source of data for the DWPF project. Cost data by year of expenditure were obtained for WVDP from the Westinghouse program managers at West Valley. Supplemental data were also obtained from the budget or program managers for each project as required.

Projected and actual annual expenditures were converted to 1997 constant dollars using an index issued by the OMB for annual Congressional budget submittal. The resulting constant dollar costs were compared to determine the cost growth for each project.

Because the projects took several years more to construct and start up than forecast in the original PDSs, the cost of government funds was applied to annual expenditures to analyze the cost of schedule slippage. The government borrows the funds from the public to finance construction of DWPF and WVDP and the opportunity cost to the government of these funds is applied to the projected and actual outlays to determine the cost of the schedule slippage. To analyze the schedule slippage cost the "real" 30-year U.S. Treasury interest rate for each year was used, as well as an approximate long-term real rate of return (i.e., $3 \%$ ).

Table 3 summarizes the analytical results for DWPF and WVDP. Comparing nominal actual Total Project Costs (TPCs) with estimated costs at the beginning of the project, DWPF's costs grew from $\$ 1.5$ billion to $\$ 2.4$ billion while WVDP's grew from $\$ 0.470$ billion to $\$ 1.4$ billion. For a more meaningful comparison, the TPC in constant $1997 \$$ for DWPF costs grew from $\$ 2.2$ billion to $\$ 3.1$ billion or $41 \%$. The WVDP costs grew more comparatively from $\$ 0.643$ billion to $\$ 1.6$ billion or $147 \%$. Four 
factors contribute to the project's cost growth: fast track construction, inflation, schedule slippage, and increases in work scope over and above the scope originally envisioned.

Table 3. Analytical Results for the Defense Waste Processing Facility and the West Valley Demonstration Project

\begin{tabular}{|c|c|c|}
\hline & $\begin{array}{c}\text { Defense Waste } \\
\text { Processing Facility }\end{array}$ & $\begin{array}{c}\text { West Valley } \\
\text { Demonstration Project }\end{array}$ \\
\hline \multicolumn{3}{|c|}{ Actual Annual Outlays Adjusted for $1980 \$ \& 1997 \$$} \\
\hline Nominal TPC & $\$ 2,443,263$ & $\$ 1,354,900$ \\
\hline $1980 \$$ TPC & $\$ 1,588,761$ & $\$ 818,749$ \\
\hline $1997 \$$ TPC & $\$ 3,079,529$ & $\$ 1,586,999$ \\
\hline \multicolumn{3}{|c|}{ Projected Costs Adjusted to Constant $1980 \$ \& 1997 \$$} \\
\hline Nominal Projected TPC & $\$ 1,529,465$ & $\$ 470,379$ \\
\hline $1980 \$$ Projected TPC & $\$ 1,124,682$ & $\$ 331,550$ \\
\hline $1997 \$$ Projected TPC & $\$ 2,179,996$ & $\$ 642,650$ \\
\hline Growth in Constant $\$$ & 0.41 & 1.47 \\
\hline \multicolumn{3}{|c|}{ Accounting for Schedule Slip (Constant 1980\$) } \\
\hline \multicolumn{3}{|c|}{ Actual Costs at Actual Real Interest Rate } \\
\hline Interest Costs & $\$ 767,528$ & $\$ 308,364$ \\
\hline End of Period & $\$ 2,356,289$ & $\$ 1,127,067$ \\
\hline \multicolumn{3}{|c|}{ Projected Costs at Actual 30-year Real Interest Rate } \\
\hline Interest Costs & $\$ 367,950$ & $\$ 76,671$ \\
\hline End of Period & $\$ 1,492,633$ & $\$ 408,221$ \\
\hline $\begin{array}{l}\text { Growth Accounting for Schedule } \\
\text { Slip }\end{array}$ & $58 \%$ & $176 \%$ \\
\hline \multicolumn{3}{|l|}{ Actual@3.00\% Real Interest } \\
\hline Interest Costs & $\$ 475,480$ & $\$ 222,262$ \\
\hline End of Period & $\$ 2,064,241$ & $\$ 1,043,545$ \\
\hline \multicolumn{3}{|l|}{ Projected@3.00\% Real Interest } \\
\hline Interest Costs & $\$ 180,457$ & $\$ 39,579$ \\
\hline End of Period & $\$ 1,305,140$ & $\$ 371,129$ \\
\hline $\begin{array}{l}\text { Growth Accounting for Schedule } \\
\text { Slip }\end{array}$ & $58 \%$ & $181 \%$ \\
\hline
\end{tabular}

To calculate the cost growth associated with schedule slippage, it was assumed that all actual and projected expenditures were refinanced annually at the real 30-year interest rate. Annual outlays in constant 1980 dollars were employed to calculate the interest costs with a half-year convention used for expenditure additions (i.e., costs) for the current year.

Referring to Table 3 , the constant $1980 \$$ plus interest costs (interest plus construction costs) for the DWPF is $\$ 2.4$ billion, including interest costs of $\$ 768$ million, while the real "projected" total finance cost is $\$ 1.49$ billion with interest costs of $\$ 368$ million for a growth of $58 \%$. For WVDP, the slippage grew to $\$ 1.1$ billion (including interest costs of $\$ 308$ million) from projected costs of $\$ 408$ million (including interest costs of $\$ 77$ million) for a growth of $176 \%$. Using the real rate of growth in the economy as the opportunity costs shows the same kind of growth. DWPF was completed approximately 6 years after its original completion date while WVDP was approximately 7.5 years later than estimated.

The interpretation of these results are that DWPF and WVDP cost $58 \%$ and $176 \%$ more, respectively, as a result of delayed construction, changing regulations, and changing technical requirements. A number of 
similar factors can result in schedule slippage for TWRS privatization including inadequate funding or delays in Congressional funding for the project, regulatory or licensing delays, changes in environmental laws and regulations, etc.

The information above was derived directly from publicly available project data sheets and was at a project level. It was adequate to guage the cost growth associated with M\&O projects. The Department of Energy-Headquarters drew together data which was more complete in trying to more closely match the high level waste glass-making scope of the DWPF and West Valley projects.

Table 4 summarizes each of the costs for the three vitrification programs at the West Valley Demonstration Project (WVDP), the Savannah River Site (DWPF), and Hanford (TWRS) i.e., BNFL, for 10- and 25-year operational periods. These costs have been normalized for actual or, in the case of TWRS, projected throughputs of the vitrification facilities. Because the WVDP facility used existing facilities to the maximum extent feasible, some efficiencies are realized in their capital costs. Also the shorter duration of the mission program facilitated savings in certain areas (e.g., facilities for melter changeout). Consequently, the cost comparisons for WVDP for the 10-year and 25-year scenarios are not as meaningful. BNFL costs were derived by PNNL. Using material provided by BNFL, costs were allocated to HLW glass making. These costs are only an estimate and are not intended to reflect what BNFL may in the end charge DOE for HLW remediation services.

Table 4. Normalized HLW Vitrification Program Costs (\$M/MT)

\begin{tabular}{|l|c|c|c|}
\hline Scenario & WVDP & DWPF & TWRS \\
\hline 10 Years & & & 0.696 \\
\hline Capital Costs & 0.221 & 0.796 & 0.205 \\
\hline Operating Costs & 0.167 & 0.389 & 0.901 \\
\hline 10 Year TOTAL & 0.388 & 1.185 & 0.199 \\
\hline 25 Years & & 0.297 & 0.140 \\
\hline Capital Costs & 0.088 & 0.373 & 0.338 \\
\hline Operating Costs & 0.165 & 0.670 & Not applicable \\
\hline 25 Year TOTAL & 0.253 & Not applicable & \\
\hline WVDP Base & & & \\
\hline Capital Costs & 1.051 & & Not applicable \\
\hline Operating Costs & 0.177 & Not applicable & \\
\hline Base TOTAL & 1.228 & & \\
\hline WVDP 5 years & & & \\
\hline Capital Costs & 0.451 & & \\
\hline Operating Costs & 0.170 & & \\
\hline 5 Year TOTAL & 0.621 & & \\
\hline
\end{tabular}




\section{Conclusions}

Treated-waste costs range from a high of $\$ 1.228$ million per metric ton at WVDP to $\$ 670,000$ at DWPF when based on the life cycles costs of the facilities. (All values are constant 1997\$.) This compares with $\$ 338,000$ per metric ton of glass for BNFL. If BNFL's facility was used only for the period of the Contract, these costs would rise to approximately $\$ 900,000$ per metric ton.

Actual costs of the project were higher than initial predicted costs for both DWPF and WVDP by $41 \%$ and $147 \%$, respectively, in constant dollars. Comparing projected versus actual costs and using the historically observed 30-year Treasury real interest rate shows that project costs (capital and interest finance costs) increased by $58 \%$ and $176 \%$ for DWPF and WVDP, respectively, as a result of slips in the construction schedule. Both had additions to work scope over the projects' construction periods amounting to approximately $10 \%$ of total costs (nominal dollars). 


\section{Analyzing Impacts of Risk Allocation}

\section{Summary}

The general results from the risk-allocation modeling and analysis effort confirm that an extended design phase, prior to determining the final firm fixed prices for waste-processing services, is beneficial to DOE. This work is discussed in more detail in Appendix F. The results further indicate that an optimal allocation of risk would consist of considerable risk-sharing, a significant equity stake by the contractor (BNFL), and a mix of public and private financing. Earlier study results (Keisler and Buehring 1996), also indicate that if a pure M\&O contractor performed the Phase I TWRS privatization scope of work, costs could be about $25 \%$ higher and have more variability than proceeding with the modified privatization approach.

\section{Introduction}

One important tool to support the cost savings determination is risk-allocation modeling analysis. The risk-allocation and modeling decision support tool is used both to analyze contractual risk-allocation strategy options and to provide another method to evaluate the price reasonableness of contractor proposals. The objective of examining the contractual risk-allocation options is to help procurement decision-makers achieve minimum TPCs. By examining the risk profile allocated to the contractor in any particular strategy, the risk-allocation model, working in conjunction with the financial model, can be used to calculate the minimum price the contractor must have to meet various reasonable required financial parameters. The following discussion briefly summarizes the risk-allocation concept, the model, the risks studied, the analysis results, and conclusions.

\section{The Concept}

The risk-allocation theoretical background combines elements of finance, game theory, decision and risk analysis, and negotiation analysis. The concept underlying risk allocation stems from an economic argument based on contracts between two parties. The party that pays for the services is known as the principal (the government in the TWRS scenario) and the party who performs the services for payment is the agent (the contractor). For a given contract, each party will do what is in its self-interest for that contract. Both parties are expected utility "maximizers." The actions each party takes can be anticipated and are rolled into each party's subjective estimates of the probability distribution over its cash flow, that is, its risk profile. The contractor has financial requirements based on its risk profile, and these financial requirements are determined by the realities of the capital markets. The contractor must obtain financing, and payments for the project must be sufficient to provide returns that cover the financing costs corresponding to the risks of the project. Thus, for a given contract to be feasible, the government must pay for risks it does not accept. From the contractor's perspective, there is an efficient frontier of feasible contracts encompassing a variety of payments and risk profiles, and the government should strive for the point on this frontier that maximizes its expected utility (usually lowest total cost).

\section{The Model}

The objective of the risk-allocation and modeling effort is twofold:

1) to estimate the effect of selected major risks on Phase I bids and DOE costs for various risk allocations between the contractor and DOE 
2) to develop an analytic framework within which the effects of risk on DOE costs and the effects of incentives in allocation are evaluated and compared.

The model itself, developed by Argonne National Laboratory, is an Excel spreadsheet-based Monte Carlo simulation that utilizes the commercially available @ Risk software. The risk-allocation model runs interactively with the financial risk model developed by Scully Capital Services, Inc. and PNNL.

The process for using the model includes describing the risks involved in a contract, and then developing several alternatives for allocating each risk. For each risk and alternative allocation, users describe the likely mitigation and prevention measures to be taken by each party. Based on these narratives, subjective probability distributions are defined over the financial impact of each risk to each party. The subjective probability distributions are based on internal expert judgments. Features of the model include an interaction filter to deal with risk independence and dependency issues, templates to aid in modeling similar risk types, and a detailed contractor response function, based on financial advisor (Scully Capital) input. Once a scenario is defined, risks quantified, and a Monte Carlo simulation performed for each risk, users can evaluate specific possible allocations of those risks in terms of the net payment and risk profile they will face. Before or after this step, the optimization feature can be used to find the lowest total cost set of allocations. This optimization can be either unconstrained over all risks, or run with some of the risks set at pre-selected allocations for specific what-if analysis and faster performance.

As currently designed, the risk-allocation model is used to screen proposed contractual risk allocations and to develop a preferred risk-allocation position based on the best available information. Hypothetical screening and allocation options are shown in Figure 1 in a theoretical total risk-allocation cost curve for a complex technical activity such as TWRS.

To determine a preferred position or strategy, specific hybrid allocations are described and represented in the model. The model processes them in conjunction with the finance model to determine if the allocation strategy could be financed. The intent here often is to demonstrate that a particular allocation could not, or should not, be proposed or accepted in the negotiations or, conversely, that the position has merit that should be considered. Comparisons of these specified strategies to other alternatives can provide further insight into the desirability of the specified risk allocation.

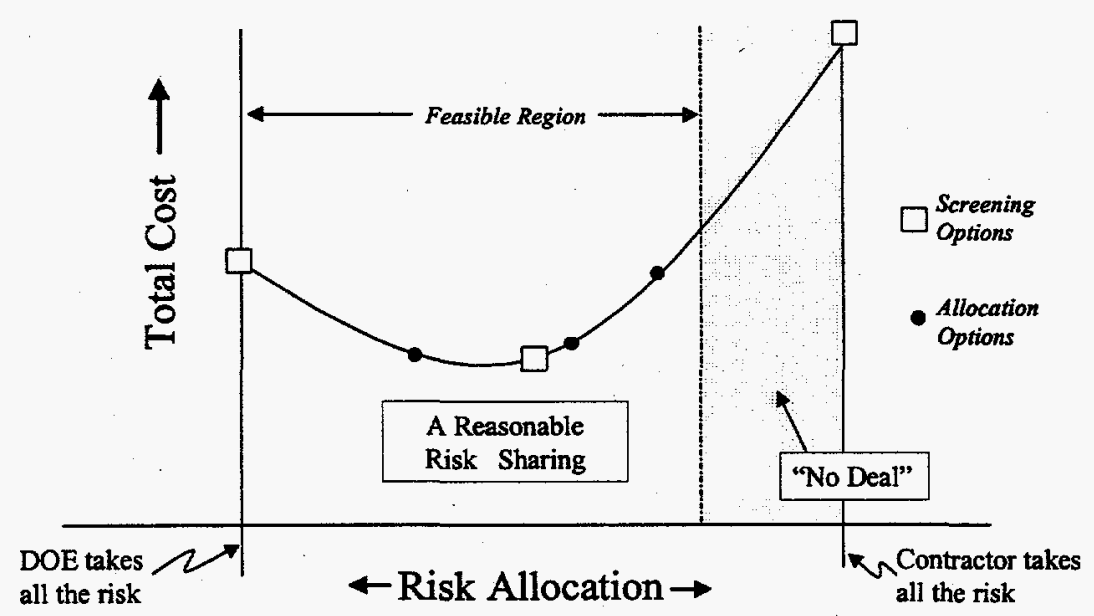

Figure 1. "Theoretical" Total Risk Allocation Curve-Complex Technical Activity 
In using the risk-allocation model to develop a position, the most cost-significant risks are identified, and three allocations of that risk (between DOE and the contractor) are described for each. These allocations include a case where DOE takes as much of the risk as practical (DOE bears), one where the contractor does the same (contractor bears), and one case that represents a logical point between the previous two (shared). In this process, the intent is to determine points that describe reasonable and logically defendable risk positions that reflect the full range of risk-allocation potential (the give-and-take available to the negotiators). Each point must have obvious merit, such that implementation could be expected under reasonable circumstances. Special care is taken not to predetermine the results by only describing cases sure to produce a certain expected or desired outcome. The cases described do not necessarily represent negotiation positions, but rather the range of viable positions available to both parties to the contract.

The "Maximum DOE Risk Case" generally refers to the greatest acceptance of risk that DOE or the federal government could reasonably be expected to consider, without immediately dismissing it as "out of bounds." This risk case must consider the fundamentals of the privatization program, the Congressional budget process, and the political environment.

The "Maximum Contractor Risk Case" similarly refers to the greatest acceptance of risk that could be financed and still meet corporate criteria for investment. This point must consider corporate profit motivation, trust and confidence between industry and government, the expected value nature of risk costs, and the financial community's typically conservative approach to uncertainty.

The "Shared Risk Case" refers to a position between them, judged to be clearly different than each of those extremes, but apparently viable from either perspective. This point is not necessarily at or near the midpoint between the extremes described above, but represents a reasonable case for shared risk based on the available information.

The model data have been developed from limited discussions with Waste Disposal Division (WDD) and Waste Disposal Integration Team (WIT) staff familiar with the dominant issues, and the specific values are the best available estimates from staff resources available to this project. A great deal of uncertainty concerning specific parameters, such as risk probabilities, costs, and cost distributions, is known to exist. These input data include consideration of risk-allocation phenomena that may be abstract, such as incentives to perform and prevention/mitigation actions, and express them in the form of discrete costs, cost distributions, and probabilities. While no assumptions are made about the degree of precision achieved, these estimates are believed to represent reasonable portrayals of the key parameters of the model. In spite of the limitations of the process, it is believed that the resulting output provides valuable insight into how risk allocation can be expected to influence expected program costs and the variability of those costs. The results have been examined to ensure that they are intuitively logical at each step in the process and are the result of systematically developed input data. While the values may not precisely represent the bottom-line costs, the relative magnitudes of costs among alternatives should be sufficiently accurate to determine the best risk-allocation strategy from among the options modeled.

\section{The Risks Modeled}

During the request for proposal process in early 1996, 12 risks were studied as part of the early initial study on risk allocation for the new TWRS privatization contracting strategy. Through this process and interactions with prospective vendors, it was learned that some of these risks, e.g., uncontrollable circumstances and changes in law, must stay with DOE if the contractors are to obtain private financing. Based on this experience, the criteria chosen for including risks in the current risk-allocation study were that risks had to be both significant, in terms of cost impact, and negotiable, as to the most efficient allocation. To focus limited time and resources where it counted most, risks that were significant but had 
to be allocated to either the government or to the contractor were not chosen for further study. Similarly, risks for which the allocation choice was not clear, but whose risk-allocation cost consequences were determined to be minimal by preliminary screening, were not included.

The BNFL "enhanced" proposal was selected to be the starting point for the study. This case was the most challenging to model as this construct included complicated incentives and tradeoffs. The BNFL construct was later determined to be the technically viable offer, so detailed modeling of the particularities of the LMAES construct was not performed. Five major risks were chosen for detailed characterization, study, and analysis. These risks were inflation, interest rate, permitting, performance during extended design phase (proceeding into Part B with firm fixed prices to be set only after successful completion of $30 \%$ design and readiness for financial closure), and process performance risk (with credit supports).

\section{Analysis Results}

The primary measures of effectiveness are total DOE cost (either "expected," $80^{\text {th }}$ percentile, or $95^{\text {th }}$ percentile) and a measure of the variability in total DOE cost expressed as the standard deviation. A secondary, and less important, measure of effectiveness is the total DOE payments to the contractor.

Of the five risks modeled, the most significant was the initial performance risk during project design period, which consisted of a 24-month period prior to setting firm fixed prices for waste-processing services. This period provides time for better project definition, completion to approximately a $30 \%$ level of design, completion of all activities in preparation for financial closure, and substantial performance of permitting requirements. In fact, this risk alone dominates the other four risks included in the risk-allocation study. Allowing this initial project design period should lower total expected project costs to DOE.

The inflation, permitting, and process performance risks were also significant. Modeling and analysis results indicate that a more broad-based inflation adjustment formula such as including both the Employment Cost Index (ECI) and the Producer Price Index (PPI) in the adjustment formula lowers costs by $1.6 \%$. Results confirmed that sharing the permitting risk is optimal. Cost would increase by $4 \%$ if allocated more to DOE or $6 \%$ if allocated more to the contractor. Reallocating the process performance risk from the contractor to shared risk reduced total costs by $1.1 \%$. However, results also showed that significant equity stake by the contractor is required for an optimal allocation. A contractor equity stake of about $\$ 750$ million appears best but may be unattainable. In addition, it appears that government credit support would be advantageous in reducing TPCs.

The interest rate risk proved to be the least significant of the five risks that were modeled and analyzed in detail. Whether this risk was kept with the contractor, shared, or taken by DOE made very little impact on TPCs.

The preferred risk allocation, based on the results of this analysis, is shown in Table 5 .

Total costs to DOE consist of three major categories: 1) the project "hard costs"; 2) costs associated mainly with profit, financing, risk premium, and taxes; and 3) other DOE costs. Other DOE costs are associated with realized risks, on a simulated expected value (cost) basis, that remain allocated to DOE. The total cost curve for the BNFL "enhanced" proposal, based on the representative risk allocation scenarios modeled, is shown in Figure 2. 
Table 5. BNFL Risk-Allocation Modeling: Preferred Risk Allocation for the BNFL Enhanced Case

\begin{tabular}{|l|l|l|}
\hline \multicolumn{1}{|c|}{ Risk } & Allocation & \multicolumn{1}{c|}{ Description } \\
\hline Inflation & Shared & $\begin{array}{l}\text { Payments are fully indexed to ECI and to PPI. Prices could } \\
\text { drop if inflation is lower than current } 2 \% .\end{array}$ \\
\hline Interest Rate & $\begin{array}{l}\text { Contractor or } \\
\text { Shared }\end{array}$ & $\begin{array}{l}\text { Contractor either takes or shares risk with DOE. If shared, } \\
\text { benefits (rate decreases) and costs (rate increases) are } \\
\text { apportioned equally. }\end{array}$ \\
\hline Permitting & Shared & $\begin{array}{l}\text { Following issuance of the Draft Permit and Notices of } \\
\text { Construction, DOE and the private contractor work together to } \\
\text { secure the final permits. Issues are handled by the most } \\
\text { appropriate party or by both on a good faith basis. Costs are } \\
\text { borne by DOE if through no fault of the private contractor. The } \\
\text { private contractor may be made whole if permits are denied } \\
\text { following a good faith effort and the problems are not the fault } \\
\text { of the contractor. }\end{array}$ \\
\hline $\begin{array}{l}\text { Extended } \\
\text { Design Phase }\end{array}$ & $\begin{array}{l}\text { She contractor develops a target price for Part B-I, preferably } \\
\text { with a ceiling price, and is permitted to establish the final fixed } \\
\text { price just prior to financial closure. Price redetermination } \\
\text { clause should be considered. }\end{array}$ \\
\hline $\begin{array}{l}\text { Performance } \\
\text { Cap }\end{array}$ & $\begin{array}{l}\text { Shared } \\
\text { pays the first \$750 million, and efficacy insurance covers } \\
\text { additional costs up to the next \$100 million. DOE pays all } \\
\text { costs that exceed \$850 million. }\end{array}$ \\
\hline
\end{tabular}

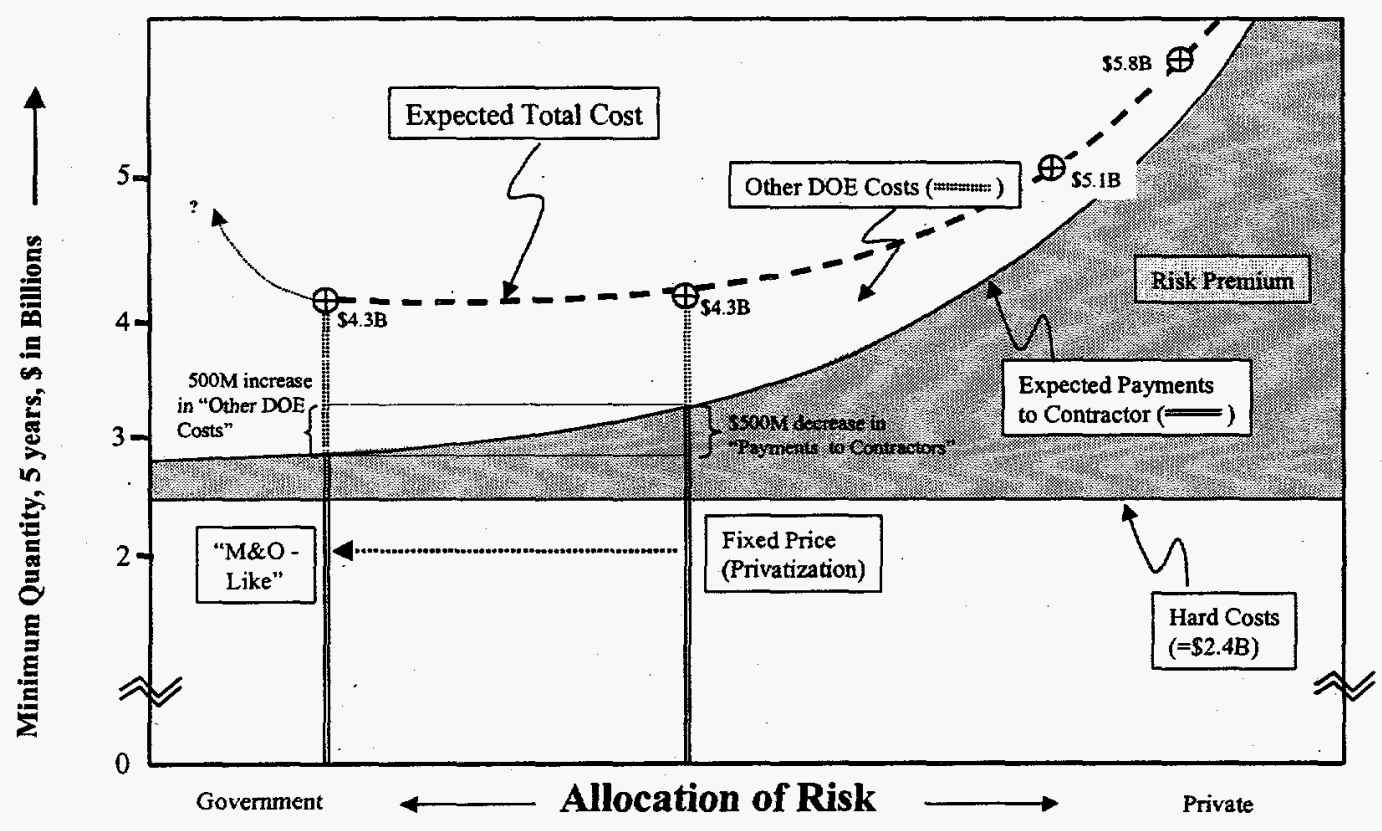

Figure 2. Government Costs as Risks Are Allocated Between the M\&O and Private Contractor 
In the near optimal region results are fairly insensitive, in terms of total cost, to modest changes in risk allocation. However, as more risk is assumed by DOE, the uncertainty band broadens, as should be expected (Figure 3). Although "Expected Total Costs" may be nearly the same, the variability in terms of the standard deviation increases from $\$ 607$ million to $\$ 907$ million. This exposes DOE to greater cost risk because of this increased uncertainty.

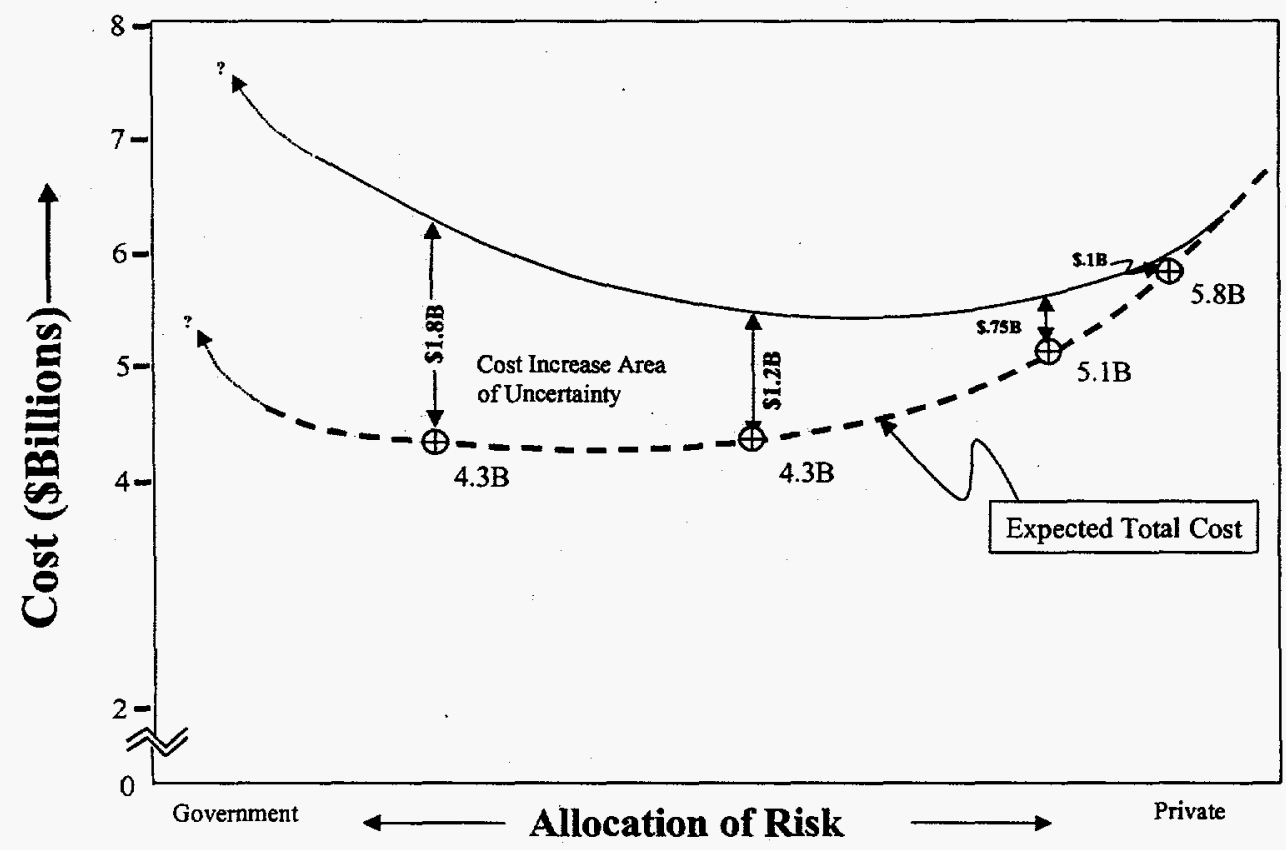

Figure 3. Total Cost Increase Uncertainty

Note that the pure $\mathrm{M} \& \mathrm{O}$ case (DOE taking virtually all the risk) was not modeled as part of the current analysis. Results from the 1996 study indicate an approximate $25 \%$ cost increase above the preferred, minimum total cost, risk allocation for an $\mathrm{M} \& \mathrm{O}$ to do the work. It is believed that the earlier results are still valid. 


\section{Acronyms and Abbreviations}

$\begin{array}{ll}\text { DOE } & \text { U.S. Department of Energy } \\ \text { DWPF } & \text { Defense Waste Processing Facility } \\ \text { ECI } & \text { Employment Cost Index } \\ \text { EM } & \text { Office of Environmental Management } \\ \text { FCS } & \text { Facility Configuration Study } \\ \text { FM } & \text { Office of Field Management } \\ \text { HLW } & \text { high-level waste } \\ \text { HQ } & \text { DOE Headquarters } \\ \text { IPM } & \text { Initial Pretreatment Module } \\ \text { LAW } & \text { low-activity waste } \\ \text { LMAES } & \text { Lockheed Martin Advanced Environmental Systems } \\ \text { M\&I } & \text { Management and Integration } \\ \text { M\&O } & \text { Management and Operations } \\ \text { MSA } & \text { major system acquisition } \\ \text { OMB } & \text { Office of Management and Budget } \\ \text { PDS } & \text { project data sheet } \\ \text { PNNL } & \text { Pacific Northwest National Laboratory } \\ \text { PPI } & \text { Producer Price Index } \\ \text { RL } & \text { Richland Operations Office } \\ \text { TPC } & \text { Total Project Costs } \\ \text { TRU } & \text { transuranic } \\ \text { TWRS } & \text { Tank Waste Remediation System } \\ \text { WBS } & \text { work breakdown structure } \\ \text { WDD } & \text { Waste Disposal Division } \\ \text { WHC } & \text { Westinghouse Hanford Company } \\ \text { WIT } & \text { Waste Disposal Integration Team } \\ \text { WVDP } & \text { West Valley Demonstration Project } \\ & \end{array}$




\section{References}

Boomer, K. D., J. Colby, T. Crawford, J. Garfield, J. Galbraith, C. Goldberg, C. Leach, D. Mitchell, F. Nankani, E. Slaathaugh, L. Swanson, T. Waldo, and C. Wrinkler. 1994. Tank Waste Remediation System Facility Configuration Study, WHC-SD-WM-ES-294, Rev. 0, Westinghouse Hanford Company, Richland, Washington.

Burns and Roe June 1998. Independent Cost Estimate to U.S. Department of Energy for Tank Waste Remediation System (TWRS DOE M\&O Contractor Cost Estimate), Burns and Rose, Inc., for the U.S. Department of Energy.

Keisler, J. M. and W. A. Buehring. 1996. Summary of the Technical Report on Estimating the Impact of Key Programmatic Risk Allocation Decisions on Phase 1 Bids and U.S. Department of Energy Costs. ANL/DIS/TM-41, Argonne National Laboratory, Argonne, Illinois.

U.S. Department of Energy Report to Congress. 1998. Treatment and Immobilization of Hanford Radioactive Tank Waste. U.S. Department of Energy, Richland, Washington.

U.S. Department of Energy. 1995. Life-Cycle Asset Management. DOE Order 430.1. U.S. Department of Energy, Washington, D.C.

Westinghouse Hanford Company. 1994. Tank Waste Remediation System Fiscal Year 1995 Baseline. WHC-SP-1101, Westinghouse Hanford Company, Richland, Washington.

Westinghouse Hanford Company. 1995. Initial Pretreatment Module Conceptual Design Report 30\% Review Package. WHC E/B-SD-W236B-RTP-031 Rev. 0A. Westinghouse Hanford Company, Richland, Washington. 


\title{
Appendix A
}

\section{DOE Cost-Savings From Private Contracting?}

\author{
Carlos Ulibarri, \\ Orman Paananen, and Mark Weimar \\ April 1998
}

Prepared for

the U.S. Department of Energy

Under Contract DE-AC06-76RLO 1830

Pacific Northwest National Laboratory

Richland, Washington 99352 


\section{Introduction}

As defined by DOE, privatization refers to a shifting of responsibilities for the completion of nuclear cleanup projects from a cost-plus Management \& Operations (M\&O) contract, to incentive-based contracts with the private sector. Private contracting is a welcome alternative to the current cost-plus approach, where $M \& O$ contractors work under DOE direction as sole source firms. In simplest terms, M\&O contractors behave as "cost-plus monopolies," their revenues reflect cost reimbursements plus predetermined profit margins proportional to project budgets. The absence of competitive bidding for contracts creates bureaucratic insularity and protects the M\&O's profit margins at the expense of taxpayers. In contrast, DOE's new vision is to arrange cleanup work around incentives-based contracts which are won via competitive bidding. Competition in awarding cleanup contracts can make use of market-incentives to lower project costs and reduce slippage time.

This study provides a normative argument for why DOE's bureaucratic contracting is economically inefficient by comparing between the bounding extremes of cost-plus and fixed-price contracting decisions. Fixed-pricing promotes a maximal incentive for contractors to minimize schedule delays and cost overruns. Conversely, cost-plus contracting makes ample room for opportunistic behavior by offering.weak incentives for contractors to select cost-minimizing production and management approaches. However an important caveat in judging between these contract choices is that competitive contractors are unlikely to seek fixed-price cleanup projects because of significant cost and managerial risks. More likely, contract agreements under cost-uncertainty will include both fixed-price and costplus elements.

Efficient-incentive contracts are an in-between solution to the allocation of cost-risk between the public and private sector. Under an incentives approach DOE would pay private contractor(s) for successful cleanup projects, and play a less active role in how contractors finance, design, build, and operate waste treatment, storage and disposal facilities. The use of competitively awarded incentive contracts to privatize these cleanup responsibilities would sharpen the penalties and rewards for completing projects on time and/or within budget, potentially yielding cost savings in performing DOE cleanup activities. This argument rests on the belief that a competitive contracting environment outperforms the current bureaucratic regime at penalizing cost overruns and schedule slippage.

An important and difficult empirical question arising in this study concerns the potential cost-savings to DOE from changing existing contracting practices. Under a conservative scenario, cost-savings from recontracting could range between 10 to $30 \%$ of an $\mathrm{M} \& \mathrm{O}$ project budget. However, the study argues that the magnitude of cost-savings from using incentive-based contracts as opposed to cost-plus contracts is critically dependent on contractor risk premiums. Specifically, a decentralized, privatized cleanup program shifts the risk of cost overruns from DOE onto the private sector. Private contractors who submit bids for nuclear cleanup projects will require risk premiums for bearing cost-risk. These risk premiums would be reflected in the competitive bidding process, and to some degree would offset some of the cost-savings of using incentive contracts. Therefore the "risk behavior" of private contractors is an important qualification in evaluating contract choices.

The study is organized as follows. Section 2 reviews cost-overrun experiences on comparable large-scale, pioneer projects completed under cost-plus and fixed-price contracts, and discusses their relations to faulty cost predictions, contractor inefficiency, and measurement bias. Section 3 develops a principalagent model to argue the benefits of auctioning incentive contracts and evaluates an optimal contract choice between the two extremes of cost-plus and fixed-price budgets. Following this, section 4 provides an approximate-estimate of adjusted cost savings from recontracting and describes why any inferences of cost-savings require a high degree of circumspection on the part of the reader. Section 5 summarizes the study. 


\section{Cost-Overruns}

Cost-overruns may be observed whenever initial cost estimates understate the expected cost of a project, or whenever contractor performance results in excessive realized costs. Both of these sources of costoverrun can be induced by bureaucratic contracts: contracts that offer no incentives for keeping realized costs under control, or for submitting unbiased estimates of expected costs. Even when bureaucratic contracts are awarded on the basis of cost-estimate bids, they can still motivate the underestimation of project costs - a manifestation of bureaucratic opportunism, making cost-plus projects costlier than envisioned. ${ }^{1}$ In the case of DOE, these projects are all "pioneer" or "first-of-a-kind" type of projects; that is, projects having high degrees of uncertainty surrounding technological and economic parameters. Given imperfect foresight, it is understandable that these initial cost estimates tend to be unreliable. ${ }^{2}$ However, it remains to explain why they are also consistently biased in a downward direction. Details of the argument are presented in Quirk and Teresawa (1986), but the intuition behind the argument can be summarized as follows.

Cost estimates are prepared in order to assist in decision making. Consider a situation where a bureaucratic decision must be made whether to initiate a project under cost uncertainty. The manager hires a cost estimator to provide an unbiased estimate of the expected cost of the project - half of the time cost is underestimated and half of the time it is overestimated. The manager acts rationally on the basis of the estimate by using Bayes' Rule to update his beliefs as to the expected cost. Clearly the estimate will trigger a "go" decision when the unbiased estimate is low. Projects for which sufficiently high estimates occur result in "no go" decisions. This gives rise to a "bottom-of-the-barrel" sample selection: even under the best of conditions with unbiased cost estimates and rational bureaucratic behavior, cost overruns will be observed on average for all completed projects. Why? Because the only projects having both cost estimates and actual costs are the projects that are actually undertaken, which tend to be the ones for which costs are underestimated.

Typically, cost overruns have been interpreted as evidence of poor cost estimates and inefficient contracting practices. But as the argument above suggests, this may not necessarily be the case. In fact, on average, initial cost estimates will tend to be less than the average realized costs for completed projects. Such (economically rational) cost overruns would not be eliminated by a change in contracting practices, say, from cost-plus to incentive contracting, nor would the elimination of such cost overruns be desirable. Moreover, the argument implies that raw data on cost overruns is fraught by noise. This fact is important in considering DOE's experience with cost overruns and schedule slippage; as summarized by the GAO (1996), this experience results from a pervasive do-loop of "managerial- and technologicalefficiency failures."

1 For example, Teresawa (1984) and Pegram (1984) examined the cost-estimate history of a number of defense projects. They find that when government cost-plus contracts are awarded on the basis of competitive bids, there are perverse incentives to misrepresent information - particularly when project uncertainties are used to justify ongoing records of large cost overruns. It should be noted that the Teresawa and Pegram results apply to the early proto-type pre-production stage of DOD projects when cost-plus contracts tend to be used, i.e., before fixed-price or incentive contracts are let for actual production of the weapons system.

${ }^{2}$ Cost-overruns appear in many facets of public procurement, as for example in the literature on defense procurement, e.g., Cummins (1977); Weitzman (1980); Peck and Scherer (1962) and Terasawa, Quirk, and Womar (1984); or the literature on privately financed construction projects, e.g., Merrow et al. $(1979,1981,1988$, and 1990); Montgomery, and Quirk (1978); Burness, Montgomery and Quirk (1980); and Quirk and Terasawa $(1981,1986)$. 
Table 1 provides descriptive statistics on cost overruns and schedule slippage for 13 DOE projects completed between 1980 and 1996 (GAO 1996). As used by GAO, cost overruns refer to "increases in projects' costs beyond original cost estimates." The GAO sample reflects "complete original cost estimates and final/current cost estimates." Cost-overrun is a random variable with a mean of $\$ 133.8$ million and standard deviation of $\$ 172.5$ million (measured in current dollars, as actual cost minus the initial cost estimate). Time slippage is also a random variable with a mean and standard deviation of 2.2 years (measured as time extension beyond the initial estimated completion date). The "observed" cost overrun variable $(Z)$ is normally distributed, as indicated by the relatively low J-B statistic (2.63).

Assuming interest rate penalties of $3 \%$ and $7 \%$ on time-slippage, full-cost overrun measures would range from $65 \%$ (at 0 interest) to $82 \%$ (at $7 \%$ interest) above initial cost estimates.

Correlation coefficients between time slippage and cost overrun measures are also reported in Table 1. A correlation coefficient of one would indicate a perfect relationship between cost overruns and time slippage, while a coefficient value of zero would indicate no relationship. Accordingly, the value of 0.67 confirms the intuition that cost overruns are strongly correlated with time slippage. Finally, the OLS regression estimates report how well time slippage (S) explains the percentage of M\&O cost overruns $\left(\mathrm{Z}_{0}, \mathrm{Z}_{1}\right.$, and $\left.\mathrm{Z}_{2}\right)$. The positive parameter estimates of $0.225,0.263$, and 0.321 are all statistically significant $(t>2)$, providing additional confirmation on the positivity of the cost overrun-time slippage relationship, implying that a 1-year project delay entails cost overruns of 22 to $32 \%$ above initial cost estimates.

These stylized facts seem illuminating, but by themselves cannot be accepted as evidence of inefficient contracting. In particular, the reader is reminded that cost overrun estimates can also be explained by underestimation biases arising from poor initial cost estimates or sample selection problems.

Consequently, there are inherent limitations in using the GAO data set for purposes of assessing the cost savings to DOE under incentive contracting. Providing definite evidence that incentive contracts would reduce project costs requires comparing realized project costs under incentive contracts with realized project costs under cost plus conditions, which is, of course, impossible in DOE's case. So instead, the present study is reduced to comparing DOE's cost overrun experience on cost-plus projects with "similar project experience" funded under fixed-price terms; obviously, such a comparative approach opens up arguments as to "how similar" and "similar in what respects?"

Finessing the comparison of two distinct contract forms rests on the observation that cost overrun and schedule slippage are a common occurence in large-scale, pioneer construction projects. In this context the literature on underestimation bias provides several well-known cases for evaluating cost overrun experiences involving fixed-price contracting under cost-risk, including: the construction of singlepurpose hydroelectric projects (Merrow et al. 1990), the contracting of nuclear reactor construction (Burness et al. 1980), and the development of advanced weapons systems (Quirk and Teresawa 1986). In considering among these cost overrun experiences, the present study focuses on cost overruns involving hydroelectric projects. These large, one-of-a-kind projects were supported by the World Bank and completed between 1970 and 1991. In most cases these projects experienced significant technical uncertainties from the time initial cost estimates were made up through completion of the projects. The World Bank study by Merrow et al. provides a careful examination of the case history.

The Merrow et al. study covers 49 hydroelectric projects completed between 1971 and 1990 with costs ranging between $\$ 35$ million and $\$ 1.6$ billion. The median project cost was about $\$ 221$ million and took an average of 6 years to complete. Among the key findings in the study is that average project costs exceeded initial appraisal estimates by about $24 \%$, with the average being skewed in the direction of higher cost-overruns. Also the projects exhibited substantial variability in cost growth as measured by the standard deviation of $32 \%$. Moreover, significant deviations exist between actual and scheduled completion dates, with the average schedule slip being about a year and a half beyond the scheduled 
completion date - some $25 \%$ over the initial appraisal. There is however significant variability in schedule slippage, as measured by the standard deviation of $27 \%$. The correlation estimate between schedule slip and project cost reveals moderate but positive relationship of 0.31 .

The interesting feature of the cost overrun and schedule slippage problems reported by Merrow et al. is that they occur under fixed-pricing, where incentives for efficiency are presumably the greatest. In most cases the authors recognize that these problems reflect significant bias in the preparation of initial cost estimates as opposed to realized cost growth (pgs. ii-iii). Technical and performance uncertainties are noted as key issues in the underestimation bias problem. From the perspective of the Bank and its borrowers, the tendency to underestimate project costs is of course troublesome; first in terms of leading planners to proceed with uneconomic projects and, subsequently, in creating additional financing difficulties during the project completion phase. Consequently, the authors recommend more preappraisal effort on project evaluations and design work to permit more accurate cost and schedule assessments. The same advice can be handed to DOE where, by comparison, cost overruns reflect measurement bias and the absence of cost-minimizing incentives. The following section makes a theoretical case for imposing these missing incentives.

\section{The Theoretical Case for Changing Contracting Practices}

Competitively awarded incentive-contracts offer DOE a rational way of reducing the misallocation of resources ascribed to current bureaucratic contracting; that is the excess of actual over minimum cost for a given level of output (Stigler 1976). In the absence of competively awarded contracts, M\&O firms have fewer (if any) incentives to minimize costs for a given output. Thus our case for privatizing cleanup projects under competitively awarded incentive contracts as opposed to cost-plus M\&O contracts is based on potential cost savings. ${ }^{3}$ As Sappington and Stiglitz (1987) put it, "competitive bidding by profitmaximizing firms for a well specified output guarantees that the product will be produced at the lowest cost. The absence of competition and profit incentives in the public sector is not likely to result in cost minimization." Imposing competition on sole source contractors would prevent them from charging abnormal profit margins and provide economic incentives for reducing the "hidden costs" in DOE's cleanup program - specifically, high rates of cost overruns and frequent schedule slippage. These problems are evidence of a smoking gun, and suggest the potential for cost savings in switching from cost-plus to competitively-awarded incentive contracts. Figure 1 illustrates the argument.

The sole-source contractor tends to exploit market-power by providing $\mathrm{Q}_{\mathrm{m}}$, units of cleanup services at a price of $P_{m}$ per unit - what amounts to a project bid $b_{m}=P_{m} \times Q_{m}$. The corresponding wedge between price $P_{m}$ and expected average costs $E(A C)$ reflects abnormal profit margins $\Pi=P_{m}-E(A C)>0$. Competitive bidding among contractors potentially results in a least-cost project bid approximating expected project costs $b^{*}=E(A C) \times Q_{c}$. The implied reduction in abnormal profit margins is desirable from the standpoint of economic efficiency. Under a fixed-fee award, the winning contractor would fulfill the project for a fixed price; the fixed price could not be readjusted to include actual cost experience. Meanwhile, incentive contracting allows DOE and the winning contractor to share cost overruns whenever actual cost experience deviates from the initial project bid. These contract choices are studied below based on a conceptual model of optimal contracting involving potential cost-saving and risk-sharing opportunities.

${ }^{3}$ Such allocation failures may arise from various primary sources, including: the degree of competitiveness in a firm's market, the extent to which the firm is incorporated into (or separated from) public-sector bureaucracy, and the nature of the regulatory regime under which a firm operates (Button and Weyman-Jones, 1992). 
DOE can obtain unbiased information concerning expected costs and achieve lower expected costs by awarding an incentive contract to the lowest bidder using a "second price" sealed bid auction, or Vickrey (1961) auction. In this setting the winning contractor is the low bidder, who is awarded the amount bid by the second lowest bidder. There is no incentive for contract bidders to misrepresent their beliefs because the bidders cannot do any better than to bid what the contract is worth to them. If all contractors were risk neutral, then each would bid what they believed to be the expected costs of the project (including a market rate of return to the bidder). With risk averse contractors, bids tend to reflect the expected cost of the project plus a premium for risk bearing, the premium rising the more risk averse is the bidder. ${ }^{4}$ This risk averting behavior is pursued on the assumption that competitive bidding among private contractors leads to an unbiased least-cost bid $b^{*}$. This least-cost bid is assumed to represent the private contractors unbiased initial cost-estimate for the project.

We extend the McAfee-McMillan model of contractor behavior (McAfee and McMillan 1986) to consider expected project cost under the Vickrey auction. Although this auction mechanism has useful theoretical properties, McAfee and McMillan (1987) and others observe it is seldom been used in practice. We assume $n(n>1)$ potential contractors bid in determining the project contractor. Let $b_{i}$ denote the bid of contractor $i$, the lowest cost bidder, and $b_{i}+\delta$ the next lowest contractor bid. In a competitive auction environment, we maintain contractor $i$ will bid to the point of remaining indifferent between winning the contract with $b_{i}$ or not winning the contract. We assume a symmetric Nash equilibrium of this bidding strategy exists and is characterized by a bid function $B$ : given the opportunity costs of the project $\left(c_{i}^{*}\right)$, contractor $i$ bids $b_{i}=B\left(c_{i}^{*}\right)$ and all other contractor bids exceed $b_{i}$. Each bidder's equilibrium strategy is to submit a bid equal to his own unbiased prediction of the project cost. In this framework, the ex post profits of contractor $i$ are independent of his own bid; in particular, his own bid determines only whether or not he wins - the amount he gets if he wins is beyond his control.

The project costs incurred by contractor $i$ are denoted by $c$ and have three components:

$$
c=c_{i}^{*}+w-e_{i}
$$

The first term, $\mathrm{c}_{\mathrm{i}}{ }^{*}$, represents the contractor's expected opportunity costs of the project which are known to contractor $\mathrm{i}$ ex ante but not known to any other contractor. Thus $\mathrm{c}_{\mathrm{i}}^{*}$ is taken as an independent realization of the distribution $\mathrm{G}\left(\mathrm{c}_{i}{ }^{*}\right)$ common to all contractors. The second term, w, denotes random project costs that are realized ex post and which take on the same value for all contractors. Thus $w$ is a random variable having a common probability distribution function denoted by $F(w)$. The third term, $e_{i}$, denotes actual cost-savings achieved from cost-reducing effort. The cost function $h\left(e_{i}\right)$ relates disutilities in achieving cost-savings; for example, the costs of supervising workers, monitoring the project managers, attending meetings, and so on.

\footnotetext{
4 A risk-neutral contractor negotiating with DOE would accept fixed-price contracts so long as the dollar amount is less than or equal to the expected project costs under an M\&O cost-plus contract - what is termed "fairinsurance." On the contrary, a risk-averse contractor would be willing to accept relatively higher fixed-price contracts. Consequently, an implication of risk-averse behavior is that contract bids beyond expected cost-overruns contain "risk premiums" that vary according to the degree of risk-aversion exhibited by private contractors.
} 
Meanwhile, the incentive contract awarded through the second-price auction mechanism has an ex ante cost to DOE reflecting the second lowest bid $\left(b_{s}\right)$, as represented by

$$
P=b_{s}+\alpha\left(c-b_{s}\right)
$$

where $\alpha$ is the share of cost overruns paid by DOE.

The profit equation for contractor i expresses the difference between DOE's payment (2) and project costs (1), minus the cost of the cost-saving effort $h\left(e_{i}\right)$; that is,

$$
\pi_{i}=(1-\alpha)\left[b_{s}-c_{i}^{*}-w\right]+k_{i}
$$

where

$$
k_{i}=(1-\alpha) e_{i}-h\left(e_{i}\right)
$$

Using the concept of order statistics, let $\left[1-\mathrm{G}\left(\mathrm{b}_{\mathrm{i}}\right)\right]^{\mathrm{n}-1}$ denote the probability of winning the contract with a bid of $b_{i}$. Hence, the contractor's expected utility from profits is

$$
E\left[U\left(\pi_{i}\left(b_{i}\right)\right)\right]=\left[1-G\left(b_{i}\right)\right]^{n-1} \int_{-i n f i n i t y}^{\text {infinity }} U\left((1-\alpha)\left(b_{i}-c_{i}^{*}-w\right)+k_{i}\right) d F(w) .
$$

This brings up the question of how contractor i chooses his bid. Because the contractor's ex post profits do not depend on the contractor's own bid, the optimal strategy is to lower the bid to the point of remaining indifferent between winning the contract with $b=b_{i}$, and not winning the contract. Given that $E[U(0)]=0$ if the contractor does not win the bid, then the lowest bid is that $b_{i}$ which results in an expected utility of 0 , assuming that the second lowest bid is arbitrarily close to $b_{i}$ (in the limit $b_{i} \rightarrow b_{s}$ ). The contractor would not bid any lower than $b_{i}$ because if he won with the second-best bid arbitrarily close to his, he ends up worse off than if he hadn't won-a "Winner's Curse." Conversely, if he bids any higher, say $b_{i}+\delta$, then he loses the contract to any bidder who comes in between $b_{i}$ and $b_{i}+\delta$, ending up worse than if he had bid $b_{i}$. The argument applies in determining the optimal bid strategy for both risk neutral and risk averse agents. Hence, to solve for the optimal bid for contractor $i$ in a Vickrey auction, $b_{i}$ is chosen so that $\mathrm{E}\left[\mathrm{U}\left(\pi_{\mathrm{i}}\right)\right]=0$; that is

$$
E\left[U\left(\pi_{i}\left(b_{i}\right)\right)\right]=\int_{-i n f i n i t y}^{\text {infinity }} U\left((1-\alpha)\left(b_{i}-c_{i}^{*}-w\right)+k_{i}\right) d F(w)=0 .
$$

In the case where all contractor utility functions are linear in profits, so that all contractors are risk neutral, the winning contractors' bid choice $\left(b_{i}\right)$ has the following closed-form solution: 


$$
b_{i}=c_{i}^{*}-\left[e_{i}-\frac{h\left(e_{i}\right)}{1-\alpha}\right]+E(w) .
$$

More generally, contractors may be risk averse toward random costs $\mathrm{w}$. In this case a risk premium must be added to (7). Letting $\rho_{\mathrm{i}}$ denote the risk premium for contractor $i$, his optimal bid becomes

$$
b_{i}=c_{i}^{*}-\left[e_{i}-\frac{h\left(e_{i}\right)}{1-\alpha}\right]+\rho_{i}+E(w) .
$$

Substituting this expression for $b_{i}$ in (6), implies $\rho_{i}$ satisfies

$$
\int_{-i n f i n i t y}^{\text {infiny }} U\left((1-\alpha)\left[\rho_{i}+E(w)-w\right]\right) d F(w)=0
$$

Assuming identical utility functions, $\rho_{i}=\rho_{j}=\rho$ for any contractor $i$ and $j$. Thus, in a Vickrey auction, the bid chosen by a risk averse bidder equals the bid in the risk neutral case plus a risk premium (relating to $\alpha$ and $w$ ), where the risk premium is solved for from (9). Accordingly if $\mathrm{E}(\mathrm{w})=0$, the risk neutral bid covers the opportunity costs in taking the project $\left(\mathrm{c}_{\mathrm{i}}{ }^{*}\right)$, minus the net social return to the contractor's costreduction activities $\left[\mathrm{e}_{\mathrm{i}}-\mathrm{h}\left(\mathrm{e}_{\mathrm{i}}\right)(1-\alpha)^{-1}\right]$.

As shown in (7) or (8), DOE's choice of cost-sharing $(\alpha)$ complicates the payment to the contractor; in particular, cost-sharing influences the level of cost-saving effort expended by the winning contractor. Following McAfee and McMillan (1986), the issue is examined from the contractors' first-order condition with respect to cost-saving effort $\left(e_{i}\right)$, where partial differentiation of $(6)$ with respect to $e_{i}$ yields

$$
\begin{gathered}
\frac{\partial E\left[U\left(\pi_{i}\left(b_{i}\right)\right)\right]}{\partial e_{i}}=E\left[U^{\prime}\left(\pi_{i}\right)\right]\left(1-\alpha-h_{e}\right)=0 \\
\text { implies } \quad e_{i}^{\dot{*}}=h_{e}^{-1}(1-\alpha) .
\end{gathered}
$$

As shown in (10), contractor i will put forth less cost-saving effort the larger the share of cost overruns paid by DOE: hence, $e \rightarrow 0$ as $\alpha \rightarrow 1$. In the limiting case of cost-plus contracting $(\alpha=0)$, cost-saving effort vanishes altogether. This principal-agent problem is central to the present study.

In a Vickrey auction, DOE's expected payment under an incentives contract would depend on its impact on the contractor's cost-controlling behavior, as well as the second lowest bid $\left(b_{s}=b_{i}+\delta\right.$, where $\delta$ denotes the bid spread). The expected payment is defined by taking the mathematical expectation of (2), having substituted (7) or (8) for $b_{i}$ and (1) for $c$, yielding 


$$
\begin{array}{cc}
(1-\alpha) \delta+c_{i}^{*}+\bar{w}-\left[e_{i}-h\left(e_{i}\right)\right] & \text { risk neutral, } \\
E(P)= & \\
(1-\alpha)(\delta+\rho)+c_{i}^{*}+\bar{w}-\left[e_{i}-h\left(e_{i}\right)\right] & \text { risk averse. }
\end{array}
$$

If risk averse contractors produce unbiased estimates of project costs, $E(w) \rightarrow 0$, then the expected payment $\mathrm{E}(\mathrm{P})$ covers DOE's share of the bid spread and risk premium $(1-\alpha)(\delta+\rho)$, plus the contractor's opportunity costs $\mathrm{c}_{i}^{*}$, minus the net social returns from the contractor's cost-reducing activities, $\left[\mathrm{e}_{\mathrm{i}}-\mathrm{h}\left(\mathrm{e}_{\mathrm{i}}\right)\right]$. Reduced cost-sharing increases the level of cost-saving effort, and the resulting cost-savings appear in (11) in the form of a lump-sum payment to DOE. Conversely, increased cost-sharing causes a moral hazard problem by lowering private cost-saving efforts, and by enabling high-cost contractors to shade their bids. Based on these arguments, DOE's cost-plus contracts result in resource misallocation by failing to select least-cost contractors. These considerations are examined below in evaluating the potential cost savings from DOE's recontracting decision.

\section{Approximating the Cost-Savings}

Saving money by recontracting DOE's pioneer megaprojects is a noble goal, but are there reasonable assurances DOE would experience cost-savings in switching from cost-plus M\&O contracts to incentive contracting? True, one does observe significant cost-overrun and schedule slippage problems in DOE's traditional cost-plus M\&O contracting. But how certain can anyone be that these cost overruns would be any less under a competitively awarded incentive contract? After all, DOE has no history on which to infer the impact of using second-price auctions in recontracting nuclear cleanup projects. Moreover, using cost overrun data from DOE cost-plus projects to estimate cost savings under incentive contracting is open to criticism - any way you cut it, the empirical estimation is mired by data limitations. ${ }^{5}$ The approach taken here reduces the problem to one of comparing actual cost overrun experiences at DOE and the World Bank based on the cost-minimizing framework described above.

As previously noted, DOE's cost overrun experience under cost-plus contracts provides a biased estimate of expected cost gains from swithching to incentive contracts. The most critical reasons for this bias concern initial cost estimation errors and the behavioral response of contractors to project cost uncertainties. First, the fact that there are no liabilities from underbidding cost-plus contracts suggests the potential for downward bias in the initial cost-plus estimates. This initial-cost bias inflates any type of cost-savings projection that is based exclusively on cost-plus overruns. Secondly, recontracting toward incentives imposes greater cost-risk on private contractors. With risk averse contractors, bids will reflect the expected cost of the project plus a premium for risk bearing, the premium rising the more risk averse the contractor. Together, these behavioral concerns make quantitative projections of cost savings an extremely difficult task-an approximation at best.

\footnotetext{
5 The technique of using cost overrun data from previous projects as a proxy for cost savings under incentive contracting was attacked during Robert McNamara's tenure at the Department of Defense. McNamara acted to replace in large part the previous system of cost-plus contracting with incentive contracts, projecting large cost savings at DOD - in the range of $10 \%$ of the DOD procurement budget. However, subsequent studies at RAND by Perry et al. (1969, 1971), Harman (1971), and Scherer (1964) cast doubt on these projections owing to a lack of incentive contracting experience at DOD. Furthermore, the studies pointed out that cost overruns at DOD were as frequent and averaged as large under the McNamara regime of incentive contracts as they had been when cost-plus contracts were used.
} 
Using the framework outlined in section 3, a simple formulation of the potential cost-savings to DOE from switching to an incentives-based contract is defined by the difference in expected payments under cost-plus and incentive contracting $E\left(P_{c p}\right)-E\left(P_{i}\right)$. Evaluating expression (11) under these two alternatives, yields the following measure of expected cost savings to DOE from recontracting

$$
E\left(P_{c p}\right)-E\left(P_{i}\right)=\left[e_{i}-h\left(e_{i}\right)\right]-(1-\alpha)(\delta+\rho)
$$

The expression recognizes the net social value afforded by the contractor's cost-saving behavior $\left[\mathrm{e}_{\mathrm{i}}-\mathrm{h}\left(\mathrm{e}_{\mathrm{i}}\right)\right]$, minus DOE's cost-sharing of the bid spread and risk premium $(1-\alpha)(\delta+\rho)$. Several qualitative comments are in order in proceeding with the estimation of these two terms.

First, a conservative estimate of initial-cost estimation bias would reflect minimum errors in prediction, which tend to be minimized in second-price auctions over fixed-price contracts wherein incentives for accurate cost appraisals are presumably the greatest. For example, consider the average cost overruns observed by Merrow et al. (1990) on World Bank funded projects, i.e., $25 \%$ over a sample of 49 projects. Analyzing initial project costs, Merrow et al. conclude that most of the observed cost overruns are due to poor initial cost estimation-a finding that supports the use of $25 \%$ as a rough proxy in adjusting for the measurement bias in DOE's initial cost estimates. Making this adjustment nets an adjusted cost overrun of $40 \%$. This cost overrun measure is taken as a point estimate of gains from the contractor's cost-saving behavior, i.e., $\left[\mathrm{e}_{\mathrm{i}}-\mathrm{h}\left(\mathrm{e}_{\mathrm{i}}\right)\right]=40 \%$.

However this measure remains an inflated projection of the gains from recontracting. The sticking point is the cost-sharing involving the Vickrey bid spread and contractor risk premium. Some qualitative remarks are warranted. First, the contractor's risk premium will tend to reflect the difference in rates of return required on any given project performed under an incentives contract as opposed to a cost-plus contract. Thus one possible way of measuring the risk premium from recontracting is to compare target profits for "similar projects" under the alternate contracts. Unfortunately, DOE's past experience with incentive contracting is limited to only a few fixed-price projects, and even these are quite removed from the nuclear cleanup program. Accordingly, the present study is not well-served by direct estimates of risk premiums in the cost savings measure. A similar shortcoming arises in measuring the spread between the first- and second-best bids: DOE has no experience in auctioning nuclear cleanup contracts. Consequently, any estimates of these incremental costs from recontracting should be viewed as rough approximations, at best.

Here, a best-case projection is based on the conservative assumptions that:

1) DOE uses a 50-50 cost-sharing of cost overruns

2) that the least-cost bid to recontract is equivalent to the initial cost estimates observed under the current bureaucratic contract, resulting in identical profit margins

3) that the corresponding bid spread between the least-cost and second-best bids has a parametric value equal to the contractor's risk premium: $\delta=\rho=0.20$. Under these parametric assumptions the incremental costs of recontracting amount to a $20 \%$ increase in costs, i.e., $0.20=(1-\alpha)(\delta+\rho)$. The scenario provides a cost-savings estimate of $20 \%$. Thus, a conservative scenario which ignores reductions in abnormal profit margins still leaves ample room for cost-savings from recontractingsomewhere between 10 and $30 \%$ of the current cost-plus contract. Clearly, this projection is a "backof-the-envelope approximation." The fact that privatization contracts have not been used in DOE's nuclear cleanup program suggests the sketchiness of any projection, including the present one. 


\section{Summary}

The absence of competition in DOE's nuclear cleanup program has resulted in M\&O contractors failing to minimize project costs. Project costs could be reduced by allowing private contractors to compete for the rights to perform cleanup projects under incentive contracts. The present study concerns the use of these contracting instruments in DOE's Environmental Management (DOE-EM) activities, which are currently carried out by M\&O contractors on a cost-plus basis. As envisioned, DOE's "privatization" effort calls for recontracting its nuclear cleanup projects under fixed-price terms based on competitive bidding among private contractors. This is a welcome change, offering the potential for greater economic efficiency in the performance of DOE's EM activities.

Awarding cleanup contracts through competitive bidding increases economic efficiency by imposing incentives to reduce abnormally high profit margins and minimize schedule delays and cost overruns. Conversely, the current bureaucratic cost-plus contracts stimulate higher profit margins while offering no meaningful incentives for sole source contractors to select cost-minimizing production and management approaches. Comparing the two extremes, the present study argues that private contractors are unlikely to agree to fixed-pricing because of the significant cost and managerial uncertainties involved in the privatization of DOE's large-scale, pioneer cleanup projects. More likely, successful privatization contracting under cost-uncertainty will include both fixed-price and cost-plus elements.

Cost-benefit analysis implies that the gains from recontracting will depend positively on competitive pressures to reduce cost overruns and sole-source profit margins, and depend negatively on the potential risk premiums required by contractors for risk-bearing under an incentives contracting regime. A conservative cost-savings projection is pursued using a sample of thirteen DOE-EM cost-plus projects completed between 1980 and 1996, and 49 World Bank fixed-price projects completed between 1971 and 1990. The study projects cost savings of between 10 to $30 \%$ relative to using cost-plus M\&O contracting - the absence of risk premium and risk-sharing information precludes making more accurate quantitative projections.

Ultimately however, the limitations of noisy data should not detract attention from the real issue at hand: that DOE's cost-plus M\&O contracts leave much to be desired by way of meeting scheduled deadlines and minimizing project costs. Given the extent of DOE's cost-plus overruns, the study concludes there is ample room for cost-savings from private contracting. The mere fact that incentive-contracting can help discipline this bureaucratic bungling makes for a chance worth taking. What is there to lose? 
Table 1

DOE Cost Overruns

Descriptive Statistics

\begin{tabular}{|c|c|c|c|c|c|c|}
\hline & Mean & $\begin{array}{l}\text { Standard } \\
\text { Deviation }\end{array}$ & Skewness & Kurtosis & $\begin{array}{l}\text { Jarque-Bera } \\
\text { statistic }\end{array}$ & $\begin{array}{l}\text { Time-slippage } \\
\text { correlation } \\
\text { coefficients }\end{array}$ \\
\hline$S=$ Time slippage & 2.2 & 2.2 & 1.17 & 3.40 & 3.04 & 1.00 \\
\hline $\mathrm{C}_{\mathrm{ic}}=$ Initial cost & 469.3 & 641.7 & 2.57 & 8.38 & 30.05 & -0.22 \\
\hline$C_{f c o}=$ Actual cost & 603.1 & 615.3 & 2.21 & 7.02 & 19.30 & -0.04 \\
\hline$C_{\mathrm{fcl}}=$ Full cost $(3 \%)$ & 620.2 & 621.6 & 2.09 & 6.53 & 16.22 & 0.01 \\
\hline $\mathrm{C}_{\mathrm{fc} 2}=$ Full Cost $(7 \%)$ & 647.5 & 637.7 & 1.90 & 5.68 & 11.74 & 0.10 \\
\hline$Z=$ Cost overrun & 133.8 & 172.5 & 1.07 & 3.53 & 2.63 & 0.67 \\
\hline $\begin{array}{l}Z_{0}=\text { Cost overrun as } \\
\% \text {-age of initial cost }(0 \%)\end{array}$ & 0.65 & 0.81 & 0.73 & 2.00 & 1.70 & 0.41 \\
\hline $\begin{array}{l}Z_{1}=\text { Full-cost overrun as } \\
\% \text {-age of initial cost }(3 \%)\end{array}$ & 0.72 & 0.88 & 0.64 & 1.69 & 1.80 & 0.49 \\
\hline $\begin{array}{l}Z_{2}=\text { Full-cost overrun as } \\
\% \text {-age of initial cost }(7 \%)\end{array}$ & 0.82 & 1.01 & 0.61 & 1.58 & 1.91 & 0.59 \\
\hline \multicolumn{7}{|l|}{ OLS Regressions } \\
\hline \multicolumn{7}{|l|}{$\begin{array}{c}\left.Z_{0}=0.225 * S \quad \text { (at } 0 \%\right) \\
(t=3.18)\end{array}$} \\
\hline $\begin{array}{c}\left.Z_{1}=0.263 * S \quad \text { (at } 3 \%\right) \\
(t=3.61)\end{array}$ & & & & & & \\
\hline $\begin{array}{c}Z_{2}=0.324 * S \quad \text { (at 7\%) } \\
(t=4.23)\end{array}$ & & & & & & \\
\hline
\end{tabular}

Notes: Initial cost, actual cost, and time slippage data are from Appendix II, GAO (1996) and relate to completed DOE Major System Acquisitions (MSA projects) completed during 1980 through 1996. Cost overrun is calculated as actual minus initial cost. Time slippage is calculated as the time period between project completion and estimated completion. Percentage cost overruns are calculated relative to initial cost estimates using $0 \%, 3 \%$ and $7 \%$ interest rate costs. The Jarque-Bera (J-B) statistic tests the normality of variables and is distributed $\chi^{2}$, with 2 d.f. Normality cannot be rejected at the $95 \%$ level for J-B statistics < 5.99. The t-statistics on OLS regression parameters are significant at the $95 \%$ level but not the $99 \%$ level. 


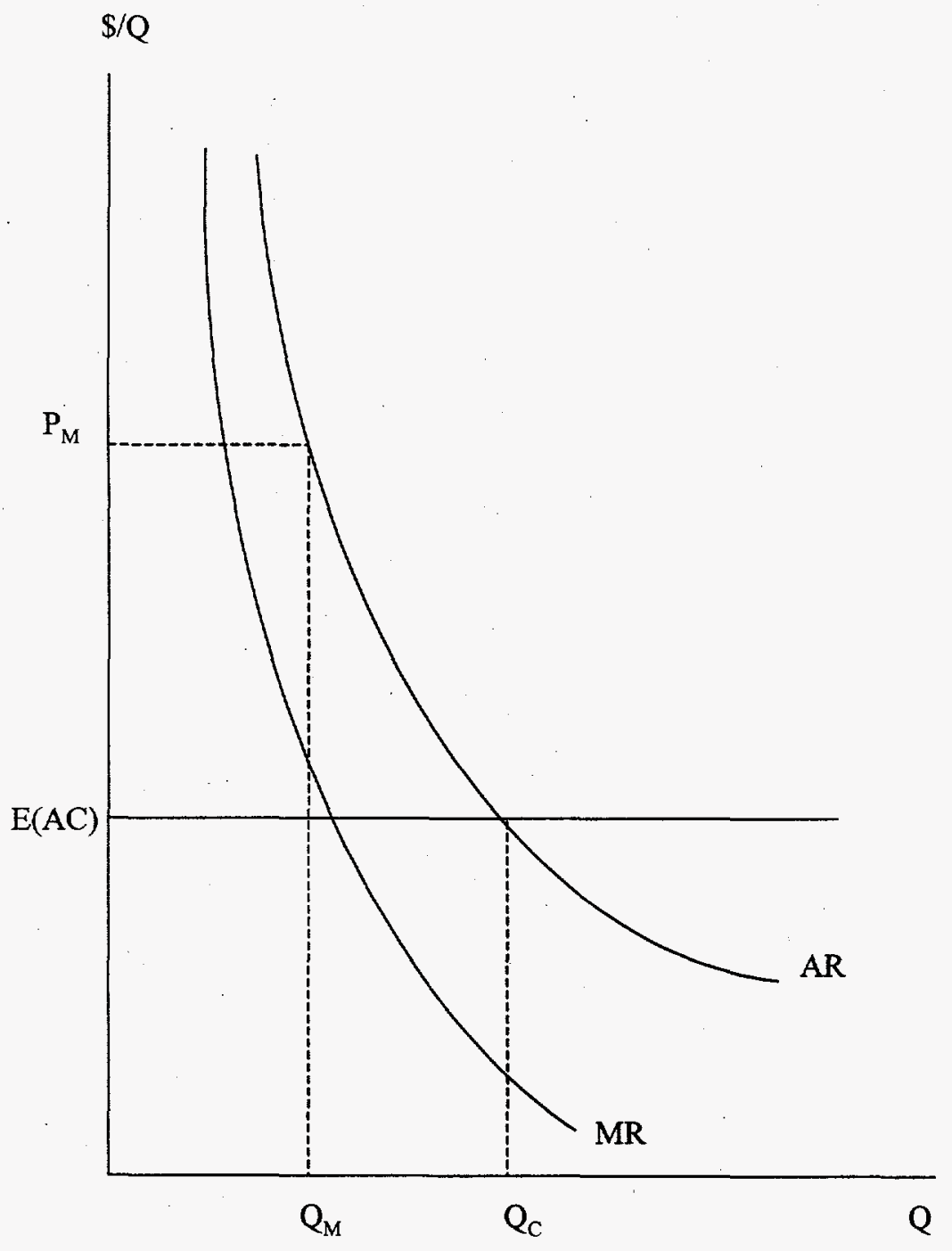

Figure 1. Efficiency Gains

\section{References}

Burness, H.S., and D. Montgomery, and J. Quirk. 1980. “The Turnkey Era in Nuclear Policy." Land Economics 56 (May): 188-202.

Button, K.J., and T.G. Weyman-Jones. 1992. "Ownership Structure, Institutional Organization and Measured X-Efficiency." American Economic Review 82(2), (May): pgs. 439-445.

Cummins, J. 1977. "Incentive Contracting for National Defense: A Problem of Optimal Risk Sharing." Bell Journal of Economics and Management 8 (Spring): 168-185.

GAO. 1996. Department of Energy: Opportunity to Improve Management of Major System Acquisitions, GAO/RCED-97-17 (November).

Harman, A. (1971). "Acquisition Cost Experience and Predictability," RAND Report P-4505 (January). 
McAfee, P, and J. McMillan. 1986. "Bidding for Contracts: A Principal-agent Analysis," Rand Journal of Economics, 17(3), (Autumn): pgs. 326-338.

McAfee, P, and J. McMillan. 1987. “Auctions and Bidding," Journal of Economic Literature, Vol. XXV (June): pgs. 699-738.

Merrow, E., K. Phillips, and C. Myers. 1981. "Understanding Cost Growth and Performance Shortfalls in Pioneer Process Plants.” R-2569-DOE, (September).

Merrow, E., R. Shangraw, et al. 1990. "Understanding the Costs and Schedules of World Bank Supported Hydroelectric Projects.” R-89-04-WB, The RAND Corporation, (July).

Merrow, E., S. Chapel and C. Worthing, 1979. "Review of Cost Estimation in New Technologies." R2481-DOE, The RAND Corporation, (July).

Merrow, E., L. McDonnell and R. Arguden, 1988. "Understanding the Outcomes of Megaprojects: A Quantitative Analysis of Very Large Civilian Projects," R-3560-PSSP, The Rand Corporation, (March).

Montgomery, D. and J. Quirk. 1978. "Cost Escalation in Nuclear Power." EQL Memorandum No. 21, Environmental Quality Laboratory, California Institute of Technology, (January).

Peck, M., and F. Scherer. 1962. The Weapons Acquisition Process. Cambridge, Mass.: Harvard University Press.

Pegram, William. 1984. "Capital Investment by Defense and Non-Defense Firms," (mimeo), Jet Propulsion Laboratory.

Perry, R. et al., 1969. “System Acquisition Experience," RAND Report RH-6072--PR, (November).

Perry, R. et al., 1971. “System Acquisition Strategies,” RAND Report R-733-PR/APRA, (June).

Quirk, J. and K. Terasawa. 1981. "Nuclear Regulation: An Historical Overview." Natural Resources Journal 21 (Oct.): 833-855.

Quirk, J. and K. Terasawa. 1986. "Sample Selection and Cost Underestimation Bias in Pioneer Projects," Land Economics 62 (May): 192-200.

Sappington, D.E. and J.E. Stiglitz. 1987. "Privatization, Information and Incentives," Journal of Policy Analysis and Management, 6(4): ppg. 567-582.

Scherer, F. 1964. "The Theory of Contractual Incentives for Cost Reduction," Quarterly Journal of Economics, Vol. 78; pgs. 692-694.

Stigler, G. 1976. "The Xistence of X-Efficiency." American Economics Review 66:213-216.

Terasawa, K., J. Quirk and K. Womar. 1984. "Turbulence, Cost Escalation and Capital Intensity Bias in Defense Contracting." Social Science Working Paper 508, California Institute of Technology; (January).

Terasawa, K. 1984. “Cost of Production Rate Uncertainty," Report AC-RR-84-002, Arroyo Center, Jet Propulsion Laboratory, (May). 
Vickroy, W. 1961. "Counterspeculation, Auctions, and Competitive Scaled Tenders.” Journal of Finance 16:8-37.

Weitzman, M. 1980. "Efficient Incentive Contracts." Quarterly Journal of Economics, 94: 719-730.

\section{Bibliography}

Cummings, R.C. et. al. 1997. "Risk Reduction and the Privatization Option: First Principles." The Joint Institute for Energy and Environment (September).

Dupuit, J. 1844. "On the Measurement of the Utility of Public Works," first published in Annales des Ponts et Chussees, ser. 2, No. 8 (1944); English translation in International Economics Papers, No. 2 (London: MacMillan, 1952).

Farrell, M.J. 1954. "The Measurement of Productive Efficiency," Journal of the Royal Statistical Society, Series A. 1957, 120(3): pgs. 253-282.

Frantz, R.S. 1988. X-Efficiency Theory, Evidence and Applications, Boston: Kluwer, 1988.

GAO. 1997a. Nuclear Waste: DOE's Estimates of Potential Savings from Privatization Cleanup Projects, GAO/RCED-97-49R (January).

GAO. 1997b. Privatization: Lessons Learned by State and Local Governments, GAO/GGD-97-48 (March).

Howe, C.W. 1971. Benefit-Cost Analysis for Water System Planning, American Geophysical Union, Washington D.C.

Klein, M. 1996. "Risk, Taxpayers, and the Role of Government in Project Finance," World Bank Publication \#1688 (December).

Leyden, D.P. and A.N. Link. 1993. "Privatization, Bureaucracy, and Risk Aversion," Public Choice 76: Pgs. 199-213.

Henderson, J.M. and R.E. Quandt. 1981. Microeconomic Theory A Mathematical Approach, 3rd edition, (New York, McGraw-Hill Book Company, 1981).

Leibenstein, H. 1978. "On the Basic Proposition of X-Efficiency Theory," American Economic Review 68(2), (May): pgs. 328-334.

Lopez-de-Silanes, F., A. Shleifer and R.W. Vishny. 1995. "Privatization in the United States," Working Paper Series No. 5113, National Bureau of Economic Research, Inc. (May).

Lopez-de-Silanes, F., A. Shleifer and R.W. Vishny. 1997. "Privatization in the United States," Rand Journal of Economics 28(3), (Autumn): pgs. 447-471.

Merrifield, J. 1997. "Sensitivity Analysis in Benefit-Cost Analysis: A Key to Increased Use and Acceptance," Contemporary Economic Policy (July): pgs. 82-92. 
E.J. Mishan. Economics for Social Decisions Elements of Cost-Benefit Analysis, (New York, Praeger Publishers).

Pack, J.R. 1987. "Privatization of Public-Sector Services in Theory and Practice," Journal of Policy Analysis and Management 6(4): pgs. 523-540.

Quirk, J. and K. Terasawa. 1991. "Choosing a Government Discount Rate: An Alternative Approach," Journal of Environmental Economics and Management 20: Pgs. 16-28.

Stevens, J.B. 1993. The Economics of Collective Choice, (Oxford, West View Press, 1993).

Varian, H.R. 1992. Microeconomic Analysis, third edition, (New York, W.W. Norton \& Company).

Williamson, O.E. 1975. Markets and Hierarchies: Analysis and Antitrust Implications, (London, MacMillan Publishers). 


\section{Appendix B}

Methodology for Assessment of Cost Savings

Under TWRS Privatization
O. Paananen
D. B. Belzer

January 1998

Prepared for

the U.S. Department of Energy

Under Contract DE-AC06-76RLO 1830

Pacific Northwest National Laboratory

Richland, Washington 99352 


\section{Methodology for Assessment of Cost Savings Under TWRS Privatization}

\subsection{Introduction}

The Department of Energy (DOE) has initiated a privatization strategy to begin processing radioactive wastes stored in large underground storage tanks at the DOE Hanford Site in the state of Washington. The wastes are a legacy from plutonium production during World War II and the Cold War. Hanford has 177 underground storage tanks, with 67 tanks leaking or suspected of leaking wastes into the soil and groundwater systems.

The tank wastes at Hanford are among the most complex and challenging environmental problems facing the United States. Unresolved technical and regulatory issues and the significant cost associated with building and operating facilities to process radioactive materials will require large financial outlays to support the Tank Waste Retrieval System (TWRS) during the next decades. At present, the current estimated cost of the tank waste cleanup is 30 to 45 billion dollars.

The first privatization activity under the Hanford TWRS program is anticipated to be liquid tank waste vitrification ${ }^{1}$. As initially designed, TWRS would be cleaned up in two phases. Phase I anticipated two contractors building pilot plants that demonstrated privately owned, designed, financed, constructed, and operated facilities that could remediate approximately 6 to $13 \%$ of the tank waste. In phase II contractors would build and operate production-sized facilities to complete the cleanup.

The TWRS privatization contracts divided Phase I into two parts, A and B. Part A of Phase I of the TWRS privatization project involved two contract teams that developed demonstration vitrification processes and proposals for Part B of Phase I (Phase I-B). During Part B, the contractors would design, finance, construct, and operate the facilities. A major goal of the TWRS privatization initiative is to reduce government costs through use of private capital to design and construct the vitrification facilities, with DOE paying for the service of vitrifying the wastes. In addition, DOE expects to issue fixed-price contracts for vitrification services rather than the traditional cost-plus contracts normally used by DOE.

The assessment of anticipated cost savings from privatization is an element of determining whether the privatization alternative in the TWRS Authorization to Proceed (ATP) provides the best value to the Government. The ATP decision recommendation will require cost savings assessment at two levels: first, evidence of cost savings during Phase I-B from selection of a privatization alternative; and second, evidence of cost savings over the full life cycle of the TWRS program. Evidence of cost savings comes from comparisons of cost estimates for privatized and cost-plus Management and Operations (M\&O) contractor options, evidence of cost growth under past $\mathrm{M} \& \mathrm{O}$ contractor and privatized projects, and discussion of the theoretical and empirical cost outcomes under privatized fixed-price and cost-plus M\&O conditions. This paper describes the methodology for the cost comparisons between the privatized and $\mathrm{M} \& \mathrm{O}$ options.

Evidence of cost savings in Phase I will vary depending on whether none, one, or two contractors are authorized to proceed into Part B of Phase I. Evidence of cost savings over the life cycle of the TWRS project will depend on the costs of Phases I and II privatization functions (including the number of

\footnotetext{
${ }^{1}$ Privatization is defined as contracting for services with a privately financed contractor. Because the Department of Energy's Management and Operations contractor is financed by the government and operates under a costreimbursable contract and has the same incentives as government employees for cost minimization, the privately financed contracting mechanism is called privatization.
} 

high level waste (HLW) vitrification, and deactivation of facilities. Decommissioning and infrastructure costs were not included since the contractors will not incur the costs. The M\& O cost estimates were developed using information from several studies. The studies included: the Westinghouse Hanford Company (WHC) Facility Configuration Study, Multi-Year Work Plan (MYWP) information, Savannah River Site Defense Waste Processing Facility (DWPF) data, WHC data supporting a Fiscal Year 1996 (FY96) independent cost estimate (ICE), and an independent cost assessment (ICA) performed by the Department of Energy's Field Management Office (FM-20) in FY96. The set of M\&O cost estimates establishes a range of M\&O Phase I hard costs. FM-20 independently developed an additional M\&O cost estimate.

In addition to developing hard cost estimates, other costs, such as the cost of federal funds, need to be included in the $M \& O$ hard cost estimate to establish full M\&O costs.

\section{Full $\mathrm{M} \& \mathrm{O}$ costs are}

- "hard" cost estimates of design, construction, operations, and decommissioning costs, including engineering cost contingencies (but not cost growth contingencies)

- government cost of capital during design and construction

- M\&O fees (profits)

- federal tax payments over Phase I.

Additionally, past experience with large cost-plus contracts shows cost and schedule overruns in many cases. The $\mathrm{M} \& \mathrm{O}$ full cost estimate needs to be adjusted to reflect expected project cost increases.

\section{M\&O cost adjustments are}

- expected cost and schedule increases under cost-plus contracting during design and construction based on past cost and schedule growth evidence

- expected cost increases under cost-plus contracts over fixed-price private sector costs during operations.

The adjusted full costs, including expected cost increases, represent the estimated overall cost to the federal government or society for Part B of Phase I activities under M\&O cost conditions. Federal tax payments are netted out since these funds represent returned revenue to the government. Cost streams are discounted to obtain a net present value (NPV) for adjusted M\&O Phase I-B costs.

Adjusted full $\mathrm{M} \& \mathrm{O}$ costs are

$$
\begin{gathered}
A F C_{m}=\left[\left(\Sigma D C_{m, t}\right)\left(C_{m, d c}\right)\right]\left(1 /(1+r)^{t}\right)+\left[\left(\Sigma O_{m, t}\right)\left(C_{m, t}\right)\right]\left(1 /(1+r)^{t}\right)+\left[\Sigma K_{m, t}(1+i)^{t}\right]\left(1 /(1+r)^{t}\right)+F_{t}(1+r)^{t} \\
-T_{t}\left(1 /(1+r)^{t}\right)
\end{gathered}
$$

where

$$
\begin{array}{ll}
\mathrm{AFC}_{\mathrm{m}} & =\text { Adjusted full cost estimate for Part } \mathrm{B} \text { Phase I M\&O scope of work } \\
\mathrm{DC}_{\mathrm{m}} & =\mathrm{M} \& \mathrm{O} \text { design and construction costs } \\
\mathrm{C}_{\mathrm{m}, \mathrm{d}} & =\mathrm{M} \& \mathrm{O} \text { expected cost growth during design and construction } \\
\mathrm{O}_{m} & =\mathrm{M} \& O \text { operating costs } \\
\mathrm{C}_{\mathrm{m}} & =\mathrm{M} \& O \text { expected cost growth during operations } \\
\mathrm{K}_{\mathrm{m}} & =\text { Government capital for design and construction } \mathrm{F}=\mathrm{M} \& O \text { fee or profit } \\
\mathrm{T} & =\mathrm{M} \& O \text { federal taxes }
\end{array}
$$




$\begin{array}{ll}\mathbf{r} & =\text { Discount rate } \\ \mathrm{I} & =\text { Federal borrowing rate } \\ \mathrm{t} & =\text { Time, in years }\end{array}$

If it is assumed that the federal borrowing rate is equal to the discount rate, the net present value of the incremental cost of government capital for design and construction will be zero.

2.2 Contractor Costs under Privatization. Full contractor costs are contractor fixed-price bids including design, contraction, operations, and decommissioning functions, and associated contingencies. In addition, contractor bids will include:

- contractor cost of capital for design and construction

- expected rate of return

- federal tax payments over Part B of Phase I.

Historical evidence exists that indicates that cost and schedule overruns do occur under fixed-price contracting for large projects, although at different (lower) rates than under cost-plus contracting regimes. Contractor bids, or the initial estimate of full contractor costs, are adjusted to reflect expected cost and schedule increases.

Contractor cost adjustments are

- expected cost and schedule increases under fixed-price contracting

- expected cost increases during operations

- expected price improvements (cost decreases to the government) during operations if competition is maintained in Part B of Phase I.

Expected cost increases and expected price decreases under competition are combined to estimate net cost change during operations to the government.

If contractors propose full firm-fixed prices for Part B of Phase I that are found to be reasonable, then contractor prices reflect all costs except expected cost growth during design and construction, and expected net cost changes during operations. Adjusted full contractor costs using contractor Part A deliverables are

$$
\mathrm{AFC}_{\mathrm{p}, \mathrm{b}}=\left[\left(\mathrm{BID}_{\mathrm{o}}\right)\left(\mathrm{C}_{\mathrm{p}, \mathrm{i}}\right)\right]\left(1 /(1+\mathrm{r})^{t}\right)-\mathrm{T}_{\mathrm{t}}\left(1 /(1+\mathrm{r})^{t}\right)
$$

Where

$\begin{array}{lll}\mathrm{AFC}_{\mathrm{p}, \mathrm{b}} & = & \text { Contractor-adjusted full cost estimate based on Part A deliverables } \\ \mathrm{BID}_{\mathrm{o}} & = & \text { Contractor bid to perform proposed Part B Phase I scope of work } \\ \mathrm{C}_{\mathrm{p}, \mathrm{i}} & = & \text { Expected contractor cost growth during Phase I } \\ \mathrm{T} & = & \text { Federal taxes paid by contractor } \\ \mathrm{r} & = & \text { Discount rate } \\ \mathrm{t} & = & \text { Time, in years }\end{array}$

Evidence is not currently available to estimate cost differentials between private sector and $M \& O$ decommissioning activities. 


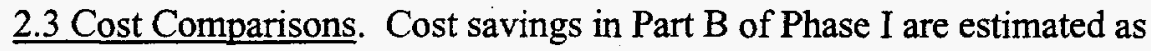

$$
C S_{P H I}=A F C_{m}-\Sigma\left(A F C_{p}\right)
$$

where contractor-adjusted full costs may reflect one, two, or no privatized Part B Phase I contractors being authorized to proceed into Part B. For example, if two contractors are selected for Phase I, the adjusted full cost for the $\mathrm{M} \& \mathrm{O}$ is adjusted to reflect a production capacity equal to the two contractor facilities. The cost comparison in the two-contractor case depends on scale efficiencies and price improvement under competition in addition to cost elements listed above.

Contractors may propose contract enhancements and changes in contract terms in conditions, such as delays for startup, additional capacity, extended operations, etc., that could have significant impacts on privatized Phase I costs. The baseline $\mathrm{M} \& \mathrm{O}$ hard cost estimates will require adjustments to maintain comparability if analysis of the proposed enhancements and changes indicate significant cost impacts.

2.4 Case Studies. Comparison of $\mathrm{M} \& \mathrm{O}$ and contractor costs require that the comparisons be based on hard cost estimates of similar maturity, since the cost estimates change as the bases for estimates moves from the conceptual level to more detailed preliminary and final design stages. If the M\&O and contractor costs are derived from cost estimates of different maturity, adjustments of the cost estimates are required to establish a common framework for cost comparisons. Case studies of changes in cost estimates as more design detail is achieved for DOE projects for waste processing scopes that are similar to TWRS waste processing will be completed. The case study information will be used to adjust the cost estimates as needed to place the $\mathrm{M} \& \mathrm{O}$ and contractor cost estimates at the same stage in project maturity.

The M\&O cost estimates are being derived from four DOE projects that are similar to TWRS privatization, i.e., waste vitrification. The four projects are

- Hanford Waste Vitrification Plant, Washington State (terminated)

- Defense Waste Processing Facility, Savannah River, Georgia (completed and operating)

- West Valley Demonstration Project, New York (completed and operating)

- Fernald Waste Vitrification Project (?), Fernald, Ohio (terminated).

DOE classifies the projects as major system acquisitions.

The M\&O project cost estimates are derived from DOE FM/HQ prepared Project Data Sheets (PDSs) for each project. The PDSs are prepared annually by FM whenever funding is requested from Congress. The PDSs by fiscal year contain information on total estimated construction costs; other estimated project costs; estimated annual operating costs upon the project's completion; and annual appropriations, project adjustments, obligations, and expenditures. The PDS format is the same for each project annually and remains fairly consistent over time; i.e., format changes and the way the information is presented do not radically change from one year to the next. Termination costs for projects that are not completed will be derived from a recently published General Accounting Office ${ }^{2}$ report and from other sources.

${ }^{2}$ U.S. General Accounting Office. Department of Energy: Opportunity to Improve Management of Major System Acquisitions. Report to the Chairman, Committee on Govemmental Affairs, U.S. Senate. Washington, DC. November 1996. GAO/RCED-97-17. 
The PDSs enable several inferences and results to be drawn from the data.

- The cost data can be adjusted for inflation enabling comparison of data across projects in constant dollars.

- Schedule slippages for each project can be derived and aggregated across projects to delineate an average percent schedule slippage for the four projects.

- Total construction and other estimated project cost increases can be calculated for the life of the project and averaged across projects to determine an overall, average estimate of schedule slippage from the project start to completion or termination.

- Estimated annual operating cost (in escalated terms) can be calculated for each project and averaged across all projects to derive an estimated percentage increase in operating costs over the life of the projects' construction.

The derived estimates for the four bulleted elements will be compared with other federal government privatized contracts of similar dollar size and type and the TWRS privatization hard cost estimates. It is expected that while the privatized contracts may demonstrate schedule slippage and cost escalation over the life of the project construction and operation that such slippages and escalations will be less than that demonstrated by the DOE M\&O projects.

2.5 Theoretical and Empirical Evidence of Cost Savings. Contractor economic decisions differ under cost-plus and fixed-pricing contracting conditions. Private firms distinguish themselves from public enterprises by having market-incentives to produce goods and services more efficiently. The theoretical and related empirical evidence of the effects of such different decision frameworks are assessed in "DOE Cost Savings from Private Contracting? ". This study concerns DOE's Environmental Management (DOE-EM) activities, which have historically been carried out by $\mathrm{M} \& \mathrm{O}$ contractors under cost-plus terms. The privatization of DOE's environmental activities focuses on greater use of fixed-price contract agreements with private contractors. Accordingly, the theoretical context for why cost-plus $\mathrm{M} \& \mathrm{O}$ contracting is inefficient is developed around the two bounding extremes of cost-plus and fixed-price contracting decisions. Cost-plus contracting provides no real incentives for the contractor to minimize costs and to select efficient production and management approaches. Under fixed-price contract, firms have the incentive to minimize cost overruns and schedule delays to increase profit opportunities.

Theoretical comparison of firms under these two bounding contracting conditions within a benefit-cost analysis framework provides added evidence that fixed-price privatized contracts will have lower project costs than cost-plus M\&O contracts, given optimal risk sharing between the government and contractors.

Theoretical comparisons of privatization contracting between the two extremes of cost-plus and fixedprice are illustrated in the context of an incentive-contract: an in-between solution to either fixed-price or cost-plus contracting. A theoretical measure of the efficiency gains under incentive contracting is derived within a cost-benefit framework which reflects a general negotiation over risk-sharing between DOE and private contractors. The efficiency gains from incentive-contracting depend on the expected cost overruns under cost-plus conditions. The study pursues an empirical application of the efficiency gains measure based on a sample of thirteen DOE-EM projects completed between 1980 and 1996.

The study derives a probabilistic range of cost overruns for the various $\mathrm{M} \& \mathrm{O}$ contractors under cost-plus conditions, and uses these probabilistic outcomes to evaluate potential cost savings under incentive contracting. Project-specific estimates of expected cost-savings from privatization contracting depend on

\footnotetext{
${ }^{3}$ Appendix A this report: Ulibarri, Carlos, Orman Paananen, and Mark Weimar. "DOE Cost Savings from Private Contracting?" in Theoretical, Methodological and Empirical Approaches to Cost Savings: A Compendium." Pacific Northwest National Laboratory, Richland, Washington, PNNL 11987.
} 
actual budget information and a probability assessment of the Phase I cost-plus overrun. The bids to perform this work under an incentive contract lie between fixed-price and cost-plus conditions, reflecting the degree of cost-risk and the settlement of risk-sharing between DOE and private contractors.

\subsection{Evidence of Life Cycle Cost Savings of Program Alternatives}

To properly evaluate the overall financial costs of various tank waste cleanup alternatives, it is essential to consider the time value of money. Positive rates of interest imply that a dollar now is not the same as a dollar later. If the Treasury can borrow at $6 \%$, then a 1-year deferral of spending of $\$ 100$ is worth $\$ 6$. Under these conditions, we cannot estimate the overall costs of a long-term project by simply adding up the costs that occur at different times. To perform a valid evaluation, we must translate all costs into comparable amounts for a specified period. If the specified period is the current year, the translation procedure is termed "discounting" and the resulting metric is called the "present value."

3.1 Life-Cycle Assessment. A rigorous evaluation of alterative program options should also take some account of social benefits and well as the governmental costs. There are two views of benefits when consideration is given to the life-cycle analysis of the tank waste program. The first view considers that, at least to a first approximation, the benefits of vitrification of tank waste are independent of its timing and completion. To be more concrete, the benefits would not vary if the wastes are treated by 2030 with any option. With this assumption, the problem reduces to one of a "cost effectiveness" calculation. The Office of Management and Budget (OMB) ${ }^{4}$ suggests this procedure when the benefits are not measurable or are deemed to be the same. In conducting a cost-effectiveness analysis, OMB directs that the government cost of borrowing - in terms of the interest rate on government bonds- be used to discount the alternative streams of government outlays to a present value. Currently, this rate is slightly less than $4 \%$ per year in real terms.

The second view assumes there are positive benefits to be gained by an early completion of the waste treatment, even prior to 2030 . There are some risks associated with the wastes currently in liquid formeither from releases to the air or leakage into the groundwater. But the largest cost may be the psychic costs born by the public in knowing that these wastes have yet to be put into a long-term stable form. One might reasonably argue that the discount rate associated with alternative completion times for the waste cleanup is also equivalent to the interest rate on government bonds (i.e., roughly the social rate of time preference).

At this point we can only assume that the political process has yielded a consensus that the benefits of treating the tank waste within the constraints of the Tri-Party Agreement (TPA) significantly exceed the originally estimated costs. Roughly speaking, the TPA calls for all waste to be vitrified by 2024 . Assume that B can represent the benefits of vitrifying all the waste, and for expositional purposes, also assume that all wastes could be treated in the year 2024. Thus, we assume that the benefits of completing the vitrification in any year other than 2024 can be related to the 2024 benefit as follows:

$$
\mathrm{B}(\mathrm{Y})=\mathrm{B}(2024)(1+\mathrm{r})^{-(\mathrm{Y}-2024)}
$$

where

$\mathrm{y}$ is the year, and

$r$ is the annual discount rate.

\footnotetext{
${ }^{4}$ Office of Management and Budget. "Guidelines and Discount Rates for Benefit-Cost Analysis of Federal Programs." Circular No. A-94 revised (posted to world wide web 3/6/97).
} 
To a first approximation, we assume that the benefits are proportional to the quantity of waste treated. Thus, more generally than assuming that all wastes can be treated in a single year, we can define a relative metric of benefits as the discounted stream of the annual quantity waste processed. (Implicitly, we are assigning a benefit value of $\$ 1$ to each unit of waste processed since we can only deal with relative benefits, it is irrelevant whether we assign $\$ 1$ or $\$ 1$ million per unit.) In spite of the limitation of working with relative benefits, we can still derive a cost-benefit metric, $\mathrm{W}$, as the ratio of discounted costs to the discounted quantities of waste processed:

$$
\mathrm{W}=\text { present value of costs/present "value" of waste treated }
$$

We can now contrast the results of comparing various cleanup scenarios between these two views. Under the first view, the cost-effectiveness value (present value of costs) will be lower the longer we can stretch out or "back load" the cost stream associated with cleanup activities. If we take the second view of discounting the benefits as well as the costs, then a 1-year delay of the program will reduce both the present value of the costs and benefits by about $4 \%$. Rather than implying an improvement in welfare, the cost-benefit metric, W, will at least be unchanged. It could be argued that the most appropriate measure of benefits is the difference between the present value of costs and benefits, i.e., net benefits. This would suggest that, even though the level of net benefits in absolute terms cannot be measured, a 1-year delay would reduce net benefits by $4 \%$.

The implications of these views have some bearing on the approach used to evaluate the various Phase I alternatives as compared to the approaches envisioned for evaluating the entire tank waste program. Some of the Phase I analytical options include extensions of the contracts beyond the present maximum order quantity. Thus, the options end up considering different quantities of waste treated and thus it is inappropriate to simply compare the total present values of costs. If the price per unit of waste charged to the government remains the same during the extension period as for the basic contract, the cost-benefit metric $\mathrm{W}$ would remain the same, suggesting that the options be differentiated on other criteria. On the other hand, if the price during the extension period were to fall, then $\mathrm{W}$ would decline. Essentially, $\mathrm{W}$ is the weighted average of annual unit processing prices, the weights varying as the convolution of a declining geometric series (whose rate of decline is equal to the discount rate) and the quantity of waste treated in each year. Without the discounting, the metric would be equal to simply the sum of constantdollar costs divided by the total quantity of waste processed. The $\mathrm{W}$ metric thus provides a measure of which alternative is the better "value" to society for the particular amount of waste processed. The metric preserves the basic nature of the discounting process in placing more emphasis on the cost of the waste that is treated earlier rather than later.

For some options, it is immaterial which view is chosen. If we evaluate a single private contractor versus an $\mathrm{M} \& \mathrm{O}$ contractor processing the same quantity of waste over the same time period, then the results of the two approaches are equivalent. The ratios of the absolute value of discounted costs between the two contracting mechanisms will be the same as the ratio of the $\mathrm{W}$ metrics, since the discounted quantities of waste are identical.

The W measure is also helpful when we examine various combinations of Phase I and Phase II options that will complete the processing of all the tank wastes. As implied above, unless each option meets the TPA constraints with roughly the same time phasing of waste processing, under the second view of benefits, it is inappropriate to simply compare the present values of costs for each of the options. To reiterate, options that completed processing later (i.e., not TPA-compliant) would be seen in terms of the present value of costs as less expensive. The use of the $\mathrm{W}$ metric at least ensures that no credit is given for any stretch-out of the entire program. 
In conclusion, the analysis of life-cycle costs among various options will entail the development of two metrics. For cases where the time-phasing and completion dates of waste treatment are very similar, the use of the present value of costs serves as an adequate indicator of the relative costs to society. Following the OMB guidance, the principal discount rate to be used in this calculation is the Treasury cost of borrowing. To help compare cases in which the time phasing, completion dates, or quantities of waste are different, the pseudo cost-benefit metric, $\mathrm{W}$, will be employed. This is in essence a weighted-average cost per unit of waste treated, the weights vary with time and with the annual amounts of waste treated.

\subsection{Basic Functions of the Economic Assessment Model. An economic assessment model has been} developed to provide a life-cycle assessment of various TWRS alternatives. An alternative is made up by one or more contracts, using either a privatization or M\&O contracting mechanism. The principal function of the model is to compute the present value cost of an alternative. The present value cost is the most appropriate measure of the societal cost of alternative options, since different options have different time sequences of costs. The discounting of costs to a present value considers the time value of government funds. The model also produces a year-by-year profile of government expenditures for major TWRS activities from 1997 through 2050.

The model has three major categories of inputs:

- financial model results for specific contracts

- PHMC costs associated with TWRS

- general economic parameters.

The first category is designed to handle up to four contract outcomes, corresponding to two contractors in each of the phases of the overall TWRS program. The second category considers the major activities that are related to vitrification: 1) tank waste retrieval, 2) waste storage and disposal, and 3) infrastructure support. The last category includes user-defined inputs such as the discount rate employed to calculate present value and the projected general inflation rate that is used to convert nominal dollars to constant FY98.

To process the results of the financial model outcomes, the economic model ensures that government costs (outlays or $\mathrm{BO}$ ) are converted to a constant-dollar basis within the appropriate time frame of the model. The model also converts the costs to a format consistent with the multi-year work plan (MYWP) -escalated dollars through 2006 and in constant 2006 dollars through 2050 . The model also produces a time profile of Budget Authority as taken from the financial model results.

The time phasing of the major PHMC activities related to vitrification would vary according to particular options. To the extent feasible, the economic model will modify the scheduling of major PHMC activities (including retrieval of wastes in Phase II). This modification will be performed at a minimum for the interim storage and disposal facilities that are anticipated to be constructed on an as-needed basis. These costs are not trivial. The projected costs for waste storage facilities in the current MYWP is nearly $\$ 2.4$ billion $^{5}$.

The model may also be used to compute one or more cost-effectiveness measures in addition to the absolute present value of costs. These alternative measures assume that the benefits derived from treating

\footnotetext{
${ }^{5}$ Project Hanford Management Contract. "Tank Waste Remediation System, Fiscal Year 1998, Multi-Year Work Plan, WBS 1.1." Richland, Washington, HNF-SP_1230 Revision 0, September 1997, page 4-3.
} 
tank waste are not constant over time. As developed elsewhere, one such measure that might be constructed as the ratio of the discounted sum of costs divided by the discounted sum of quantities of waste processed.

These measures may be useful in comparing alternatives that do not include all of the activities that would be required to analyze the full life-cycle costs of treating all tank waste (e.g., Phase I in isolation).

A more detailed discussion of the model and its applications is found in the paper, "The TWRS Economic Assessment Model. ${ }^{6}$

${ }^{6}$ Appendix C this report: Belzer, D.B. "The TWRS Economic Assessment Model." In Theoretical, Methodological and Empirical Approaches to Cost Savings: A Compendium." Pacific Northwest National Laboratory, Richland, Washington, PNNL 11987. 


\section{Appendix C}

\section{The TWRS Economic Assessment Model}

D. B. Belzer

January 30, 1998

Prepared for

the U.S. Department of Energy

Under Contract DE-AC06-76RLO 1830

Pacific Northwest National Laboratory

Richland, Washington 99352 


\section{The TWRS Economic Assessment Model}

\subsection{Introduction}

Radioactive waste has been stored in large underground storage tanks at the Hanford Site since 1944. These wastes were created during the production of plutonium and are a legacy from World War II and the Cold War. Recent reports have verified that contamination from leaking underground storage tanks has begun to reach the groundwater below the Hanford Site; this contamination may eventually reach the Columbia River. Hanford has 177 underground storage tanks of which 149 are older, single-shell tanks. Sixty-seven of these tanks are listed with regulators as having leaked or assumed to have leaked by the Department of Energy (DOE).

The caustic wastes in Hanford's tanks are in the form of liquids, slurries, saltcakes, and sludge; these wastes are estimated to contain 177 megacuries of radionuclides. In 1991, the Tank Waste Remediation System (TWRS) was established to manage, retrieve, treat, immobilize, and dispose of these wastes in a safe, environmentally sound, and cost-effective manner.

The environmental hazards posed by tank waste at Hanford represents perhaps the nation's most challenging and most complex environmental problem. Many of the technical issues involved in retrieving and treating the wastes have not yet been resolved and further research is required to develop safe and cost-effective approaches. These unresolved issues, as well as the shear magnitude of the wastes that need to be stabilized, will require substantial federal outlays to accomplish this task over the next three decades. At present, the overall estimated cost of the tank cleanup ranges between $\$ 30$ and $\$ 45$ billion dollars.

Given the magnitude of the projected federal expenditures for the TWRS mission as well as environmental cleanup at other DOE sites, DOE is seeking strategies that will achieve greater efficiencies than has been the case in the past. As a potential cost-saving approach, in recent years DOE has come to the view that it is feasible to privatize portions of these remediation activities. In pursuing this strategy, DOE is changing its traditional contracting approach. In general, work at the Hanford Site (as well as at other DOE nuclear weapons materials production sites) has involved a Government-owned, contractoroperated facility operating under a cost-plus-award-fee contract. Under a privatization strategy, DOE purchases services from a contractor-owned, contractor-operated facility under a fixed-price type of contract.

The first privatization activity under the TWRS program at Hanford is expected to involve the vitrification of liquid tank waste. The vitrification process essentially incorporates the tank waste into a stable glass form which then can be stored or disposed of with little potential for radioactivity to reach the environment. The privatization of the vitrification activity is expected to be conducted in two separate phases. The first phase is aimed toward the vitrification of 6 to $11 \%$ of the total low-activity waste (LAW). In both phases, either one or two private contractors will be employed. Under this approach, the private contractors will finance the construction of the vitrification plants, operate the facilities to treat the waste, and deactivate the facilities.

The economic assessment model was developed to help assess alternative strategies for completing the TWRS mission. The privatization approach still involves a decision of how many contractors should be employed and over what time frames. Depending upon the magnitude of proposed unit prices charged by the private contractors to vitrify wastes in Phase $I$, there is still a potential for a traditional contracting approach to be pursued. Given the level of technical uncertainty seen by the private contractors and 
accounted for by risk premiums in their bid prices, it may be more cost-effective for the government to build a vitrification plant on its own account.

The economic assessment model combines the costs associated with the vitrification of the tank waste together with supporting activities that will be provided by the Project Hanford Management Contractor (PHMC). The key supporting activities include the retrieval of the wastes from the tanks, development of infrastructure to support the vitrification plants, and finally the disposal and storage of the vitrified waste products. The PHMC will perform these functions under the traditional contractual mechanism.

\subsection{Methodological Framework}

Section 2 provides an overview of the methodological framework for the TWRS economic assessment model. At the outset, some discussion is devoted to the separate financial model that was developed to generate estimates of unit prices that may be charged by private contractors, given input assumptions regarding construction, operating, and financing costs. A very brief discussion of how the financial and economic models are linked is given in Section 2.1.

The economic assessment model has two primary objectives. The first is to develop an appropriate economic framework in which to evaluate contractual and timing alternatives related solely to the vitrification of tank waste. The methods by which this issue is addressed are described in Section 2.2. The second objective is to estimate the impact upon other TWRS activities-waste retrieval, storage/disposal of vitrified waste, support infrastructure for the vitrification plants, and program management-from various approaches to the vitrification activity. The model generates estimates of the total life-cycle cost of completing the TWRS mission and as well as annual projections of required budget authority (BA) and budget outlays (BO). The general methods by which these estimates are produced are described in Section 2.3.

As mentioned at the outset, the economic model uses as input the costs of waste treatment that are developed in the financial model. The financial model operates entirely in a nominal or escalated dollar framework and its cost projections by year are made in that context. For a variety of analytical purposes it is insightful to measure the costs of the TWRS mission in terms of the purchasing power of a base year-i.e., constant dollars. This is certainly the case in developing measures of the life-cycle cost of the program or its various major elements. For budgeting, however, it is useful to show the actual number of dollars that are expected to be expended by the federal government in each fiscal year. As a result of these considerations, one important function of the economic model is to produce cost metrics in both constant and escalated dollars.

\subsection{Relation to Financial Model}

The costs associated with the vitrification of the tank wastes are provided by a sophisticated project finance model. The "financial model" takes the estimated "hard costs" of the plant construction and annual operating expenses along with parameters such as the relative amounts of debt and equity financing, interest rates, banking fees, and required rate of return to estimate the price per unit of waste treated. This price is used to calculate the annual revenue stream required by the contractor and, on the opposite site of ledger, the annual budget outlays by the federal government.

The financial model is designed to evaluate a single contract, which consists of the construction of a vitrification plant and the subsequent capital cost recovery as a portion of the fixed payment per ton of waste treated. As stated earlier, the completion of the TWRS mission will likely require more than a single contract. The economic model assembles the costs and quantities of waste treated in all of the contracts that define a given alternative. Thus, one of the key purposes of the economic model is to show 
the total cost and quantity implications from all of the various contracts for the entire mission. The model also provides some insights as to the key differences in the various contracts, primarily stemming from variations in construction and operating costs.

\subsection{Economic Evaluation of Alternative Vitrification Alternatives}

As mentioned above, one of the key objectives of the TWRS economic model is to assist in the evaluation of various strategies to vitrify tank waste at Hanford. This evaluation takes at least two tacks. The first is to compare the cost-effectiveness of a fixed-price privatization approach versus that of a Maintenance and Operations (M\&O) contractor working under the traditional type of cost-reimbursable contract. The second is to evaluate the scope of proposed contracts-in Phase I and Phase II-to complete the waste processing element of the TWRS mission. One aspect of this analysis would attempt to compare the benefits of competition of using two contractors against the benefits of the economies of scale that would accrue to the choice of a single contractor.

\section{Privatization versus Cost-Reimbursable Contracts}

One output from the economic model is to put the true costs to the government from the alternative contractual mechanisms on a comparable basis. Much of the methodology by which this is done is described in a separate report-- "Methodology for Assessment of Cost Savings Under TWRS Privatization." The discussion here highlights some of the key issues. Generally, three types of adjustments are necessary to make the costs of different approaches comparable: 1) adjust cost profiles to present value via discounting, 2) adjust for federal taxes, and 3) adjust for probable overruns from initially estimated costs.

Discounting. Privatization yields a very different timing of government expenditures from that of a traditional M\&O contract. Since the private contractor arranges its own financing of the vitrification plants, the government does not incur any costs until waste is processed. Because of the time value of money, discounting to a present value basis is the appropriate way to compare these two cost streams. (More specific discussion of how the discounting procedure is applied to a situation such as TWRS is contained in Attachment A.)

There is some controversy concerning the appropriate value of the discount rate to be applied. One position is to strictly conform to the guidance provided by the Office of Management and Budget (OMB) in evaluating the cost-effectiveness of government projects. In its Circular A-94, OMB indicates that in situations in which the benefits of a project are constant, and only the stream of costs differ from the choice of alternative program elements, the appropriate discount rate is the real rate of return on government bonds. From the guidelines issued by OMB in January 1998, this rate is roughly 3.8\% per year. A second position is to use a higher rate that may correspond more closely to the average after-tax rate of return from private investment. The TWRS model has the capability to show present values computed under two selected discount rates that may reflect both of these positions.

Tax Adjustment. The higher levels of profits that would be achieved by a firm operating under a fixedprice contract, as compared to a firm under an M\&O arrangement, generates a significantly higher level of taxes paid. Thus, to appropriately calculate the net cost to the federal government, the amount of federal taxes paid must be subtracted from the payments for waste treatment. The financial model calculates both federal and state taxes paid based a calculation of gross profits. For an M\&O contract, it is assumed that the contractor's gross profits, based upon a percentage fee over cost, is subject to the same federal tax rate. Several of the tables provided by the economic model display the federal outlays net of federal taxes paid. 
Cost Overruns. The methodology report cited previously indicates the substantial historical evidence that supports the view that an $\mathrm{M} \& \mathrm{O}$ contractor has a much greater potential to overrun the initial cost estimate for similar types of projects. In one of the standard output tables of the model, user-defined percentage overrun factors are applied to the overall project costs. The percentages are assigned to each type of contract. This method assumes that the engineering costs estimated for the project ("hard costs") are equivalent for either type of contractual mechanism. The model can also be applied to cases in which hard cost estimates for the M\&O contractor might differ from that of a privatization contractor.

\section{Choice of Contract Scopes}

The second arena in which the TWRS economic model can be valuable is to choose among alternative contractual scopes and strategies. Thus, for example, the model could be used to help evaluate the cost of completing the TWRS mission for the following alternatives:

1) two contractors in Phase I, one contractor in Phase II

2) one contractor in Phase I, one contractor in Phase II

3) a single-phase approach with one contractor treating the entire waste inventory.

The principal issue in this type of evaluation is the potential for economies of scale in a larger plant or plants in Phase I to substantially reduce the life-cycle cost of processing the entire waste inventory. This potential might argue for a smaller Phase I scope, with perhaps only a single contractor. This line of reasoning ignores the impact on lowering costs that would result from the competitive environment engendered by two contractors. A small portion of the TWRS economic model attempts in a crude manner to show how these opposing forces could influence the overall cost of the TWRS mission.

\subsection{Estimation of Costs for Other TWRS Activities}

The vitrification of radioactive waste is currently estimated to represent only about half of the total cost of cleaning up the tank waste at the Hanford Site. A number of key activities are required to support the vitrification itself. Some of the major actitivities are listed in Table 1.

As with other major environmental restoration activities at Hanford, a detailed work breakdown structure (WBS) has been developed to support the overall management and budgeting of the TWRS program. Currently, a little more than 300 individual activities are separately identified in the WBS. For example, the design and construction of the electric sub-station to feed the Phase I vitrification plants is titled "Electrical Systems Subproject" and classified as WBS element 1138010301. At a higher level of the WBS is the category to cover all of the Phase I infrastructure: 113801. All of the privatization activities-Phase I and Phase II-fall under the 4-digit WBS 1138. (The WBS does not contain the most detailed level of specific task descriptions available, but it was the best structure in which to base the lifecycle cost model.) Generally, the individual WBS elements fall within one of four general functional categories: 1) management and planning, 2) design, 3) construction, and 4) operations.

The number of individual WBS elements were deemed to be more than could be satisfactorily handled within the economic model. As a result, an aggregation to about 100 activities was performed. The criteria for combining WBS elements included the similarity of functions, magnitude of cost, and approximate congruence of schedule. An annual fiscal year cost profile was developed for each of the combined WBS activities. Costs were converted to constant 1998 dollars. 
Table 1. Major TWRS Activities, excluding Vitrification

Activity
\begin{tabular}{|l|l|}
\hline Mobilization and retrieval of waste from tanks & $\begin{array}{l}\text { Initial waste for vitrification is in liquid form in } \\
\text { double-shelled tanks. Retrieval of waste from } \\
\text { single-shelled tanks to start soon after start of } \\
\text { vitrification. }\end{array}$ \\
\hline $\begin{array}{l}\text { Develop infrastructure to support vitrification plants } \\
\text { (roads, water, electric sub-station) }\end{array}$ & Precedes startup of vitrification plants \\
\hline $\begin{array}{l}\text { Operation of infrastructure to support vitrification } \\
\text { plants (electricity and water consumption, } \\
\text { disposition of solid and liquid wastes) }\end{array}$ & Concurrent with operation of vitrification plants \\
\hline $\begin{array}{l}\text { Construction of below-grade vaults to dispose of } \\
\text { low-activity waste }\end{array}$ & $\begin{array}{l}\text { First vaults in place prior to initial container } \\
\text { production, remaining vaults built as needed }\end{array}$ \\
\hline $\begin{array}{l}\text { Construction of facilities to store high-level waste } \\
\text { on interim basis }\end{array}$ & $\begin{array}{l}\text { First facility in place prior to initial container } \\
\text { production, remaining facilities built as needed }\end{array}$ \\
\hline $\begin{array}{l}\text { Shipment of high-level waste to long-term } \\
\text { repository }\end{array}$ & Currently scheduled around the period 2033-2045 \\
\hline Program Management & Ongoing through entire program life \\
\hline
\end{tabular}

The costs by fiscal year are those summarized in the 1998 Hanford Multi-Year Work Plan (MYWP). The sequencing of costs in the MYWP is based upon a planning case for tank waste vitrification that has been developed since 1996. It is consistent with a scenario of a two-phase privatization approach for vitrifying the tank waste. The first-phase vitrification plants operate from 2002 through 2011. The Phase II plants operate from 2012 through 2028.

A principal objective of the TWRS economic model is to allow the timing, and to a lesser degree the magnitude, of the costs of these activities to be sensitive to scenarios other than the one assumed for the MYWP. Thus, for example, if the start of the vitrification activities were to be delayed by 5 years, what would be the impact on the overall TWRS budget by year and would there be an impact on the total cost of the cleanup? The economic model is intended to provide a rough indication of how the pattern of the overall TWRS budget would vary in response to various alternatives related to the vitrification activity.

Given the resources and time for this effort, a substantial simplification of the interrelationships among the various activities is necessary. This is especially the case for the retrieval of wastes from the tanks. This activity is very complex, involving various retrieval technologies, transferring waste from one tank to another, and finally mixing wastes to develop a satisfactory chemical composition for vitrification. The economic model incorporates none of the various physical processes and detailed planning that compose this overall activity.

Although the model does not incorporate many of the physical processes in the TWRS mission, the approach is judged to be able to provide a reasonable representation of how the major activities would 
interact in terms of sequencing. In general, five different methods are used to develop a cost profile for each of 100 or so aggregated WBS activities. These methods are described briefly below.

\section{1) Fixed Time Profiles}

For some activities, the magnitude and timing of costs is deemed to be essentially independent of the vitrification scenario. Some of these activities involve near-term research activities that will be carried out regardless of when the vitrification plants are started. Another set of activities that is expected to be independent of the vitrification scenario involves the shipments of high-level waste to the long-term repository.

\section{2) Sliding Time Profiles}

A greater number of activities are modeled by simply changing the starting year. These starting years are varied according the starting years of key dates in the MYWP: 1) start of Phase I vitrification operations, 2) start of Phase II vitrification activities, or 3) start of single-shell tank retrieval. To take one example, consider the design of the Interim Storage System Tank Retrieval System (ISSTRS). (This system is expected to demonstrate the use of specific retrieval technologies for retrieving wastes from single-shell tanks.) The research and design aspects of this activity are expected to extend over 7 years. As taken from the MYWP database, the annual time profile expenditures in thousands of dollars looks like:

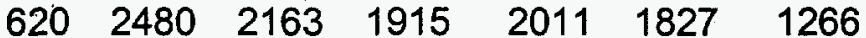

Currently, this activity is scheduled to begin in FY 1998 and tank retrieval is assumed to begin in 2003. Thus, we assume a fixed 5-year interval between the beginning of this activity and the start of (singleshell tank retrieval). If , for example, an alternative scenario calls for tank retrieval to begin in 2009 , then the model initiates the ISSTRS design cost profile in 2004.

\section{3) Fixed Annual Costs of Varying Duration}

A few activities are expected to cost a roughly constant amount each year, but the number of years for which the activity is undertaken may vary by the scenario. Perhaps the most important example of this type of activity relates to "minimum safe" operations for the tanks. After a number of planned near-term activities, the expectation is that the tanks can be put into an essentially stable condition. Between $\$ 40$ and $\$ 60$ million per year is expected to be expended to monitor the tanks and perform mixing and other activities to maintain the tanks in this stable condition. Thus, if the vitrification activity is delayed, the cost of these "minimum safe". operations would continue as long as waste remained in the tanks (for modeling purposes, this cost is roughly linked to the number of unretrieved tanks). Two other major activities fall into this category: 1) some overall management costs that are assumed continue even if the TWRS were delayed, and 2) operation of facilities used to treat liquid effluents from the vitrification plants.

\section{4) Costs Directly Related to Processing Activity}

The cost elements in this category generally involve aspects of infrastructure support. The principal cost will be for electricity purchased from the Bonneville Power Administration. Other cost elements assumed to vary proportionately to production rates involve process water and solid radioactive waste disposal. 


\section{5) Specific Construction Projects Related to Processing Schedule}

Where possible, the economic model varies the scheduling of specific construction projects that can be related to the cumulative amount of waste processed by the vitrification plants. For most part, these projects relate to the individual facilities that will be built to dispose or store the containers of vitrified waste. Based upon the projected time profile of the containers production, the model looks ahead and initiates a 4 to 6 year design/construction activity in order to make available sufficient storage or disposal capacity when it is required.

This process is illustrated in Table 2 below in the case of the interim storage facilities that will be built to handle the canisters of high-level waste. The results in the table are based on containers production schedule that corresponds to the FYWP baseline. The first column shows the facility capacities by the number of canisters. The second column is the cumulative capacity. The third column shows the modeldetermined start and end years of construction based upon the expected time profile of canister production. Column four shows an estimated breakdown of the costs for each facility. The first module is expected to cost more than the later modules since it requires more design work. As developed for this particular table, the costs of the facilities to be built after the CSB are calibrated to match the total cost of all modules shown in the MYWP.

Table 2. IHLW Storage Construction: Baseline

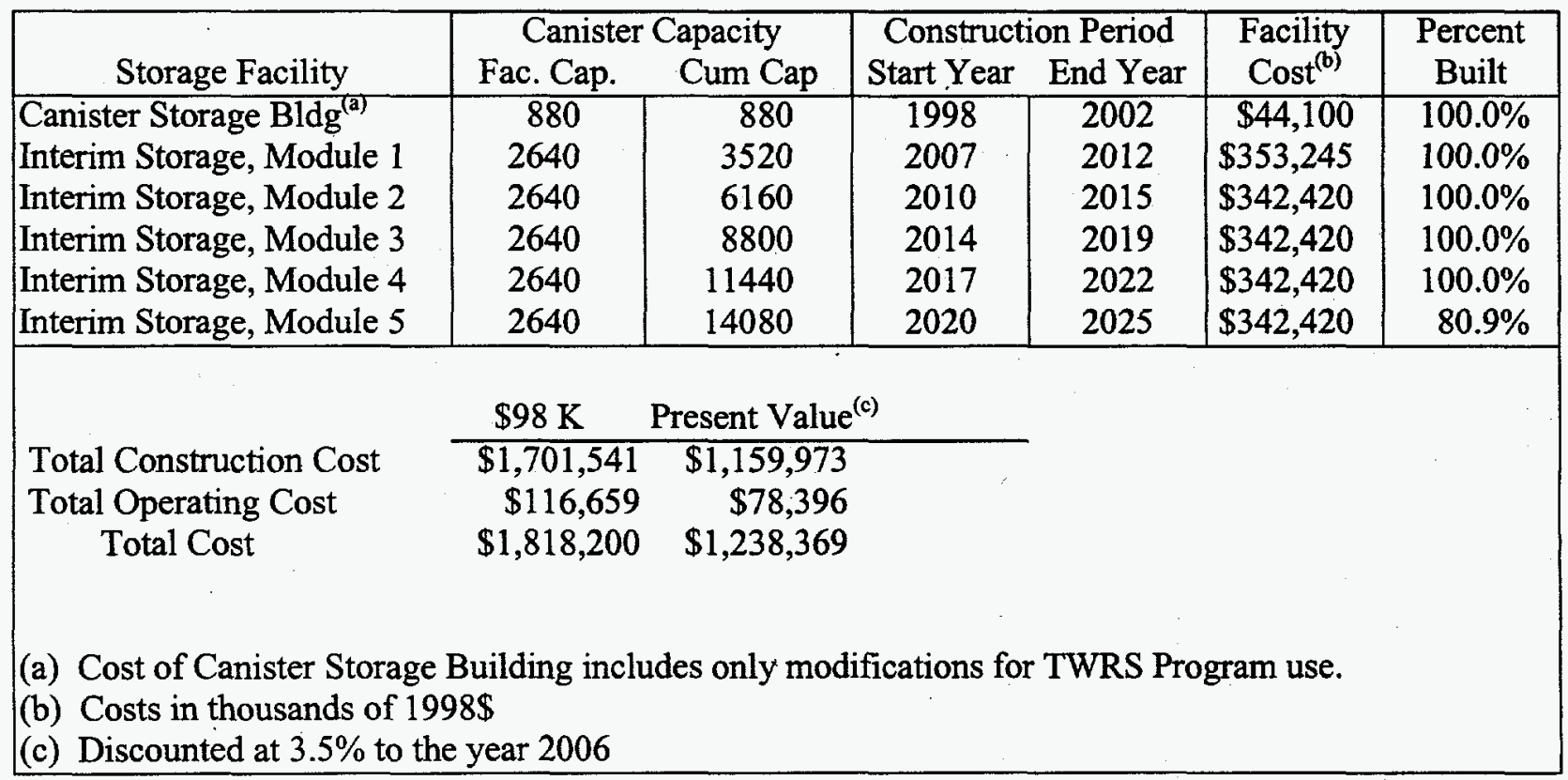

The module capacities in Table 2 were used to help develop the TWRS baseline and the small number (5) is convenient for the Excel spreadsheet that defines the economic model. Each of the modules includes six separate vaults and, thus the size of the modules is assumed to somewhat adjustable. For costing purposes, we in fact ignore the issue of a minimum size capacity and assume that a module could be scaled down to any desired capacity. The last column in Table 2 shows the last module would be scaled to $81 \%$ of its nominal capacity. We assume that the costs would scale proportionately as well.

The lower part of the table shows the total life-cycle costs associated with the interim storage function. The total construction cost about $\$ 1.7$ billion in 1998 constant dollars. Total operating cost is based upon 
the estimation of simple cost function that assumes a fixed annual cost and a variable cost that depends upon the number of canisters shipped to the interim storage facilities; in this case the total operating cost is projected to be about $\$ 150$ million. The present values were constructed by discounting all costs after 2006 back to 2006 by a $3.5 \%$ rate of discount. The year 2006 was chosen since it represents a period near the start of the HLW production in Phase I.

\section{Descriptions of Standard Output Tables}

The initial version of the economic model generates ten standard tables. The first six tables provide various measures of life-cycle costs and the annual budget outlays. Tables 7 through 9 show the quantities of waste treated and the implications for temporary storage requirements in double-shell tanks and the number of containers for long-term disposal. Table 10 applies a number of key economic assumptions that adjust various cost measures for the effects of government financing cost, federal taxes, and competitive structure. These adjustments are designed to aid in evaluating the total costs of various alternatives. A brief description of the key elements of each of the standard tables is given below.

An example set of tables is provided at the end of this section. The scenario presented in this table is taken from an exercise conducted (in mid-January 1998) to test the complete analytical framework for evaluating "best value" alternatives for completing the TWRS mission. The scenario in the table assumes two contractors will treat waste in Phase I and two contractors will treat waste in Phase II. For Phase I, three contracts are shown: two for low-level waste and one for high-level waste. The high-level waste contract should not be construed as a third plant operating in Phase I-the separation of costs for highlevel processing was done for analytical purposes. As these results do not represent the costs that will be finally proposed by the contractors in Phase I; they should be viewed as illustrative only. As a result, the discussion of the tabular output in the pages below focus primarily upon the methodological and definitional issues, rather than specific results of this scenario.

Table 1.

Table 1 provides a number of cost subtotals associated with the completion of the TWRS mission. To provide correspondence with the tables in the site MYWP, two sub-periods are shown. The top panel shows costs for the 10-year planning cycle, FY 1997-FY 2006. The second panel shows the costs out to the year 2055 (includes final tank closure activities and shipment of high-level wastes to the long-term repository). The third panel shows the costs for the entire life-cycle, FY 1997 through FY 2055.

The costs are broken into nine major TWRS cost categories defined in the MYWP. The waste processing costs for Phase I and Phase II have been combined, since some planning alternatives may not include a specific Phase II plant.

Four types of costs are presented in the table. The totals in the column labeled MYWP are based upon escalated costs through 2006 and then held at the 2006 price level thereafter. This hybrid approach to handling the expected increases in overall price levels is the one used in the MYWP. For activities ending before 2007 , these costs would be equivalent to projected current-dollar costs. The escalation rate currently applied is $2.7 \%$ per year.

The remaining columns are all based upon costs converted to constant 1998 dollars. The differences are in discount rates applied to take account of the time value of money. With a zero discount rate (column 2 ), the costs are simply the sum of the constant-dollar values over the life of the activity. The last two columns show the costs discounted at two different rates. The lower rate, shown here at $3.8 \%$, is designed to conform to the guidance provided by the Office of Management and Budget (OMB) in evaluating the cost-effectiveness of government projects. OMB indicates that in situations in which the benefits of a 
project are constant, and only the stream of costs differ from the choice of alternative programs, the appropriate discount rate is the real rate of return on government bonds. From the guidelines issued in January 1998, this rate is roughly $3.8 \%$ per year for long-term projects (the long-term nature of TWRS suggested the use of the 30 -year bond rate for this situation).

In spite of this $\mathrm{OMB}$ guidance, there remains controversy over the choice of discount rates. For general cost-benefit analyses, OMB suggests a higher rate- $7 \%$. The last column of the table shows the costs discounted to 1998 using this higher rate. The economic model allows the user to easily alter the assumptions regarding these discount rates.

\section{Table 2.}

This table provides a year-by-year profile for the Budget Authority (BA) and Budget Outlays (BO) needed to support the waste processing component of TWRS. The first two columns show the BA/BO projections on an MYWP basis, i.e., current (or escalated) dollars through 2006 and then at 2006 constant dollars. The second two columns show the profiles expressed in constant $1998 \$$.

TWRS privatization yields a BA profile that is quite different from the $\mathrm{BO}$ profile, since under privatization the federal government will pay only for waste treatment as it occurs. The BA must be established prior to the actual waste treatment payments, since funding must be available in the event of a termination-for-convenience by the government.

The $\mathrm{BA} / \mathrm{BO}$ profiles are based directly upon the outputs from the financial model, which performs an elaborate accounting to develop the BA and BO profiles. (The BA is the more complicated construct; BO is basically equal to the private contractor gross revenues from treatment payments.) Over the life of the contract, the total BA and BO are equivalent and this feature is maintained in the financial model, which operates solely in a current-dollar framework. This identity does not hold exactly in Table 2 because of the conversion of some or all of the costs to constant dollars. As shown at the bottom of the table, the total $\mathrm{BO}$ is slightly lower than the BA.

\section{Table 3.}

This table provides a year-by-year profile for Budget Outlays (BO) for the major program elements associated with the entire TWRS mission. The first column shows costs of activities that are essentially independent of the vitrification of tank waste and generally involve currently scheduled activities related to stabilize tanks on a temporary basis. In terms of the classification in Table 1, this column combines the costs of four elements: 1) Tank Characterization, 2) Tank Safety Issue Resolution (TW02), Tank Farm Operations (TW03), and TWRS Management Support (TW10). The rationale for including the last element in this category is that the management for the overall mission is expected to transfer from TW10 to Process Waste Support (TW05) in 2006.

The next three columns detail the year-by-year spending for the major support activities for the vitrification: 1) Tank Retrieval (retrieval of waste from single-shell and double-shell tanks), 2) Storage/Disposal (disposal of low-activity waste and storage of high-level waste, and 3 ) infrastructure (electricity, water, secondary waste disposal). The column labeled "Process Waste Support" covers the management of the TWRS program. As mentioned above, this category covers all management activities for TWRS after 2005.

The final two columns provide the budget outlays to support both phases of the waste processing. In scenarios involving a single large $\mathrm{M} \& \mathrm{O}$ contractor to process the entire waste inventory, the outlays are all under Phase I. For privatization scenarios, one should note that the financial model has the ability to 
use different prices for waste processing during various phases of a contract (e.g., lowering the per unit price after the cost of plants has been recovered). Thus, a comparison of values of the outlays between different time periods may not be indicative of the quantities of waste treated.

\section{Table 4.}

This table provides a year-by-year profile for the BA needed to support the complete TWRS program. The table simply combines information from Tables 2 and 3. The column labeled PHMC covers all of the ongoing and supporting activities covered in the left-most five columns of Table 3. For the most part, it is expected that the activities will be performed by the PHMC. Under this Management and Integration contract, the budgeting process will generally yield an equivalence between $\mathrm{BA}$ and $\mathrm{BO}$ for these activities. The BA profiles for the waste processing activity is taken from Table 2 .

The left side of the table shows the BA projections on an MYWP basis, i.e., current dollars through 2006 and then at 2006 constant dollars. The right half of the table shows the profiles expressed in constant $1998 \$$.

\section{Table 5.}

Table 5 adjusts total TWRS costs for federal taxes paid by the private contractors performing the waste treatment. The top panel repeats the cost totals for the TWRS sub-programs shown in Table 1. The bottom panel shows the same costs, with the exception of the removal of federal taxes paid by the private contractors in the waste processing category.

The adjustment for federal taxes may be most appropriate to making a cost comparison between a privatization approach and a Maintenance and Operations (M\&O) contractor. Table 8 provides a more detailed analysis of this issue.

\section{Table 6.}

Table 6 provides some key attributes of the various contracts that compose the overall alternative. The top panel of the table shows values that correspond to the life of each contract. The bottom panel shows annual values, for years in which the plant is operating at full capacity. The number of years shown at the left of both panels corresponds to the number of "full capacity" years of operation, not calendar length.

The column labeled "BO" shows the budget outlays associated with each contract. The totals at the bottom of the top panel correspond to the constant-dollar (undiscounted) totals shown in each of the prior tables. The next two columns in the top panel show the total construction cost and the total operating costs over the life of the contract. The sum of these costs are lower than the BO since the contractor's borrowing costs and required rate of return are ignored.

The final four columns of the top panel show the quantities of waste treated and the average costs to the government, based upon the outlays per ton of waste treated. For contracts in which both low-activity waste (LAW) and high-level waste (HLW) are vitrified, no attempt is made to separate costs associated with each type of waste.

The $\mathrm{BO}$ values in the bottom panel of the table are straightforward; they represent the budget outlay in years in which the plant is operating at full capacity. To "annualize" the construction costs, a specific interest rate is chosen to amortize the total construction cost over the life of contract. A $20 \%$ rate was chosen to roughly approximate the before-tax rate of return required by some of the private contractors. 
The purpose of this amortization is to at least provide a reasonable comparison of the capital costs with the annual operating costs. The annual operating costs are shown in the column to the right of the annualized construction cost.

The next two columns indicate the plant capacities in terms of the annual amounts of waste processed. These values are used in the last three columns to provide a broad disaggregation of unit costs. The third column from the right provides a measure of capacity costs-total construction cost is divided by the annual tons of LAW treated at capacity. The next column divides the amortized construction cost by the annual tons of LAW. This metric accounts for three aspects of the processing regime: 1) plant design/construction (hard) cost, 2) rate of return, and 3) plant operating life. The last column of the table shows the annual operating cost per ton of LAW.

If construction were completed in 1 year and financed entirely by equity with a $20 \%$ return, the sum of the per unit annualized construction cost and the annual operating cost would be equivalent to the $\mathrm{BO}$ cost. Since these conditions are seldom met, the sum of the annualized construction and operating costs will approximate the $\mathrm{BO}$ cost by differing degrees. The objective of this approximation in Table 6 is to allow the user to better evaluate the differences in the cost structures of the various contracts.

[Note: The number of rows in Table 6 is designed to vary with the number of contracts in the alternative. Unfortunately, a seamless method within Excel that would blank out unneeded rows has not yet been developed. Thus, some rows with entries \#NA remain in the table and should be ignored.]

\section{Table 7.}

Table 7 shows the amounts of LAW processed by each contractor and by phase for each fiscal year. The table shows the ability of the model to adjust the total amount of low-activity waste to the total amount that requires processing. The adjustment factor is shown in the last column of the table. This adjustment may be required since the sum of the processed amounts of LAW from the contracts simulated independently within the financial model may not equal the total LAW available.

\section{Table 8.}

The purpose of Table 8 is to show the implications of the alternative upon the requirements for waste storage of double-shell tanks (DSTs). ${ }^{1}$ The basic strategy is to retrieve waste from the single-shell tanks (SSTs) and store the resulting liquid waste in the double-shell tanks for eventual transfer to the vitrification plants. The Tri-Party Agreement (TPA) calls for the retrieval of wastes in the SSTs by 2018.

Column four of Table 8 shows a schedule of SST retrieval which meets the 2018 TPA constraint. It approximates a retrieval schedule that was incorporated in the 1996 FM-20 study of the TWRS mission.

Column five provides an alternative SST retrieval schedule that is tied to the amount of LAW processed. This schedule is designed to complete tank retrieval 4 years prior to the completion of the LAW vitrification.

The choice of whether SST retrieval is fixed to meet the TPA milestone (column four) or is tied to processing rate (column five) is made by the user. Column six in Table 8 shows the final retrieval schedule in this particular simulation of the economic model. The choices available to the user for the SST retrieval strategy are described in Section B.2 of Attachement B.

\footnotetext{
${ }^{1}$ Most of the logic in Table 8 (and Table 9) was originally developed in a spreadsheet by Bill Richmond and subsequently enhanced by Pete McLaughlin, both PNNL staff members.
} 
The next two columns show the total amounts of LAW (measured as metric tons of sodium) in both the SSTs and DSTs at the end of each year. Roughly $80 \%$ of the initial waste volume is in the SSTs.

The final two columns show the required volumes of wastes in the DSTs. Since the average capacity of a DST is approximately one million gallons, the values labeled as millions of gallons are equivalents to the number of DSTs. The total number of DSTs required to temporarily store retrieved waste from the SSTs and for other uses are shown in the last column. The actual number of DSTs on the Hanford site is 28 . Thus, numbers exceeding 28 in column 11 provide an indication that DST capacity may be insufficient to handle the waste retrieved from the SSTs.

\section{Table 9.}

Table 9 converts the quantities of waste treated (tons) into the quantities of glass produced (tons) and, finally, into the number of containers that will be used for final disposal of the vitrified waste. The left half of the table applies to the low-activity waste (LAW). The unit of waste for LAW is the amount of sodium (Na) in the waste stream. The waste loading fraction then defines the amount of glass that is produced for each ton of sodium. The packing density defines how much waste on a weight basis can be put into each rectangular container (box) that will be used to transport the vitrified LAW. The dimensions of the containers are $1.2 \times 1.2 \times 1.6$ meters.

The right side of the table shows the equivalent metrics for high-level waste (HLW). The unit of waste for HLW is the weight of waste oxides. As with LAW, the waste loading fraction defines the weight of glass for each unit of waste oxides. The container for $\mathrm{HLW}$ is a cylindrical canister, 1.3 meters in diameter and approximately 5 meters high.

The time profiles of the numbers of containers for LAW and HLW can be used within the economic model to vary the timing of the costs incurred for the TWRS storage/disposal activities. If this mode is selected by the user, the model will compute the costs of the disposal (LAW) or the interim storage (HLW) modules as they are needed.

Table 10.

Table 10 applies some assumptions outside the framework of the financial model to assist in making appropriate economic evaluations of various alternatives. The top portion of the table is most useful in examining a single contract and tries to evaluate what an $M \& O$ contractor would cost for the equivalent scope of work and employing the same technology (i.e., identical hard costs). The bottom portion of the table is aimed toward multi-contractor privatization approaches and attempts to evaluate the cost implications of using one versus two contractors.

In the example tables following the main text, Table 10 has been generated for two cases. The first case involves the complete set of contracts that make up the complete TWRS mission, as discussed at the outset of this section. In the second case, only the first contract is analyzed (Firm 1 treating both LAW and HLW).

The first line of the top panel of Table 10, labeled Gross Costs to Federal Government, shows the same costs developed for the private contractor(s) that were shown in Tables 1 through 4 . The next line shows the hypothetical costs for an M\&O contractor for the same quantity of waste treated. The M\&O costs consists of the hard costs for construction and operations along with a fee based upon a percentage markup over costs. The percentage fee applied is shown in the Notes below panel C. Savings due to privatization are shown as the difference between the privatization and $\mathrm{M} \& \mathrm{O}$ approaches. Generally, in this panel the costs for an $M \& O$ approach are smaller than for privatization. 
Panel B shows the total costs after adjustment for federal taxes. Since the taxable profits are generally much higher for the private contractor(s) as compared to the $\mathrm{M} \& \mathrm{O}$, the adjustment is much greater for the private contractor.

The last panel shows adjustments for the expected degree of cost overruns associated with each type of contracting mechanism. These adjustments are based upon an examination of historical evidence of similar contracts and is documented elsewhere. The percentages assigned to each type of contract are shown in the first column of the table.

In the second example of Table 10 results, note the very large difference these adjustments can have. In terms of constant 1998 dollars, panel A at the top of the table would indicate that the private contractor would cost the government nearly double (ratio of 1.98) that of an M\&O. After adjusting for the cost of government financing-accomplished by using the first discounted cost basis-this ratio falls to 1.69. Subsequently adjusting for federal taxes paid, the ratio falls dramatically to 1.06 (see panel B). And, finally, if we account for the most likely degree of cost overruns, the private contractor is some $17 \%$ less expensive that the $M \& O$ (as shown in panel $C$ ).

The addendum in Table 10 applies to situations in which comparisons will be made between alternatives that employ different numbers of contractors. The objective is to explicitly recognize the cost reduction that would stem from the use of two contractors in the same phase of the program. For consistency with the top portion of the table, it is assumed that a single private vendor would still incur a cost overrun in range of 15 to $25 \%$ of the basic costs developed in the financial model. A competitive framework with two contractors might reduce this overrun-adjusted cost by 10 or $15 \%$. The second line in the addendum portion incorporates this adjustment if two contractors are present. The adjustment is made separately for Phase I and Phase II.

The last line of the table incorporates one further adjustment to take account of cost reductions in Phase II that may result from the use of two contractors in Phase I. The assumption here is that the additional experience from the use of a second contractor will have a beneficial effect on the cost structure for Phase II.

Without these adjustments, the economic model would generally support a decision to use the least number of contractors to perform the overall mission, since economies of scale from larger plants would generate the lowest unit costs of vitrification. Obviously, the principal challenge for the model user is to assign appropriate percentage reduction factors that reflect this behavior. 
Alternative I (Phase Firm I-LAW/HLW, Firm 2-LAW Phase //: Firms 3\&4)

\section{Chapter 2 Table 1. TWRS Life-Cycle Cost Summary}

\begin{tabular}{lrrrr}
\multicolumn{5}{c}{ FY1997-FY2006 (\$000s) } \\
\hline \multicolumn{1}{c}{ Dollar Basis: MYWP } & $1998 \$$ & $1998 \$$ & $1998 \$$ & $7.0 \%$ \\
\hline Costs discounted at: & $0.0 \%$ & $0.0 \%$ & $3.8 \%$ & 206,631 \\
Tank Characterization (TW01) & 228,319 & 222,766 & 213,466 & 119,053 \\
Tank Safety Issue Resolution (TW02) & 128,865 & 126,549 & 122,244 & 747,287 \\
Tank Farm Operations (TW03) & 932,670 & 874,721 & 799,441 & 604,235 \\
Retrieval Project (TW04) & 987,537 & $811,159$. & 687,239 & 167,451 \\
Process Waste Support (TW05) & 145,401 & 227,341 & 191,205 & $2,179,494$ \\
Process Waste-Phase I (TW06) & $4,073,717$ & $3,408,508$ & $2,661,052$ & 0. \\
Process Waste-Phase II (TW07) & 0 & 0 & 0 & 162,583 \\
Privatization Infrastructure (TW08) & 283,931 & 226,691 & 188,048 & 208,371 \\
Waste Storage and Disposal (TW09) & 376,651 & 291,273 & 241,142 & 226,654 \\
TWRS Management Support (TW10) & $\underline{299,075}$ & $\underline{275,536}$ & $\underline{246,471}$ &
\end{tabular}

FY 2007-FY 2055_(\$000s)

\begin{tabular}{|c|c|c|c|c|}
\hline $\begin{array}{l}\text { Dollar. Basis: } \text { MYWP } \\
\text { Costs discounted at: }\end{array}$ & $\begin{array}{r}1998 \$ \\
0.0 \% \\
\end{array}$ & $\begin{array}{r}1998 \$ \\
0.0 \% \\
\end{array}$ & $\begin{array}{r}1998 \$ \\
\underline{3.8 \%} \\
\end{array}$ & $\underline{7.0 \%}$ \\
\hline Tank Characterization (TW01) & $\underline{1,175}$ & $\underline{949}$ & $\underline{663}$ & $\underline{495}$ \\
\hline Tank Safety Issue Resolution (TW02) & $\underline{0}$ & $\underline{0}$ & $\underline{0}$ & $\underline{0}$ \\
\hline Tank Farm Operations (TW03) & $\underline{29,359}$ & $\underline{23,723}$ & $\underline{16,748}$ & $\underline{12,616}$ \\
\hline Retrieval Project (TW04) & $3,7 \overline{92,598}$ & $3,0 \overline{77,978}$ & $1,6 \overline{02,805}$ & $9 \overline{90,191}$ \\
\hline Process Waste Support (TW05) & $\underline{819.569}$ & 456,000 & $\underline{276,192}$ & $\underline{188,124}$ \\
\hline Process Waste-Phase I (TW06) & $\underline{3,262,555}$ & $2, \overline{636,297}$ & $1,802,483$ & $1,325,124$ \\
\hline Process Waste-Phase II (TW07) & $12,677,631$ & $10,244,117$ & $5,191,774$ & $3,023,478$ \\
\hline Privatization Infrastructure (TW08) & $1,751,670$ & $1,994,225$ & 974,302 & 558,873 \\
\hline Waste Storage and Disposal (TW09) & $8,459,745$ & $\overline{7,104,675}$ & $2, \overline{269,054}$ & $.1,055.874$ \\
\hline TWRS Management Support (TW10) & $\underline{0}$ & $\underline{0}$ & $\underline{0}$ & $\underline{0}$ \\
\hline
\end{tabular}

FY 1997-FY 2055 (\$000s)

\begin{tabular}{|c|c|c|c|c|}
\hline $\begin{array}{l}\text { Dollar Basis: } \\
\text { Costs discounted at: }\end{array}$ & $\frac{\text { MYWP }}{0.0 \%}$ & $\begin{array}{r}1998 \$ \\
0.0 \% \\
\end{array}$ & $\begin{array}{r}1998 \$ \\
3.8 \% \\
\end{array}$ & $\begin{array}{r}1998 \$ \\
7.0 \% \\
\end{array}$ \\
\hline Tank Characterization (TW01) & 229,494 & 223,716 & 214,129 & 207,126 \\
\hline Tank Safety Issue Resolution (TW02) & 128,865 & 126,549 & 122,244 & $\overline{119.053}$ \\
\hline Tank Farm Operations (TW03) & 962,029 & 898,445 & 816,189 & $\overline{759,903}$ \\
\hline Retrieval Project (TW04) & $4.780,135$ & $\underline{3,889,137}$ & $2,290,044$ & $\underline{1,574,426}$ \\
\hline Process Waste Support (TW05) & $\underline{964,970}$ & $\underline{683,341}$ & $\underline{467,397}$ & $\underline{353,574}$ \\
\hline Process Waste-Phase I (TW06) & $7,336,272$ & $\underline{6,044,805}$ & $4,463,536$ & $3,504,618$ \\
\hline Process Waste-Phase II (TW07) & 12.677 .631 & $10,244,117$ & $\overline{5,191,774}$ & $\underline{3,023,478}$ \\
\hline Privatization Infrastructure (TW08) & $2,035,601$ & $\underline{2,220,916}$ & $1,162,351$ & $\underline{721.455}$ \\
\hline Waste Storage and Disposal (TW09) & $8,836,396$ & $7,395,948$ & $2,510,195$ & $1, \overline{264,245}$ \\
\hline TWRS Management Support (TW10) & $\underline{299,075}$ & $\underline{275,536}$ & $\underline{246,471}$ & $\underline{226,554}$ \\
\hline Total & $\underline{38, \overline{250,467}}$ & $\underline{32,002,509}$ & $\underline{17, \overline{484,329}}$ & $\underline{11, \overline{754,432}}$ \\
\hline LAW Processed by Contractor (MT) & Phase I & Phase II & & \\
\hline Contractor A & $\underline{5,103}$ & $\underline{41,341}$ & & \\
\hline Contractor B & $\underline{5,101}$ & $\underline{33,910}$ & & \\
\hline \multirow[t]{2}{*}{ Scenario-sensitive PHMC Costs?: } & $\underline{\text { Retrieval }}$ & \multicolumn{2}{|c|}{ Storage/Dispose Infrastructure } & \\
\hline & Yes & $\underline{\text { Yes }}$ & $\underline{\text { Yes }}$ & \\
\hline
\end{tabular}


Alternative 1 (Phase 1: Firm 1-LAW/HLW, Firm 2-LAW Phase II: Firms 3\&4)

Table 2. Waste Processing BA/BO by Fiscal Year (\$ Million)

\begin{tabular}{|c|c|c|c|}
\hline \multicolumn{2}{|c|}{ MYWP Basis } & \multicolumn{2}{|c|}{$1998 \$$} \\
\hline$\underline{\mathrm{BA}}$ & $\underline{\mathrm{BO}}$ & BA & $\underline{\mathrm{BO}}$ \\
\hline$\underline{70.5}$ & $\underline{0.0}$ & 72.3 & $\underline{0.0}$ \\
\hline $2 \overline{57.3}$ & $5 \overline{4.0}$ & $2 \overline{57.3}$ & $5 \overline{4.0}$ \\
\hline 531.8 & $\underline{0.0}$ & $\overline{517.8}$ & $\underline{0.0}$ \\
\hline 681.2 & $\underline{0.0}$ & 645.8 & $\underline{0.0}$ \\
\hline 687.6 & $\overline{0.0}$ & $\overline{634.8}$ & $\overline{0.0}$ \\
\hline$\underline{563.8}$ & $\overline{0.0}$ & $\overline{506.8}$ & $\overline{0.0}$ \\
\hline$\overline{474.7}$ & $41 \overline{2.2}$ & 415.5 & $36 \overline{0.8}$ \\
\hline 673.0 & $\underline{1,185.8}$ & $\underline{573.6}$ & $\underline{1,010.6}$ \\
\hline 613.1 & $\overline{1,202.4}$ & $\overline{508.8}$ & 997.9 \\
\hline $1 . \overline{019.0}$ & $\overline{1,219.3}$ & $\overline{823.4}$ & $\overline{985.2}$ \\
\hline$\underline{1.035 .8}$ & $1,203.8$ & 836.9 & 972.7 \\
\hline $1,002.8$ & $\underline{1,188.6}$ & $\overline{810.3}$ & $\overline{960.4}$ \\
\hline 659.2 & 256.7 & $\overline{532.7}$ & 207.4 \\
\hline $1,515.5$ & 253.4 & $1,224.6$ & 204.8 \\
\hline $1,483.8$ & 250.2 & $1,199.0$ & 202.2 \\
\hline$\underline{1,139.3}$ & 1.420 .8 & 920.6 & $\underline{1,148.1}$ \\
\hline$\underline{738.7}$ & $\underline{1,533.4}$ & 596.9 & $1,239.1$ \\
\hline 653.4 & $\overline{1,748.4}$ & $\overline{528.0}$ & $1,412.8$ \\
\hline $1, \overline{349.0}$ & $\overline{1,726.3}$ & $1, \overline{090.0}$ & $\overline{1,394.9}$ \\
\hline $1,403.7$ & $1,704.4$ & $1,134.2$ & $\underline{1,377.3}$ \\
\hline$\underline{803.5}$ & $\overline{1,005.5}$ & 649.3 & 812.5 \\
\hline 682.0 & 682.0 & $\underline{551.1}$ & $\underline{551.1}$ \\
\hline 413.6 & 413.6 & $\underline{334.2}$ & $\underline{334.2}$ \\
\hline 408.3 & 408.3 & 329.9 & 329.9 \\
\hline$\overline{403.2}$ & $\overline{403.2}$ & $\overline{325.8}$ & $\overline{325.8}$ \\
\hline 398.1 & 398.1 & 321.6 & $\underline{321.6}$ \\
\hline$\underline{393.0}$ & 393.0 & $\underline{317.6}$ & 317.6 \\
\hline 388.0 & 388.0 & 313.6 & $\underline{313.6}$ \\
\hline$\overline{308.3}$ & 308.3 & $\underline{249.1}$ & $\overline{249.1}$ \\
\hline 85.8 & 85.8 & 69.3 & 69.3 \\
\hline 84.7 & 84.7 & 68.4 & 68.4 \\
\hline 83.6 & $\underline{83.6}$ & $\overline{67.6}$ & $\underline{67.6}$ \\
\hline 0.0 & $\underline{0.0}$ & $\underline{0.0}$ & $\underline{0.0}$ \\
\hline$\underline{0.0}$ & $\underline{0.0}$ & $\overline{0.0}$ & $\overline{0.0}$ \\
\hline 0.0 & $\underline{0.0}$ & $\underline{0.0}$ & $\underline{0.0}$ \\
\hline$\underline{0.0}$ & $\underline{0.0}$ & $\underline{0.0}$ & $\underline{0.0}$ \\
\hline 0.0 & $\underline{0.0}$ & $\underline{0.0}$ & $\underline{0.0}$ \\
\hline 0.0 & $\underline{0.0}$ & $\underline{0.0}$ & $\underline{0.0}$ \\
\hline$\underline{0.0}$ & $\underline{0.0}$ & $\underline{0.0}$ & $\underline{0.0}$ \\
\hline$\underline{0.0}$ & $\underline{0.0}$ & $\underline{0.0}$ & $\underline{0.0}$ \\
\hline$\overline{0.0}$ & 0.0 & $\overline{0.0}$ & $\overline{0.0}$ \\
\hline$\underline{0.0}$ & $\underline{0.0}$ & 0.0 & $\overline{0.0}$ \\
\hline$\underline{0.0}$ & $\underline{0.0}$ & $\underline{0.0}$ & $\underline{0.0}$ \\
\hline 0.0 & 0.0 & 0.0 & 0.0 \\
\hline $21,005.3$ & $20,013.9$ & $17,426.9$ & \\
\hline
\end{tabular}


Alternative 1 (Phase I: Firm 1-LAWIHLW, Firm 2-LAW Phase II: Firms 3\&4)

Table 3. TWRS BO by Major Activity and Fiscal Year (Million 1998 )

\begin{tabular}{|c|c|c|c|c|c|c|c|c|}
\hline \multirow[b]{2}{*}{ Year } & \multirow{2}{*}{$\begin{array}{c}\text { Schedule } \\
\text { Tank Oper }\end{array}$} & \multirow{2}{*}{$\begin{array}{c}\text { Tank } \\
\text { Retrieval }\end{array}$} & \multirow{2}{*}{$\begin{array}{l}\text { Storage/ } \\
\text { Disposal } \\
\end{array}$} & \multirow{2}{*}{$\begin{array}{l}\text { Infrastruc- } \\
\text { ture }\end{array}$} & \multirow{2}{*}{$\begin{array}{c}\text { Process } \\
\text { Waste Spt } \\
\end{array}$} & \multicolumn{2}{|c|}{ Process Waste } & \multirow{2}{*}{$\begin{array}{c}\text { Total } \\
\text { BO }\end{array}$} \\
\hline & & & & & & Phase I & Phase II & \\
\hline 1997 & 288.0 & 26.9 & 5.0 & 5.9 & 6.2 & 0.0 & 0.0 & 332.0 \\
\hline 1998 & 230.8 & 16.6 & 12.9 & 6.3 & 17.8 & 54.0 & 0.0 & 338.4 \\
\hline 1999 & 214.6 & 72.3 & 14.2 & 18.7 & 18.7 & 0.0 & 0.0 & 338.5 \\
\hline 2000 & 178.1 & 73.3 & 33.7 & 15.8 & 17.0 & 0.0 & 0.0 & 317.8 \\
\hline 2001 & 146.4 & 101.5 & 33.3 & 10.2 & 18.7 & 0.0 & 0.0 & 310.0 \\
\hline 2002 & 124.7 & 101.0 & 14.9 & 18.3 & 17.0 & 0.0 & 0.0 & 275.9 \\
\hline 2003 & 107.7 & 98.0 & 11.9 & 26.5 & 20.0 & 360.8 & 0.0 & 625.0 \\
\hline 2004 & 88.3 & 101.6 & 17.5 & 41.3 & 27.0 & $1,010.6$ & 0.0 & $1,286.3$ \\
\hline 2005 & 96.5 & 90.0 & 73.8 & 41.0 & 30.0 & 997.9 & 0.0 & $1,329.2$ \\
\hline 2006 & 24.5 & 130.0 & 74.0 & 42.6 & 55.0 & 985.2 & 0.0 & $1,311.3$ \\
\hline 2007 & 16.1 & 149.3 & 28.5 & 41.3 & 55.0 & 972.7 & 0.0 & $1,262.9$ \\
\hline 2008 & 8.4 & 139.3 & 49.5 & 44.3 & 55.0 & 960.4 & 0.0 & $1,257.0$ \\
\hline 2009 & 0.1 & 133.7 & 140.0 & 60.0 & 55.0 & 207.4 & 0.0 & 596.2 \\
\hline 2010 & 0.0 & 129.6 & 249.7 & 41.7 & 55.0 & 204.8 & 0.0 & 680.8 \\
\hline 2011 & 0.6 & 125.2 & 141.8 & 40.8 & 48.0 & 202.2 & 0.0 & 558.0 \\
\hline 2012 & 0.0 & 162.1 & 152.3 & 123.9 & 23.0 & 88.7 & $1,059.3$ & $1,609.4$ \\
\hline 2013 & 0.0 & 210.7 & 204.5 & 117.5 & 23.0 & 0.0 & $1,239.1$ & $1,794.8$ \\
\hline 2014 & 0.0 & 216.6 & 113.5 & 122.5 & 23.0 & 0.0 & $1,412.8$ & $1,888.4$ \\
\hline 2015 & 0.0 & 215.4 & 117.0 & 122.1 & 23.0 & 0.0 & $1,394.9$ & $1,872.4$ \\
\hline 2016 & 0.0 & 213.5 & 161.5 & 122.0 & 23.0 & 0.0 & $1,377.3$ & $1,897.3$ \\
\hline 2017 & 0.0 & 212.6 & 185.5 & 122.0 & 22.0 & 0.0 & 812.5 & $1,354.7$ \\
\hline 2018 & 0.0 & 211.8 & 143.5 & 122.0 & 22.0 & 0.0 & 551.1 & $1,050.4$ \\
\hline 2019 & 0.0 & 211.0 & 196.5 & 122.0 & 21.0 & 0.0 & 334.2 & 884.7 \\
\hline 2020 & 0.0 & 208.9 & 100.4 & 122.0 & 8.0 & 0.0 & 329.9 & 769.3 \\
\hline 2021 & 0.0 & 52.8 & 56.4 & 122.0 & 0.0 & 0.0 & 325.8 & 557.0 \\
\hline 2022 & 0.0 & 84.1 & 80.3 & 122.0 & 0.0 & 0.0 & 321.6 & 608.1 \\
\hline 2023 & 0.0 & 153.2 & 102.1 & 122.0 & 0.0 & 0.0 & 317.6 & 695.0 \\
\hline 2024 & 0.0 & 96.4 & 39.8 & 122.0 & 0.0 & 0.0 & 313.6 & 571.7 \\
\hline 2025 & 0.0 & 10.1 & 23.2 & 98.2 & 0.0 & 0.0 & 249.1 & 380.6 \\
\hline 2026 & 0.0 & 10.1 & 11.1 & 27.0 & 0.0 & 0.0 & 69.3 & 117.5 \\
\hline 2027 & 0.0 & 10.1 & 16.4 & 27.0 & 0.0 & 0.0 & 68.4 & 121.9 \\
\hline 2028 & 0.0 & 10.1 & 27.3 & 27.0 & 0.0 & 0.0 & 67.6 & 132.0 \\
\hline 2029 & 0.0 & 10.1 & 19.1 & 1.0 & 0.0 & 0.0 & 0.0 & 30.2 \\
\hline 2030 & 0.0 & 17.4 & 10.6 & 1.0 & 0.0 & 0.0 & 0.0 & 29.0 \\
\hline 2031 & 0.0 & 17.4 & 2.2 & 1.0 & 0.0 & 0.0 & 0.0 & 20.6 \\
\hline 2032 & 0.0 & 17.4 & 2.2 & 0.0 & 0.0 & 0.0 & 0.0 & 19.6 \\
\hline 2033 & 0.0 & 17.4 & 126.5 & 0.0 & 0.0 & 0.0 & 0.0 & 143.9 \\
\hline 2034 & 0.0 & 17.3 & 375.7 & 0.0 & 0.0 & 0.0 & 0.0 & 393.1 \\
\hline 2035 & 0.0 & 7.3 & 376.9 & 0.0 & 0.0 & 0.0 & 0.0 & 384.2 \\
\hline 2036 & 0.0 & 7.3 & 376.9 & 0.0 & 0.0 & 0.0 & 0.0 & 384.2 \\
\hline 2037 & 0.0 & 0.0 & 376.9 & 0.0 & 0.0 & 0.0 & 0.0 & 376.9 \\
\hline 2038 & 0.0 & 0.0 & 376.9 & 0.0 & 0.0 & 0.0 & 0.0 & 376.9 \\
\hline 2039 & 0.0 & 0.0 & 376.9 & 0.0 & 0.0 & 0.0 & 0.0 & 376.9 \\
\hline 2040 & 0.0 & 0.0 & 376.9 & 0.0 & 0.0 & 0.0 & 0.0 & 376.9 \\
\hline$>2040$. & 0.0 & 0.0 & $1,966.0$ & 0.0 & 0.0 & 0.0 & 0.0 & $1,966.0$ \\
\hline Totals: & $1,524.2$ & $3,889.1$ & $7,395.9$ & $2,220.9$ & 683.31 & $6,044.8$ & $10,244.1$ & $32,002.5$ \\
\hline
\end{tabular}


Alternative 1 (Phase I: Firm 1-LAWIHLW, Firm 2-LAW Phase II: Firms 3\&4)

Table 4. TWRS BA by Fiscal Year (\$ Million)

\begin{tabular}{|c|c|c|c|c|c|c|c|c|}
\hline & \multicolumn{4}{|c|}{ MYWP Basis (escalated thru 2006) } & \multicolumn{4}{|c|}{$1998 \$$} \\
\hline & PHMC & Phase I & Phase II & Total & PHMC & Phase I & Phase II & Total \\
\hline 1997 & 322.0 & 70.5 & 0.0 & 392.5 & 332.0 & 72.3 & 0.0 & 404.3 \\
\hline 1998 & 284.4 & 257.3 & 0.0 & 541.7 & 284.4 & 257.3 & 0.0 & 541.7 \\
\hline 1999 & 347.7 & 531.8 & 0.0 & 879.5 & 338.5 & 517.8 & 0.0 & 856.4 \\
\hline 2000 & 335.1 & 681.2 & 0.0 & $1,016.3$ & 317.8 & 645.8 & 0.0 & 963.6 \\
\hline 2001 & 335.8 & 687.6 & 0.0 & $1,023.4$ & 310.0 & 634.8 & 0.0 & 944.8 \\
\hline 2002 & 307.0 & 563.8 & 0.0 & 870.8 & 275.9 & 506.8 & 0.0 & 782.8 \\
\hline 2003 & 301.8 & 474.7 & 0.0 & 776.5 & 264.2 & 415.5 & 0.0 & 679.7 \\
\hline 2004 & 323.5 & 673.0 & 0.0 & 996.5 & 275.7 & 573.6 & 0.0 & 649.3 \\
\hline 2005 & 399.3 & 613.1 & 0.0 & $1,012.4$ & 331.4 & 508.8 & 0.0 & 840.1 \\
\hline 2006 & 403.6 & 828.7 & 190.3 & $1,422.6$ & 326.1 & 669.6 & 153.8 & $1,149.5$ \\
\hline 2007 & 359.1 & 791.9 & 243.9 & $1,394.9$ & 290.2 & 639.9 & 197.1 & $1,127.1$ \\
\hline 2008 & 367.0 & 699.0 & 303.7 & $1,369.7$ & 296.5 & 564.9 & 245.4 & $1,106.8$ \\
\hline 2009 & 481.2 & 300.5 & 358.8 & $1,140.4$ & 388.8 & 242.8 & 289.9 & 921.5 \\
\hline 2010 & 589.1 & 302.1 & $1,213.5$ & $2,104.6$ & 476.0 & 244.1 & 980.5 & $1,700.7$ \\
\hline 2011 & 440.3 & 307.6 & $1,176.2$ & $1,924.1$ & 355.8 & 248.5 & 950.4 & $1,554.8$ \\
\hline 2012 & 570.9 & 159.1 & .980 .3 & $1,710.2$ & 461.3 & 128.5 & 792.1 & $1,381.9$ \\
\hline 2013 & 687.7 & 0.0 & 738.7 & $1,426.4$ & 555.7 & 0.0 & 596.9 & $1,152.6$ \\
\hline 2014 & 588.6 & 0.0 & 653.4 & $1,242.0$ & 475.6 & 0.0 & 528.0 & $1,003.6$ \\
\hline 2015 & 591.0 & 0.0 & $1,349.0$ & $1,939.9$ & 477.5 & 0.0 & $1,090.0$ & $1,567.5$ \\
\hline 2016 & 643.5 & 0.0 & $1,403.7$ & $2,047.2$ & 520.0 & 0.0 & $1,134.2$ & $1,654.2$ \\
\hline 2017 & 670.9 & 0.0 & 803.5 & $1,474.5$ & 542.2 & 0.0 & 649.3 & $1,191.4$ \\
\hline 2018 & 617.9 & 0.0 & 682.0 & $1,299.9$ & 499.3 & 0.0 & 551.1 & $1,050.4$ \\
\hline 2019 & 681.3 & 0.0 & 413.6 & $1,094.8$ & 550.5 & 0.0 & 334.2 & 884.7 \\
\hline 2020 & 543.7 & 0.0 & 408.3 & 952.0 & 439.3 & 0.0 & 329.9 & 769.3 \\
\hline 2021 & 286.1 & 0.0 & 403.2 & 689.3 & 231.2 & 0.0 & 325.8 & 557.0 \\
\hline 2022 & 354.4 & 0.0 & 398.1 & 752.5 & 286.4 & 0.0 & 321.6 & 608.1 \\
\hline 2023 & 467.0 & 0.0 & 393.0 & 860.0 & 377.4 & 0.0 & 317.6 & 695.0 \\
\hline 2024 & 319.5 & 0.0 & 388.0 & 707.5 & 258.1 & 0.0 & 313.6 & 571.7 \\
\hline 2025 & 162.7 & 0.0 & 308.3 & 471.0 & 131.4 & 0.0 & 249.1 & 380.6 \\
\hline $2026^{\circ}$ & 59.6 & 0.0 & 85.8 & 145.4 & 48.2 & 0.0 & 69.3 & 117.5 \\
\hline 2027 & 66.2 & 0.0 & 84.7 & 150.9 & 53.5 & 0.0 & 68.4 & 121.9 \\
\hline 2028 & 79.7 & 0.0 & 83.6 & 163.3 & 64.4 & 0.0 & 67.6 & 132.0 \\
\hline 2029 & 37.4 & 0.0 & 0.0 & 37.4 & 30.2 & 0.0 & 0.0 & 30.2 \\
\hline 2030 & 35.9 & 0.0 & 0.0 & 35.9 & 29.0 & 0.0 & 0.0 & 29.0 \\
\hline 2031 & 25.5 & 0.0 & 0.0 & 25.5 & 20.6 & 0.0 & 0.0 & 20.6 \\
\hline 2032 & 24.2 & 0.0 & 0.0 & 24.2 & 19.6 & 0.0 & 0.0 & 19.6 \\
\hline 2033 & 178.1 & 0.0 & 0.0 & 178.1 & 143.9 & 0.0 & 0.0 & 143.9 \\
\hline 2034 & 486.4 & 0.0 & 0.0 & 486.4 & 393.1 & 0.0 & 0.0 & 393.1 \\
\hline 2035 & 475.5 & 0.0 & 0.0 & 475.5 & 384.2 & 0.0 & 0.0 & 384.2 \\
\hline 2036 & 475.5 & 0.0 & 0.0 & 475.5 & 384.2 & 0.0 & 0.0 & 384.2 \\
\hline 2037 & 466.4 & 0.0 & 0.0 & 466.4 & 376.9 & 0.0 & 0.0 & 376.9 \\
\hline 2038 & 466.4 & 0.0 & 0.0 & 466.4 & 376.9 & 0.0 & 0.0 & 376.9 \\
\hline 2039 & 466.4 & 0.0 & 0.0 & 466.4 & 376.9 & 0.0 & 0.0 & 376.9 \\
\hline 2040 & 466.4 & 0.0 & 0.0 & 466.4 & 376.9 & 0.0 & 0.0 & 376.9 \\
\hline$>2040$ & $2,433.1$ & 0.0 & 0.0 & $2,433.1$ & $1,966.0$ & 0.0 & 0.0 & $1,966.0$ \\
\hline Totals. & $19,024.6$ & 41.8 & 663.5 & $40,029.9$ & $15,713.6$ & $6,871.0$ & 555.9 & $33,140.5$ \\
\hline
\end{tabular}


Table 5. TWRS Life-Cycle Costs, with Accounting for Federal Taxes Paid

A. Gross Costs to Federal Gov't

Dollar Basis

Costs discounted at:

Tank Characterization (TW01)

Tank Safety Issue Resolution (TW02)

Tank Farm Operations (TW03)

Retrieval Project (TW04)

Process Waste Support (TW05)

Process Waste (TW06, TW07)

Privatization Infrastructure (TW08)

Waste Storage and Disposal (TW09)

TWRS Management Support (TW10)
FY 1997-FY2055 (\$000s)

\begin{tabular}{|c|c|c|c|}
\hline $\begin{array}{c}\text { MYWP } \\
0.0 \%\end{array}$ & $\begin{array}{c}1998 \$ \\
0.0 \%\end{array}$ & $\begin{array}{c}1998 \$ \\
3.8 \%\end{array}$ & $\begin{array}{c}1998 \$ \\
7.0 \%\end{array}$ \\
\hline 229,494 & 223,716 & 214,129 & 207,126 \\
\hline 128,865 & 126,549 & 122,244 & 119,053 \\
\hline 962,029 & 898,445 & 816,189 & 759,903 \\
\hline $4,780,135$ & $3,889,137$ & $2,290,044$ & $1,574,426$ \\
\hline 964,970 & 683,341 & 467,397 & 353,574 \\
\hline $7,336,272$ & $6,044,805$ & $4,463,536$ & $3,504,618$ \\
\hline $2,035,601$ & $2,220,916$ & $1,162,351$ & 721,455 \\
\hline $8,836,396$ & $7,395,948$ & $2,610,195$ & $-1,264,245$ \\
\hline 299,075 & 275,536 & 246,471 & 226,554 \\
\hline $25,572,837$ & $21,758,392$ & $12,292,555$ & $8,730,955$ \\
\hline
\end{tabular}

\section{B. Net Costs to Federal Gov't}

Dollar Basis:

Costs discounted at:

Tank Characterization (TW01)

Tank Safety Issue Resolution (TW02)

Tank Farm Operations (TW03)

Retrieval Project (TW04)

Process Waste Support (TW05)

Process Waste (TW06, TW07)

Privatization Infrastructure (TW08)

Waste Storage and Disposal (TW09)

TWRS Management Support (TW10)

\begin{tabular}{rrrr} 
MYWP & $1998 \$$ & $1998 \$$ & \multicolumn{1}{c}{$1998 \$$} \\
$0.0 \%$ & $0.0 \%$ & $3.8 \%$ & \multicolumn{1}{c}{$7.0 \%$} \\
\hline \hline 229,494 & 223,716 & 214,129 & 207,126 \\
128,865 & 126,549 & 122,244 & 119,053 \\
962,029 & 898,445 & 816,189 & 759,903 \\
$4,780,135$ & $3,889,137$ & $2,290,044$ & $1,574,426$ \\
964,970 & 683,341 & 467,397 & 353,574 \\
$3,569,007$ & $2,940,516$ & $2,432,928$ & $2,016,017$ \\
$2,035,601$ & $2,220,916$ & $1,162,351$ & 721,455 \\
$8,836,396$ & $7,395,948$ & $2,510,195$ & $1,264,245$ \\
299,075 & 275,536 & 246,471 & 226,554
\end{tabular}

$21,805,572 \quad 18,654,103 \quad 10,261,948$ 


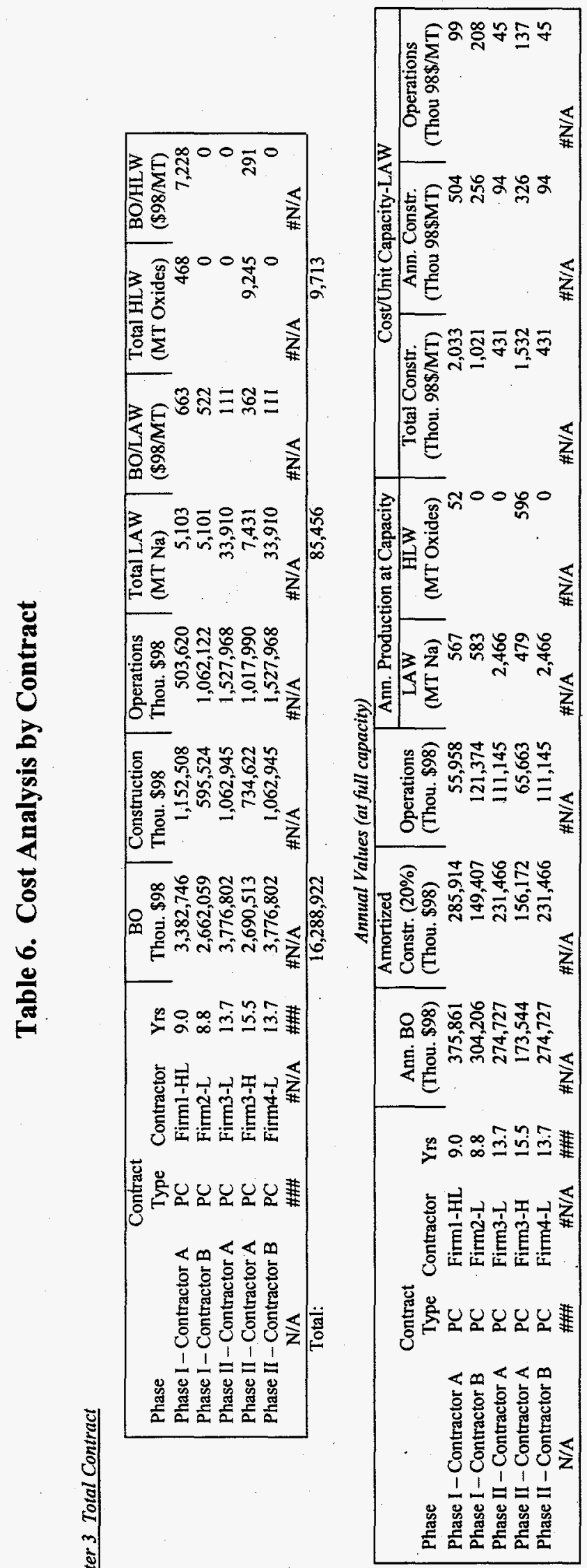

C-19 
Alternative 1: (Phase I: Firm 1 - LAW/HLW, Firm 2-LAW Phase II: Firms 3 \& 4)

Table 7. LAW Processing by Plant and Year

\begin{tabular}{|c|c|c|c|c|c|c|c|c|}
\hline Year & $\begin{array}{c}\text { Phase I: } \\
\text { Plant A LAW } \\
\text { Processed } \\
\text { (MT Na/yr) } \\
\text { Financial } \\
\text { Model }\end{array}$ & $\begin{array}{c}\text { Phase 1: } \\
\text { Plant B LAW } \\
\text { Processed } \\
\text { (MT Na/yr) } \\
\text { Financial } \\
\text { Model }\end{array}$ & $\begin{array}{l}\text { Phase 2: } \\
\text { Plant A LAW } \\
\text { Processed } \\
\text { (MT Na/yr) } \\
\text { Financial } \\
\text { Model }\end{array}$ & $\begin{array}{c}\text { Phase 2: } \\
\text { Plant B LAW } \\
\text { Processed } \\
\text { (MT Na/yr) } \\
\text { Financial } \\
\text { Model }\end{array}$ & $\begin{array}{c}\text { (from FM) } \\
\text { Total LAW } \\
\text { Processed } \\
\text { (MT Na/yr) } \\
\text { Financial } \\
\text { Model }\end{array}$ & $\begin{array}{c}\text { (adjusted) } \\
\text { Total LAW } \\
\text { Processed } \\
\text { (MT Na/yr) } \\
\text { Financial } \\
\text { Model }\end{array}$ & $\begin{array}{l}\text { Cumulative } \\
\text { Sodium } \\
\text { Processed } \\
\text { (MT) }\end{array}$ & $\begin{array}{l}\text { Processing } \\
\text { Adjustment } \\
\text { Factor }\end{array}$ \\
\hline$<1997$ & 0 & 0 & 0 & 0 & 0 & 0 & 0 & 0.000 \\
\hline 1997 & 0 & 0 & 0 & 0 & 0 & 0 & 0 & 0.000 \\
\hline 1998 & 0 & 0 & 0 & 0 & 0 & 0 & 0 & 0.000 \\
\hline 1999 & 0 & 0 & 0 & 0 & 0 & 0 & 0 & 0.000 \\
\hline 2000 & 0 & 0 & 0 & 0 & 0 & 0 & 0 & 0.000 \\
\hline 2001 & 0 & 0 & 0 & 0 & 0 & 0 & 0 & 0.000 \\
\hline 2002 & 0 & 0 & 0 & 0 & 0 & 0 & 0 & 0.000 \\
\hline 2003 & 142 & 292 & 0 & 0 & 433 & 433 & 433 & 1.000 \\
\hline 2004 & 567 & 583 & 0 & 0 & 1,150 & 1,150 & 1,583 & 1.000 \\
\hline 2005 & 567 & 583 & 0 & 0 & 1,150 & 1,150 & 2,733 & 1.000 \\
\hline 2006 & 567 & 583 & 0 & 0 & 1,150 & 1,150 & 3,883 & 1.000 \\
\hline 2007 & 567 & 583 & 0 & 0 & 1,150 & 1,150 & 5,033 & 1.000 \\
\hline 2008 & 567 & 583 & 0 & 0 & 1,150 & 1,150 & 6,183 & 1.000 \\
\hline 2009 & 567 & 583 & 0 & 0 & 1,150 & 1,150 & 7,333 & 1.000 \\
\hline 2010 & 567 & 583 & 0 & 0 & 1,150 & 1,150 & 8,483 & 1.000 \\
\hline 2011 & 567 & 583 & 0 & 0 & 1,150 & 1,150 & 9,633 & 1.000 \\
\hline 2012 & 425 & 146 & 2,466 & 2,466 & 5,504 & 5,504 & 15,137 & 1.000 \\
\hline 2013 & 0 & 0 & 2,706 & 2,466 & 5,172 & 5,172 & 20,309 & 1.000 \\
\hline 2014 & 0 & 0 & 2,946 & 2,466 & 5,412 & 5,412 & 25,721 & 1.000 \\
\hline 2015 & 0 & 0 & 2,946 & 2,466 & 5,412 & 5,412 & 31,133 & 1.000 \\
\hline 2016 & 0 & 0 & 2,946 & 2,466 & 5,412 & 5,412 & 36,545 & 1.000 \\
\hline 2017 & 0 & 0 & 2,946 & 2,466 & 5,412 & 5,412 & 41,957 & 1.000 \\
\hline 2018 & 0 & 0 & 2,946 & 2,466 & 5,412 & 5,412 & 47,369 & 1.000 \\
\hline 2019 & 0 & 0 & 2,946 & 2,466 & 5,412 & 5,412 & 52,781 & 1.000 \\
\hline 2020 & 0 & 0 & 2,946 & 2,466 & 5,412 & 5,412 & 58,192 & 1.000 \\
\hline 2021 & 0 & 0 & 2,946 & 2,466 & 5,412 & 5,412 & 63,604 & 1.000 \\
\hline 2022 & 0 & 0 & 2,946 & 2,466 & 5,412 & 5,412 & 69,016 & 1.000 \\
\hline 2023 & 0 & 0 & 2,946 & 2,466 & 5,412 & 5,412 & 74,428 & 1.000 \\
\hline 2024 & 0 & 0 & 2,946 & 2,466 & 5,412 & 3,522 & 77,950 & 0.651 \\
\hline 2025 & 0 & 0 & 2,329 & 1,849 & 4,178 & 0 & 77,950 & 0.000 \\
\hline 2026 & 0 & 0 & 479 & 0 & 479 & 0 & 77,950 & 0.000 \\
\hline 2027 & 0 & 0 & 479 & 0 & 479 & 0 & 77,950 & 0.000 \\
\hline 2028 & 0 & 0 & 479 & 0 & 479 & 0 & 77,950 & 0.000 \\
\hline 2029 & 0 & 0 & 0 & 0 & 0 & 0 & 77,950 & 0.000 \\
\hline 2030 & 0 & 0 & 0 & 0 & 0 & 0 & 77,950 & 0.000 \\
\hline 2031 & 0 & 0 & 0 & 0 & 0 & 0 & 77,950 & 0.000 \\
\hline 2032 & 0 & 0 & 0 & 0 & 0 & 0 & 77,950 & 0.000 \\
\hline 2033 & 0 & 0 & 0 & 0 & 0 & 0 & 77,950 & 0.000 \\
\hline 2034 & 0 & 0 & 0 & 0 & 0 & 0 & 77,950 & 0.000 \\
\hline 2035 & 0 & 0 & 0 & 0 & 0 & 0 & 77,950 & 0.000 \\
\hline 2036 & 0 & 0 & 0 & 0 & 0 & 0 & 77,950 & 0.000 \\
\hline 2037 & 0 & 0 & 0 & 0 & 0 & 0 & 77,950 & 0.000 \\
\hline 2038 & 0 & 0 & 0 & 0 & 0 & 0 & 77,950 & 0.000 \\
\hline 2039 & 0 & 0 & 0 & 0 & 0 & 0 & 77,950 & 0.000 \\
\hline 2040 & 0 & 0 & 0 & 0 & 0 & 0 & 77,950 & 0.000 \\
\hline 2041 & 0 & 0 & 0 & 0 & 0 & 0 & 77,950 & 0.000 \\
\hline 2042 & 0 & 0 & 0 & 0 & 0 & 0 & 77,950 & 0.000 \\
\hline 2043 & 0 & 0 & 0 & 0 & 0 & 0 & 77,950 & 0.000 \\
\hline 2044 & 0 & 0 & 0 & 0 & 0 & 0 & 77,950 & 0.000 \\
\hline 2045 & 0 & 0 & 0 & 0 & 0 & 0 & 77,950 & 0.000 \\
\hline 2046 & 0 & 0 & 0 & 0 & 0 & 0 & 77,950 & 0.000 \\
\hline 2047 & 0 & 0 & 0 & 0 & 0 & 0 & 77,950 & 0.000 \\
\hline 2048 & 0 & 0 & 0 & 0 & 0 & 0 & 77,950 & 0.000 \\
\hline 2049 & 0 & 0 & 0 & 0 & 0 & 0 & 77,950 & 0.000 \\
\hline 2050 & 0 & 0 & 0 & 0 & 0 & 0 & 77,950 & 0.000 \\
\hline
\end{tabular}


Alternative 1: (Phase I: Firm 1-LAW/HLW, Firm 2 - LAW Phase II: Firms 3 \& 4)

Table 8. Single-Shell Tank Retrieval and Double-Shell Capacity Requirements

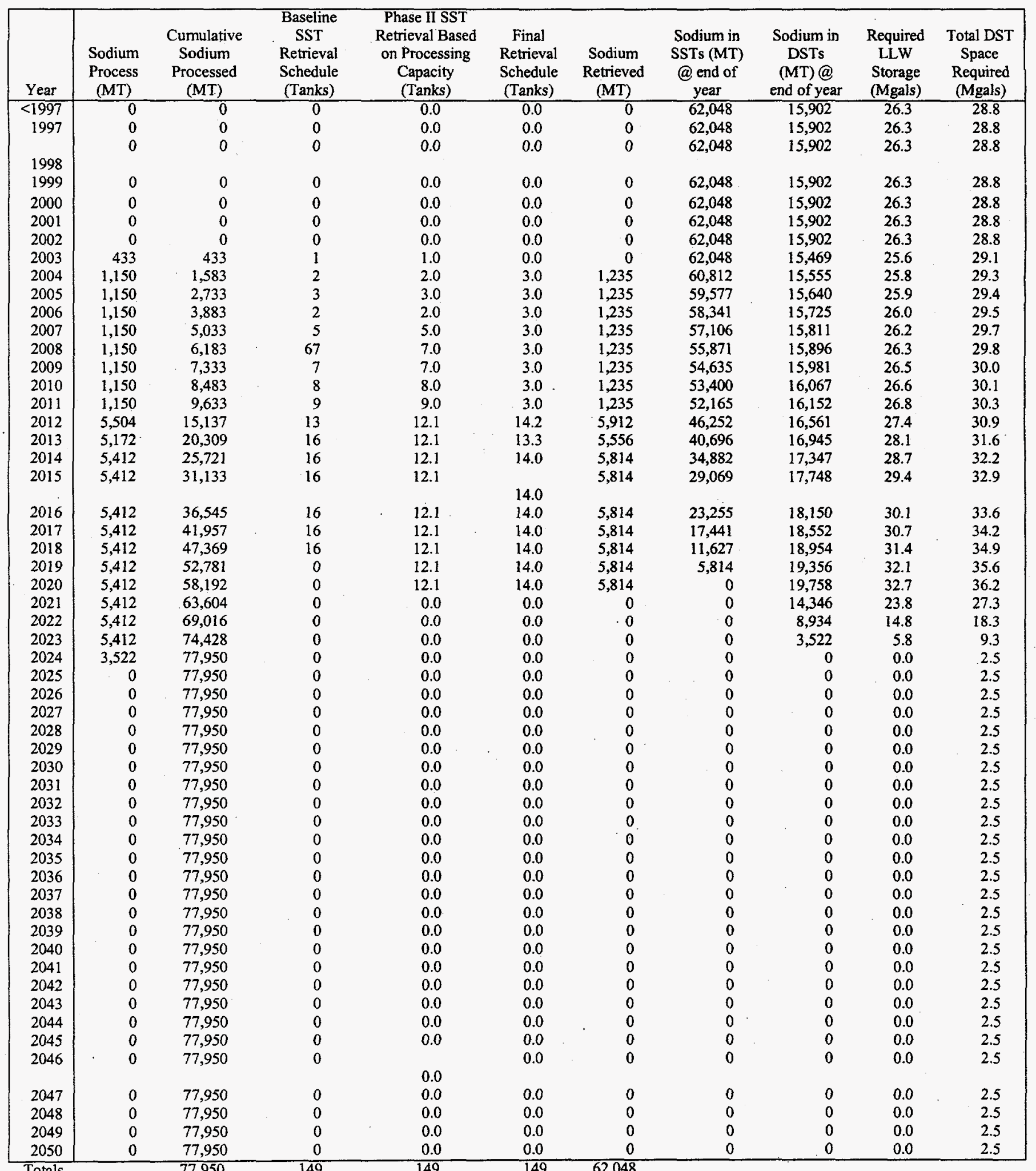


Alternative 1: (Phase I: Firm 1 - LAW/HLW, Firm 2 - LAW Phase II: Firms 3 \& 4

Table 9. Glass and Waste Containers Produced, LAW and HLW

\begin{tabular}{|c|c|c|c|c|c|c|c|c|}
\hline Year & $\begin{array}{c}\text { Sodium } \\
\text { Process } \\
\text { (MT) }\end{array}$ & $\begin{array}{l}\text { ILAW Glass } \\
\text { Produced } \\
\text { (MT) }\end{array}$ & $\begin{array}{l}\text { ILAW Glass } \\
\text { Packages } \\
\text { Produced }\end{array}$ & $\begin{array}{c}\text { Cumulative } \\
\text { ILAW Glass } \\
\text { Packages } \\
\text { Produced }\end{array}$ & $\begin{array}{c}\text { HLW } \\
\text { Oxide } \\
\text { Processed } \\
\text { (MT) }\end{array}$ & $\begin{array}{l}\text { IHLW Glass } \\
\text { Produced } \\
\text { (MT) }\end{array}$ & $\begin{array}{l}\text { IHLW } \\
\text { Canisters } \\
\text { Produced }\end{array}$ & $\begin{array}{l}\text { Cumulative } \\
\text { IHLW } \\
\text { Canisters } \\
\text { Produced }\end{array}$ \\
\hline$<1997$ & 0 & 0 & 0 & 0 & 0 & 0 & 0 & 0 \\
\hline 1997 & 0. & 0 & 0 & 0 & 0 & 0 & 0 & 0 \\
\hline 1998 & 0 & 0 & 0 & 0 & 0 & 0 & 0 & 0 \\
\hline 1999 & 0 & 0 & 0 & 0 & 0 & 0 & 0 & 0 \\
\hline 2000 & 0 & 0 & 0 & 0 & 0 & 0 & 0 & 0 \\
\hline 2001 & 0 & 0 & 0 & 0 & 0 & 0 & 0 & 0 \\
\hline 2002 & 0 & 0 & 0 & 0 & 0 & 0 & 0 & 0 \\
\hline 2003 & 433 & 2,166 & 532 & 532 & 13 & 52 & 18 & 18 \\
\hline 2004 & 1,150 & 5,750 & 1,411 & 1,943 & 52 & 208 & 73 & 91 \\
\hline 2005 & 1,150 & 5,750 & 1,411 & 3,354 & 52 & 208 & 73 & 164 \\
\hline 2006 & 1,150 & 5,750 & 1,411 & 4,765 & 52 & 208 & 73 & 236 \\
\hline 2007 & 1,150 & 5,750 & 1,411 & 6,177 & 52 & 208 & 73 & 309 \\
\hline 2008 & 1,150 & 5,750 & 1,411 & 7,588 & 52 & 208 & 73 & 382 \\
\hline 2009 & 1,150 & 5,750 & 1,411 & 8,999 & 52 & 208 & 73 & 454 \\
\hline 2010 & 1,150 & 5,750 & 1,411 & 10,410 & 52 & 208 & 73 & 527 \\
\hline 2011 & 1,150 & 5,750 & 1,411 & 11,822 & 52 & 208 & 73 & 600 \\
\hline 2012 & 5,504 & 27,518 & 6,754 & 18,576 & 39 & 156 & 55 & 654 \\
\hline 2013 & 5,172 & 25,862 & 6,348 & 24,923 & 299 & 1,194 & 417 & 1,071 \\
\hline 2014 & 5,412 & 27,060 & 6,641 & 31,564 & 596 & 2,386 & 834 & 1,905 \\
\hline 2015 & 5,412 & 27,060 & 6,641 & 38,206 & 596 & 2,386 & 834 & 2,738 \\
\hline 2016 & 5,412 & 27,060 & 6,641 & 44,847 & 596 & 2,386 & 834 & 3,572 \\
\hline 2017 & 5,412 & 27,060 & 6,641 & 51,489 & 596 & 2,386 & 834 & 4,406 \\
\hline 2018 & 5,412 & 27,060 & 6,641 & 58,130 & 596 & 2,386 & 834 & 5,239 \\
\hline 2019 & 5,412 & 27,060 & 6,641 & 64,771 & 596 & 2,386 & 834 & 6,073 \\
\hline 2020 & 5,412 & 27,060 & 6,641 & 71,413 & 596 & 2,386 & 834 & 6,906 \\
\hline 2021 & 5,412 & 27,060 & 6,641 & 78,054 & 596 & 2,386 & 834 & 7,740 \\
\hline 2022 & 5,412 & 27,060 & 6,641 & 84,695 & 596 & 2,386 & 834 & 8,574 \\
\hline 2023 & 5,412 & 27,060 & 6,641 & 91,337 & 596 & 2,386 & 834 & 9,407 \\
\hline 2024 & 3,522 & 17,609 & 4,322 & 95,659 & 596 & 2,386 & 834 & 10,241 \\
\hline 2025 & 0 & 0 & $: 0$ & 95,659 & 596 & 2,386 & 834 & 11,074 \\
\hline 2026 & 0 & 0 & 0 & 95,659 & 596 & 2,386 & 834 & 11,908 \\
\hline 2027 & 0 & .0 & 0 & 95,659 & 596 & 2,386 & 834 & 12,742 \\
\hline 2028 & 0 & 0 & 0 & 95,659 & 596 & 2,386 & 834 & 13,575 \\
\hline 2029 & 0 & 0 & 0 & 95,659 & 0 & 0 & 0 & 13,575 \\
\hline 2030 & 0 & 0 & 0 & 95,659 & 0 & 0 & 0 & 13,575 \\
\hline 2031 & 0 & 0 & 0 & 95,659 & 0 & 0 & 0 & 13,575 \\
\hline 2032 & 0 & 0 & 0 & 95,659 & 0 & 0 & 0 & 13,575 \\
\hline 2033 & 0 & 0 & 0 & 95,659 & 0 & 0 & 0 & 13,575 \\
\hline 2034 & 0 & 0 & 0 & 95,659 & 0 & 0 & 0 & 13,575 \\
\hline 2035 & 0 & 0 & 0 & 95,659 & 0 & 0 & 0 & 13,575 \\
\hline 2036 & 0 & 0 & 0 & 95,659 & 0 & 0 & 0. & 13,575 \\
\hline 2037 & 0 & 0 & 0 & 95,659 & 0 & 0 & 0 & 13,575 \\
\hline 2038 & 0 & 0 & 0 & 95,659 & 0 & 0 & 0 & 13,575 \\
\hline 2039 & 0 & 0 & 0 & 95,659 & 0 & 0 & 0 & 13,575 \\
\hline 2040 & 0 & 0 & 0 & 95,659 & 0 & 0 & 0 & 13,575 \\
\hline 2041 & 0 & 0 & 0 & 95,659 & 0 & 0 & 0 & 13,575 \\
\hline 2042 & 0 & 0 & 0 & 95,659 & 0 & 0 & 0 & 13,575 \\
\hline 2043 & 0 & 0 & 0 & 95,659 & 0 & 0 & 0 & 13,575 \\
\hline 2044 & 0 & 0 & 0 & 95,659 & 0 & 0 & 0 & 13,575 \\
\hline 2045 & 0 & 0 & 0 & 95,659 & 0 & 0 & 0 & 13,575 \\
\hline 2046 & 0 & 0 & 0 & 95,659 & 0 & 0 & 0 & 13,575 \\
\hline 2047 & 0 & 0 & 0 & 95,659 & 0 & 0 & 0 & 13,575 \\
\hline 2048 & 0 & 0 & 0 & 95,659 & 0 & 0 & 0 & 13,575 \\
\hline 2049 & 0 & 0 & 0 & 95,659 & 0 & 0 & 0 & 13,575 \\
\hline 2050 & 0 & 0 & 0 & 95,659 & 0 & 0 & 0 & 13,575 \\
\hline
\end{tabular}


Chapter 4 Alternative 1 (Phase 1: Firm 1-LAW/HLW, Firm 2-LAW Phase 1l: Firms 3 \& 4)

Table 10. Cost Comparisons: Privatization vs. M\&O Approaches FY 1997 - FY 2055, (\$000s)

\begin{tabular}{|c|c|c|c|c|c|}
\hline \multicolumn{6}{|l|}{ A. Gross costs to Federal Govt } \\
\hline Dollar Basis: & & MYWP & $1998 \$$ & $1998 \$$ & $1998 \$$ \\
\hline Costs discounted at: & & $\underline{0.0 \%}$ & $\underline{0.0 \%}$ & $\underline{3.8 \%}$ & $\underline{7.0 \%}$ \\
\hline Privatization & & $20,013,902$ & $16,288,922$ & $9,655,310$ & $\underline{6,528,095}$ \\
\hline M\&O & & $12,701,511$ & $10,555,659$ & $\underline{6,658,018}$ & $4,839,456$ \\
\hline Privatization Savings & & $-7,312,391$ & $-5,733,263$ & $-2,997,291$ & $-1,688,639$ \\
\hline Ratio: Privatization $/ M \& O$ & & $\underline{1.58}$ & 1.54 & 1.45 & $\underline{1.35}$ \\
\hline \multicolumn{6}{|c|}{ B. Net costs to Federal Govt. - Adjustment for Federal Taxes } \\
\hline Dollar Basis: & & MYWP & $1998 \$$ & $1998 \mathrm{~S}$ & $\underline{1998 \$}$ \\
\hline Costs discounted at: & & $0.0 \%$ & $0.0 \%$ & $3.8 \%$ & $7.0 \%$ \\
\hline Privatization & & $\underline{16,246,638}$ & $13,184,633$ & $7,624,702$ & $\underline{5,039,495}$ \\
\hline M\&O & & $\underline{12,590,527}$ & $10,463,425$ & $6,599,841$ & $4,797,170$ \\
\hline Privatization Savings & & $-3,656,111$ & $-2,721,208$ & $-1,024,861$ & $\underline{-242,325}$ \\
\hline Ratio: Privatization $M \& \underline{\mathrm{O}}$ & & 1.29 & $\underline{1.26}$ & $\underline{1.16}$ & $\underline{1.05}$ \\
\hline \multicolumn{6}{|c|}{ C. Net costs to Federal Govt - Adjustment for Overruns } \\
\hline Dollar Basis: & & MYWP & $\underline{19985}$ & $1998 \$$ & $1998 \$$ \\
\hline \multirow[t]{2}{*}{ Costs discounted at: } & & $0.0 \%$ & $0.0 \%$ & $3.8 \%$ & $7.0 \%$ \\
\hline & \% overrun & & & & \\
\hline Privatization & $\underline{25 \%}$ & $20,308,297$ & $16,480,792$ & $9,530,878$ & $6,299,368$ \\
\hline M\&O & $\underline{60 \%}$ & $20,144,843$ & $16,741,480$ & $10,559,746$ & $7,675,471$ \\
\hline Privatization Savings & & $-163,454$ & 260,688 & $\underline{1,028,868}$ & $1,376,103$ \\
\hline Ratio: Privatization/M\&O & & $\underline{1.01}$ & 0.98 & $\underline{0.90}$ & $\underline{0.82}$ \\
\hline \multicolumn{6}{|l|}{ Notes: } \\
\hline After Tax IRR - Private Contractor & $31.7 \%$ & & & & \\
\hline M\&OFee Rate & $3.0 \%$ & & & & \\
\hline \multicolumn{6}{|c|}{ Addendum Cost Comparisons: Adjustment for Competition and Learning } \\
\hline \multicolumn{6}{|c|}{ FY 1997-FY 2055, (\$000s) } \\
\hline \multicolumn{6}{|l|}{ Gross costs to Federal Govt. } \\
\hline & & & & & \\
\hline Dollar Basis: & & MYWP & $1998 \$$ & $1998 \$$ & $1998 \$$ \\
\hline Costs discounted at: & & $0.0 \%$ & $\underline{0.0 \%}$ & $\underline{3.8 \%}$ & $\underline{7.0 \%}$ \\
\hline \multicolumn{6}{|l|}{ Privatization } \\
\hline Unadiusted & & $20,013,902$ & $16,288,922$ & $\underline{9,655,310}$ & $\underline{6,528,095}$ \\
\hline Adjusted for Overruns & $25 \%$ & $25,017,378$ & $20,361,153$ & $12,069,137$ & $8,160,119$ \\
\hline Adjusted for Overruns \&Competition & & $21,264,771$ & $17,306,980$ & $10,258,766$ & $6,936,101$ \\
\hline Adjusted for All above \& Learning & & $19,917,773$ & $16,218,542$ & $9,707,141$ & $6,614,857$ \\
\hline M\&O, Adjusted for Overruns & $60 \%$ & $20,322,418$ & $16 ; 889 ; 054$ & $10,652,829$ & $7,743,130$ \\
\hline Privatization Savings & & $4 \underline{404,645}$ & 670,512 & $\underline{945,689}$ & $\underline{1,128,273}$ \\
\hline Chapter 1 Ratio: Privatization $/ M O$ & & 0.98 & 0.96 & 0.91 & $\underline{0.85}$ \\
\hline \multicolumn{6}{|l|}{ Notes: } \\
\hline Competition effect, $>1$ contractor & $-15 \%$ & & & & \\
\hline Learning effect: $>1$ contractor in $\mathrm{Ph} 1$ & $-10 \%$ & & & & \\
\hline
\end{tabular}


Privatization vs. M\&O Firm 1-LAW/HLW

Table 10. Cost Comparisons: Privatization vs. M\&O Approaches

FY 1997 - FY 2055, (\$000s)

\begin{tabular}{|c|c|c|c|c|c|}
\hline \multicolumn{6}{|l|}{ A. Gross costs to Federal Govt. } \\
\hline Dollar Basis: & & MYWP & $\underline{1998 \$}$ & $1998 \$$ & $1998 \$$ \\
\hline Costs discounted at: & & $\underline{0.0 \%}$ & $\underline{0.0 \%}$ & $3.8 \%$ & $7.0 \%$ \\
\hline Privatization & & $4,108,100$ & $3,382,746$ & $2,502,247$ & $1,966,452$ \\
\hline M\&O & & $1,872,912$ & $1,705,812$ & $1,482,024$ & $1,341,529$ \\
\hline Privatization Savings & & $-2,235,188$ & $-1,676,934$ & $-1,020,223$ & $-624,922$ \\
\hline Ratio: Privatization/M\&O & & $\underline{2.19}$ & 1.98 & $\underline{1.69}$ & 1.47 \\
\hline \multicolumn{6}{|c|}{ B. Net costs to Federal Govt. - Adjustment for Federal Taxes } \\
\hline Dollar Basis: & & MYWP & $1998 \mathrm{~S}$ & $1998 \mathrm{~S}$ & 1998\$ \\
\hline Costs discounted at: & & $\overline{0.0 \%}$ & $0.0 \%$ & $3.8 \%$ & $7.0 \%$ \\
\hline Privatization & & $2,670,738$ & $2,174,436$ & $\underline{1,564,466}$ & $1,199,986$ \\
\hline M\&O & & $1,856,547$ & $1,690,907$ & $\overline{1,469,074}$ & $1,329,807$ \\
\hline Privatization Savings & & $-814,191$ & $-483,529$ & $-95,392$ & 129,821 \\
\hline Ratio: Privatization/M\&O & & $\underline{1.44}$ & 1.29 & $\underline{1.06}$ & $\underline{90}$ \\
\hline \multicolumn{6}{|c|}{ C. Net costs to Federal Govt - Adjustment for Overruns } \\
\hline Dollar Basis: & & MYWP & $1998 \$$ & $1998 \$$ & $1998 \$$ \\
\hline \multirow[t]{2}{*}{ Costs discounted at: } & & $\underline{0.0 \%}$ & $\underline{0.0 \%}$ & $3.8 \%$ & $7.0 \%$ \\
\hline & $\%$ overrun & & & & \\
\hline Privatization & $\underline{25 \%}$ & $3,338,422$ & $2,718,046$ & $1,955,583$ & $1,499,983$ \\
\hline M\&O & $\underline{60 \%}$ & $2,970,475$ & $2,705,451$ & $2,350,518$ & $2,127,692$ \\
\hline Privatization Savings & & $-367,948$ & $-12,594$ & 394,936 & $\underline{627,709}$ \\
\hline Ratio: Privatization/M\&O & & $\underline{1.12}$ & 1.00 & .83 & .70 \\
\hline \multicolumn{6}{|l|}{ Notes: } \\
\hline After Tax IRR - Private Contractor & $6.2 \%$ & & & & \\
\hline M\&O Fee Rate & $3.0 \%$ & & & & \\
\hline \multicolumn{6}{|c|}{ Addendum Cost Comparisons: Adjustment for Competition and Learning } \\
\hline \multirow{2}{*}{\multicolumn{6}{|c|}{ FY 1997-FY 2055.(\$000s) }} \\
\hline \multicolumn{4}{|l|}{ Gross costs to Federal Govt } & & \\
\hline Dollar Basis: & & MYWP & $1998 \$$ & $1998 \$$ & $1998 \$$ \\
\hline Costs discounted at: & & $0.0 \%$ & $\underline{0.0 \%}$ & $3.8 \%$ & $7.0 \%$ \\
\hline \multicolumn{6}{|l|}{ Privatization } \\
\hline Unadjusted & & $\underline{4,108,100}$ & $3,382,746$ & $2,502,247$ & $\underline{1,966,452}$ \\
\hline Adjusted for Overruns & $25 \%$ & $\overline{5,135,125}$ & $\overline{4,228,432}$ & $\overline{3,127,809}$ & $\overline{2,458,065}$ \\
\hline Adjusted for Overruns \&Competition & & $5,135,125$ & $4,228,432$ & $3,127,809$ & $2,458,065$ \\
\hline Adjusted for All above \& Learning & & $\underline{5,135,125}$ & $4,228,432$ & $3,127,809$ & $2,458,065$ \\
\hline M\&O, Adjusted for Overruns & $60 \%$ & $2,996,659$ & $2,729,300$ & $2,371,238$ & $2,146,447$ \\
\hline Privatization Savings & & $-2,138,466$ & $-1,499,133$ & -756.571 & $-311,618$ \\
\hline Ratio: Privatization/MO & & $\underline{1.71}$ & $\underline{1.55}$ & $\underline{1.32}$ & $\underline{1.15}$ \\
\hline \multicolumn{6}{|l|}{ Notes: } \\
\hline Competition effect, $>1$ contractor & $-15 \%$ & & & & \\
\hline Learning effect: $>1$ contractor in $\mathrm{Ph} 1$ & $-10 \%$ & & & & \\
\hline
\end{tabular}




\section{Attachment A}

\section{Project Evaluation and Discount Rates: Application to the TWRS Program}

To properly evaluate the overall financial costs of various tank waste cleanup alternatives, it is essential to consider the time value of money. Positive rates of interest imply that a dollar now is not the same as a dollar later. If the Treasury can borrow at $6 \%$, then a 1 -year deferral of spending of $\$ 100$ is worth $\$ 6$. Under these conditions, we cannot estimate the overall costs of a long-term project by simply adding up the costs that occur at different times. To perform a valid evaluation, we must translate all costs into comparable amounts for a specified period. If the specified period is the current year, the translation procedure is termed "discounting" and the resulting metric is called the "present value." Alternatively, we could express the total costs at the termination of the project-this cost would include accumulated (imputed or actual interest charges) and would be termed the "future value."

The privatization of the tank waste vitrification leads to a quite different path of federal outlays than the normal DOE approach of using a Maintenance and Operations (M\&O) contractor to perform the same work. With privatization, the government has no budget outlays until the plant is producing a productin this case "glass logs" of radioactive waste. Under an M\&O approach, the government uses its own resources to direct the $\mathrm{M} \& \mathrm{O}$ to both build and operate the vitrification facility. The critical difference is the financing of the very expensive facility, which is expected to require up to 10 years to design and construct. Under the privatization approach, the private contractor uses his own internal funds or secures private financing from banks (or both). Under the M\&O approach the government must provide funding for the construction, via taxes or borrowing on the open market.

These alternative approaches thus lead to quite different time profiles of government spending. With privatization, as stated above, the government spends only after the plant is producing vitrified waste. The outlays for this product will include both a capital and operations component, the former related to how the capital cost is amortized over the expected operating life. For the M\&O approach, the government incurs large expenses during the construction phase, but smaller expenses during operations.

The comparison of the costs between the two approaches is best viewed as a "cost-effectiveness" analysis. This type of analysis is suggested by the Office of Management and Budget (OMB) when the benefits of the two alternatives are not measurable or deemed to be the same. This is clearly the case here, as the social benefits of vitrification are strictly related to environmental damages that are mitigated by putting the tank waste into a stable glass form. These benefits are the same regardless of the contractual mechanism that is pursued by the federal government.

In conducting a cost-effectiveness analysis, $\mathrm{OMB}$ directs that the government cost of borrowing -in terms of the interest rate on government bonds--be used to discount the alternative streams of government expenditures to a present value. In Appendix A of OMB Circular A-94, the rate for use during 1997 is given as $3.5 \%$ in real terms for 10 -year bonds ( $3.6 \%$ in real terms for 30 -year bonds). The alternative with the lowest present value is deemed to be the government's most cost-effective alternative.

The use of this simple discounting approach is thought by some to significantly bias the results of such an analysis in favor of the M\&O approach. The amortization of the construction expense in the privatization approach clearly involves an interest cost, which seemingly is not present in the M\&O approach. This may lead some to believe that discounting approaches ignore the government cost of financing for employing the $\mathrm{M} \& \mathrm{O}$. 
A simple example may help to illustrate the various cost measures that may be used to differentiate between these alternative approaches. The example shown in Table A.1 illustrates a 14-year project separated into two phases: 1) 4 years of construction and 2) 10 years of operation. Total construction cost is $\$ 1000$ (to be nominally realistic all dollar figures in the table would be in millions, but in what follows we will dispense with reference to millions). Operating costs are $\$ 50$ annually. For the $M \& O$ approach, the government simply expends what is required in each year for construction and then for operations. This expenditure stream is shown in column (3) of the top panel of the table.

The private contractor is assumed to secure private financing of the plant and will incur finance charges as the construction proceeds. In this first example here, the private contractor is assumed to be able to borrow at the government cost of borrowing-here taken as $4 \%$ in real terms. To simplify the analysis, it is assumed that each draw of the construction loan is made at the beginning of the year and that accumulated interest is due 1 year later. Thus, the cumulative amount of construction debt at the beginning of year 2 is $\$ 100$ for year $1, \$ 4$ of interest, and $\$ 200$ for the second installment. At the beginning of year 4 , total construction cost including interest is $\$ 1044.80$. This amount is amortized over the 10 years of operations, yielding an annual stream of $\$ 128.80$. Total annual cost is $\$ 178.80$; this is the amount to be paid by the federal government to the private contractor each year for producing vitrified waste.

Following the OMB guidance for a cost-effectiveness analysis, we discount both of these expenditure streams at the Treasury cost of borrowing-i.e., $4 \%$. These discount factors are shown in column (8). The final two columns show the discounted values for each of the annual expenditure profiles.

As shown at the bottom of the right-most two columns [(9) and (10)], the present values of both expenditure streams - the sum of the discounted annual amounts - are exactly the same. This result stems from the assumption that the discount rate used for calculating the present value is the same as the private financing rate. The equivalence does, however, indicate that if the government borrowed during the construction phase in the same manner as the private contractor and then "paid back" the loans over the 10-year operating period, the present value would be the same as the pay-as-you-go approach normally associated with an M\&O. The result also makes it clear the importance of discounting. Given the assumption of zero inflation in this example, the outlays in columns (3) and (8) can be viewed as constant-dollars outlays. By simply summing these values, the $\mathrm{M} \& \mathrm{O}$ has an apparent cost advantage of $\$ 288.20(\$ 1,788.20-\$ 1,500)$. This result stems only from not considering that the larger outlay figures for the privatization approach are deferred until year 5 of the overall project.

Another way of looking at this issue is to assume that the government borrows for both construction and operations during the entire 14-year project. The accumulated government debt-with interest-for the $\mathrm{M} \& \mathrm{O}$ is shown in column 3 of the bottom panel of Table 1 . At the end of the period the total debt is $\$ 2,146.9$. Of course, this debt can be considered the "future value" of the total cost, the counterpart to "present value" in normalizing the costs of different years to a common basis.

Column (8) shows the same procedure applied to the privatization approach. Here the government accumulates debt - at $4 \%$ - to pay the private contractor for each of the 10 years of operations. The accumulated debt is identical to the $\mathrm{M} \& \mathrm{O}$ case, $\$ 2,146.9$. Finally, note that the present value associated with this level of debt is computed by simply multiplying the debt by the discount factor for this terminal year, 0.601 . The computed present value is equivalent to the conventional discounting results in the upper panel, $\$ 1,289.4$. In the $M \& O$ case, it should be clear from this example that the opportunity cost of funds, in this case at a $4 \%$ annual rate, is reflected in the simple discounting of the government expenditure stream. 
Table A.1. Private Finance Rate Equivalent to Government Borrowing Rate

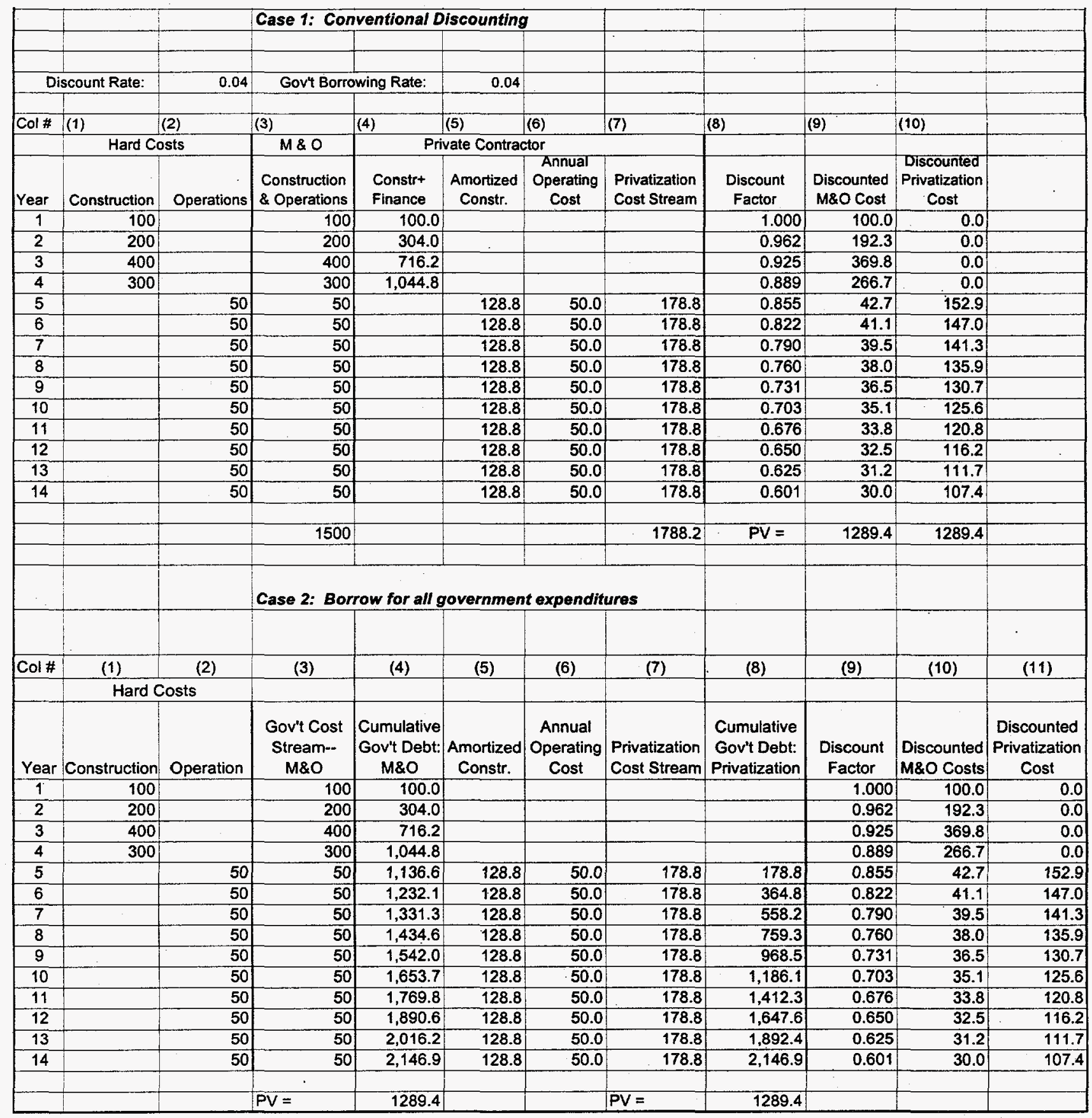


As stated at the outset, one view of the simple discounting approach is that it essentially imputes a zero opportunity cost of government expenditures. In other words, the government is borrowing at an interestfree rate. Hopefully the above examples have dispelled this notion. For a true interest-free loan, the future value of the cost of the program in the above example is $\$ 1,500$. That is, assume that in some extraordinary circumstance that the government could simply borrow what it needs for the entire life of the TWRS program at zero interest cost. Thus, the future value of $\$ 1,500$ is considerably less than the $\$ 2,147$ with a $4 \%$ interest charge. But, in general, through the government bond market, the government could still transfer between present and future claims at a positive interest rate. In present value termsusing a discount rate of $4 \%$ - the interest-free loan has a present value cost of $\$ 900$. This result is consistent with a present value of $\$ 1,289.4$ when a $4 \%$ interest rate is assumed.

Table A. 2 shows a case in which a private contractor incurs a significantly higher finance rate than the government is able to achieve with its own borrowing. Under a fixed-price contract, much of this differential is due to the increased risk the private contractor takes on in order to realize a satisfactory return.

For project evaluation, we continue to use the risk-free government rate to discount the streams of costs. In this case the present value of the $\mathrm{M} \& \mathrm{O}$ alternative is significantly greater than that of the privatization approach, $\$ 2,051.0$ as compared to the $\$ 1,289.4$ from above. As in Table A.1, this value is equivalent to a terminal year value of $\$ 3,415.0$, as seen in the bottom panel.

If we were to use a higher discount rate to calculate the present value, for example $7 \%$, the present values of both alternatives would be lower (the future values would be higher). The results of this discounting are shown at the bottom of the top panel in Table 2 . At $7 \%$, the present value of costs for the M\&O is $\$ 1,167.8$ and the present value of costs for the private contractor is $\$ 1,630.8$. As expected, the difference between the two approaches narrows the closer the discount rate is to finance rate applied to the private contractor. At the $4 \%$ discount rate, the ratio of the privatization to the M\&O cost is 1.59 . At $7 \%$, this ratio drops to 1.40. As shown in the table, the absolute difference associated with these discount rates is about $\$ 300$.

This result reinforces the importance of the discounting procedure as stated above. At a zero discount rate, the exercise turns into comparing the sum of constant dollars of outlays. For the $M \& O$, this figure remains at $\$ 1,500$. Because the private contractor passes along the higher finance costs associated with the risky project, the total constant-dollar costs are nearly double that of the $M \& O, \$ 2,844.4$ versus $\$ 1500$. Clearly, this is very misleading and could lead to an incorrect assessment of the true cost differences between the alternatives.

\section{Postscript}

The discussion above relates only to the discounting of program costs and does not purport to indicate the ultimate differences in expected cost between the two approaches. Thus, one should not conclude from these examples that an $\mathrm{M} \& \mathrm{O}$ approach is always less costly than a private contractor, stemming solely from the lower borrowing rates available to the government. Historical experience has shown that an $\mathrm{M} \& \mathrm{O}$ contractor has a much greater tendency to overrun the initial cost estimate as compared to a private firm operating under a fixed-price contract. When a measure of this tendency is included in the analysis, the privatization approach may indeed be the most cost-effective approach. 
Table A.2. Private Finance Rate Higher than Discount Rate

\begin{tabular}{|c|c|c|c|c|c|c|c|c|c|c|c|}
\hline & & & \multicolumn{3}{|c|}{ Case 1: Conventional Discounting } & & & & & & \\
\hline \multirow{2}{*}{\multicolumn{2}{|c|}{ Discount Rate: }} & & \multirow{2}{*}{\multicolumn{2}{|c|}{ Private Finance rate: }} & \multirow{3}{*}{0.15} & & & & & & \\
\hline & & 0.04 & & & & & $\cdot$ & & & & \\
\hline & & & & & & & & & & & \\
\hline \multirow[t]{2}{*}{ Col \# } & (1) & (2) & (3) & (4) & (5) & $(6)$ & (7) & (8) & (9) & $(10)$ & \\
\hline & \multicolumn{2}{|c|}{ Hard Costs } & \multicolumn{5}{|c|}{ Private Contractor } & & & & \\
\hline Year & Construction & Operations & $\begin{array}{l}\text { Construction } \\
\& \text { Operations }\end{array}$ & $\begin{array}{l}\text { Constrt } \\
\text { finance }\end{array}$ & $\begin{array}{c}\text { Amórtized } \\
\text { Constr. }\end{array}$ & $\begin{array}{c}\text { Annual } \\
\text { Operating } \\
\text { Cost }\end{array}$ & $\begin{array}{l}\text { Privatization } \\
\text { Cost Stream }\end{array}$ & $\begin{array}{l}\text { Discount } \\
\text { Factor }\end{array}$ & $\begin{array}{l}\text { Discounted } \\
\text { M8O Cost }\end{array}$ & $\begin{array}{c}\text { Discounted } \\
\text { Privatization } \\
\text { Cost }\end{array}$ & \\
\hline 1 & 100 & & 100 & 100.0 & & & & 1.000 & 100.0 & 0.0 & \\
\hline 2 & 200 & & 200 & 315.0 & & & & 0.962 & 192.3 & 0.0 & \\
\hline 3 & 400 & & 400 & 762.3 & & & & 0.925 & 369.8 & 0.0 & \\
\hline 4 & 300 & & 300 & $1,176.6$ & & & & 0.889 & 266.7 & 0.0 & \\
\hline 5 & & 50 & 50 & & 234.4 & 50.0 & 284.4 & 0.855 & 42.7 & 243.1 & \\
\hline 6 & & 50 & 50 & & 234.4 & 50.0 & 284.4 & 0.822 & 41.1 & 233.8 & \\
\hline 7 & & 50 & 50 & & 234.4 & 50.0 & 284.4 & 0.790 & 39.5 & 224.8 & \\
\hline 8 & & 50 & 50 & & 234.4 & 50.0 & 284.4 & 0.760 & 38.0 & 216.1 & \\
\hline 9 & & 50 & 50 & & 234.4 & 50.0 & 284.4 & 0.731 & 36.5 & 207.8 & \\
\hline 10 & & 50 & 50 & & 234.4 & 50.0 & 284.4 & 0.703 & 35.1 & 199.8 & \\
\hline 11 & & 50 & 50 & & 234.4 & 50.0 & 284.4 & 0.676 & 33.8 & 192.2 & \\
\hline 12 & & 50 & 50 & & 234.4 & 50.0 & 284.4 & 0.650 & 32.5 & 184.8 & \\
\hline 13 & & 50 & 50 & & 234.4 & 50.0 & 284.4 & 0.625 & 31.2 & 177.7 & \\
\hline \multirow[t]{6}{*}{14} & & 50 & 50 & & 234.4 & 50.0 & 284.4 & 0.601 & 30.0 & 170.8 & \multirow[b]{2}{*}{ Diff. } \\
\hline & & & & & & & & & & & \\
\hline & & & 1500 & & & & 2844.4 & $P V=$ & 1289.4 & 2051.0 & 761.6 \\
\hline & & & & & & & & & 1167.8 & 1630.8 & 462.9 \\
\hline & & & \multicolumn{5}{|c|}{ Case 2: Borrow for all govemment expenditures } & & & & \\
\hline & & & & & & & & & & & \\
\hline \multirow[t]{2}{*}{ Col \# } & (1) & (2) & (3) & (4) & (5) & (6) & $(7)$ & (8) & (9) & $(10)$ & (11) \\
\hline & \multicolumn{2}{|c|}{ Hard Costs } & \multicolumn{2}{|l|}{$\mathrm{M} \& \mathrm{O}$} & \multicolumn{4}{|c|}{ Privatization } & & & \\
\hline Year & Construction & Operations & $\begin{array}{l}\text { Gov't Cost } \\
\text { Stream-M\&O }\end{array}$ & $\begin{array}{l}\text { Cumulative } \\
\text { Gov't Debt: } \\
\mathrm{M} \& \mathrm{O}\end{array}$ & $\begin{array}{l}\text { Amortized } \\
\text { Constr. }\end{array}$ & $\begin{array}{l}\text { Annual } \\
\text { Operating } \\
\text { Cost }\end{array}$ & $\begin{array}{l}\text { Privatization } \\
\text { Cost Stream }\end{array}$ & $\begin{array}{l}\text { Cumulative } \\
\text { Gov't Debt: } \\
\text { Privatization }\end{array}$ & $\begin{array}{l}\text { Discount } \\
\text { Factor }\end{array}$ & $\begin{array}{l}\text { Discounted } \\
\text { M\&O Costs }\end{array}$ & $\begin{array}{l}\text { Discounted } \\
\text { Privatization } \\
\text { Cost }\end{array}$ \\
\hline 1 & 100 & & 100 & 100.0 & & & & & 1.000 & 100.0 & 0.0 \\
\hline 2 & 200 & & 200 & 304.0 & & & & & 0.962 & 192.3 & 0.0 \\
\hline 3 & 400 & & 400 & 716.2 & & & & & 0.925 & 369.8 & 0.0 \\
\hline 4 & 300 & & 300 & $1,044.8$ &. & & & & 0.889 & 266.7 & 0.0 \\
\hline 5 & & 50 & 50 & $1,136.6$ & 234.4 & 50.0 & 284.4 & 284.4 & 0.855 & 42.7 & 243.1 \\
\hline 6 & & 50 & 50 & $1,232.1$ & 234.4 & 50.0 & 284.4 & 580.3 & 0.822 & 41.1 & 233.8 \\
\hline 7 & & 50 & 50 & $1,331.3$ & 234.4 & 50.0 & 284.4 & 887.9 & 0.790 & 39.5 & 224.8 \\
\hline 8 & & 50 & 50 & $1,434.6$ & 234.4 & 50.0 & 284.4 & $1,207.9$ & 0.760 & 38.0 & 216.1 \\
\hline 9 & & 50 & 50 & $1,542.0$ & 234.4 & 50.0 & 284.4 & $1,540.6$ & 0.731 & 36.5 & 207.8 \\
\hline 10 & & 50 & 50 & $1,653.7$ & 234.4 & 50.0 & 284.4 & $1,886.7$ & 0.703 & 35.1 & 199.8 \\
\hline 11 & & 50 & 50 & $1,769.8$ & 234.4 & 50.0 & 284.4 & $2,246.6$ & 0.676 & 33.8 & 192.2 \\
\hline 12 & & 50 & 50 & $1,890.6$ & 234.4 & 50.0 & 284.4 & $2,620.9$ & 0.650 & 32.5 & 184.8 \\
\hline 13 & & 50 & 50 & $2,016.2$ & 234.4 & 50.0 & 284.4 & $3,010.1$ & 0.625 & 31.2 & 177.7 \\
\hline 14 & & 50 & 50 & $2,146.9$ & 234.4 & 50.0 & 284.4 & $3,415.0$ & 0.601 & 30.0 & 170.8 \\
\hline & & & & & & & & & & & \\
\hline & & & $P V=$ & 1289.4 & & & $P V=$ & 2051.0 & & & \\
\hline
\end{tabular}




\section{Attachment B - Spreadsheet Structure}

This appendix describes briefly the major elements of the spreadsheet structure that composes the economic assessment model. The model is developed in the Excel spreadsheet environment and takes full advantage of the individual worksheet capability afforded by modern spreadsheet software. The individual worksheets offer some degree of modularity within the overall structure and help to organize the separate elements associated with different TWRS functions.

The economic assessment model uses 24 separate worksheets to calculate the TWRS life-cycle cost and annual budget requirements. The worksheets can be categorized as falling into five distinct functional areas: 1) inputs from financial model, 2) general economic parameters, 3) waste quantities and containers, 4) PHMC cost estimation, and 5) life-cycle costs and budget requirements.

The life-cycle costs are expressed in three different ways: 1) constant dollars, 2) escalated dollars through 2006 (to correspond to the 1998 MYWP), and 3) present value. The individual cost inputs to the model are generally in terms of 1998 constant dollars. Currently, the final tables generate 1997 constant-dollar magnitudes to conform to the 1997 constant-dollar measures used by the privatization contractors. The present values of costs are computed with a $3.8 \%$ real discount rate, as specified by OMB in its February 1998 guidance for evaluation of long-term projects-and a higher $7 \%$ rate. Both of these rates can be changed by the model user.

As mentioned above, this appendix describes some of the general structure of the model and selected key variables. The first (left-most) worksheet in the model is Notes; this worksheet provides some specific guidance on how to run the key scenarios that were developed for the evaluation of TWRS alternatives during March-April 1998.

\section{B.1 Inputs from Financial Model}

The financial model generates price and revenue estimates for an individual contract to vitrify an assumed quantity of waste over a specific time frame. The inputs to the financial model are "hard" construction and operating costs and assumptions regarding required rates of return and miscellaneous financing costs.

The key outputs generated in the financial model to be used in the economic model are put into a special worksheet in the financial model. This special worksheet is copied in its entirety into one of twelve predefined worksheets set up for that purpose in the economic model. These worksheets are set up to support a capability of using up to three separate contracts for each of two private contractors (or consortiums) in both phases of the TWRS program. Generally labeling the two contractors in each phase as " $A$ " and " $B$," the nomenclature for these worksheets is as follows:

Phase I-Contractor A

Contract 1: FMIA1

Contract 2: FMIA2

Contract 3: FMIA3

Phase I-Contractor B

Contract 1: FMIB1

Contract 2: FMIB2

Contract 3: FMIB3 
Phase II-Contractor A

Contract 1: FMIIA1

Contract 2: FMIIA2

Contract 3: FMIIA3

Phase II-Contractor B

Contract 1: FMIIB1

Contract 2: FMIIB2

Contract 3: FMIIB3

From each worksheet employed in a particular scenario are drawn annual (fiscal year) values for seven variables:

1) Budget Outlays (BO) [Row 52]

2) Budget Authority (BA) [Row 54]

3) Federal taxes paid [Row 106]

4) Construction cost [Row 23]

5) Operating cost [Row 17]

6) Low-activity waste processed [Row 10]

7) High-level waste processed [Row 11]

The top lines of the worksheet provide the fiscal years over which the financial model was run. These years are used to place the financial model outputs into the correct time frame in the economic model; columns of the economic model basically are generally defined over a constant 1997-2050 time frame.

\section{B.2 General Economic Parameters (Econ_ASM)}

Worksheet Econ_ASM contains general economic and other control parameters that are used to develop the life-cycle and other cost metrics. Table B.1 shows the key parameters that can be changed by the user. The names on the right side of the table are those used internally by the spreadsheet.

The projected general inflation rate used by the model is ASM_General_Inflation (Cell G22). This rate should be set to match the general inflation rate employed in the financial model.

The discount rates are straightforward and require no explanation here. The next section is entitled Case Sensitivity. The user has the choice of allowing major categories of PHMC costs be sensitive to the schedule and magnitude of waste processing. If the user answers NO $(N)$ in any of these cells, the PHMC costs are taken as in an approximate manner from the MYWP.

Five options are open to the user to adjust the schedule for retrieving waste from single-shell tanks (SSTs). The values for the parameter labeled Tank Retrieval Strategy can be specified as:

1 Baseline SST retrieval schedule (MYWP)

$2 \quad$ Phase II SST retrieval schedule based upon processing capacity

3 Entire SST retrieval schedule based upon processing capacity

4 Same as (3), but TPA compliant

$5 \quad$ Entire SST retrieval schedule, based upon processing capacity and available double-shell tank (DST) capacity 
For option 3, SST retrieval begins 1 year after the start of processing of low-activity waste and ends 4 years before the last year of waste processing. For option (4), SST retrieval also begins 1 year after the start of low-activity waste processing, but ends in 2018. For these options (as well as for the Phase II portion of option 2 the number of tanks retrieved in each year of the retrieval period is proportional to the quantity of low-activity waste treated in that year.

Option 5 allows the retrieval to proceed at a maximum rate, as limited by DST space and processing through-put. Thus, under this option, single-shell tanks can be retrieved (prior to the start of processing) to the point at which DST capacity is exceeded.

Storage/Disposal Loading Multipliers These variables can be used to effectively adjust the number of containers that will be produced for a given amount of waste treated in the vitrification plants. At present, one multiplier is defined to adjust the number of canisters of high-level waste for Contractor A in Phase I. Thus, if the value chosen is 1.25 , then the number of canisters produced during Phase I by Contractor A will be $25 \%$ higher than that calculated from using the standard assumptions.

M\&O Assumptions These assumptions are used to convert the hard cost information passed through by the financial model into an estimate of what it would cost the government to pursue M\&O approach. The assumption is very simplistic - the M\&O would add a small percentage fee to the hard cost estimates. To be consistent with the tax treatment applied to the private contractors, some portion of this fee would be returned to the federal government in the form of federal taxes.

Cost Savings Assumptions. The parameters in this portion of the assumptions worksheet are used to adjust the life-cycle cost estimates for the type of contract approach. The overrun factors are applied to the initial cost estimates and used as means of comparing the privatization and $M \& O$ approaches. The effect of these factors is shown in Table 10 of the standard model output.

The competition and learning effect parameters are used to compare approaches that differ by their use of one versus two contractors. The way in which these parameters are used is in the description of Table 10 output in Section 3 of the main report. 
Table B.1. Key Economic Parameters

\begin{tabular}{|c|c|c|}
\hline \multicolumn{3}{|l|}{ Discount Rates for Project Evaluation } \\
\hline Base & $3.8 \%$ & ASM_Base_Discount \\
\hline Alternative & $7.0 \%$ & ASM_Alternative_Discount \\
\hline Case Sensitivity ( $Y=$ Yes, $N=$ No) & $\begin{array}{l}\text { (left } \\
\text { justify) }\end{array}$ & \\
\hline Retrieval & $\mathrm{Y}$ & ASM_PHMC_Retrieval \\
\hline Storage/Disposal & $\mathrm{Y}$ & ASM PHMC Storage \\
\hline Infrastructure & Y & ASM_PHMC_Infrastructure \\
\hline Management Support & Y & ASM_PHMC_Management \\
\hline Tank Retrieval Strategy & 3 & ASM_Tank_Retrieval_Strategy \\
\hline \multicolumn{3}{|l|}{ Storage/Disposal Loading Multipliers } \\
\hline Phase I - Contractor A & 1.00 & ASM_PhaseIA_HLWfac \\
\hline \multicolumn{3}{|l|}{ M\&O Assumptions } \\
\hline M\&O Fee (Percent) & $2 \%$ & MandO_Fee_Pct \\
\hline Federal Tax Rate & $30 \%$ & Federal_Tax_Rate \\
\hline \multicolumn{3}{|l|}{ Cost Savings Assumptions } \\
\hline Overrun Factor-Privatization & $25 \%$ & Overrun PC \\
\hline Overrun Factor-M\&O & $60 \%$ & Overrun_MO \\
\hline Competition effect & $-15 \%$ & Competition_Effect \\
\hline Learning effect & $-10 \%$ & Learning_Effect \\
\hline
\end{tabular}




\section{B.3 Waste Quantities and Container Production}

One large worksheet labeled "Containers" aggregates the quantities of waste processed by each contractor and phase of the program and develops a time profile of container production for both low-activity and high-level waste (containers for low-activity waste, canisters for high-level waste). This spreadsheet is useful for checking whether the sum of the individual contract quantities of waste processed is sufficient to treat all of the waste inventories estimated to be in the tanks.

The time profiles of cumulative container and canister production developed in this worksheet are used in the worksheets LAW_Disposal and IHLW_Storage to modify the construction schedule of the storage and disposal facilities. The storage/loading multipliers as discussed in the prior section can also be used to examine the schedule and cost implications of a higher (or lower) number of canisters or containers.

This worksheet also implements the strategy chosen for retrieving tank waste from the single shell tanks. Columns $\mathrm{AB}$ through $\mathrm{AF}$ show tank retrieval under the five retrieval strategy options defined in the previous section. A HLOOKUP function is used to select the final option which is shown in column AG.

This worksheet is the source of three of the standard output tables- $-7,8$, and 9. These tables reside at the far right of the worksheet.

\section{B.4 PHMC Cost Estimation}

The worksheets described in this section incorporate the methods described in Section 2.3 to develop cost and schedule sensitivity of the PHMC functions to the waste processing scenario.

Retrieval The Retrieval worksheet develops cost estimates for the retrieval of waste from single-shell tanks during Phase II. The basis for this information is the set of cost estimates developed during 1996 to support a privatized tank retrieval program during the latter portion of the TWRS program (roughly 2011-2022). The calculations in this spreadsheet were aimed toward developing a per tank retrieval cost and an annual cost associated with the maintenance of the tank farms.

$\underline{\text { Retrieval2 }}$ This worksheet develops the cost profile for tank retrieval that is consistent with the schedule of waste processing activity and tank retrieval strategy chosen (see worksheet econ_ASM). The worksheet defines 18 separate activities that use the sliding schedule approach defined in Section 2.3 of the report. For approximately the first 30 single-shell tanks, the model employs the cost elements and ordering of the various phases of the ISSTRS and SSSTRS programs. For the remainder of the SST retrieval operations, the cost per tank is taken primarily from the analysis shown in the Retrieval worksheet. The Retrieval2 worksheet also defines a "minimum safe" level of annual expenditures for an average ("unretrieved") SST and for an average unretrieved DST.

Law Disposal The Law_Disposal worksheet uses the cumulative production of low-activity waste containers to modify the construction schedule of vaults for this disposal. The initial construction activity - the conversion of the grout vaults for this purpose (project W-465)-is not influenced by the scenario chosen. Vaults constructed under Project W-520 are scheduled to accept containers after the grout vaults are full. The capacity of the W-520 vaults is assumed to be 20,000 containers. Subsequent projects are assumed to be the same size as W-520 and of roughly comparable cost.

IHLW Storage The IHLW_Storage worksheet is similar to LAW_Disposal in that it uses the cumulative production of high-level canisters to modify the construction schedule of storage facilities. Approximately the first 900 canisters will be stored in a facility named simply the Canister Storage Building, currently undergoing modification to accept canisters produced by the TWRS program. Storage 
for the remaining 12,000 or so canisters currently is planned to be provided by five additional, larger facilities. The model brings these facilities on-line consistent with the canister production scenario. This procedure was described briefly in Section 2.3 of the methodology report.

Infrastructure This worksheet calculates the costs of the operational aspects of the supporting infrastructure for the vitrification plants. The infrastructure elements handled in this worksheet are 1) electricity, 2) process water, 3) potable water, and 4) radioactive solid waste. The worksheet develops cost estimates from three separate parameters: 1) an annual fixed use, 2) a constant intensity with respect to LAW, and 3) a constant intensity with respect to HLW. Thus, for example, the electricity intensities for LAW and HLW are defined as $\mathrm{kWh} /$ ton processed. (The results of these calculations are added to the estimated fixed electricity consumption.) Separate intensities are defined for low-activity waste (defined in terms of tons of sodium content) and for high-level waste (defined in terms of tons of waste oxides processed). Using the intensity approach, one can define a constant proportional relationship between the amount of waste processed in each phase and the operating costs associated with infrastructure. As more information is available about the extent these intensities would differ by contractor or size of facility, the intensities can be essentially altered for each segment of the overall processing activity. The override of the simple intensity approach is accomplished by the user specifying a consumption rate at capacity (e.g., MW of electricity at LAW or HLW capacity). These values are shown in blue in the worksheet. (Since the intensities differ for various combinations of contractors/phases, the case-specific vectors of consumption rates are defined in the left-most three columns of the worksheet, [Rows 29:166]).

Cost_Profiles. The Cost_Profiles worksheet combines the results from the $L A W_{-}$Disposal and $I H L \bar{W}_{-}$Storage worksheets along with other cost elements to develop summary cost profiles for Storage/Disposal, Infrastructure, and Management. The other cost elements essentially involve the fixed and sliding cost profiles that make up the remainder of these TWRS program activities.

\section{B.5 Life-Cycle and Other Cost Summaries}

These worksheets process the information provided by the financial model (worksheets defined in Section B.1) and the PHMC costs (worksheets defined in Section B.3) to roll up life-cycle cost estimates and $\mathrm{BA} / \mathrm{BO}$ profiles for entire TWRS mission.

Econ1 The Econ1 worksheet assembles the information from the various worksheets containing results from the financial model. By examining the starting years of each contract, the worksheet employs the OFFSET command within Excel to translate the time profiles into the correct column locations that correspond to a fixed 1997-2050 time period. At the top of the Econ1 worksheet is a time series of price deflators that are used to convert the nominal values from the financial model into constant 1998 dollars. The constant-dollar values are aggregated for BO, BA, and federal taxes paid. This worksheet also computes discount factors associated with the assumed discount rates and applies these factors to construct present values for $\mathrm{BO}$.

The top portion of the worksheet processes information regarding BA, BO, and federal taxes. Summary tables for present-value costs follow this information. Below the summary tables, the worksheet processes information related to the construction and operating costs that are also passed from the financial model. This information is used along with an estimate of an M\&O fee percentage to yield an estimate of what an $\mathrm{M} \& \mathrm{O}$ approach would cost for the same scope of work.

Near the bottom of the worksheet reside the calculations that end up in Table 4. Table 4 provides detailed cost and (waste) quantity information by all of the individual contracts defined for the given scenario. 
PHMC Sum The PHMC_Sum worksheet assembles the PHMC cost estimates at the broad activity level shown in the MYWP. This worksheet contains the projected cost estimates contained in the MYWP. If the choice is "Yes" to making a particular PHMC cost element sensitive to the waste processing scenario, the model-generated cost is substituted for the MYWP estimate. This process is shown by the IF statements in rows 10,11 , and 13 of the worksheet.

TWRS LCC The TWRS_LCC worksheet assembles the life-cycle cost estimates from the waste processing activity (as calculated in Econ1) and the life-cycle costs estimates for the PHMC. The results of this process are shown in Table 1 of the set of standard output tables. The worksheet also puts together the estimates of the net government costs of the program, by taking the cost estimates of the waste processing activity net of federal taxes (Table 5).

BA BO The BA_BO worksheet develops the BA and BO time profiles from 1997 through 2040 (with an aggregate value for costs beyond 2040). Three tables are developed in this worksheet. The BA estimates for the waste processing activity in Table 2 are taken from the TWRS_LCC worksheet (and indirectly from Econ1). Table 3 summarizes the budget outlays in constant dollars required for the major TWRS activities. (Table 3 a was later added to this worksheet; it shows budget outlays in escalated dollars through 2006). Table 4 shows the budget authority for the entire TWRS program by year. In this table, the annual BA estimates for the PHMC portions of the program are assumed to be equivalent to the $\mathrm{BO}$.

This worksheet performs a transposition of the costs from rows to columns (Rows 3:21 and Rows 50:54 -at left of worksheet). Input values by row are taken from PHMC_Sum and TWRS_LCC. These values are transposed to the columns that appear in Tables 2-4 that reside at the right side of the worksheet.

\section{B.6 Tables}

The ten standard output tables defined in Section 3 of the main documentation report are pre-defined as macros in the Excel spreadsheet defining the economic model. To prompt the printing of a particular table, the user must go to the Tools|Options|Macros menu and then run the macro of choice. The macros are labeled Ptab1 for Table 1, Ptab2 for Table 2, and so forth. 


\title{
Appendix D
}

Development of the DOE Cost Estimate that Compares Cost Reimbursable to Fixed Price Work Scope for the Tank Waste Remediation System Privatization

\author{
Peter T. Furlong \\ Department of Energy, Richland Operations Office \\ Tank Waste Remediation System, Waste Disposal Division \\ January 1998
}




\section{Executive Summary}

The purpose of this document is to provide an indication of the cost estimate that the DOE would receive for the performance of the Phase I Scope of Work by a cost-reimbursable contractor. This document provides the background, methodology, review results, conclusions, and recommendations for the development of a comparable Cost Reimbursable equivalent estimate to the work scope that DOE agreed to at the time of the TWRS privatization contract awards in September 1996.

TWRS privatization requires DOE to purchase services from contractor-owned, contractor-operated facilities under a fixed-price type of contract. DOE will be able to purchase an identifiable, measurable service that provides deliverables that are clearly specified. The Privatization Contractors will be able to recover only resources that it has invested through the delivery of acceptable services paid for by the DOE on a fixed-unit-prices basis. The underlying intent is to transfer from the Government to the Privatization Contractors the primary share of financial, performance, and operational responsibility for the treatment effort. This involves the allocation of project risks in an equitable manner that both protects the Government and encourages industry participation.

A result of the Privatization initiative is that the DOE will save money and require less funding to perform a comparable work scope. Determining cost savings has proven to be a significant task, due to the difficulty in establishing a cost comparison between an on-going activity (TWRS Privatization) and a former activity (Cost Reimbursable contractor performance of the Privatization scope of work). In an era of unlimited resources, it would be possible to issue two different types of contracts (one fixed price for the Privatization Contractors, and a cost plus for the Cost Reimbursable contractor) for the performance of comparable work scopes. After the completion of their prescribed work, DOE would have a quantified number for the cost savings. However, DOE is not working in an unlimited funds arena and must therefore select a contracting process that DOE believes will require the lowest funding level.

In selecting fixed-price contracting as the procurement process, DOE is still faced with the question "How much money is Privatization saving?". In attempting to answer this question, DOE has taken several approaches, which are summarized in the Secretarial Decision Package. One of the processes that DOE used was the development of an estimate that reflects a pre-conceptual design estimate of the costs DOE could expect to see from a Cost Reimbursable contractor. The estimate uses data developed by the M\&O contractor when the treatment and immobilization of the tank waste was within the M\&O contractor work scope.

No comparison of the Cost Reimbursable contractor estimate to the Privatization Contractors prices are provided in this cost estimate. The purpose of the cost estimate is to provide DOE with an indication of the estimate that the DOE would receive for the performance of the Phase I Scope of Work. The DOE prepared estimate is not intended to reflect data that would be submitted in a Construction Project Data Sheet. If the Cost Reimbursable contractor were to proceed with the Phase I Scope of Work, the DOE would request and fund the M\&I to develop a cost estimate and prepare a Construction Project Data Sheet. In preparing cost estimates for Cost Reimbursable contractor performance of a proposed privatization scope of work, there needs to be a review of the information available, the funds available to perform support cost estimates, and the value gained from expending any funds on cost estimating work.

Where there is well documented cost history for having the Cost Reimbursable contractor perform a scope of work, it is easy to prepare a Cost Reimbursable contractor cost estimate for a Privatization scope of work. The Cost Reimbursable contractor cost estimates would be based solely on the cost history, with some increases/decreases based upon assumed efficiencies. A cost estimate for having a Private Contractor perform the work could be performed any number of ways, an in-house estimate, having a 
private firm develop an estimate based on their experience in the field, or procure the services via the open market. An estimate of the cost savings would be based solely on the differences between the cost for the services before and after privatizing. A model for this calculation would be the Indianapolis Airport privatization where there is cost information available for pre-privatization and post privatization operations.

Without considerable cost history for having the Cost Reimbursable contractor perform a scope of work, DOE needs to be very judicious in expending funds for the development of cost estimates. Without judicious expenditure of funds, DOE could be preparing a large number of cost estimates for work that will never be accomplished. There are competing priorities that must be reconciled, the need to have an equivalent Cost Reimbursable contractor cost estimate for the work being performed by the Private Contractors, and the need for funds to perform other site cleanup work. Without the development of a cost estimating process that meets both criteria, there will be criticism of the DOE funding process. DOE believes that the cost estimating process that has been used to estimate the Cost Reimbursable contractor costs for the TWRS Privatization scope of work provides a reasonable indication of the type of cost that DOE could incur. The DOE prepared Cost Reimbursable contractor cost estimate is not intended to act as a capital project cost estimate. DOE never intended the cost estimate to be of that quality.

Cost estimates must be reviewed from the perspective of purpose. A cost estimate for a capital project rightfully requires a high degree of accuracy and a commensurate level of expenditures. Where the cost estimate is intended to provide a barometer of the savings that could be expected, i.e., no funding is being requested for the Cost Reimbursable contractor work, then there needs to be a review of the expenditures required for the level of accuracy required. Judicious expenditure of funding for cost estimates is difficult to judge. Some people believe that no expenditure is too small in order to maintain a high level of accuracy in cost estimates, whereas there are some people who believe that reasonable attempts should be made to estimate the range of costs. Selection of the cost estimating process is dependent upon funding, time, and resources available to support the estimate process. The correct cost estimating process is a subject of considerable discussion. An agreement or understanding between the different factions should be accomplished prior to the preparation of the cost estimates. Funding, time and resources should be provided as necessary to support the desired level of detail and accuracy in the cost estimate.

\section{Purpose}

In 1994, the U.S. Department of Energy (DOE) initiated a significant acquisition reform program. The conventional means of contracting for the DOE had been the utilization of cost-reimbursable types of contracting in which the Government assumed the risks and paid for services on a continuous basis. Cost escalation with the cost-reimbursable types of contracts and production of low quality products requiring significant rework were driving mission costs to unacceptable levels and demonstrating to Congress an inability to control budgets. The contract reform effort examined and warranted the use of fixed-price contracting for the DOE to reduce overall costs to the Government, share risks with private industry, and bring experience and technologies to facilitate the accomplishment of its mission. Fixed-price contracting is commonly referred to as "privatization" since the resources of private industry are utilized to accomplish the work. In 1994, the Tank Waste Remediation System at the Hanford Site in Richland, Washington, was evaluated to determine if portions of its mission were feasible for potential privatization. A feasibility study determined that portions of the mission could be privatized in a two-phase approach and contracts were signed in September 1996. Obviously, a result of the privatization initiative is that DOE saves money and requires less funding to perform a comparable work scope. Determining the costs savings has proven to be a significant and complex task, due to the difficulty in establishing a cost comparison between the fixed-price activity (TWRS privatization) and the Cost Reimbursable equivalent scope of work. This paper describes the background, methodology, review results, conclusions, and 
recommendations for the development of a comparable Cost Reimbursable equivalent to the work scope that DOE agreed to at the time of the TWRS Privatization contract awards in September 1996.

\section{Background}

High-level radioactive waste (HLW) has been stored in large underground storage tanks at the Hanford Site since 1944. Approximately 54 million gallons of waste are currently being stored in 177 tanks. These caustic wastes consist of many different chemicals in the form of liquids, slurries, saltcakes, and sludges. In 1992, the Tank Waste Remediation System (TWRS) Project was established to manage, retrieve, treat, immobilize, and dispose of these wastes in a safe, environmentally sound, and cost-effective manner. Since its inception, the TWRS Project contracting strategy has been a government-owned, contractor-operated (GOCO) facility under a cost-plus-award-fee contract. Under this arrangement, the DOE, the federal government, and the taxpayer bears the full responsibility, accountability, and liability for development work, design, permitting, construction, and operations of the facilities. Within this context, the Department pays for and will continue to pay for activities until the remediation process is complete, no matter how ineffectual the contractor is or how long it takes to complete the effort.

Since 1993, a number of initiatives are driving the consideration of privatizing the TWRS. Those initiatives include:

- Vice President Gore's initiative to reinvent government

- The DOE Contract Reform initiative

- Declining federal budgets

- Projected cost of the TWRS baseline program

- An unsolicited concept by industry to perform part of the TWRS functions on a fixed-price basis.

The January 1997 Report to the Secretary of Energy, "Harnessing the Market: The Opportunities and Challenges of Privatization," (DOE/S-0120), defines privatization as the transfer of ownership and control of a good or service currently provided by the government to a private (commercial) sector firm. The report states that the Department will emphasize three major types of privatization: 1) divestiture of functions, 2) contracting out or out-sourcing, and 3) asset transfers.

DOE has focused on contracting out or out-sourcing to reach its programmatic goals, and has selected, as its privatization method, the purchase of an end product or service through an open fixed-price competition. A privatization contractor is held responsible for completing the work and delivering the product or service. The privatization contractor is not paid until the product or service is delivered to the government in accordance with contract specification requirements. If the work requires facility construction and operation, facilities are contractor-owned/contractor-operated and privately financed. The financing and payment structure is a significant departure from the traditional cost-reimbursable type contracts DOE has used for decades. Fixed-price contracting also requires a change in how contracts are written and administered, with increasing reliance on well-defined contract requirements and performance specifications.

One of the major benefits of privatization is that it can be used to efficiently reduce project costs through competition. Cost-effective privatization enables the DOE to perform more cleanup for the funds expended. A fixed-price contract provides a substantial performance incentive compared to many other contract types. Historically, fixed-price contracts with specific work scopes allow contractors to be leaner and more efficient than the traditional full-service, fee-based contracts that govern DOE Management and Operations (Cost Reimbursable) contractors. The purpose of the DOE Prepared Cost Reimbursable 
Estimate has been to provide some basis for demonstrating that there will be cost savings as a result of pursuing privatization.

The principal objective of the TWRS Project is to reduce the risk to the public and the environment that results from approximately 54 million gallons of mixed and high-level waste (HLW) stored in 177 underground storage tanks at the Hanford Site. The primary contracting strategy used by the DOE to perform services to store, treat, and dispose of the waste was cost reimbursement. In the mid-1990s, the life cycle cost of remediating and disposing of the waste continued to escalate and as a result became a viable candidate for potential fixed-price contracting (privatization). A feasibility study was conducted in 1994 and determined that portions of the TWRS mission could be privatized but the privatization needed to be conducted in two phases-a demonstration phase remediating 6 to $13 \%$ of the waste followed by a production phase for most of the remainder of the waste. The Demonstration Phase would select multiple contractors to design and permit facilities, ensuring competition and facilitating cost control. The objectives of the Demonstration Phase are to:

- demonstrate technologies and processes in a production-level environment, treat and immobilize sufficient waste to demonstrate early progress in remediating the tank situation to the stakeholders, understand better the costs, risks, and benefits of a fixed-price privatization framework

- ascertain the financial viability of the private marketplace to accomplish the TWRS mission

- establish conditions for the Department to be a "smart buyer" and for private industry to be a "smart provider" of treated waste products for Phase II, and to balance the private vendors' objectives with DOE objective.

The second phase of TWRS Privatization is the Full-Scale Production phase. Facilities will be sized so all of the remaining waste can be processed and immobilized on a schedule that will accommodate removing the waste in single-shell tanks by 2018. Objectives of the Full-Scale Production Phase (Phase II) are to implement the lessons learned from the Proof-of-Concept/Commercial Demonstration Phase; to process all tank waste into forms suitable for final disposal while meeting environmental, health, and safety requirements to achieve price competition and cost savings throughout the Full-Scale production phase; to meet or exceed the TPA benchmark performance milestones; and to balance the private vendor's objectives with the DOE objectives.

Portions of the TWRS mission such as storage of the waste are not currently feasible to privatize since there were no easy ways to establish fixed prices for the services.

As the DOE is signing the contracts to initiate Phase IB of TWRS privatization, it is essential that the cost savings to the DOE are evident. The next section of this report describes the methodology used to develop a comparable cost for the same work scope under two different contracting methods.

\section{Methodology}

To develop a comparable cost estimate, key features of the comparison were analyzed. This section describes how comparative scope, capacity, scenarios, estimate relationships, structures, critical assumptions, and methodology were selected.

\section{Work scope comparison}

In developing the cost estimate for comparing cost-reimbursable performance to fixed-price activities, a review was performed of the contractually required work scope. Differences in work scope invalidate the comparability of the cost savings, lead to providing incomplete and inaccurate information to decision 
makers, and can result in the DOE committing itself to a path forward (either fixed price or cost reimbursable) that is not in the best interest of the taxpayer.

In the initial phases of the TWRS Privatization initiative, documents were prepared (such as the Request for Proposals [RFP]) that outlined the scope of work proposed for the Privatization Contractor(s). The RFP provided a standard for the development of a Cost Reimbursable estimate. By having this standard statement of work for both types of contracts, comparison of costs could be performed. However, comparability between the cost reimbursable and fixed-price estimates was not possible immediately after receipt of the proposals from the Privatization vendors because work scope proposed by the private vendors was modified from the original solicitation. Both Contractors decided that the orginal DOE scope was not viable because of commercial and safety concerns. Several of the major technical changes proposed by the Privatization vendors included:

- Construction of large concrete structures: DOE's original work scope for Phase I assumed the construction of buildings with portable shielding, which dramatically reduced the capital cost but increased the operating cost of the facilities. Both Privatization Contractor's proposed the construction of large concrete structures. These large structures allow for better radiation shielding and ensure that seismic qualification requirements can be met. Construction of larger facilities provides DOE with the capability to continue operation of the facilities for an extended period of time. Since the piping and equipment associated with the processing of waste does not wear out, the only constraint to longer operations is the ability of personnel to perform routine maintenance on equipment. Large concrete structures allow the inclusion of personnel shielding features which allow the plant to operate during routine maintenance and allow personnel to perform major repairs without violating the ALARA principles.

- Use of hot cells for the performance of work: The original DOE work scope for Phase I assumed the use of components that did not require routine maintenance. As a result, the facility processing systems were not segregated. Required maintenance activities would result in facility shutdowns. Both Privatization proposals described construction and operations of facilities commonly referred to as "hotcells" that would allow maintenance to be performed continuously. Continuous maintenance would require the installation of shielding internal to the facility for personnel and equipment protection purposes. This type of facility is more costly construct than the DOE's original work scope, but has a longer design life.

- Level of occupancy for maintenance: The DOE's original work scope assumed that a facility could be constructed that did not require operator intervention for maintenance during operation of the facility. As a result, equipment could be installed in tighter more compact areas, i.e., more equipment in a smaller structure. The Privatization proposals recommended the construction of facilities that allowed personnel to perform work, such as maintenance, continuously. As a result, walkways, cutup facilities, ventilation, etc., were required. This feature allows facilities to operate while routine maintenance is being performed, thereby increasing the efficiency of the facility. If a facility must be shut down for routine maintenance, the efficiency of the facility declines, and since the private contractors are paid by the amount of waste processed, the prices of services provided must be increased in order to compensate for that inefficiency.

- Extended operating life: The DOE's original work scope assumed an operating life of 5 years for the radioactive waste treatment facility. Since the facility was only intended to be a demonstration facility (providing proof of the technical and business viability of using private industry to perform waste treatment functions) there was no need to invest a large amount of capital dollars in a longerlife and larger facility. Both privatization proposals recommended that the facilities be designed and 
built to operate for much longer periods of time ( 20 years). A longer operating life decreases the total capital cost to the program and provides for the construction of a safer facility.

DOE agreed that the technical solutions proposed by each of the Privatization vendors provided better ways to treat and immobilize Hanford tank waste. DOE anticipated each vendor/contractor to provide additional improvements as part of their future Phase I deliverables. As the Privatization Contractors work scope evolved, the DOE attempted to update the cost-reimbursable estimate to reflect those changes. Without these continuous revisions/changes, the DOE would have lost any degree of comparability between a fixed price and cost-reimbursable estimate. In order to assess that the total life cycle cost for the TWRS mission is cost effective, work scope of the activities performed by the Cost Reimbursable contractor were examined outside of this effort. Work scope that would be performed by the Cost Reimbursable contractor outside of the private contractors' scope of work was eliminated and not part of the direct comparison. For example, providing feed to the privatized Contractors is a role that would be completed under a cost-reimbursable contract and was not part of the comparison.

In order to prove unequivocally that there were savings from fixed-price contracting in comparison to cost-reimbursable contracting, the DOE would have had to complete a "dual universe" analysis. A "dual universe" analysis required that the DOE fund both a Cost Reimbursable contractor and a private contractor to complete identical scopes of work. Each of the contractors would be required to operate in their own regulatory environment and the DOE would be required to treat both the Cost Reimbursable contractor and the Privatization Contractors in a manner that is consistent with their contracts.

A "dual universe" was neither practical nor realistic. DOE and the taxpayers had a very limited funding basis for the performance of work. If the DOE had requested the existing Cost Reimbursable contractor to perform an estimate of fixed-price work scope, an extensive and expensive amount of work would have been needed to be performed by the existing Cost Reimbursable contractor. The DOE would have had to provide the Cost Reimbursable contractor with approximately $\$ 50 \mathrm{M}$ to develop a comparable cost estimate. This was not considered to be an effective use of funds, so other techniques were utilized.

\section{Cost Estimation Method}

Different methods exist for estimating DOE projects. This section discusses those methods and the advantages and disadvantages of using those methods. DOE Order 5700.2D, Cost Estimating, Analysis, and Standardization, establishes the policy and responsibilities for: (a) developing and reviewing project cost estimates; (b) preparing independent cost estimates and analyses; (c) standardizing cost estimating procedures; and (d) improving overall cost estimating and analytical techniques, cost data bases, cost and economic escalation models, and cost estimating systems. During a normal DOE capital project life cycle, cost estimates are prepared at several different times. The various stages of capital projects require differing levels of confidence regarding cost estimates. Initial planning stages may require only "ball park" estimates to assist with feasibility studies and management decision making. Subsequent stages of a project may require detailed analyses of material and labor costs to develop budget requests. Generally, the more advanced a project is, the greater the amount of detail necessary to achieve the appropriate level of accuracy, and the more likely and easier that a bottoms up estimate can be developed. As the project develops, it is common for a cost estimator to use parametric estimates for less developed aspects of a project and a bottoms up estimate for the aspects of where the design is more complete. Different types of DOE capital cost estimates reflect the movement of a project from conception through construction as follows:

- Engineering Studies: A cost estimate is prepared for general planning and budgeting purposes only. Planning estimates are used when there is a need for a magnitude estimate, where sufficient definitive information is lacking that would allow the development of a total estimated cost. Engineering study 
estimates are developed for each project at the time of project definition. Since engineering estimates are developed before conceptual design, estimates are order of magnitude only and have the least amount of accuracy and lowest confidence level. Care is taken in these estimates to ensure that the magnitude of the estimate is correct, since a tendency exists to avoid changing, particularly upward, the estimate, once established.

- Conceptual Design: Conceptual design estimates are required for line item construction projects that require congressional authorization. The conceptual design estimate is prepared prior to requesting approval for the project. The purpose of the estimate is to develop an appropriate project scope, reliable cost estimates, and realistic schedule. Bottoms-up estimates may be first utilized at this time.

- Title I: Title I design is the initial work accomplished under an approved project. Criteria to be followed in the performance of the Title I design are based essentially upon the conceptual design for the project. In Title I, the design criteria are defined in greater detail, and if necessary, the conceptual design drawings are expanded with more detailed information, including additional drawings. Also further refined descriptive information and more detailed specifications are developed as required to serve as a firm basis to proceed with Title II definitive design. From these detailed drawings and information developed during the course of Title I design, more accurate cost estimates and schedules are developed. The Title I design estimate normally is prepared in accordance with the standardized construction cost code system, which permits ready comparison of the components making up the Title I estimate with those in the conceptual design estimate.

- Title II: Title II estimates are developed for each segment of the project based on the completion of definitive design. Title II design is accomplished by the design contractors based upon the approved Title I design and the design criteria. Title II estimates are prepared in accordance with the approved Title II drawings and specifications. The Title II construction costs normally would be prepared in accordance with the standardized construction cost code system, which permits ready comparison of the components of the Title I estimate.

- Current working estimate: This estimate is required for cost control in large projects; it is conducted periodically throughout the life of the project. The estimate is kept under constant review to ensure that it reflects the latest cost and design data available, the estimated cost to complete, the allowance for contingency based on the latest detailed contingency analysis, and uncertainties remaining within the project.

The information available to support the preparation of a cost estimate varies depending upon the stage in the project life cycle at which the cost estimate is prepared. Table I provides a summary of the type of information available to support project life cycle cost estimates.

Conventional cost methodologies were not appropriate for fixed-price estimating at this point in time. Because of the current level of information that the TWRS Privatization Contractors would be developing during the Phase IA work scope, the Privatization Contractors were capable of only developing a cost estimate that was comparable to a Conceptual Design estimate. These estimates had a level of detail sufficient for the Privatization Contractors to estimate the capital requirements needed for their facilities. 
Table I

Information Available to Support Cost Estimates During the Project Life Cycle

\begin{tabular}{|c|c|c|c|c|}
\hline \multirow[b]{2}{*}{$\begin{array}{l}\text { Types of Cost } \\
\text { Estimates }\end{array}$} & \multicolumn{4}{|c|}{ Features } \\
\hline & $\begin{array}{l}\text { Uncertainty/ } \\
\text { Knowledge }\end{array}$ & $\begin{array}{c}\text { Availability of Design } \\
\text { Drawings }\end{array}$ & Cost Control & $\begin{array}{l}\text { Etc. (relationship to } \\
\text { contracting strategy?) }\end{array}$ \\
\hline $\begin{array}{l}\text { Engineering } \\
\text { Studies }\end{array}$ & $\begin{array}{l}\text { Low degree of } \\
\text { certainty about the } \\
\text { final processes and } \\
\text { design. }\end{array}$ & $\begin{array}{l}\text { Preliminary drawings } \\
\text { and sketches are } \\
\text { available. }\end{array}$ & $\begin{array}{l}\text { Cost control is not } \\
\text { applicable at this } \\
\text { Phase. It is important } \\
\text { to establish an order of } \\
\text { magnitude estimate. }\end{array}$ & $\begin{array}{l}\text { Cost estimate is applicable } \\
\text { to a cost-plus or fixed-price } \\
\text { contract. This estimate is a } \\
\text { decision-making tool. }\end{array}$ \\
\hline $\begin{array}{l}\text { Conceptual } \\
\text { Design }\end{array}$ & $\begin{array}{l}\text { Medium degree } \\
\text { of uncertainty. } \\
\text { Possible technical } \\
\text { solutions have been } \\
\text { explored. }\end{array}$ & $\begin{array}{l}\text { Conceptual deign } \\
\text { drawings have been } \\
\text { prepared. Piping } \\
\text { diagrams and electrical } \\
\text { schematics are } \\
\text { complete. }\end{array}$ & $\begin{array}{l}\text { The Conceptual } \\
\text { Design cost estimate } \\
\text { establishes the cost } \\
\text { baseline for the } \\
\text { proposed project. }\end{array}$ & $\begin{array}{l}\text { A conceptual design cost } \\
\text { estimate is required for a } \\
\text { cost-plus project but may } \\
\text { not be required for a fixed- } \\
\text { price contract. }\end{array}$ \\
\hline Title I & $\begin{array}{l}\text { Additional } \\
\text { information is } \\
\text { available. The } \\
\text { components have } \\
\text { been selected and } \\
\text { more detailed } \\
\text { specifications are } \\
\text { developed. }\end{array}$ & $\begin{array}{l}\text { Major piping and } \\
\text { electrical system } \\
\text { installation drawings } \\
\text { are complete. }\end{array}$ & $\begin{array}{l}\text { The costs for the } \\
\text { project are better } \\
\text { defined. The } \\
\text { uncertainty of the } \\
\text { project cost decreases. }\end{array}$ & $\begin{array}{l}\text { A Title I design cost } \\
\text { estimate is required for a } \\
\text { cost-plus project but may } \\
\text { not be required for a fixed- } \\
\text { price contract. }\end{array}$ \\
\hline Title II & $\begin{array}{l}\text { The facility design } \\
\text { has been complete. } \\
\text { Minor changes may } \\
\text { occur to reflect } \\
\text { new information. }\end{array}$ & $\begin{array}{l}\text { Facility configuration } \\
\text { drawings are complete } \\
\text { or nearing completion. }\end{array}$ & $\begin{array}{l}\text { The costs for the } \\
\text { project are well } \\
\text { defined. Accuracy of } \\
\text { the estimate is } \\
\text { assumed to be } \pm 10 \text {. }\end{array}$ & $\begin{array}{l}\text { A Title II design cost } \\
\text { estimate is required for a } \\
\text { cost-plus project but may } \\
\text { not be required for a fixed- } \\
\text { price contract. }\end{array}$ \\
\hline
\end{tabular}

In order for the DOE to obtain a cost estimate that was of comparable detail to the Privatization vendors, the DOE has several alternatives. The DOE could have requested the existing Cost Reimbursable contractor prepare a Conceptual Design and a cost estimate for the scope of work as defined in the RFP. The DOE could have utilized prior studies created by past Cost Reimbursable contractors to prepare a cost estimate. A third alternative was for the DOE to request that each Privatization Contractor provide sufficient cost, schedule, and technical data to allow an independent cost estimate to be developed. Each of these alternatives were possible but had specific concerns.

If the Cost Reimbursable contractor prepared an estimate, the DOE would have a fairly well documented cost estimate that would be of a detail comparable the to Privatization Contractors' estimates. The costreimbursable-contractors estimate would have to be based on a defined work scope and technical solution to the treatment and immobilization problem. Using experience with large capital projects at Hanford, the cost estimate for a conceptual design could be about $\$ 40 \mathrm{M}$ ( 3 to $5 \%$ of the estimated capital cost) and taken approximately 2 years. The cost-reimbursable-contractor's cost estimate would be a single point solution. However, due to the ability of each of the Privatization Contractors to propose technical and financial improvements (per Standard 6 of the privatization contracts) the comparability of proposed work scope for the two cost estimates (private contractor and Cost Reimbursable contractor) could be limited. The work scope for the Cost Reimbursable contractor's estimate was only valid for a single point in time. If DOE desired comparability of work scope between the Privatization Contractors and the costreimbursable-contractor's estimate, it would have required continuous maintenance and additional costs to provide a real-time comparisons. 
In order to maintain work scope comparability between a cost-reimbursement contract and a fixed-price contract, the DOE would have to require the cost-reimbursement contractor to prepare several conceptual designs and cost estimates. For just one set of proposed changes, the DOE would require the costreimbursement contractor prepare 12 unique cost estimates.

Another source for obtaining technical information regarding a possible cost reimbursable estimate was to review prior studies. In the mid 1990s, the DOE funded studies for the Cost Reimbursable contractor to determine the cost and technical feasibility of treatment and immobilization facilities. These studies allowed the Cost Reimbursable contractor to determine the size, number, physical layout, and technology used in the treatment and immobilization facilities. The largest such study conducted in the FY94-FY95 time frame, was the Facilities Configuration Study (FCS), reference (1). This study was performed by the existing cost-reimbursement contractor with the assistance of several contractors (Fluor Daniel, BNFL, and Kaiser Engineers). From these studies came various cost estimates for facilities of different configurations (combined with other facilities, or separate), different sizes (multiple small facilities or large facilities), and different technologies (use of monolithic glass or cullets). These estimates provided DOE with a reasonable database for obtaining information about the costs associated with having a costreimbursement contractor provide treatment and immobilization services.

In addition to facility cost, the FCS provided estimates for the major phases of the project life, including facility design, facility startup, development of plant processes, etc. This information was important in developing a life-cycle cost for a Cost Reimbursable contractor to treat and immobilize the wastes.

Normally the cost-reimbursement contractor provides a source of cost information annually for the DOE in the Multi-Year Work Plan (MYWP). The MYWP provides a breakdown of costs for the performance of major work scopes. It is possible to determine the cost for the construction of a facility and the operation of the facility from the MYWP. However, any data obtained from the MYWP must be taken as several costs combined into one number and limited detail is available. The operation of a facility for a particular year can be assumed based upon information in the MYWP. However, the cost associated with even major pieces of equipment cannot be obtained from the MYWP data.

When the privatization contracts were initially prepared, limited data was requested from the Privatization vendors to minimize up-front costs to DOE. If the DOE choose to require incremental information, contract modifications were required and would have resulted in significant cost growth of the contract. Also, additional cost and technical information to the DOE would potentially reduce the negotiation stance of the contractor since this information would reveal some of the benefits to the contractor of how they would effectively earn their money. DOE did not receive detailed information from the Privatization Contractors during Phase IA. Limited data was available for the development of a Government Fair Cost estimate, but the level of information that was made available would not have met Conceptual Design requirements.

\section{Cost Estimation Scenarios}

At the start of Phase IA there were two contractors competing to provide treatment and immobilization services. Since each contractor was able to propose enhancements to the basic contract requirements, there were various combinations that $\mathrm{DOE}$ was required to evaluate to make a decision to proceed with the second portion of Phase I:

a. Only Contractor A provides treatment and immobilization services for Low Activity Waste

b. Only Contractor B provides treatment and immobilization services for Low Activity Waste

c. Both Contractor A and B provide treatment and immobilization services for Low Activity Waste 
d. Only Contractor A provides treatment and immobilization services for Low Activity Waste and High Level Waste

e. Only Contractor B provides treatment and immobilization services for Low Activity Waste and High Level Waste

f. Contractor B provides treatment and immobilization services for Low Activity Waste and High Level Waste and Contractor A provides treatment and immobilization services for Low Activity Waste

g. Contractor B provides treatment and immobilization services for Low Activity Waste and High Level Waste, Contractor A provides treatment and immobilization services for Low Activity Waste.

The eight privatization contracting alternatives required that the DOE develop four separate costreimbursable cost estimates as follows:

a. An estimate for providing only treatment and immobilization services for Low Activity Waste equivalent to one contractor

b. An estimate for providing treatment and immobilization services for Low Activity Waste equivalent to two contractors

c. An estimate for providing treatment and immobilization services for Low Activity Waste and High Level Waste

d An estimate for providing treatment and immobilization services for High Level Waste and doubled capacity for Low Activity Waste.

\section{Capacity Considerations}

As the number of capacity options increases, DOE is required to prepare cost estimates for the costreimbursement contractor to perform comparable work scope. For each separate capacity option proposed by a Privatization contractor, the number of cost estimates that DOE would need to prepare increases by four. In addition to the capacity options being proposed by the Privatization Contractors there is no limit to the improvements that can be proposed. Each of the improvements proposed by the Privatization Contractors requires that a comparative cost reimbursable estimate be prepared. These cost estimates must be prepared to ensure that if DOE decides to go forward with any one of the particular capacity options proposed by the Privatization Contractor(s), there is a Cost Reimbursable comparative estimate for that scope of work.

If, as a result of the initial Phase I work, one of the contractors proposed a modification to the waste treatment capacity for their facility, the number of alternatives that must be evaluated by DOE increases. If Contractor A proposes that the throughput of their facility be tripled, then DOE must not only evaluate the single capacity plants of both contractors but DOE must also evaluate the triple capacity option. This increases the number of alternatives to be considered and the number of cost-reimbursable estimates for privatization work scope that must be prepared. The alternatives to be considered include:

a. Only Contractor A provides single capacity treatment and immobilization services for Low Activity Waste

b. Only Contractor B provides single capacity treatment and immobilization services for Low Activity Waste

c. Contractor A provides triple capacity treatment and immobilization services for Low Activity Waste

d. Contractors A and B each provide single capacity treatment and immobilization services for Low Activity Waste 
e. Contractor B provides single capacity and Contractor A provides triple capacity treatment and immobilization services for Low Activity Waste

f. Only Contractor A provides treatment and immobilization services for Low Activity Waste and High Level Waste

g. Contractor A provides treatment and immobilization services for Low Activity Waste (at triple capacity) and High Level Waste

h. Only Contractor B provides treatment and immobilization services for Low Activity Waste and High Level Waste

I. Contractor B provides treatment and immobilization services for Low Activity Waste and High Level Waste, Contractor A provides treatment and immobilization services for Low Activity Waste

j. Contractor B provides treatment and immobilization services for Low Activity Waste and High Level Waste, Contractor A provides triple capacity treatment and immobilization services for Low Activity Waste

k. Contractor A provides treatment and immobilization services for Low Activity Waste and High Level Waste, Contractor B provides treatment and immobilization services for Low Activity Waste

1. Contractor A provides treatment and immobilization services for Low Activity Waste (at triple capacity) and High Level Waste, Contractor B provides treatment and immobilization services for Low Activity Waste.

As a result of the proposed change (triple the capacity of the pretreatment line) by a contractor, the DOE would be required to prepare a large number of estimates for having the cost-reimbursable contractor perform the proposed work scope. Prior to requesting the cost estimate, it would be necessary for DOE to prepare a scope of work, (obtaining significant technical data from the proposing contractor), ensure that the cost estimators understand the new technical proposal, resolve all discrepancies, identify the funding required to perform the estimate, have the cost estimate prepared, and review the cost estimate. Based upon a single proposed change from the Privatization Contractor the following cost estimates would have to be prepared.

a. An estimate for providing only treatment and immobilization services for Low Activity Waste equivalent to one contractor.

b. An estimate for providing triple capacity treatment and immobilization services for Low Activity Waste equivalent to one contractor.

c. An estimate for providing treatment and immobilization services for Low Activity Waste equivalent to a double capacity facility (each Privatization Contractor providing single capacity throughput).

d. An estimate for providing treatment and immobilization services for Low Activity Waste equivalent to a quadruple capacity facility (one Privatization Contractor providing single capacity throughput and the other Privatization Contractor providing triple capacity).

e. An estimate for providing treatment and immobilization services for Low Activity Waste and High Level Waste.

f. An estimate for providing treatment and immobilization services for Low Activity Waste (at triple capacity) and High Level Waste (at single capacity).

g. An estimate for providing treatment and immobilization services for High Level Waste and twice the capacity for Low Activity Waste (each Privatization Contractor providing single capacity LAW facilities).

h. An estimate for providing treatment and immobilization services for High Level Waste and quadruple capacity for Low Activity Waste (one Privatization Contractor providing single capacity throughput and the other Privatization Contractor providing triple capacity). 
Any changes proposed by the Privatization Contractor would be considered "Competition Sensitive." This would require all the cost estimators to sign non-disclosure agreements, and their employers to sign corporate non-disclosure agreements. The corporate and individual non-disclosure agreements would have been difficult to obtain since one of the Privatization Contractor's partners would also be responsible for preparing the DOE requested cost estimates.

DOE cost estimators, if any were available even from HQ, could have been used to prepare the individual cost estimates. However, RL has only one individual cost estimator on staff and a large number of cost estimators would be required to respond to the number of possible cost estimating scenarios.

\section{Uncertainty}

In the Department of Energy's Office of Environmental Management program, cost estimates may be developed for programs in operation for many years, for which most parameters are known with a relatively high degree of certainty. In other cases, the program being estimated may not be scheduled to start for many years, and basic parameters such as technologies to be used or throughput capacity may not be determined. Although some degree of uncertainty is common to all programs, the degree of uncertainty is frequently higher for programs lacking well-defined scope.

It is therefore common in the estimating profession to designate categories of estimates that reflect the maturity of a program and the degree of definition of the program scope. For capital cost estimates DOE procedures, reference (3), provide distinct categories of estimates. In preparing cost estimates for Waste Management operations, the following categories were used:

- Planning/Feasibility Study Estimate

- Budget or Conceptual Design Estimate

- Title I Design Estimate

- Title II Design Estimate.

Each estimate type is a unique effort and requires different techniques. Some of these techniques include extrapolation, analogy, parametric Cost Estimating Relationships (CERs), and detailed estimating. Table II shows characteristics of each of the different types of estimates.

Magnitude estimates and Planning/Feasibility Estimates are appropriate to projects lacking significant detail in implementation definition. Such programs can typically be described only in engineering study or conceptual terms. Often such projects are in an early stage of planning, or involve the use of new or innovative technologies. Key factors such as the process to be used in the operation, capacity, and throughput are assumed based on an educated guess by the cost estimator and the program manager, but such assumptions can be supplanted by subsequent program decisions. 
Table II - Characteristics of Estimate Development Stages

\begin{tabular}{|c|c|}
\hline Estimate Stages: & Characteristics \\
\hline $\begin{array}{l}\text { Planning/Feasibility } \\
\text { Estimate }\end{array}$ & $\begin{array}{l}\text { Purpose: These estimates are normally prepared for a proposed project prior to } \\
\text { completing a conceptual design. } \\
\text { Basis: Must describe the purpose of the project, general design criteria, significant } \\
\text { features and components, proposed methods for accomplishment, proposed construction } \\
\text { schedule, and any known research and development requirements. } \\
\text { Design Scheme: Sufficient criteria must be provided to enable the estimator to prepare a } \\
\text { planning estimate. } \\
\text { Degree of Accuracy: Generally } \pm 40 \% \text {. }\end{array}$ \\
\hline $\begin{array}{l}\text { Budget or Conceptual Design } \\
\text { Estimate }\end{array}$ & $\begin{array}{l}\text { Purpose: Required to request Congressional authorization for funding. } \\
\text { Basis: Includes many of the detailed requirements in the Conceptual Design Report } \\
\text { (CDR) as possible. } \\
\text { Design Scheme: Conceptual design sketches and specifications, as well as the } \\
\text { functional/operational requirements. } \\
\text { Degree of Accuracy: } \pm 30 \% \text {. }\end{array}$ \\
\hline Title I Design Estimate & $\begin{array}{l}\text { Purpose: An intermediate estimate to verify that the Title I design details still remain } \\
\text { within the project funding. } \\
\text { Basis: Includes all items mentioned in the CDR estimate bases, plus all the refinements } \\
\text { developed during the course of producing the Title I Engineering package. } \\
\text { Design Scheme: Based on the Title I drawings and specifications. } \\
\text { Degree of Accuracy: } \pm 20 \% \text {. }\end{array}$ \\
\hline Title II Design Estimate & $\begin{array}{l}\text { Purpose: Estimate the construction costs as accurately as possible, prior to the } \\
\text { commencement of competitive bidding and construction activities. } \\
\text { Basis: Includes all the approved engineering data, methods or performance, final project } \\
\text { definition and parameters, project schedule, and final exact detailed requirements. } \\
\text { Design Scheme: Based in the Title II drawings and specifications } \\
\text { Degree of Accuracy: }+15 \% \text { to - } 5 \% \text {. }\end{array}$ \\
\hline
\end{tabular}

In preparing the estimate, the technical program manager provides a brief scope description of functional and operational requirements to the cost estimator. This scope description may include

- sketches of alternative product throughput processes

- assumptions regarding regulatory requirements under which the program will operate

- assumptions regarding throughput, capacity, and other operating requirements.

The estimate is usually performed using extrapolation, analogy, and possibly parametric methodologies. It is imperative that the cost estimator document all assumptions fully, and that exclusions be explicitly stated. The accuracy of this stage of estimate is $\pm 50 \%$.

Budget or Conceptual Design estimates are appropriate to projects with a moderate level of detail in implementation definition. Such projects may have a known technology and process and a known rate of throughput volume, but both the process and throughput are subject to potential change or variation as further planning occurs.

In preparing the estimate, the project manager typically provides a scope description of program functional and operational requirements to the cost estimator including the following:

- preliminary drawings of process, including process block diagrams 
- description of regulatory requirements

- planned throughput; capacity, and other operating requirements.

The estimate is performed using parametric and cost estimating relationships methodologies. Utilize detailed technique if possible with available information. As in every estimate, it is important that the estimate include explicit assumptions and exclusions. The accuracy of this stage of estimate is $\pm 20 \%$.

Title I and Title II Estimates are typically prepared for an operation with relatively complete process definition and with experience-based production capacities and throughput. Factors such as the volumeof material to be processed and delivery capacity is reliably known. The technology is known and proven.

The project manager and other members of the project team provide a complete description of program functional and operational requirements to the cost estimator including the following:

- process drawings, including process flow diagrams

- logs of operating history regarding throughput, capacity, and other operating requirements from the program or similar programs operating at other locations

- description of regulatory requirements.

The estimate is performed using detailed estimating techniques and methodologies. As in every estimate, it is important that the estimate include explicit assumptions and exclusions. The accuracy of a Stage A estimate is $\pm 5 \%$.

In every stage of an estimate, the program manager and cost estimator encounter numerous uncertainties that may affect program scope and cost. For example, materials to be processed often are outputs from other facility operations or programs, which may themselves be variable. Regulatory requirements may change, remain to be determined, or may be unknown at the time of the estimate. Such uncertainties may be critical to program definition. These uncertainties, which may be outside the control of the project manager must therefore be resolved through well documented assumptions and conclusions.

In selecting the type of estimate to be developed DOE had to review

- the available options for developing a cost reimbursable estimate

- the purpose of the cost reimbursable estimate

- the cost associated with preparing estimates

- the information available to prepare and estimate.

The purpose of the cost-reimbursable estimate of the privatized work scope is not to pursue the construction of a capital project. The cost-reimbursable estimate is designed to provide DOE with an indication that there will or will not be cost savings as a result of pursuing privatization. Since any costreimbursable estimate must represent a comparable work scope, DOE was faced with a significant cost estimating task. In FY96 each of the Privatization Contractors were proposing changes to the throughput capacity of their facilities. Therefore DOE planned on having cost estimates prepared for each of the capacity options being offered to DOE by the Privatization Contractors. In early FY96 it appeared that DOE would have to have a minimum of 36 cost-reimbursable estimates prepared to be ready to perform a cost comparison. This effort represented a significant investment on the part of DOE. As the Privatization Contractors proceeded into privatization design, the number of plant throughput and plant 
startup options increased dramatically. DOE was faced with a daunting task of preparing an ever increasing number of cost estimates to ensure that a comparable cost-reimbursable estimate was available for the decision to proceed with advanced design and construction.

Despite the size of the cost estimating task, the true purpose of the cost-reimbursable estimate was to provide an indication to DOE of the cost savings obtained by pursuing Privatization. If the costreimbursable estimate (when adjusted for comparable work scope, risk, anticipated cost growth, and cost of funds) was reasonably close to or less than the Privatized Contractors prices, then DOE would have an indicator that a program review should be considered. The programmatic review would assess the issues associated with privatization to determine if the

- scope of work as defined is appropriate for privatization

- financial requirements of the contract lead to excessive costs

- regulatory requirements are too onerous and need to be re-evaluated

- procurement methodology is correct, should DOE obtain the requested services via a costreimbursable contract?

- risks that private industry is being requested to absorb are costing the government too much. Should DOE absorb more risk?

If DOE were to formally request that the cost reimbursement contractor pursue the TWRS Privatization work scope, there would be a subsequent effort on the part of the cost-reimbursement contractor to prepare a specific cost estimate for a defined work scope.

\section{Methodology}

DOE recognized that preparing large numbers of expensive cost estimates did not provide a reasonable rate of return for the funds expended. DOE needed to implement a cost estimating process that would provide an indication of cost savings in a more effective manner.

DOE recognized that for Planning/Feasibility estimates, which are typically prepared for engineering studies and portions of Conceptual Designs, that the use of analogies and extrapolations was feasible. Before pursuing any cost estimating process DOE performed research, using Hanford sources to determine the level of technical and cost data available to support the estimating process. Prior to the Privatization Initiative, the FCS had been developed. This study performed by the cost reimbursement contractor examined the size, number, physical layout, and technology employed in the treatment and immobilization facilities. From this study came various cost estimates for facilities of different configurations (combined with other facilities or separate), different sizes (multiple small facilities or large facilities), and different technologies (use of monolithic glass or cullets). These estimates provide DOE with a reasonable database for obtaining information about the costs associated with a costreimbursement contractor for the treatment and immobilization services.

In addition to Hanford Site information, DOE obtained information from the Defense Waste Processing Facility (DWPF) at Savannah River (SR). The purpose of this information was to provide a validation of some of the costs used in the DOE cost-reimbursement estimate. DWPF costs represent costs that DOE is actually incurring for the production of borosilicate glass. Only estimated costs are available for the Hanford Waste Vitrification Plant (HWVP) operations costs. DWPF operating costs were used as an indicator of the estimated operating costs developed for the Cost Reimbursable contractor cost estimate. 
Prior to the development of the Cost Reimbursable contractor cost estimate it was essential that DOE prepare a technical description of the processes and facilities that would be built and operated by the Cost Reimbursable contractor. Brief descriptions of the major divisions of this scope of work are provided below:

- Treatment

- Separations involves the removal of small particles and debris from the waste feed. It is assumed that a cost-reimbursement contractor would use centrifuges as the filtration process. This process is comparable to the processes proposed by the M\&O in the Facility Configuration Study and proposed as part of the Initial Pretreatment Module.

- Transuranics (TRU)/strontium (Sr) removal requires the use of chemical addition to force the precipitation of TRU and Sr. The precipitated chemicals are removed by a filtration process. The means of accomplishing TRU/Sr removal is a DOE assumption using data available from the Privatization Contractors.

- Cesium (Cs) removal is accomplished by the use of an elutable resin. This process requires the use of multiple ion exchanger columns in series and parallel and installation of support systems that allow the installation, removal, and storage of resin. This process is comparable to the processes proposed by the Cost Reimbursable contractor in the Facility Configuration Study and proposed as part of the Initial Pretreatment Module.

- Technetium (Tc) removal is accomplished via the use of an elutable resin. This process requires the use of multiple ion exchangers in series and parallel and installation of support systems that allow the installation, removal, and storage of resin. This is not the same resin that is used for Cs removal. The means of accomplishing Tc removal is a DOE assumption using data available from the Privatization Contractors.

- Low Activity Waste Immobilization will be accomplished via vitrification. This process requires the use of multiple melters. Immobilized Low Activity Waste is placed in packages, comparable to those required by the Privatization Contracts. The immobilization process is comparable to that proposed by the cost-reimbursement contractor, but the major difference is the final waste form. In the FCS the cost-reimbursement contractor proposed a waste form consisting of glass cullets (fractured glass) in a sulphur polymer cement. In order to ensure technical comparability DOE has assumed a common waste form for both types of contracts.

- High Level Waste Immobilization will be accomplished via vitrification. This process requires the use of a single melter. Immobilized High Level Waste is placed in canisters, comparable to those required by the Privatization work scope. The immobilization process is comparable to that proposed by the cost-reimbursement contractor.

A more detailed description of the processes and facilities is included as a part of the cost estimating report, see Appendix A.

DOE determined that preparing a parametric cost estimate was the most reasonable process for developing the Cost Reimbursable contractor cost estimates. The parametric estimate is a Type C cost estimate, but one with a high level of uncertainty. The decision to use parametric cost estimating methods was based upon the amount of information available to prepare an estimate, the number of estimates that would be required to be performed, the fact that the estimate was designed to be used as a tool to compare 
costs and not to request capital funds, and the limited funding available to support the preparation of a cost estimate.

After determining that the parametric cost estimating process presented the most reasonable method for developing the cost estimate, it was necessary to develop a list of parametric factors that could be used. One of the industry standards for cost estimating information, Timmerhaus reference (2), provides a list of parametric numbers for chemical processing equipment. Since the privatization work scope is comparable to chemical processing, it was determined that the factors presented by Timmerhaus were applicable to this cost estimate. Attempts were made to determine if there were other standards that provided parametric values. DOE was unable to find additional cost estimating parametrics. Table III data prepared by DOE cost estimating contractors shows comparability to the factors presented in Timmerhaus.

The data shown in Table II was reviewed against the data developed by DOE for preparation of the Phase IB Fair Cost Government Estimate. For example, reference (2) provides a parametric factor of 0.48 for pumps. The parametric developed using pump data from the Fair Cost Government Estimate indicated that a parametric factor of 0.43 . The differences in the parametric values appears to be reasonable based upon the differences in the databases used to develop the parametrics. For consistency, the parametrics listed in reference (2) are used throughout the DOE Prepared Cost Estimate.

\section{Assumptions}

If DOE used parametric cost estimating factors to estimate major pieces of capital equipment, it would still be necessary for DOE to estimate the other costs that would be attributable to a cost-reimbursable estimate. In the preparation of the FCS cost estimates, there was agreement among all the participating organizations regarding the percentages that would be used to calculate major cost adders. The agreed upon percentages were

- Engineering - Title I and Title II design - costs were assumed to be $40 \%$ of the cost attributable to equipment and structures.

- Construction Management costs were assumed to be $10 \%$ of the costs attributable to equipment and structures.

- Project Management costs were assumed to be $10 \%$ of the cost attributable to equipment and structures, Engineering and Construction Management.

In addition to these costs, there were other costs that DOE should expect to pay for capital projects.

These costs were

- Conceptual Design costs are assumed to be $3 \%$ of the capital cost of the project, which includes equipment, structures, and engineering.

- Development costs are those costs attributable to the technology development program that accompanies the capital project. The FCS provided an estimate for the technology development program that would be necessary for accomplishing the FY95 MYWP work scope. DOE used the cost-reimbursement estimates for technology development as a basis for estimating the technology development program. 


\section{Table III - Power Factors Used in Development of the DOE Prepared Cost Reimbursable Estimate}

\begin{tabular}{|c|c|c|}
\hline Equipment & Exponential & Source \\
\hline Blender, double cone rotary & 0.49 & Timmerhaus, Table 5, pg 170 \\
\hline Blower, centrifugal & 0.59 & Timmerhaus, Table 5, pg 170 \\
\hline Centrifuge & 0.67 & Timmerhaus, Table 5, pg 170 \\
\hline Crystallizer & 0.37 & Timmerhaus, Table 5, pg 170 \\
\hline Compressor, reciprocating, air cooled, two stage & 0.69 & Timmerhaus, Table 5, pg 170 \\
\hline Compressor, rotary, single-stage, sliding vane & 0.79 & Timmerhaus, Table 5, pg 170 \\
\hline Dryer, drum, single vacuum & 0.76 & Timmerhaus, Table 5, pg 170 \\
\hline Dryer, drum, single atmosphere & 0.4 & Timmerhaus, Table 5, pg 170 \\
\hline Evaporator (installed), horizontal tank & 0.54 & Timmerhaus, Table 5, pg 170 \\
\hline Fan, centrifugal & 0.44 & Timmerhaus, Table 5, pg 170 \\
\hline Fan, centrifugal & 1.17 & Timmerhaus, Table 5, pg 170 \\
\hline Heat exchanger, shell and tube, floating head & 0.6 & Timmerhaus, Table 5, pg 170 \\
\hline Heat exchanger, shell and tube, fixed sheet & 0.44 & Timmerhaus, Table 5, pg 170 \\
\hline Kettle, cast iron, jacketed & 0.27 & Timmerhaus, Table 5, pg 170 \\
\hline Kettle, glass lined, jacketed & 0.31 & Timmerhaus, Table 5, pg 170 \\
\hline Motor, squirrel cage, induction, 440 volts, $5-20 \mathrm{hp}$ & 0.69 & Timmerhaus, Table 5, pg 170 \\
\hline Motor, squirrel cage, induction, 440 volts, $20-200 \mathrm{hp}$ & 0.99 & Timmerhaus, Table 5, pg 170 \\
\hline Pump, reciprocating, horizontal cast iron & 0.34 & Timmerhaus, Table 5, pg 170 \\
\hline Pump, reciprocating, horizontal cast steel & 0.33 & Timmerhaus, Table 5, pg 170 \\
\hline Reactor, glass lined, jacketed & 0.54 & Timmerhaus, Table 5, pg 170 \\
\hline Reactor, stainless steel & 0.56 & Timmerhaus, Table 5, pg 170 \\
\hline Separator, centrifugal, stainless steel & 0.49 & Timmerhaus, Table 5, pg 170 \\
\hline Tank, flat head, carbon steel & 0.57 & Timmerhaus, Table 5, pg 170 \\
\hline Tank, carbon steel, glass lined & 0.49 & Timmerhaus, Table 5, pg 170 \\
\hline Tower, carbon steel & 0.62 & Timmerhaus, Table 5, pg 170 \\
\hline Tray, bubble cup, carbon steel & 1.2 & Timmerhaus, Table 5, pg 170 \\
\hline Tray, sieve, carbon steel & 0.86 & Timmerhaus, Table 5, pg 170 \\
\hline Component that is not size specific (chemicals) & 1 & Assumed \\
\hline Component that does not fit the Timmerhaus classifications & 0.6 & Assumed \\
\hline LLW or HLW Vitrification components & 0.42 & Timmerhaus, Table 16, page 187 \\
\hline Pretreatment Components - not traceable to above & 0.6 & Timmerhaus, Table 16 , page 187 \\
\hline Combined Components (LLW/TPM/HLW) & 0.48 & Timmerhaus, Table 16, page 187 \\
\hline Size Independent Component & 0 & Assumed \\
\hline Westinghouse Hanford Company Power Factor & 0.2 & $\begin{array}{l}\text { Westinghouse Hanford } \\
\text { Company developed parametric } \\
\text { for Hanford Site treatment and } \\
\text { immobilization facilities }\end{array}$ \\
\hline Building volume dependent - processing volume & 0.498 & Calculated \\
\hline
\end{tabular}


- Startup costs are those costs associated with bringing a new construction project on line for the operational staff. There are a variety of time frames that could be used for estimating costs; however, DOE assumed that it would take approximately 16 months to bring the facility on line. Since the operational staff would be necessary during facility startup, DOE assumed that the costs associated with 16 months of facility operations could be used as an estimate for startup costs.

- The initial load of maintenance parts are not a large cost driver for the facility but represent a cost that the DOE must take into account. Using an industry standard of 5\%, page 203 of reference (2), of . capital equipment costs, an estimate for the initial load of spare parts could be established.

Besides the specific cost assumptions, other critical assumptions were necessary to develop the estimate. Those assumptions include the following:

- Privatization continued through receipt of proposals from contractors. This assumption allowed DOE to prepare a cost estimate for identical work scope to the Privatization Contractors. Both the cost-reimbursement estimate and the Privatized estimates are based on comparable initial information. All the information that DOE obtained initially from the Privatization Contractors in Phase IA was not available for a cost-reimbursable estimate.

- The Cost Reimbursable contractor proposal for the treatment and immobilization of tank waste meets the requirements of the contract. The technical requirements for the privatization contract are not technically different nor more difficult than the technical requirements that DOE would have imposed on the cost-reimbursement work scope.

- The cost reimbursement work scope uses glass monoliths for both immobilized low-activity waste and immobilized high-level waste. In FY95, the FCS proposed the immobilization of low-activity waste using cullet (fractured glass) sealed in a sulphur polymer cement. The on-site disposal facility for the Immobilized Low Activity Waste would have been large concrete structures that are filled with the cullet/cement mixture. To ensure that there is comparability in the support costs for both a fixed-price and cost-reimbursement scope of work, DOE has assumed that the cost reimbursement scope of work uses glass monoliths as the waste form for both high-level and low-activity waste.

- Additionally it is assumed that despite the failure of TWRS Privatization, there is no change in the chosen technical solution for the treatment and immobilization of the Hanford tank waste. Various alternative immobilization waste forms previously have been proposed, glass was the selected waste form.

- Technology development is required to ensure that the technology chosen for a cost-reimbursement scope of work is viable. Since one of the driving assumptions is that privatization failed prior to receipt of the Contractor proposals, there were few technology lessons learned. The Cost Reimbursable contractor is assumed to initiate a technology development program. The Cost Reimbursable contractor's cost estimate assumes that privatization failed prior to receipt of the contractor's proposals. Therefore, no lessons learned about technology could have been applied to the cost-reimbursable contractor's designs.

- Technology development occurs in a just-in-time basis. There are no construction or design delays that result from delays in the development of technology. 
- A key decision process, comparable to DOE Order 4700.1 , is implemented. This would require the Cost Reimbursable contractor to plan work around the following key decisions:

- KD-0 Justification of Mission Need

- KD-1 Title I Design

- KD-2 Title II Design

- KD-3 Start of Construction

- KD-4 Authorization to Operate.

The key decision process requires that DOE prepare specific deliverables and submit these deliverable to DOE-HQ prior to DOE-RL receiving permission/funding to proceed to the next phase of work. This process has been used by DOE to judge the viability of proceeding with the next phase of a project.

- Key decisions must be made at HQ. All key decisions require 6 months to obtain. Due to the size and complexity of the project, DOE-HQ would not delegate to $\mathrm{RL}$ the approval of key decisions.

- DOE oversight of the facility is consistent with the pre-FY96 philosophy. TWRS Privatization proposes changes to the way DOE oversees its contractors. This new philosophy was not implemented in the Cost Reimbursable scope of work.

- Funding is available to support the construction of the facility. Funding changes can impact the progress made by DOE and the Cost Reimbursable contractor. In order to avoid developing estimates for the impact of funding changes, both increases and decreases, DOE assumed that there were no funding changes after Conceptual Design.

- There are no additional costs factored into the estimate. The costs associated with technology changes were work scope changes and not included in the estimate. The technical baseline for the project was not changed after completion of the conceptual design. This was a simplifying assumption.

- The schedule for the design, construction, permitting, startup, and operation of the facility is met. There are no delays in meeting the schedule of the project. This assumption is complementary to the assumptions regarding funding changes and technical baseline changes. In addition, this assumption states that the cost reimbursement contractor will complete the desired work scope in the stated time frame and DOE will perform their reviews in a timely manner to support that work scope.

- There are no delays in providing critical site services for the support of facility construction. A source of problems with any large construction project is the availability of support services.

- The Stakeholders and Regulators agree with the processes chosen by the cost-reimbursement contractor for treatment and immobilization of the waste.

- There are no technical changes in the processing facility requirements.

- The cost-reimbursement contractor staffed and operated the TWRS facilities in a manner comparable to pre-Privatization. There is no assumed efficiency/deficiency in the management processes used by the cost-reimbursement contractor. 


\section{Estimate Structure}

The DOE Prepared Cost Reimbursable contractor estimate was intended to provide to DOE an indication of the capital and operating cost estimate that would be expected if the cost-reimbursement contractor were to perform the Phase I work scope. The purpose of this document is to provide a structure for the presenting this estimate. This cost estimate is broken into several sections to allow the reader to understand the estimate. These sections are as follows:

- Appendix A provides a description of the scope of the estimate. The proposed construction project is described. The scope section provides a description of the project and what activities are included.

- Appendix B provides the Work Breakdown Structure (WBS) used for developing the cost estimate.

- Appendix $\mathrm{C}$ provides a schedule for the construction and operation of the proposed facility.

- Appendix D provides a summary of the costs that resulted from the estimate. These costs are broken down at the second level of the WBS.

- Appendix E provides the cost estimate. The estimate provides a list of specific functions that are provided in the facility, the equipment that is assumed necessary to support the functions, the quantity of each piece of equipment required, and the estimated cost (labor and material) for each piece of equipment. In addition to the actual processing facility the estimate includes the cost of various support facilities and structures required to support operations.

- Appendix F provides a description of major functions, and the basis for the costs of major pieces of equipment. Appendix F provides detail for developing the estimate for particular pieces of equipment.

- Appendix G provides the process that DOE used to estimate the operating cost for the facility.

\section{$\underline{\text { Review Results }}$}

Due to the size of this contract and the unique nature, there was a great deal of scrutiny regarding the cost estimate. This scrutiny came from DOE internal reviewers, Congressional Reviews, General Accounting Office (GAO) reviews, and representatives of the Maintenance and Operations Contractors. Therefore it was essential that the DOE Prepared cost reimbursement estimate represent a scope comparable to the work scope proposed by the fixed-price contract.

The Cost Reimbursable contractor cost estimate is based upon information developed by the Cost Reimbursable contractor in FY95. This cost estimate is being compared to a cost estimate developed by private industry for comparable work scope. It is important to note that comparable work scope does not imply comparable approach. The Cost Reimbursable contractor approach may be different than a private contractor, just as the two private contractors could propose different approaches to solve identical work scopes. For future comparison bases, the Cost Reimbursable contractor cost estimate should be reviewed and revised to reflect information as it is made available from the private contractors. Future reviews could look at

- Technical Approach

- Cost of Components 
- Cost of Management

- Cost of the Structure.

A review of the technical approach of the Private Contractors is required to ensure that the Cost Reimbursable contractor estimate did not include/exclude processes. For example, in the Cost Reimbursable contractor estimate, technetium removal processes assumed the use of ion exchangers of the same size and quantity as would be used for cesium removal. If this assumption is not correct, then the Cost Reimbursable contractor estimate should be revised to reflect the correct assumptions. The assumptions related to technetium removal are important since the process was not originally included in the M\&O work scope in FY95.

A review of the cost of individual components is important. Since the Cost Reimbursable contractor estimate is based on a parametric analysis of an M\&O facility, the accuracy of the estimate is dependent upon the accuracy of the parametrics used. A review of the high cost elements (i.e., melters, ion exchangers, mixing tanks, etc.) will allow some quantification to be made of the accuracy of the parametric cost estimating process.

Management costs for the Cost Reimbursable contractor are typically $25 \%$ of the capital cost of the facility. A review of the costs associated with management of a private contractors operations versus cost of a Cost Reimbursable contractor's operations may bring some valuable lessons learned that can be applied by the DOE.

Estimating the cost of the structure proved to be a more difficult process than developing the parametric costs for the equipment. Since no parametrics based on process capacity were found for facilities, DOE was required to develop a parametric process that combines process throughput, volumetric relationships, and process volumetric assumptions. By reviewing the private contractors' cost for construction of the facility, it is hoped that a better process can be developed for estimating construction costs.

These reviews are heavily dependent upon the quality of the cost data from the private contractors. As the quality and availability of information increases, DOE should be able to perform the above stated reviews.

\section{Conclusions}

One of the benefits of Privatization is the reduced outlays required to complete a specific scope of work. In order to determine if there are reduced outlays, DOE has undertaken efforts to estimate the cost of performing the privatization work scope via a Cost Reimbursable contractor. By comparing the cost of the Privatization Contractors to the cost of having a Cost Reimbursable contractor perform the work scope, DOE believes that it is possible to state the degree of cost savings, reduced outlays. Developing a cost estimate for having the Cost Reimbursable contractor perform the work is not an easy task. There are expenditures required: having the Cost Reimbursable contractor prepare an estimate, preparing the backup data for the estimate, and preparing a technical description of the work. When the privatization contracts provide the contractors flexibility (in cost, schedule, or technical requirements), it is important that the DOE have a cost estimate that reflects the changes. Without comparability, there would be reasons to claim that any "cost savings" are the result of differences in work scope.

The level of knowledge that the Privatization Contractors bring to DOE cannot be matched by the Cost Reimbursable contractor. Any difference in knowledge is not due to the superiority of the Privatization Contractors but rather is due to the application of knowledge that the Privatization Contractors bring to the table. The Cost Reimbursable contractor is only funded at a level desired by the DOE, if the DOE loses "interest" in developing treatment and immobilization technologies, a knowledge gap is created, 
since the Private Contractors are always looking for better means of accomplishing their work. In conjunction with the technology knowledge gaps comes gaps in cost estimating and operations knowledge. The Private Contractors have operating facilities from which to gain operations and cost data. Private Contractor data is not easily adaptable by the Cost Reimbursable contractor since the Cost Reimbursable contractor must operate in accordance with DOE requirements. Lessons learned are corporate in nature and can only be applied from industry in a general sense.

The contracts that DOE signed with the Privatization Contractors allowed changes to be made without any agreement or concurrence on the part of DOE. Changes were possible in all technological aspects of the project, the contractors only had to meet the minimum technological requirements of the contractors. There was no maximum (excluding cost) that limited the contractors. No formal change control process was instituted with the privatization contractors. In order to for DOE to match this unlimited change aspect of the Privatization Contractors, DOE was required to adopt a cost estimating methodology that allowed numerous changes to be reflected in the cost estimates.

In an ideal world, DOE would have established the bounds (both upper and lower) for the Private Contractors. Any change that exceeded or which did not meet the requirements would not be accepted. This process would have easily allowed DOE to commission the Cost Reimbursable contractor to prepare a conceptual design and a cost estimate for the design, construction, operation and deactivation of the facility. After the completion of the Cost Reimbursable contractor estimate, DOE could have compared the cost proposals of the Privatization Contractors to the cost proposal of the Cost Reimbursable contractor. After normalizing the two estimates for the amount of risk absorbed by DOE, a review could have been performed to determine if there were savings from implementing Privatization. However, DOE adopted a very mature attitude by requesting the Privatization Contractors to optimize the contracts to provide the best deal to the Government. By allowing the Privatization Contractors to optimize their facilities, DOE introduced a cost estimating process that would have strained the standard DOE cost estimating methods. DOE would have requested the M\&O to prepare numerous cost estimates in response to the perceived and real proposals being made by the Privatization Contractors. Ignoring the Competition Sensitive issues, the funding required to keep the $M \& O$ preparing cost estimates prepared in response to the Privatization Contractors proposals would have strained the TWRS budget to the point that other projects would suffer. By taking a conservative approach to preparing the cost estimates, DOE was able to prepare numerous cost estimates without impacting the other critical TWRS projects. A trade-off was made between preparing a large number of cost estimates and allowing other TWRS cleanup projects to continue.

\section{Recommendations}

In preparing cost estimates for Cost Reimbursable contractor performance of a proposed Privatization scope of work, there needs to be a review of the information available, the funds available to perform support cost estimates, and the value gained from expending any funds on cost estimating work.

Where there is well documented cost history for having the Cost Reimbursable contractor perform a scope of work, it is easy to prepare Cost Reimbursable contractor cost estimates for a Privatization scope of work. The Cost Reimbursable contractor cost estimates would be based solely on the cost history, with some increases/decreases based upon assumed efficiencies. A cost estimate for having a Private Contractor perform the work could be performed any number of ways, an in-house estimate, having a private firm develop an estimate based on their experience in the field, or procure the services via the open market. An estimate of the cost savings would be based solely on the differences between the cost for the service before and after privatizing. A model for calculation would be the Indianapolis Airport privatization. 
Without considerable cost history for having the Cost Reimbursable contractor perform a scope of work, DOE needs to be very judicious in expending funds for the development of cost estimates. Without judicious expenditure of funds, DOE could be preparing a large number of cost estimates for work that will never be accomplished. There are competing priorities that must be reconciled, the need to have an equivalent Cost Reimbursable contractor cost estimate for the work being performed by the Private Contractors, and the need for funds to perform other site cleanup work. Without the development of a cost estimating process that meets both criteria, there will be criticism of the DOE funding process. DOE believes that the cost estimating process that has been used to estimate the Cost Reimbursable contractor costs for the TWRS Privatization scope of work provides a reasonable indication of the types of cost that DOE could incur. The DOE prepared Cost Reimbursable contractor cost estimate is not intended to act as a capital project cost estimate. DOE never intended the cost estimate to be of that quality.

Cost estimates must reviewed from the perspective of purpose. A cost estimate for a capital project rightfully requires a high degree of accuracy and a commensurate level of expenditures. Where the cost estimate is intended to provide a barometer of the savings that could be expected, i.e., no funding is being requested for the Cost Reimbursable contractor work, then there needs to be a review of the expenditures required for the level of accuracy required. Judicious expenditure of funding for cost estimates is difficult to judge. There are factions that believe no expenditure is too small in order to maintain a high level of accuracy, whereas there is a faction that believes that reasonable attempts should be made to estimate the range of costs. Selection of the cost estimating process is dependent upon funding, time, and resources available to support the estimate process. The correct cost estimating process is a subject of considerable discussion. An agreement or understanding between the different factions should be accomplished prior to the preparation of the cost estimates. Funding, time, and resources should be provided as necessary to support the desired level of detail and accuracy in the cost estimate.

\section{References}

(1) WHC-SD-WM-ES-295 TWRS Facilities Configuration Study, dated July 13, 1994.

(2) Plant Design and Economics for Chemical Engineers, Peters and Timmerhaus.

(3) DOE Cost Estimating Guide, Volume 6 Cost Guide. 


\title{
Appendix E
}

\author{
Comparison of Cost Growth and \\ High Level Waste Glass Costs \\ at Savannah River and West Valley \\ with a Comparison to BNFL's Estimated Costs at Hanford
}

John Jaksch, PNNL

Kenneth G. Picha, DOE-EM

Jeff Yocum, TRW

Ben Gannon, SAIC

Mark Weimar, PNNL

Kim DeTienne, PNNL

\author{
June 1998 \\ Prepared for \\ the U.S. Department of Energy \\ Under Contract DE-AC06-76RLO 1830
}

Pacific Northwest National Laboratory

Richland, Washington 99352 


\section{Comparison of Cost Growth and High Level Waste Glass Costs at Savannah River and West Valley with a Comparison to BNFL's Estimated Costs at Hanford}

\section{Introduction}

One gauge of price reasonableness is to analyze cost growth and to derive the costs per metric ton of vitrified wastes produced at comparable projects to TWRS within the U.S. Department of Energy's (DOE) complex of sites. The analysis of cost growth of projects undertaken by Management and Operations $(\mathrm{M} \& \mathrm{O})$ contracts and fixed priced or market driven contracts is a significant variable in determining the cost savings associated with the TWRS Privatization Contract. This paper reports on cost growth and the derivation of costs to construct two major system acquisitions (MSA) at DOE sites managed by a M\&O contractor. The two projects are the Defense Waste Processing Facility (DWPF) at DOE's Savannah River Site, South Carolina, and the West Valley Demonstration Project (WVDP) at West Valley, New York. Both sites are operated by Westinghouse, the M\&O contractor to DOE. ${ }^{1}$ Both sites, as planned with TWRS privatization, vitrify high level wastes for storage in canisters for final disposal. The paper is divided into two parts. The first section analyses cost growth for each site. The second section compares costs of making glass for stabilizing high level waste to meet specifications at the High Level Waste repository for the two sites, plus a comparison to BNFL's costs at Hanford. Line management at Savannah River and West Valley provided the costs.

\section{Project Descriptions}

\section{West Valley Demonstration Project}

The Western New York Nuclear Service Center near West Valley, New York, reprocessed nuclear fuel from 1966 to 1972 . During that time, approximately 560,000 gallons of alkaline high-level waste were generated by this activity and stored in a carbon steel tank located in an underground vault. The alkaline waste is similar to that stored at the DOE's Savannah River and Hanford sites. These wastes consist of a supernatant liquid and sludge that has formed on the tank bottom. A smaller amount (about 12,000 gallons) of acidic Thorex waste, stored in a stainless steel tank located in a separate underground concrete vault, also will be treated at West Valley. West Valley's costs also include Low Level Waste treatment costs and Infrastructure costs.

Public Law 96-368, West Valley Demonstration Project Act of 1980, directed the DOE to carry out a high-level liquid nuclear waste management demonstration project at the West Valley facility. The purpose was to demonstrate the solidification and preparation of high-level radioactive waste for disposal: By virtue of demonstrating the solidification of liquid high-level wastes, the hazards associated with continued storage of the liquid waste at the Center will be eliminated.

At WVDP, considerable emphasis was focused on moving forward quickly (Action TraK) while completing designs for the project. The 1980 pre-project cost and schedule estimates were very rough, at $\$ 800$ million (1980 \$) and 12 to 14 years. In 1982, a DOE project review resulted in significant shortening of the project schedule, with a subsequent reduction in the project cost estimate to $\$ 450$ million. The DOE based the choice of a shorter schedule and resulting lower cost on the following project assumptions:

\footnotetext{
${ }^{1}$ The Hanford Waste Vitrification Plant (HWVP) and the Fernald Vitrification Pilot Plant (FVPP) were initially examined as well. Construction at HWVP was terminated before it was completed. FVPP ran into a number of difficulties. The construction on FVPP is not completed, although it has not been terminated.
} 
- use of existing technology

- sufficient funding provided as requested

- minimal institutional requirements

- no activities, except caretaking, associated with on-site fuel storage and burial grounds, with spent fuel removed by FY87

- quick resolution of waste form and solidification process

- reasonable support from waste programs outside of WVDP.

Several of these assumptions were not met, resulting in cost and schedule increases. Construction on the WVDP started in the early 80s and was completed in 1996.

\section{Defense Waste Processing Facility}

The Defense Waste Processing Facility (DWPF) is solidifying defense high-level radioactive waste at the Savannah River Site (SRS) for temporary on-site storage and eventual transportation to and disposal in a Federal repository. The project provided facilities to immobilize the high-level waste in borosilicate glass in stainless steel canisters. The canisters will be stored at the SRS until a Federal repository is available. Decontaminated salt will be solidified as a monolith with low permeability for disposal on-site in concrete vaults as an industrial solid waste. The radioactive cesium separated from the salt will be combined with the sludge waste for vitrification. Construction at DWPF was initiated in the early 80 s as well and was completed in 1996. DWPF, which began operation in 1996, will process the waste backlog inventory over approximately a 20 to 25 year period (current estimates are 22 years).

\section{Objectives of the Analysis}

The objective of the analysis is to determine the costs growth and costs comparability (construction and operating) of the projects built and managed under the auspices of the M\&O contractor with the cost estimates derived for TWRS privatization. The costs are compared with the TWRS privatization costs in the last section. The TWRS cost estimates are derived from BNFL's bids received at the end of Part A and cost estimates generated from them by PNNL.

The purposes of obtaining the MSA estimates are to answer the following questions:

- What is the growth in constant ${ }^{2}$ dollars between the MSA's initial projected $\operatorname{cost}^{3}$ (before construction actually begins and at the time of the first initial Congressional request for funding) and what the project actually costs to construct? ${ }^{4}$

- What is the growth in constant dollar terms attributable to project delays and schedule slippage?

- What are the costs to produce one metric ton of treated, vitrified waste at each facility?

\footnotetext{
${ }^{2}$ The terms "constant or real" and "nominal or year-of-expenditure" dollars are use often in this paper. Constant dollars are nominal dollars with inflation removed so the dollars are dollars of constant purchasing power and are comparable from one year to the next.

${ }^{3}$ Both projects ended up costing more then the initial project cost estimates. Both projects experienced schedule slippage that resulted in the projects taking longer to construct than originally estimated.

${ }^{4}$ See Tables 1, 2, and 3 and the analytical section later in this chapter for a complete discussion of these differences.

${ }^{5}$ A number of factors can result in schedule slippage including inadequate or delays in Congressional funding for the project, regulatory or licensing delays, changes in environmental laws and regulations, etc. While it is difficult to delineate a dollar cost for each contributing factor, one can estimate the constant dollar cost of the overall delays.
} 
- How do the actual costs of completing the construction of an MSA under an M\&O contractor compare with the estimated and submitted bid cost of a like kind TWRS privatization project?

\section{Data Sources}

Several costs and cost estimates were obtained for each project:

- the initial projected costs of project construction

- the actual construction costs

- the annual operating costs of the completed project

- the product through-put on an annual basis.

Project Data Sheets (PDSs) were an important contributing source of data for each project. The PDSs, developed by each site, are prepared annually when there is a Congressional budget request for the project. These numbers then become the "actual" numbers upon which the cost analysis is based. The format of the PDSs is more or less consistent. This facilitates comparison of the PDSs within a given project and with other projects ${ }^{6}$. The PDSs contain a substantive amount of high-level data including the following:

- The project's title and location.

- The initiation date for the project's architecture and engineering work.

- The date physical construction started and the project's estimated completion.

- The project's funding profile - past, present, and future. The funding profile is divided between construction costs and other project costs (e.g., research and development, other related project costs, etc.). The costs are expressed in nominal or year-of-expenditure dollars.

- A brief description of the project and a section on project purpose, justification, and scope.

- The estimated project life and annual operating costs.

The PDSs are prepared each fiscal year (FY). Initially the cost numbers reflect what DOE plans to spend over the project's construction and consequently represents an estimated funding profile for Congressional appropriation. The FY for which the PDS is submitted to Congress represents the actual Congressional request for funding by DOE for that year. The out-year numbers are presented for planning purposes only. Congress may, or may not, appropriate the amount that DOE has requested for the current FY. Consequently, the next FY-submitted PDSs might contain a different number from the previous year's PDSs, which represents the actual Congressional funding. As one moves forward through time with each FY's PDS, the future projected costs change to actual costs. These numbers then become the "actual" numbers upon which the cost analysis is based. The PDSs are the primary source of data for the DWPF project. Cost data by year of expenditure were obtained for WVDP from the Westinghouse program managers at West Valley. Supplemental data were also obtained from the budget or program managers for each project as required.

\section{Cost Escalation and Finance Indices}

Several factors contribute to increase actual project costs over initial cost projections. These include inflation, schedule slippage, and work scope changes among other factors. For the cost numbers to be comparable from one year to the next, it is necessary to put each year's cost on a comparable or constant basis using costs or inflation indices. DOE employs several escalation rates. First are the escalation rates

\footnotetext{
${ }^{6}$ WVDP's PDSs were different in format from DWPF's. More precise cost data were available from West Valley and used in the analysis.
} 
for construction projects, which are developed by the Program/Project Management Division, Office of Procurement, Assistance and Program Management. The escalation rates are based on the materials and labor data contained in DOE's Energy Supply and Planning Model and appropriate escalation rates forecasted by Data Resources, Inc. The escalation rates are provided each FY for the out-years (estimated) and past years (actuals). Construction indices are prepared for each of the major DOE programs: Energy Research and Nuclear; Fossil; Conservation and Solar; and Defense Programs, Environmental Management and General Construction. The applicable index for the DWPF and WV is the Defense Programs, Environmental Management and General Construction index. The applicable indices were available for each year of the project's construction life.

The other half of project construction cost is non-construction, but related costs. These costs, commonly referred to within the DOE lexicon as Other Project Costs (OPC) or expense dollars, are escalated by another set of indices. These indices are issued by the Office of Management and Budget (OMB) for annual Congressional budget submittal. These indices were also available for each year of the project's construction. This index is used to calculate the actual, real cost growth in the project over initial projected cost estimates.

The decision was made, for purposes of this analysis, to use the budget escalation, as opposed to the construction index. The reason is the WVDP was constructed using non-construction or expense dollars. Approximately half of DWPF's costs were non-construction dollars. In addition, it was concluded that the OMB budget escalation index was more reflective of actual inflation conditions than the applicable construction index.

To finance construction of DWPF and WVDP, the government had to borrow the funds from the public either through bonds or taxes. There is a cost to the government, and by implication the U.S. taxpayer, of using these funds. For purposes of this analysis we used the "real," 30-year U.S. Treasury interest rate. The real, or constant-dollar values, measures dollar expenditures over time in stable purchasing power absent the effects of inflation. Thus dollar finance expenditures on a given project can be compared from one year to the next, without the effects of inflation, and expenditures on multiple projects can be compared in like manner. The 30-year real Treasury rate was used because the projects themselves have a useful life 30 years or greater. In addition, the government, in its deficit financing, uses a combination of short-, mid-, and long-term debt financing. It is difficult to determine the actual mix of debt financing for any one project. The 30-year real interest rate also was felt to be more conservative with respect to the available rates of real interest to chose. The 30-year rate was employed to calculate the growth in project and finance costs caused by slippage in the projects' construction schedules.

It is a commonly held belief that the "real" rate of return to government lenders is $3 \%$. In essence, absence inflation, a borrower requires a $3 \%$ annual rate of real return to lend funds to the government. A 3\% real interest rate is used as a check on the appropriateness of using the annual 30-year bond rate to discount outlays. The results of the check indicated little or no difference between the two rates.

\section{Analytical Approach}

Table 1 shows the summary results for DWPF and WVDP. The analytical results of Table 1 are based on Tables 2 and 3, which show the detail, cost, and analytical data for DWPF and WVDP, respectively. The format and analytical approach displayed in Tables 2 and 3 are similar. Thus the analytical approach for both projects are discussed as one, with the analytical results for each project presented in Table 1 (combined) and shown separately in Tables 2 and 3.

DWPF cost data from the PDSs were available from the FY-81 through FY-89 and FY-94 through FY-95. Supplemental data were obtained from the staff familiar with the project to fill in the data gaps from 
FY-90 through FY-93; to convert dollars from FY-94 and FY-95 from estimated to actual, nominal dollars expended; and to determine actual expenditures for FY-96 and FY-97. West Valley cost data were available for the period FY-81 through FY-97 with estimated data provided for FY-98. Actual yearof-expenditure, or nominal, dollars were obtained from Westinghouse project personnel at West Valley and used in the analysis. As previously mentioned, a draft of this paper was reviewed by West Valley (WV) program personnel working for Westinghouse and by DWPF personnel working for DOE. DWPF felt the analysis employed adequately reflected the conditions at DWPF. WV personnel did not. The intent of this paper is not to compare WVDP to DWPF, because the two projects are not comparable and were designed for different purposes. DWPF is designed to last 30 years in the processing of tank waste. The mission of WVDP will be completed in approximately 5 years. ${ }^{7}$ DWPF is processing wastes from a number of tanks, while WVDP has consolidated its wastes into one tank. The purpose of the analysis is to bound the costs from the TWRS privatization contractors. The TWRS Phase 1B plants high level waste capacities lie between the WVDP on the lower end, and the DWPF on the higher end.

\section{Project Growth in Constant Dollars}

\section{Actual Costs}

In Tables 2 and 3, the fiscal years of project construction are illustrated in the first row (FY-81 through FY-97). The second row shows the DOE budget escalation index for each of those FYs ranging from a high of $10.5 \%$ in FY-80 to a low of $2.3 \%$ in FY-94 and FY-96. ${ }^{8}$

The next group of rows shows the "Actual Annual Outlays Adjusted for (DWPF or WVDP) to Constant 1980 and 1997 dollars." In Table 2, the "TEC Actuals" show the total estimated costs of construction over the life of the project. The TECs start out as estimated costs in the PDSs and then are changed to actual costs when these values become known. TECs are not available for WVDP (Table 3) because "expense" dollars were employed in project construction. However analogous project elements were identified and tracked.

The next row in Table 2, "OPC Actuals," represents the nominal dollar amount by FY of other project costs, such as R\&D expenditures, etc. In DOE terminology, these are also known as expense dollars. The row in Table 2 entitled "TPC," or Total Project Costs, is the summation of TEC and OPC. For the WVDP (Table 3), there is only one row representing TPC since only one type of funding was employed on the project. The TPC in nominal year dollars for (see Table 1) is \$2.4 and \$1.4 billions for DWPF and WV, respectively.

Each nominal yearly TPC is deescalated to 1980 constant dollars using DOE's budget escalation index (see Tables 2 and 3). The results are then summed to derive a total project cost in constant 1980 dollars (1980 Constant $\$$ in Tables 2 and 3). The 1980 constant TPC is then escalated to 1997 constant dollars (1997 Constant $\$$ in Tables 2 and 3). The TPC in constant 1980 dollars (see Table 1) is $\$ 1.6$ billion and $\$ 818$ million for DWPF and WV, respectively. The TPC in constant 1997 dollars is $\$ 3.1$ and $\$ 1.6$ billion for DWPF and WV, respectively.?

\footnotetext{
${ }^{7}$ This does not mean that WVDP could not operate longer that 5 years, it could. This issue is that the waste treatment will be completed in 5 years.

${ }^{8}$ A "one" must be subtracted from each FY value to determine the actual percentage escalation for that year. The "one" is added to each FY escalation index for purposes of calculating escalation or de-escalation values from one year to the next; e.g., 1980 dollars are escalated $1.103 \%$ to derive 1981 dollars.

${ }^{9}$ Note that the reported numbers are rounded up or down and thus do not track exactly to the numbers reported in Tables 1,2 , or 3 .
} 


\section{Projected Costs}

The next section of rows in Tables 2 and 3 entitled "Projected Costs Adjusted to Constant 1980\$ and $1997 \$$ " follows a similar analytical approach as the previous section. The cost data are taken from the earliest available PDSs for each project and represent the projection at that time of project costs by year as first portrayed to Congress. These costs are in nominal dollars. The annual projected total project costs are summed to arrive at total projected project costs. The total projected project costs for DWPF and WV are $\$ 1.5$ billion and $\$ 470$ million, respectively (see Table 1 ). The annual projected project costs are then deescalated to 1980 dollars expenditure (1980 Constant $\$$ in Tables 2 and 3) and summed to derive total projected 1980 constant dollars. The total projected 1980 constant dollar costs for DWPF and WVDP are $\$ 1.1$ billion and $\$ 332$ million, respectively (see Table 1 ). The 1980 constant dollar total projected project costs are then escalated to 1997 constant dollar values. The values are \$2.2 and \$643 million for DWPF and WV, respectively (Table 1 ).

\section{Growth in Constant Dollars}

The actual and projected total project costs are then compared to arrive at a calculation of the project's growth in constant dollars. The growth in constant dollars (projected versus actual) is $41 \%$ and $147 \%$ for DWPF and WV, respectively (see Table 1). The basic conclusion to be drawn from these numbers is the initial project estimates grossly underestimated the actual project costs. Three factors contribute to the projects' cost growth: inflation, schedule slippage, and increases in work scope over and above the scope originally envisioned. Work scope increases occurred as DOE modified its policies on safety rigor of operations, and environmental compliance at nuclear sites. Examples included adding a catalytic reactor to control nitrous oxide at WVDP and extensive fire protection and safety system modifications at DWPF.

\section{Schedule Slippage}

\section{Year Real Treasury Rate of Interest}

The next question is how much project schedule slippage contributed to cost growth. The approach employed for actual and projected expenditures (Tables 2 and 3 ) is to assume that all actual and projected expenditures are refinanced annually at the real 30-year interest rate published for that year by OMB. Constant 1980 dollars were employed to calculate the finance costs. A half-year convention is used for additions (i.e., costs) for that year. The half-year convention is employed because it is not known when within the FY the expenditures were actually incurred. Thus, it was assumed that the expenditures were made in the middle of the FY.

Interest on expenditures in the given FY is calculated and carried forward to the following FY. Interest on the amount of costs carried forward from the previous FY is calculated using a full year, not a halfyear convention. The reason is the previous year's funding is financed for the entire 12 months of the current FY. The process is then repeated for each FY until the project's construction is completed.

Each FY total actual and projected annual expenditures (1980 dollars) are then summed across all FYs to arrive at the project's actual and projected real finance costs. Referring to Table 1, the real total "actual" financed cost (interest plus construction) for the DWPF is $\$ 2.4$ billion, and finance costs of \$768 million, while the real "projected" total finance cost is $\$ 1.5$ billion with finance costs $\$ 368$ million. For WVDP, it is $\$ 1.1$ billion, finance costs of $\$ 308$ million, and projected costs of $\$ 408$ million with finance costs of $\$ 77$ million. An estimate attributable to the increased real costs associated with schedule slippage can be calculated by taking the ratio of the total actual financed costs to the total projected finance cost in 1980 
dollars. The growth in costs attributable to schedule slippage on DWPF is $58 \%$ and $176 \%$ for WV (see Table 1).

The basic interpretation of these results are that DWPF and WVDP cost $58 \%$ and $176 \%$, respectively, more as a result of their construction schedule being delayed. Again, these delays can result from a number of reasons as previously delineated. DWPF was completed approximately 6 years after its original completion date while WVDP was approximately 7.5 years.

\section{Three Percent Real Rate of Interest}

As a check on the 30-year Treasury rate, an annual real rate of interest of $3 \%$ was assumed. The $3 \%$ rate reflects long-term growth and if the rate of increase in costs is similar, then the variation in the Treasury rate did not significantly impact the slippage cost. The same procedures as illustrated in the previous section are employed to calculate total actual and projected project finance costs. The total actual costs for DWPF employing the 3\% rate of interest is $\$ 2.1$ billion, or a difference of $\$ 292$ million less in interest costs when compared to the 30-year real Treasury rate of interest. Actual interest costs are $\$ 475$ million. The total projected finance costs are $\$ 1.30$ billion, or a difference of $\$ 187$ million in total government financed costs when compared to the higher 30-year interest rate (see Table 1). Interest costs are $\$ 180$ million on the projected costs at the 3\% rate versus $\$ 368$ million at the higher 30-year real interest rate. The $58 \%$ increase in total costs was the same as using the 30 -year Treasury rate.

The total actual cost for WVDP employing the 3\% interest rate is $\$ 1.0$ billion, or a difference of $\$ 90$ million in finance costs when compared to the 30-year real Treasury rate of interest. The total projected costs are $\$ 371$ million, or a difference of $\$ 37$ million in government finance costs at the higher interest rate. Again the percent cost increase was similar to that found using the Treasury rate. The growth in costs attributable to schedule slippage on DWPF using the $3 \%$ rate is $58 \%$ and $181 \%$ for WV (see Table 1). This is almost the same as the growth in cost employing the 30-year Treasury rate. The 30-year real Treasury rate was on average $2.1 \%$ higher than the $3 \%$ rate over the projects' approximate 17 -year construction period. Essentially the approach of using the 30-year Treasury rate was consistent with longterm interest rate for WVDP and DWPF.

\section{Production Costs Per Metric Ton of Vitrified Waste}

This section compares the predicted cost of vitrifying the Hanford high-level waste (HLW) employing a privatization approach with DOE's M\&O experience at DWPF and WVDP. A fair and accurate comparison is made difficult by differences between the three sites. As recognized earlier, there are differences in the process configurations, design-life of the plants, design and realized throughput, and the methods of processing the low activity waste (LAW). These differences had to be "normalized" or made as comparable as possible. Furthermore, this approach does not attempt to adjust differences in timing of outlays.

DOE manages the Hanford HLW program as the Tank Waste Remediation System (TWRS). DOE intends to vitrify both the LAW and high activity waste (HAW) fractions of the high-level waste at Hanford. DWPF and WVDP both use a grout or cement immobilization approach to the LAW fraction of their tank wastes. The LAW fractions produced by the three sites were not compared because the two process approaches (vitrification and cementation) are too dissimilar. Removing the LAW costs from the total, in some cases, requires prorating certain shared costs such as site services, utilities, etc. Additionally, only certain HLW management functions occurring prior to vitrification are included. Attachment 1 identifies specific HLW functions that are included and excluded for each of the three sites. 


\section{$\underline{\text { Approach }}$}

Determining which plant processes and functions to include was accomplished by using TWRS as the base site for comparison purposes. If the TWRS process configuration utilized a certain function, that function was accounted for in the DWPF and WVDP costs. Some functions, like interim storage was not included in the TWRS HAW costs. The costs of interim storage are therefore subtracted out of the DWPF and WVDP costs.

One of the more difficult tasks in normalizing the differences is determining the life expectancies of the three sites. Linked directly to life expectancy is the amount of time that construction cost can be amortized. Longer amortization periods allow large, one-time costs associated with projects of this scale to be spread out over many years thus reducing any unit cost. WVDP's actual production operations lasted less than $21 / 2$ years whereas DWPF is expected to operate for 22 years, and the TWRS Program will have an initial contract of 9 to 11 years but will be designed for 30 years.

Table 1. Analytical Results

\begin{tabular}{|c|c|c|}
\hline & $\begin{array}{c}\text { Defense Waste } \\
\text { Processing Facility }\end{array}$ & $\begin{array}{c}\text { West Valley } \\
\text { Vitrification Project }\end{array}$ \\
\hline \multicolumn{3}{|l|}{ Actual Costs for the Project } \\
\hline $1980 \$$ TPC & $\$ 1,588,761$ & $\$ 818,749$ \\
\hline $1997 \$$ TPC & $\$ 3,079,529$ & $\$ 1,586,999$ \\
\hline \multicolumn{3}{|c|}{ Projected Costs Adjusted to Constant 1980 S \& $1997 \$$} \\
\hline Nominal Projected TPC & $\$ 1,529,465$ & $\$ 470,379$ \\
\hline $1980 \$$ Projected TPC & $\$ 1,124,682$ & $\$ 331,550$ \\
\hline 1997\$ Projected TPC & $\$ 2,179,996$ & $\$ 642,650$ \\
\hline Growth in Constant $\$$ & $41 \%$ & $147 \%$ \\
\hline \multicolumn{3}{|c|}{ Accounting for Schedule Slip (Constant 1980\$) } \\
\hline \multicolumn{3}{|c|}{ Actual costs at actual 30 -year real interest rate } \\
\hline Interest Costs & $\$ 767,528$ & $\$ 308,364$ \\
\hline End of Period & $\$ 2,356,289$ & $\$ 1,127,067$ \\
\hline \multicolumn{3}{|c|}{ Projected costs at actual 30-year real interest rate } \\
\hline Interest Costs & $\$ 367,950$ & $\$ 76,671$ \\
\hline End of Period & $\$ 1,492,633$ & $\$ 408,221$ \\
\hline Growth accounting for schedule slip & $58 \%$ & $176 \%$ \\
\hline \multicolumn{3}{|l|}{ Actual costs@3.00\% real interest } \\
\hline Interest Costs & $\$ 475,480$ & $\$ 222,262$ \\
\hline End of Period & $\$ 2,064,241$ & $\$ 1,043,545$ \\
\hline \multicolumn{3}{|l|}{ Projected costs@3.00\% real interest } \\
\hline Interest Costs & $\$ 180,457$ & $\$ 39,579$ \\
\hline End of Period & $\$ 1,305,140$ & $\$ 371,129$ \\
\hline Growth accounting for schedule slip & $58 \%$ & $181 \%$ \\
\hline
\end{tabular}




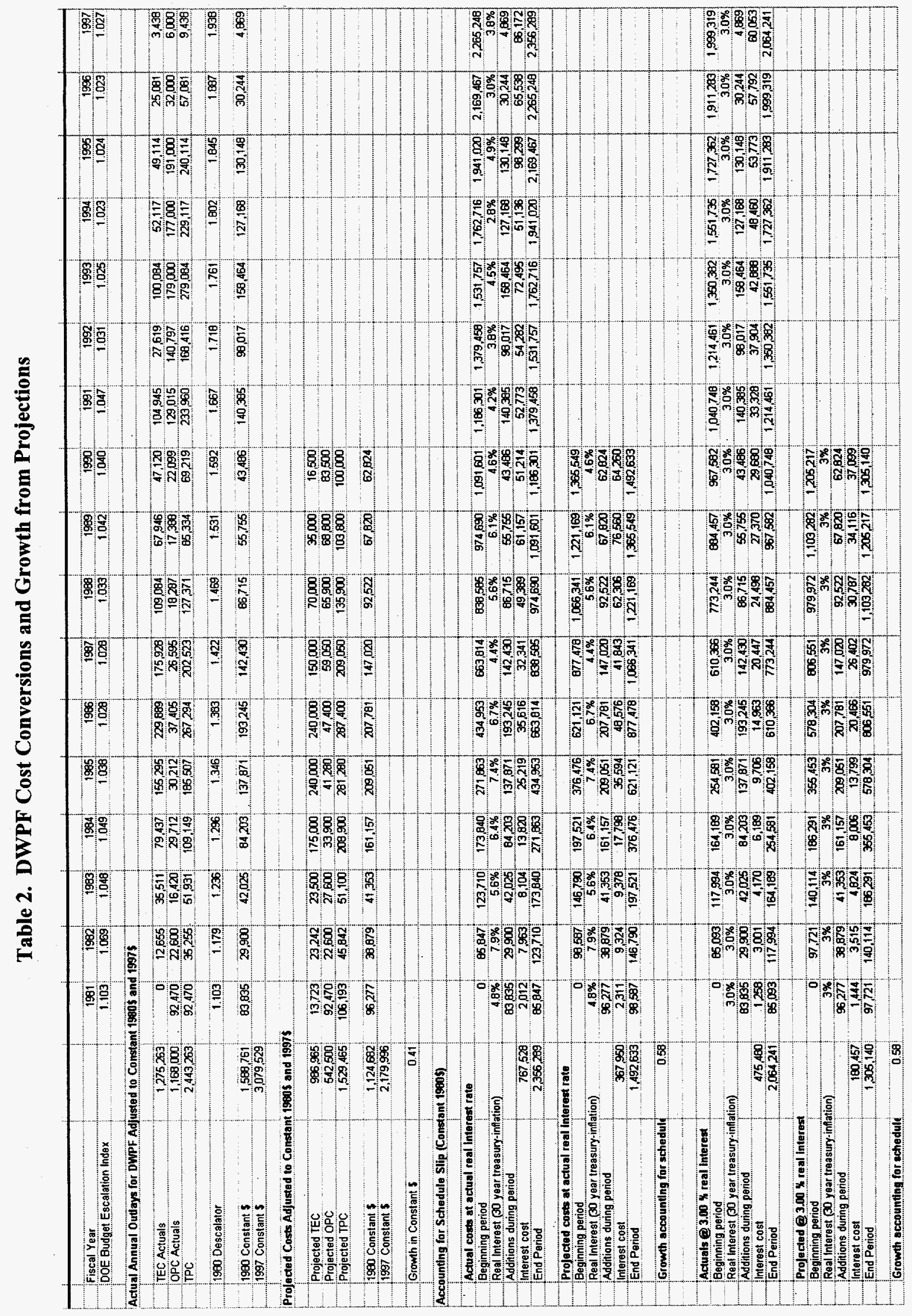




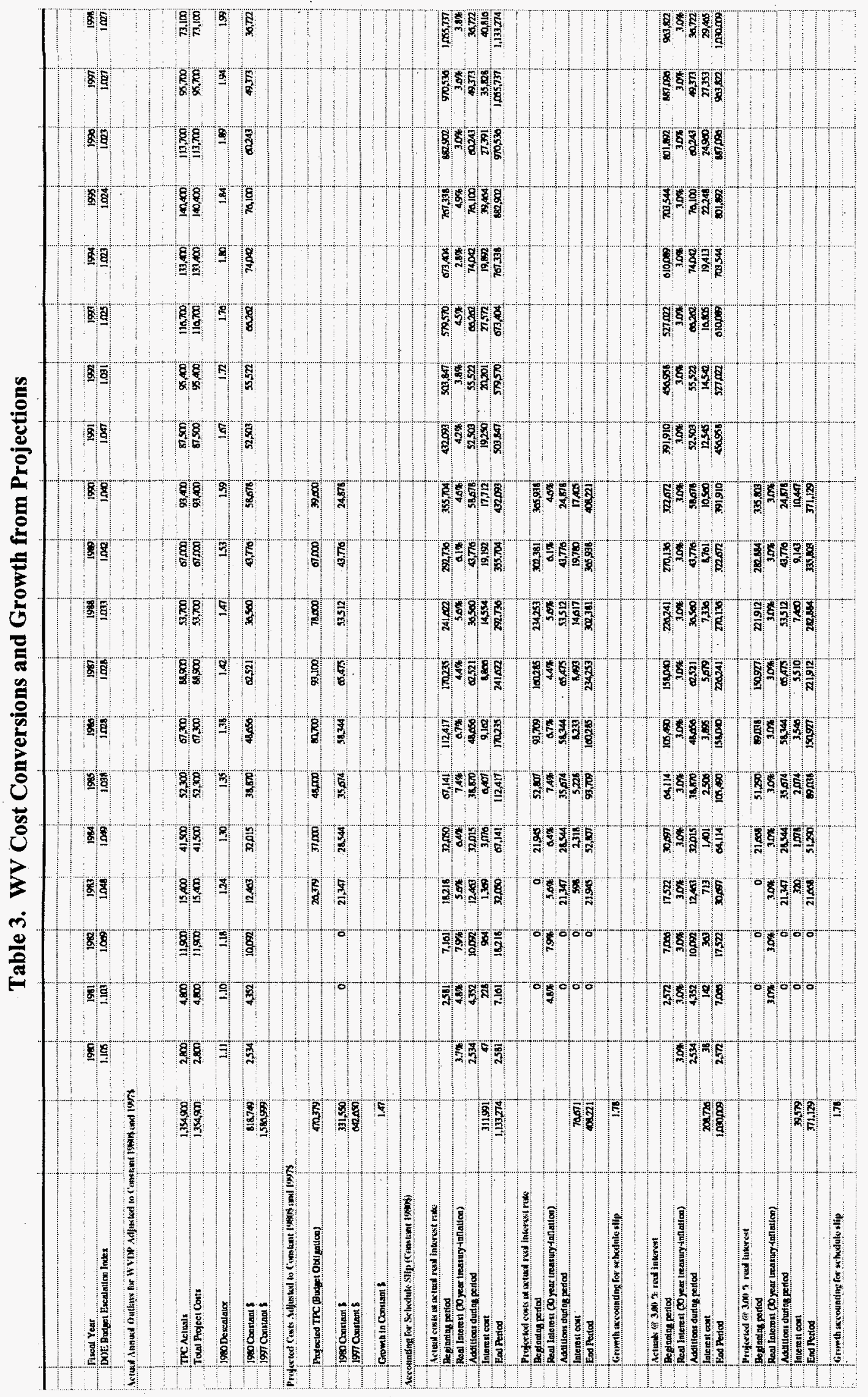

옴 
Development of costs is based on a cost per metric ton of vitrified product instead of cost per canister basis. The canisters at the three sites vary in volume, percentage of maximum filling, and waste loading. The canisters at WVDP and DWPF are comparable in overall volume but WVDP's wider neck allows for greater fill height. The TWRS canisters have a greater overall volume than both DWPF and WVDP, and the differences in waste loading (concentration of radioactive waste in the glass matrix) vary for each site. Operating costs for all three sites included waste qualification functions, portions of site services, feed materials operations and the actual vitrification operational costs. Rolled into the site services are costs for utilities, security, radiation protection and industrial safety services, low-level waste management, etc. Feed material operations included the costs of preparing and keeping materials ready for transfer to the vitrification operations. The costs for TWRS were estimated from BNFL's WBS. These costs are a best estimate based upon professional judgment and do not reflect BNFL's estimate of HLW glass making costs. BNFL's price in the contract translates to a considerably lower cost for making glass. The difference arises from BNFL not priced based upon an allocation of construction and operating costs but rather on total waste to be remediated. It is expected that BNFL will provide a better estimate prior to the end of the B-1, the Extended Development Phase.

\section{Normalized Costs}

One method to obtain costs on a comparable basis is to adjust costs for the throughput of each vitrification facility. This normalization can be based on either design capacity or on actual throughput. Because actual throughput values are known at DWPF and WVDP and are predicted for the TWRS privatized facility, it was decided to use the actual throughput values. (As noted above the throughput is expressed in terms of metric tons of glass per year.) Actual throughput for the first years of operations is included to account for startup experience. Predicted throughput is assumed for the TWRS facility. These values are as shown below:

Table 4. Vitrification Facility Throughput

\begin{tabular}{|l|c|c|c|}
\hline Vitrification Facility Throughput (MT/year) \\
\hline & DWPF & WVDP & TWRS $^{2}$ \\
\hline Avg. 10 Year Rate & 404.0 & 235.7 & 180 \\
\hline Avg. 25 Year Rate & 434.1 & 238.3 & 252.0 \\
\hline
\end{tabular}
'WVDP was designed/constructed for a shorter mission
(less than 5 years). These values are extrapolated.
${ }^{2}$ The $180 \mathrm{MT} /$ year is based on the minimum order quantity.

These throughput values are mathematically divided into annualized capital costs and annual operating costs and subsequently added to determine a cost per metric ton that takes into account differences in actual production throughput.

\section{Capital Costs}

Capital costs for DWPF and WVDP include the costs of design, construction, project management, startup testing, operational readiness, and other activities associated with major system acquisitions under the Department's project management system. Under the DOE project management system these costs are typically segregated into construction costs or Total Estimated Costs (TEC) and support costs or Other Project Costs (OPC). The annualized capital costs for DWPF and WVDP include both TEC and OPC costs. For TWRS a total capital cost, including interest on borrowed construction funds, was provided.

Two major contributors to the OPC costs are the costs for startup testing and the costs for developing a high-level waste form that will meet the performance requirements for high-level waste forms imposed by 
the Office of Civilian Radioactive Waste. At WVDP these costs included the construction and operation of a simulated nonradioactive vitrification system that operated for 5 years. At DWPF these costs included the costs of several simulated nonradioactive process systems including a pilot feed preparation system and a scale vitrification melter. Those facilities were operated more than 5 years.

To determine annualized capital costs, the total capital costs for each of the three facilities were divided by the number of years being evaluated, either 10 or 25 years.

\section{$\underline{\text { DWPF Costs }}$}

Table 4 above provides the actual production rates for each of the three facilities. The information for DWPF was obtained from actual production rates for fiscal years 1996,1997 , and is projected for fiscal year 1998, based upon the first 6 months of production. The estimated throughputs for all subsequent years are based on the Savannah River Site Draft High Level Waste System Plan, Rev. 9, which provides cost and throughput information for the completion of the SRS high-level waste program.

The capital costs for DWPF include those costs identified in the capital cost section above for the vitrification facility and the sludge processing facility to make it consistent with the TWRS costs. As the DWPF project also funded completion of certain other facilities not comparable to the activities in the TWRS cost section, these were removed. Specifically, these included:

- low-activity treatment and storage facility (Saltstone)

- vitrified canister storage facility (Glass Waste Storage Building).

As noted in the approach section, costs for high-level waste separations, waste retrieval, evaporation, etc., were also excluded from these costs.

The capital costs for DWPF in 1997 dollars are $\$ 3,063.2$ million for the vitrification facility and $\$ 53.4$ million for the extended sludge processing facility. Annualized capital costs for the 10-year and 25 -year scenarios are $\$ 311.7$ million/year and $\$ 124.7$ million/year respectively. Normalized capital costs for 10 years and 25 years are as follows:

- 10 years $-(\$ 311.7$ million/year $) /(404 \mathrm{MT} /$ year $)=\$ 0.771 \mathrm{million} / \mathrm{MT}$

- 25 years $-(\$ 124.7$ million/year $) /(434 \mathrm{MT} /$ year $)=\$ 0.287 \mathrm{million} / \mathrm{MT}$.

Annual weighted operating costs are determined by taking actual operating costs in fiscal years 1996 , 1997 , and projected operating costs for the next 8 years in the 10-year scenario and the next 23 years in the 25 -year scenario. Approximately $15 \%$ of these operating costs is for the extended sludge processing facility and $85 \%$ for the vitrification facility. Weighted operating costs for the 10 -year scenario is $\$ 157.1$ million/year and $\$ 161.7$ million for the 25-year scenario. Normalized operating costs for 10 years and 25 years are as follows:

- 10 years $-(\$ 157.1 \mathrm{million} /$ year $) /(404 \mathrm{MT} /$ year $)=\$ 0.389$ million/MT

- 25 years $-(\$ 161.7$ million/year $) /(434 \mathrm{MT} /$ year $)=\$ 0.373$ million $/ \mathrm{MT}$.

Total normalized costs per metric ton are the sums of the normalized capital and operating costs. These are provided in Table 5 below. 
Table 5. Normalized Costs for DWPF

\begin{tabular}{|l|c|c|}
\hline & 10 Year Scenario & 25 Year Scenario \\
\hline Capital Costs (\$M/MT) & 0.771 & 0.287 \\
\hline Operating Costs (\$M/MT) & 0.389 & 0.373 \\
\hline Total costs (\$M/MT) & 1.160 & 0.660 \\
\hline
\end{tabular}

\section{WVDP Costs}

The capital costs for WVDP include those costs identified in the capital cost section above for the vitrification facility and the sludge mobilization facilities to make it consistent with the TWRS costs. As the WVDP also funded completion of certain other functions not comparable to the activities in the TWRS cost section, these were removed. Specifically, these are most of the components of the Integrated Radwaste Treatment System that separated the HLW into HAW and LAW fractions and subsequently immobilized the LAW fraction. Also included in the capital costs are the waste qualification expenditures, approximately $\$ 325$ million. Most of these costs were incurred prior to or during construction of the vitrification facility.

As noted in the approach section, other costs such as waste retrieval, evaporation, etc., are also excluded from these costs.

The capital costs for WVDP in 1997 dollars are $\$ 522.07$ million for all comparable facilities related to vitrification. Annualized capital costs for the 10-year and 25-year scenarios are $\$ 52.21$ million/year and $\$ 20.88$ million/year respectively. Normalized capital costs for 10 years and 25 years are as follows:

- 10 years $-(\$ 52.21 \mathrm{million} /$ year $) /(235.7 \mathrm{MT} /$ year $)=\$ 0.221$ million $/ \mathrm{MT}$

- 25 years $-(\$ 20.88 \mathrm{million} /$ year $) /(238.3 \mathrm{MT} /$ year $)=\$ 0.088 \mathrm{million} / \mathrm{MT}$.

Annual weighted operating costs are determined to be $\$ 39.24$ million/year in constant 1997 dollars. No specific accounting of actual vitrification operating costs are readily available; however a rough order of magnitude is $\$ 30$ million/year for the vitrification facility, $\$ 2$ million for sludge mobilization and transfer facilities, and $\$ 7.24$ million/year for prorated site services. Normalized operating costs for 10 years and 25 years are as follows:

- 10 years $-(\$ 39.24$ million/year $) /(235.7 \mathrm{MT} /$ year $)=\$ 0.167$ million/MT

- 25 years $-(\$ 39.24$ million/year $) /(238.7 \mathrm{MT} /$ year $)=\$ 0.165$ million/MT.

Total normalized costs per metric ton are the sums of the normalized capital and operating costs.

These are provided in Table 6 below.

Table 6. Normalized Costs for WVDP

\begin{tabular}{|l|c|c|}
\hline & 10 Year Scenario & 25 Year Scenario \\
\hline Capital Costs (\$M/MT) & 0.221 & 0.088 \\
\hline Operating Costs (\$M/MT) & 0.167 & 0.165 \\
\hline Total costs (\$M/MT) & 0.388 & 0.253 \\
\hline
\end{tabular}




\section{WVDP Alternative Case Costs}

Evaluating the unit costs for WVDP using 10- and 25-year production runs does not appear to be as meaningful for comparative purposes as using WVDP's actual production time (2 1/4 years, the base case) and its intended design operational period (5 years). WVDP initially had only one HLW tank full of waste, therefore, its vitrification facility production life is shorter. Its design-life is primarily limited by the life of the melter. Although the melter could be replaced, the facility was not designed and constructed for melter replacement as part of the HLW process campaign.

For these scenarios, the average annual throughput is also reduced somewhat, since they are more affected by the startup experience; however, the difference is not significant. In the base case the average throughput is $220.8 \mathrm{MT} /$ year and in the 5-year scenario it is $231.4 \mathrm{MT} /$ year.

As noted above the WVDP capital costs are $\$ 522.07$ million. The annualized capital costs for the base case and the 5-year scenario are \$232.0 million/year and \$104.4 million/year respectively. Normalized capital costs for the base case and 5-year scenarios are as follows:

Base case - $(\$ 232.0 \mathrm{million} /$ year $) /(220.8 \mathrm{MT} / \mathrm{year})=\$ 1.051 \mathrm{million} / \mathrm{MT}$

5-year scenario - (\$104.4 million/year)/(231.4 MT/year) $=\$ 0.451$ million/MT.

The annual weighted operating costs for these two cases are determined above as $\$ 39.24$ million/year. (This number does not change with differing durations as it is an estimate.) The normalized operating costs for the base case and 5-year scenarios are as follows:

Base case - $(\$ 39.24$ million/year $) /(220.8 \mathrm{MT} /$ year $)=\$ 0.177$ million $/ \mathrm{MT}$

5 -year scenario $-(\$ 39.24$ million/year $) /(231.4 \mathrm{MT} /$ year $)=\$ 0.170 \mathrm{million} / \mathrm{MT}$.

Total normalized costs per metric ton are the sums of the normalized capital and operating costs. These are provided in Table 7 below:

Table 7. Normalized Costs for WVDP (Alternative Comparison)

\begin{tabular}{|l|c|c|}
\hline & Base Case Scenario & S Year Scenario \\
\hline Capital Costs (\$M/MT) & 1.051 & 0.451 \\
\hline Operating Costs (\$M/MT) & 0.177 & 0.170 \\
\hline Total costs (\$M/MT) & 1.228 & 0.621 \\
\hline
\end{tabular}

\section{$\underline{\text { TWRS Costs }}$}

The TWRS capital and operating costs were derived from information provided by BNFL and do not represent what BNFL may charge for the HLW service. The costs were extracted from their WBS and the costs of finance were added. 
The assumed capital costs for TWRS in 1997 dollars are $\$ 1,254$ million for the vitrification and sludge preparation facilities and cost of capital. Annualized capital costs for the 10-year and 25-year scenarios are $\$ 125$ million/year and $\$ 50$ million/year respectively. These annualized capital costs divided by the throughputs gives the normalized capital costs during the contract period years and 25 years as follows:

- 10 years $-(\$ 125.4 \mathrm{million} /$ year $) /(180 \mathrm{MT} /$ year $)=\$ 0.696 \mathrm{million} / \mathrm{MT}$

- 25 years $-(50.2$ million/year $) /(252 \mathrm{MT} /$ year $)=\$ 0.199$ million $/ \mathrm{MT}$.

Weighted annual operating costs for the 10-year scenario is $\$ 36.9$ million/year and is $\$ 35.3$ million for the 25 -year scenario. This difference exists because predicted operations costs during the first 4.5 years of operation are about $\$ 62$ million/year. Operating costs are projected to decrease to $\$ 27$ million after the initial 4.5 year startup period. Normalized operating costs for 10 years and 25 years are as follows:

- 10 years $-(\$ 36.9$ million/year $) /(180 \mathrm{MT} /$ year $)=\$ 0.205$ million $/ \mathrm{MT}$

- 25 years $-(\$ 35.3$ million/year $) /(252 \mathrm{MT} /$ year $)=\$ 0.140$ million $/ \mathrm{MT}$.

Total normalized costs per metric ton are the sums of the normalized capital and operating costs. These are provided in Table 8 below.

Table 8. Normalized Costs for TWRS

\begin{tabular}{|l|c|c|}
\hline & 10 Year Scenario & 25 Year Scenario \\
\hline Capital Costs (\$M/MT) & .696 & .199 \\
\hline Operating Costs (\$M/MT) & .205 & .140 \\
\hline Total costs (\$M/MT) & 0.901 & 0.338 \\
\hline
\end{tabular}

\section{Conclusion}

Table 9 summarizes each of the costs for the three vitrification programs at the West Valley Demonstration Project (WVDP), the Savannah River Site (DWPF), and Hanford (TWRS) for 10 and 25 year operational periods. These costs have been normalized for actual or, in the case of TWRS and DWPF, projected throughputs of the vitrification facilities. Because the WVDP facility used existing facilities to the maximum extent feasible, some efficiencies are realized in their capital costs. Also the shorter duration of the mission program facilitated savings in certain areas (e.g., facilities for melter changeout). Consequently, the cost comparisons for WVDP for the 10-year and 25-year scenarios are not as meaningful. 
Table 9. Normalized HLW Vitrification Program Costs (\$M/MT)

\begin{tabular}{|c|c|c|c|}
\hline Scenario & WVDP & DWPF & TWRS \\
\hline 10 years & & & 0.696 \\
\hline Capital Costs & 0.221 & 0.771 & 0.205 \\
\hline Operating Costs & 0.167 & 0.389 & $\mathbf{0 . 9 0 1}$ \\
\hline 10 Year TOTAL & $\mathbf{0 . 3 8 8}$ & $\mathbf{1 . 1 6 0}$ & 0.199 \\
\hline 25 Years Capital Costs & 0.088 & & 0.140 \\
\hline Operating Costs & 0.165 & 0.287 & $\mathbf{0 . 3 3 8}$ \\
\hline 25 Year TOTAL & $\mathbf{0 . 2 5 3}$ & 0.373 & Not applicable \\
\hline WVDP Base & & $\mathbf{0 . 6 6 0}$ & \\
\hline Capital Costs & 1.051 & Not applicable & \\
\hline Operating Costs & 0.177 & & Not applicable \\
\hline Base TOTAL & $\mathbf{1 . 2 2 8}$ & & \\
\hline WVDP 5 years & & Not applicable & \\
\hline Capital Costs & 0.451 & & \\
\hline Operating Costs & 0.170 & & \\
\hline
\end{tabular}

\section{Conclusions}

\section{Increases in Actual Real versus Projected Costs}

The initial projected project cost and the actual costs of the project were higher for both DVPF and WVDP by $41 \%$ and $147 \%$, respectively, in real dollars. Three items contributed to these higher costs. Slips in the construction schedule, the addition of work scope beyond that originally envisioned at the time the projected cost estimates were initially derived, and inflation.

\section{Schedule Slippage}

A number of factors can result in schedule slippage including inadequate or delays in Congressional funding for the project, regulatory or licensing delays, changes in environmental laws and regulations, etc. While it is difficult to delineate and cost for any one specific item, one can estimate the overall costs of the delays for each project. Work scope changes, while not specifically delineated in the cost estimates, add to the overall project costs and contribute to schedule slippage.

Comparing projected versus actual costs and using the 30-year Treasury real interest rate, shows growth in the projects' costs (capital and interest finance costs) increased by $58 \%$ and $176 \%$ for DWPF and WVDP, respectively as a result of the slips in the construction schedule. Employing the 3\% real interest rate results in a cost increase of a similar amount of 58\% (DWPF) and 181\% (WVDP). Both had additions to work scope over the projects' construction period amounting to approximately $10 \%$ of total costs (nominal dollars).

\section{Costs Per Metric Ton of Treated Waste}

The average costs per metric ton of treated waste for the mission life of the three facilities ranges from a high of $\$ 1.228$ million per metric ton of glass for WVDP to $\$ 660,000$ for DWPF and $\$ 338,000$ for BNFL. 
The costs for West Valley and Savannah River have not been adjusted for the government's cost of capital. The cost comparisons reflect only the constant dollar comparison that DOE will pay.

If BNFL's costs included only the contract period, these costs would rise to approximately $\$ 900,000$ per metric ton of glass. BNFL's costs have not been adjusted for the Federal taxes that would be paid on profits earned, nor have the DWPF and WVDP costs been adjusted for the government cost of money.

\section{Acknowledgments}

A number of people were instrumental in getting data, answering questions, and generally being extremely helpful in pulling the information together on WVDP and DWPF. For WVDP, the authors would like to thank Richard Humphrey and Joel Wagner (Westinghouse). For DWPF, special thanks go to Soni Blanco (DOE, SR) who pulled together a lot of cost information from historical records. In addition, John W. Geiger and Frederick Schultz, Jr. (DOE, SR) were extremely helpful in answering questions and providing data on the pre-1990 stages of DWPF. For HWVP Dee Willis (RL budget), Forest Day (Fluor Daniel, RL, Senior Cost Estimator), Connie Ritter (Lockheed Martin, RL, Project Cost Analysis), and Jack Donnelley (Fluor Daniel, Irvine, California, Principal Estimator) were extremely helpful. On Fernald special thanks goes to Nina Akgunduz (Budget Office at Fernald) who pulled together a tremendous amount of information on the Fernald project for our use. Finally special thanks to Martin Newdorf (FM-20, DOE Headquarters) and his staff for finding and pulling the PDSs, providing escalation indices, and answering numerous questions on DWPF and WVDP. 


\section{Attachment 1. Guidelines for WVDP and DWPF Cost Studies to Support TWRS Privatization Evaluation}

\section{$\underline{\text { ASSUMPTIONS }}$}

Listed below is my understanding of the assumptions that would guide costs of glass at DWPF and WVDP:

- Costs for vitrification facilities at WVDP and DWPF can only be realistically compared to HAW vitrification plant costs and not LAW vitrification plants because of the following characteristics of DWPF and WVDP:

- Extensive waste acceptance development process (strict QA requirements, rigorous process control, extensive testing to develop adequate glass recipes)

- Canyon-style operations requiring remote maintenance (DWPF does have the capability for some hand-on maintenance, but it's an extra cell in the facility) because of source term

- Safety-class components in certain DWPF systems and components, and similar grade of systems at WVDP due to hazards.

If DWPF/WVDP costs are compared to LAW plant, adjustment factors need to be developed and applied to DWPF and WVDP costs.

- Comparing costs of LAW streams at SRS and WVDP are not comparable to Hanford LAW stream, because of different waste forms (grout vs. glass).

- Costs should be developed on a basis of unit mass (e.g., metric ton or $\mathrm{kg}$ ) to account for differences in waste loading at different plants and to avoid concerns about different fill heights.

- Capital costs are amortized over the operating life of the facility to complete its mission:

- DWPF - baseline scenario in Rev. 9 of HLW System Plan (i.e., 5084 canisters at 250 canisters/year and completing vitrification in 2017)

- WVDP - assume production campaign ends at end of Phase I, so duration is about 2.25 years and total glass mass is that in 260 canisters.

- Tank closure and facility D\&D costs are not included in DWPF and WVDP costs.

- Separations part of HLW pretreatment are not included in pretreatment costs. Only sludge washing costs are included.

- Escalation factors are from OMB used for congressional budget submittals. All costs are to be escalated, or de-escalated to FY1997 dollars. 


\section{$\underline{\text { Interfaces }}$}

For equivalent comparisons with Richland HLW privatization treatment services the following interfaces or services are included in DWPF and WVDP costs:

- Certain utilities

- raw water

- potable water

- electrical power

- HLW canister transfer costs from vitrification building/cell to storage facility

- HLW feed tanks

- Tanks 42 and 51 for DWPF

- Tank 8D-2 for WVDP

- HLW sampling

- Liquid sanitary wastes

- Air emissions (offgas and monitoring equipment).

\begin{tabular}{|c|c|c|c|c|}
\hline \multirow[t]{2}{*}{ FUNCTION } & \multicolumn{2}{|c|}{$\overline{\text { DWPF }}$} & \multicolumn{2}{|c|}{ WVDP } \\
\hline & Included & Excluded & Included & Excluded \\
\hline Vitrification & $\begin{array}{l}\text { - Construction and } \\
\text { operation of } \\
\text { vitrification } \\
\text { facilities (TPC for } \\
\text { DWPF) } \\
\text { - Product } \\
\text { development and } \\
\text { testing } \\
\text { - Cost of transporting } \\
\text { canisters to GWSB, } \\
\text { i.e., SCT } \\
\text { procurement and } \\
\text { operation } \\
\text { - Laboratory support } \\
\text { - Electrical power, } \\
\text { steam, water, etc. }\end{array}$ & $\begin{array}{l}\text { - Construction and } \\
\text { operation of GWSB } \\
\text { - Construction and } \\
\text { operation of saltstone } \\
\text { - DWPF waste-water } \\
\text { treatment facility } \\
\text { - Construction and } \\
\text { operation of Late } \\
\text { Wash facility }\end{array}$ & $\begin{array}{l}\text { - Construction and } \\
\text { operation of vitrification } \\
\text { facility, including } \\
\text { design and engineering } \\
\text { - Site services pro-rated } \\
\text { to vitrification facility } \\
\text { (electrical, sanitary, } \\
\text { water, etc.) } \\
\text { - Product development } \\
\text { and testing, e.g., } \\
\text { FACTS } \\
\text { - Operating costs to } \\
\text { transport canisters to } \\
\text { CPC }\end{array}$ & $\begin{array}{l}\text { - Costs of procuring } \\
\text { and installing storage } \\
\text { racks in CPC } \\
\text { - Remainder of WVDP } \\
\text { Phase I not associated } \\
\text { with vitrification } \\
\text { except: } \\
\text { - some TPC } \\
\text { associated with vit. } \\
\text { Facility construction } \\
\text { and startup } \\
\text { - Individual functions } \\
\text { below }\end{array}$ \\
\hline $\begin{array}{l}\text { Sludge } \\
\text { Pretreatment }\end{array}$ & $\begin{array}{l}\text { - Construction and } \\
\text { Operation of ESP }\end{array}$ & $\begin{array}{l}\text { - Construction and } \\
\text { operation of } \\
\text { ITP/replacement }\end{array}$ & $\begin{array}{l}\text { - Construction and } \\
\text { operation of sludge } \\
\text { washing portion of STS }\end{array}$ & $\begin{array}{l}\text { Construction and } \\
\text { operation of LWTS } \\
\text { and CSS and } \\
\text { remaining portion } \\
\text { of STS }\end{array}$ \\
\hline HAW staging & $\begin{array}{l}\text { - Included in ESP } \\
\text { costs }\end{array}$ & $\begin{array}{l}\text { - Construction and } \\
\text { operation of pump } \\
\text { pits/diversion boxes, } \\
\text { e.g., DB-8 }\end{array}$ & $\begin{array}{l}-50 \% \text { of } 8 D-2 \text { operations } \\
\text { costs not included in } \\
\text { STS operating costs }\end{array}$ & $\begin{array}{l}\text { Operations costs for } \\
\text { 8D-2 that is not part } \\
\text { of STS, if separable }\end{array}$ \\
\hline $\begin{array}{l}\text { Tank Farm } \\
\text { Operations }\end{array}$ & None & $\begin{array}{l}\text { 2F, } 2 \mathrm{H} \text { and } \mathrm{RHLW} \\
\text { evaporator } \\
\text { construction and } \\
\text { operations } \\
\text { - ETF }\end{array}$ & None & $\begin{array}{l}\text { Remainder of tank farm } \\
\text { operations not covered } \\
\text { in other activities above }\end{array}$ \\
\hline
\end{tabular}




\begin{tabular}{|l|l|l|l|l|}
\hline & & $\begin{array}{l}- \text { Remainder of tank } \\
\text { farm operations } \\
\text { including upgrades }\end{array}$ & & \\
\hline LAW processing & None & $\begin{array}{l}\text { Construction and } \\
\text { operation of: } \\
-\begin{array}{l}\text { Saltstone processing } \\
\text { facility } \\
- \text { Saltstone vaults }\end{array}\end{array}$ & None & $\begin{array}{l}\text { Construction and } \\
\text { operation of: } \\
\text { Cement } \\
\text { Solidification } \\
\text { System }\end{array}$ \\
\hline Waste Retrieval & None & $\begin{array}{l}\text { Waste Removal project } \\
\text { activities }\end{array}$ & $\begin{array}{l}\text { Construction and } \\
\text { operation of transfer } \\
\text { facilities from 8D-2 to } \\
\text { CFMT }\end{array}$ & $\begin{array}{l}\text { Transfer facilities for } \\
\text { transferring waste from } \\
\text { 8D-1 to 8D-2 }\end{array}$ \\
\hline $\begin{array}{l}\text { D\&D and } \\
\text { Facility Closure }\end{array}$ & None & $\begin{array}{l}\text { Nank closure } \\
\text { D\&D of HLW } \\
\text { storage and treatment } \\
\text { facilities }\end{array}$ & None & $\begin{array}{l}- \text { Tank closure } \\
\text { D\&D of HLW } \\
\text { storage and } \\
\text { treatment facilities }\end{array}$ \\
\hline
\end{tabular}

\begin{tabular}{|c|c|c|}
\hline \multirow[t]{2}{*}{ FUNCTION } & \multicolumn{2}{|c|}{ BNFL } \\
\hline & Included & Excluded \\
\hline Vitrification & $\begin{array}{l}\text { - Construction and operation of } \\
\text { vitrification facilities } \\
\text { - Product development and } \\
\text { testing } \\
\text { - Cost of transporter (operating } \\
\text { costs unknown) } \\
\text { - Laboratory support } \\
\text { - Electrical power, water, roads, } \\
\text { piping, etc. }\end{array}$ & $\begin{array}{l}\text { - Construction and operation } \\
\text { of LAW and Pretreatment } \\
\text { Facilities }\end{array}$ \\
\hline Sludge Pretreatment & $\begin{array}{l}\text { - Enhanced sludge washing } \\
\text { equipment }\end{array}$ & $\begin{array}{l}\text { - All pretreatment not included } \\
\text { in enhanced sludge washing }\end{array}$ \\
\hline HAW staging & $\begin{array}{l}\text { - PHMC training costs for BNFL } \\
\text { personnel on tank operations }\end{array}$ & - PHMC operating costs \\
\hline Tank Farm Operations & None & - All tank farm operations \\
\hline LAW processing & None & $\begin{array}{l}\text { - All LAW construction and } \\
\text { operations }\end{array}$ \\
\hline Waste Retrieval & $\begin{array}{l}\text { - Retrieval from tank provided to } \\
\text { BNFL }\end{array}$ & - PHMC costs for retrieval \\
\hline$\overline{\mathrm{D} \& \mathrm{D} \text { and Facility Closure }}$ & - Deactivation & $\begin{array}{l}\text { - Tank closure } \\
\text { - D\&D of HLW storage and } \\
\text { treatment facilities }\end{array}$ \\
\hline
\end{tabular}




\section{BNFL ASSUMPTIONS}

\section{Operating Costs}

- Intitial startup period operating costs

- 4.5 years duration

- $\$ 284$ million total for 4.5 year period

- Average annual operating costs over startup period

- $\quad(284 / 4.5)=\$ 63.11$ million per year

- Average annual operating costs after initial 4.5 year startup period

- $\quad \$ 27$ million

\section{HAW Glass Production}

- First 4.5 years

- 243 metric tons (MT)/year@ 25\% waste oxide loading

- Total of $972 \mathrm{MT}$ for the 4.5 year period

- After first 4.5 years

- $260 \mathrm{MT}$ of glass/year

\section{Capital Costs}

- Capital costs to be annualized

- $\$ 1,254$ million (includes construction and investment recovery costs). 


\title{
Appendix F
}

\section{Price Reasonableness and Cost Savings Risk Allocation Modeling and Analysis}

\author{
Mark A. Robershotte \\ Peter D. McLaughlin
}

Prepared for

the U.S. Department of Energy

Under Contract DE-AC06-76RLO 1830

Pacific Northwest National Laboratory

Richland, Washington 99352

Caveat: This appendix reflects the state of the risk allocation analysis as of late February 1998. Definitions, descriptions and other input values were revised subsequently. The final analysis is described in McLaughlin et al. Analysis of the Risk Allocation for TWRS Privatization Phase IB, PNNL-12028, October 1998. 


\section{Price Reasonableness and Cost Savings Risk Allocation Modeling and Analysis}

Summary Conclusion The general results from the risk allocation modeling and analysis effort confirm that an extended development period, prior to determining the final firm fixed prices for waste processing services, is beneficial to DOE. The results further indicate that an optimal allocation of risk would consist of considerable risk sharing, a significant equity stake by the contractor (BNFL), and some mix of public and private financing. Earlier study results, still believed to be valid, also indicate that if a pure M\&O contractor did the Phase I TWRS Privatization scope of work, costs would be about $25 \%$ higher and have significantly more variability than proceeding with the modified privatization approach consisting of appropriate and efficient risk allocation. This confirms significant cost savings over other possible allocations of risk.

Introduction One important tool to support the price reasonableness and cost savings determination is risk allocation modeling and its supporting analysis. The risk allocation and modeling decision support tool is used both to analyze contractual risk allocation strategy options and to provide another method to evaluate the price reasonableness of the contractor's proposals. The objective of the examination of the contractual risk allocation options is to help procurement decision-makers achieve minimum total project costs. By examining the risk profile allocated to the contractor in any particular strategy, the risk allocation model, working in conjunction with the financial model, determines the minimum price the contractor must have to meet various reasonable required financial parameters. The following discussion briefly summarizes the risk allocation concept, the model, the risks studied, the analysis results, and conclusions.

The Concept The risk allocation theoretical background combines elements of finance, game theory, decision and risk analysis, and negotiation analysis. The concept underlying risk allocation stems from an economic argument based on contracts between two parties. The party that pays for the services is known as the principal (the government in the TWRS scenario) and the party who performs the services for payment is the agent (the contractor). For a given contract, each party will do what is in its self-interest for that contract. Both parties are expected utility "maximizers." The actions each party takes can be anticipated and are rolled into each party's subjective estimates of the probability distribution over its cash flow, that is, its risk profile. The contractor has financial requirements based on its risk profile and these financial requirements are determined by the realities of the capital markets. The contractor must obtain financing and the payments for the project must be sufficient to provide returns that cover the financing costs corresponding to the risks of the project. Thus, for a given contract to be feasible, the government must pay for risks it does not accept. From the contractor's perspective, there is an efficient frontier of feasible contracts encompassing a variety of payments and risk profiles, and the government should strive for the point on this frontier that maximizes its expected utility (usually lowest total cost).

A large principal, such as the government, is likely to have greater risk tolerance than the contractor. When the government allocates risk to a contractor, the contractor will be more efficient if he has significant control over the outcome, but will also require a greater risk premium to the extent that these risks are not under his control. If the government also has some control over a risk, it can signal its willingness to prevent or mitigate the risk by bearing some of it, which should improve the risk profile as perceived by the contractor.

The Model The objective of the risk allocation and modeling effort is twofold: 1) to estimate the effect of selected major risks on Phase I bids and DOE costs for various risk allocations between the contractor and DOE and 2) to develop an analytic framework within which the effects of risk on DOE costs and the effects of incentives in allocation are evaluated and compared. The model itself, developed by Argonne 
National Laboratory, is an Excel spreadsheet-based Monte Carlo simulation that utilizes the commercially available@ Risk software. The risk allocation model runs interactively with the financial risk model developed by Scully Capital Inc. and PNNL.

The process for using the model includes describing the risks involved in a contract, and then developing several alternatives for allocating each risk. For each risk and alternative allocation, referred to as a case or a scenario, users describe the likely mitigation and prevention measures to be taken by each party. Based on these narratives, subjective probability distributions are defined over the financial impact of each risk to each party. The subjective probability distributions are based on internal expert judgments. Features of the model include an interaction filter to deal with risk independence and dependency issues, templates to aid in the modeling of similar risk types, and a detailed contractor response function, based on financial advisor (Scully Capital) input. Once a scenario is defined, risks have been quantified, and a Monte Carlo simulation has been performed for each risk, users can evaluate specific possible allocations of those risks in terms of the net payment and risk profile they will face. Before or after this step, the optimization feature can be used to find the lowest total cost set of allocations. This optimization can be either unconstrained over all risks, or run with some of the risks set at pre-selected allocations for specific what-if analysis and faster performance.

As currently designed, the Risk Allocation Model is used to screen proposed contractual risk allocations and to develop a preferred risk allocation position based on the best available information. Hypothetical screening and allocation options are shown in Figure 1 in a theoretical total risk allocation cost curve for a complex technical activity such as TWRS.

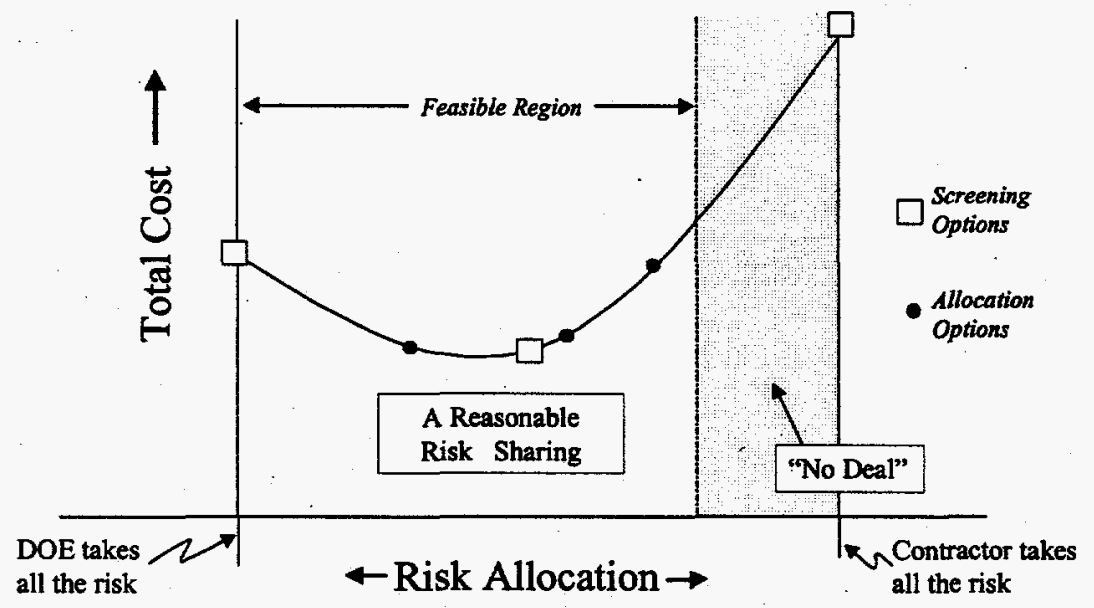

Figure 1. Theoretical Total Risk Allocation Curve

In the screening case, the model can be used to determine how the expected costs might compare if specific risks were allocated primarily to DOE, as in a more "M\&O like" contract, or primarily to the contractor, as in a simple or pure form of privatization, or to points between. These contrasts can be used to determine allocations which would be nonviable (either unfinanceable or deal-breakers) and to locate the boundaries of the feasible region. This process can also be used to determine which individual risks most significantly affect program costs so that the analysis can be focused on those risks that make the most difference. 
To determine a preferred position or strategy, specific hybrid allocations are described and represented in the model. The model processes them in conjunction with the finance model to determine if the allocation strategy could be financed. The intent here often is to demonstrate that a particular allocation could not, or should not, be proposed or accepted in the negotiations or, conversely, that the position has some merit that should be considered. Comparisons of these specified strategies to other alternatives can provide further insight into the desirability of the specified risk allocation.

In using the risk allocation model to develop a position, the most cost significant risks are identified and three allocations of those risks (between DOE and the contractor) are described for each. These allocations include a case where DOE takes as much of the risk as practical (DOE bears), one where the contractor does the same (contractor bears), and one case that represents a logical point between the previous two (shared). In this process, the intent is to determine points that describe reasonable and logically defendable risk positions that reflect the full range of risk allocation potential (the give and take available to the negotiators). Each of these points must have some obvious merit such that implementation could be expected under some reasonable circumstances. Special care is taken not to predetermine the results by only describing cases sure to produce a certain expected or desired outcome. The cases described do not necessarily represent posited negotiation positions, but rather describe the range of viable positions available to both parties to the contract.

The "Maximum DOE Risk Case" generally refers to the greatest acceptance of a single or aggregate risk that DOE or the Federal government could reasonably be expected to consider, without immediately dismissing it as "out of bounds." This must consider the fundamentals of the privatization program, the congressional budget process, and the political environment.

The "Maximum Contractor Risk Case" similarly refers to the greatest acceptance of risk that could be financed and still meet corporate criteria for investment. This point must consider corporate profit motivation, trust and confidence between industry and government, the expected value nature of risk costs, and the financial community's typically conservative approach to uncertainty.

The "Shared Risk Case" refers to a position between them, judged to be clearly different from each of those extremes, but apparently viable from either perspective. This point is not necessarily at or near the midpoint between the extremes described above, but represents the most likely case for shared risk based on the available information.

Risk can be viewed as an investment opportunity that a contractor might buy if the price were right. Therefore the contractor can be expected to have studied the situation well enough to project an expected cost and have added to that cost a risk premium as a contingency for the uncertainty. For many reasons, that arrangement may be attractive to DOE, especially in the cases where DOE is less capable of managing the risk or where responsibility for the risk may create an important incentive for the contractor to improve performance.

The model data have been developed from limited discussions with WDD/WIT staff familiar with the dominant issues, and the specific values are the best available estimates from the staff resources available to this project. A great deal of uncertainty concerning specific parameters, such as risk probabilities, costs, and cost distributions, is known to exist. These input data include consideration of some risk allocation phenomena which can be very abstract, such as incentives to perform and prevention/mitigation actions, and expresses them in the form of discrete costs, cost distributions, and probabilities. While no assumptions are made about the degree of precision achieved, these estimates are believed to represent reasonable portrayals of the key parameters of the model. In spite of the limitations of the process, it is believed that the resulting output provides valuable insight into how risk allocation can be expected to influence expected program costs and the variability of those costs. The results have been examined to 
ensure that they are intuitively logical at each step in the process and are the result of systematically developed input data. While the values may not precisely represent the bottom line costs, the relative magnitudes of costs among alternatives should be sufficiently accurate to determine the best risk allocation strategy from among the options modeled.

The Risks Modeled During the RFP process in early 1996, twelve risks were studied as part of the early initial study on risk allocation for the new TWRS Privatization contracting strategy. Through this process and interactions with prospective vendors it was learned that some of these risks, e.g., uncontrollable circumstances and changes in law, must stay with DOE if the contractors are to obtain private financing. Based on this experience, the criteria chosen for the inclusion of risks in the current risk allocation study were that risks had to be both significant, in terms of cost impact, and negotiable, as to the most efficient allocation. To focus limited time and resources where it counted most, risks that were significant but had to be allocated to either the government or to the contractor were not chosen for further study. Similarly, risks for which the allocation choice was not clear but whose risk allocation cost consequences were determined to be minimal by preliminary screening, were not included.

The BNFL "Enhanced Case" proposal was selected to be the starting point for the study. This case was chosen because it was the most challenging to model. This construct included complicated incentives and tradeoffs. Five major risks were chosen for detailed characterization, study, and analysis. These risks were inflation, interest rate, permitting, extended development period (proceeding into Part B with firm fixed prices to be set only after successful completion of $30 \%$ design and readiness for financial closure), and performance "cap" risk (amount of equity at risk).

Analysis Results The primary measures of effectiveness are total DOE cost (either "expected," $80^{\text {th }}$ percentile, or $95^{\text {th }}$ percentile) and a measure of the variability in total DOE cost expressed as the standard deviation. A secondary, and less important, measure of effectiveness is the total DOE payments to the contractor.

Of the five risks modeled, the most significant was the extended project development period, which consisted of a 20 to 24 month period prior to the setting of the firm fixed prices for waste processing services. This period provides time for better project definition, completion to approximately a $30 \%$ level of design and completion of all activities in preparation for financial closure. In fact, this risk alone involves more cost than the total of the other four risks included in the risk allocation study. Allowing this extended project development period lowers total expected project costs to DOE by about $20 \%$ compared to the case where DOE demands a firm fixed price now.

The inflation, permitting, and performance cap risks were also significant. Modeling and analysis results indicate that a more broad based inflation adjustment formula such as including both the Employment Cost Index (ECI) and the Producer Price Index (PPI) in the adjustment formula lowers costs some 1.6\%. Results confirmed that sharing the permitting risk is optimal. Cost would increase by $4 \%$ if allocated more to DOE or $6 \%$ if allocated more to the contractor. Reallocating the performance cap risk from the contractor (no cap, all risk to contractor) to shared reduced total costs by $1.1 \%$. However, results also showed that some significant equity stake by the contractor is required for an optimal allocation. A contractor equity stake of about $\$ 750$ million appears best.

The interest rate risk proved to be the least significant of the five risks modeled and analyzed in detail. Whether this risk was kept with the contractor, shared, or taken by DOE made very little impact on total project costs.

The preferred risk allocation, based on the results of this analysis, is shown in Table 1. 
Table 1. Preferred risk allocation for the BNFL Enhanced Case

\begin{tabular}{|c|c|c|}
\hline Risk & Allocation & Description \\
\hline Inflation & Shared & $\begin{array}{l}\text { Payments are fully indexed to Employment Cost Index (ECI) and to Producer } \\
\text { Price Index (PPI). Prices could drop if inflation is lower than current } 2 \% \text {. }\end{array}$ \\
\hline Interest Rate & $\begin{array}{l}\text { Contractor } \\
\text { or Shared }\end{array}$ & $\begin{array}{l}\text { Contractor either takes or shares risk with DOE. If shared, benefits (rate } \\
\text { decreases) and costs (rate increases) are apportioned equally. }\end{array}$ \\
\hline Permitting & Shared & $\begin{array}{l}\text { Following issuance of the Draft Permit and Notices of Construction, DOE and } \\
\text { the private contractor work together to secure the final permits. Issues are } \\
\text { handled by the most appropriate party or both on a good faith basis. Costs are } \\
\text { borne by DOE if failure through no fault of the private contractor. Private } \\
\text { contractor is made whole if permits are denied following a good faith effort } \\
\text { and the problems are not the fault of the contractor. }\end{array}$ \\
\hline $\begin{array}{l}\text { Extended } \\
\text { Development } \\
\text { Period }\end{array}$ & Shared & $\begin{array}{l}\text { The contractor develops a target price for part B-1, preferably with a ceiling } \\
\text { price, and is permitted to establish the final fixed price just prior to financial } \\
\text { closure. In the event of technical problems during conceptual design, DOE } \\
\text { will make the contractor whole. Price redetermination clause should be } \\
\text { considered. }\end{array}$ \\
\hline $\begin{array}{l}\text { Performance } \\
\text { Cap. }\end{array}$ & Shared & $\begin{array}{l}\text { In the event of technical performance failure, the contractor pays the first } \\
\$ 750 \text { million and efficacy insurance covers any additional costs up to the next } \\
\$ 100 \text { million. DOE pays all costs that exceed } \$ 850 \text { million. }\end{array}$ \\
\hline
\end{tabular}

The plot of representative risk allocation cases on a total DOE cost curve, Figure 2, shows that the curve is fairly flat in the allocation region explored.

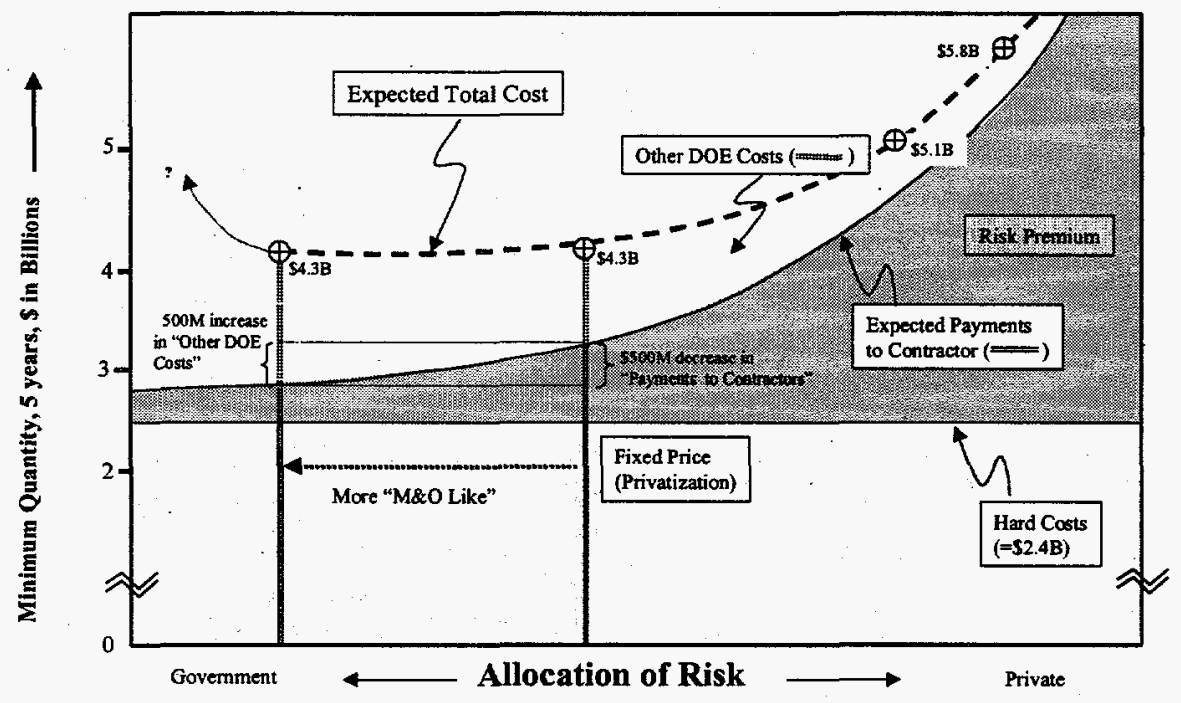

Figure 2. DOE Cost Curve

Results are fairly insensitive, in terms of total cost, to modest changes in risk allocation. However, as more risk is assumed by DOE, the uncertainty band broadens, as should be expected. Although "Expected Total Costs" may be nearly the same, the variability in terms of the standard deviation increases from $\$ 607$ million to $\$ 907$ million. This exposes DOE to greater cost risk due to this increased uncertainty. See Figure 3. 


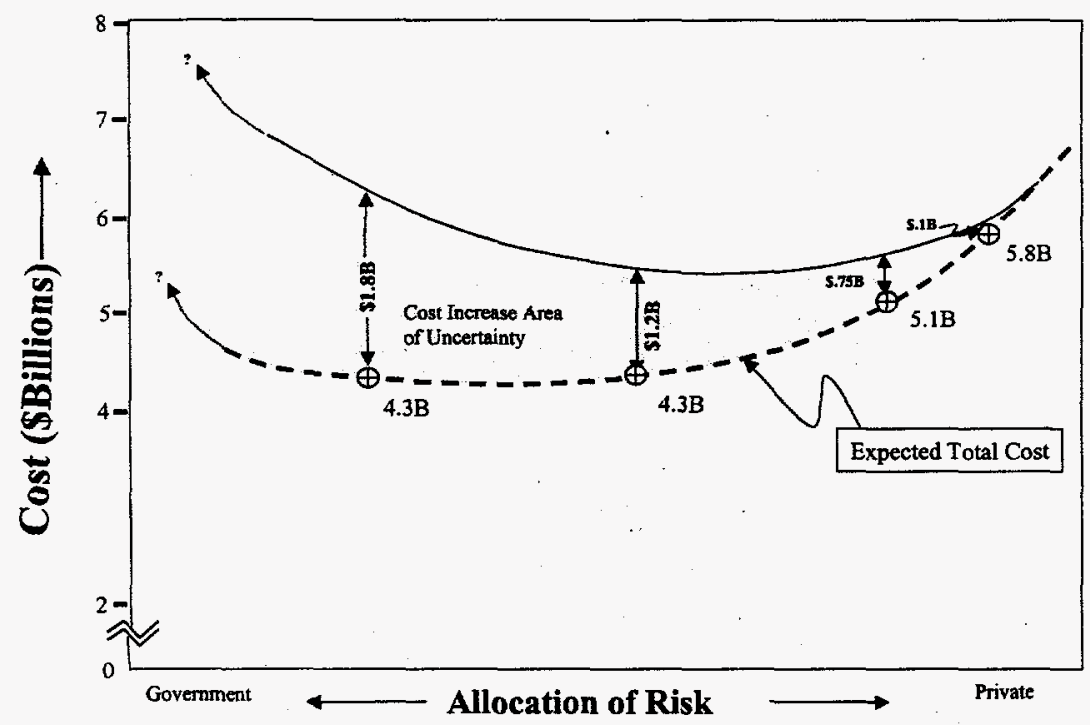

Figure 3. Cost Increase Uncertainty

Note that the pure M\&O case, where DOE is taking virtually all the risk, was not modeled as part of the current analysis. 1996 results indicate an approximate $25 \%$ cost increase above the preferred, minimum total cost, risk allocation for an $M \& O$ to do the work. We believe that the earlier results are still valid.

Conclusions The risk allocation modeling and analysis results confirm that an extended development period, prior to determining the final firm fixed prices for waste processing services, is significantly beneficial to DOE. This period should result in considerable risk reduction and clearer project definition, and thus reduce the total expected costs of the program. However, DOE should seriously consider measures to bound the price during this extended development period. In addition, appropriate risk sharing, particularly in the permitting and performance cap risks, is advantageous. The results further indicate that an optimal allocation of risk would entail a significant equity stake on the part of the contractor and some mix of public and private financing.

These results also confirm that the privatization approach provides cost savings over the other possible risk allocations. 


\section{Distribution}

No. of

Copies

\section{OFFSITE}

N. T. Folta

Office of Project and Fixed Asset

Management, FM-20

U.S. Department of Energy

1000 Independence Ave, S.W.

Washington, D.C. 20585

M. Gaffigan

U.S. General Accounting Office

441 G Street, N.W.

Room 2964

Washington, D.C. 20548

W. S. Howes

Contract Reform \& Privatization Office,

PC-1

U.S. Department of Energy

1000 Independence Ave, S.W.

Washington, D.C. 20585

T. T. Knopnicki,

Office of the Deputy Assistant Secretary for

Environmental Restoration, EM-40

U.S. Department of Energy

1000 Independence Ave, S.W.

Washington, D.C. 20585

K. T. Lang.

Office of Hanford Operations, EM-38

U.S. Department of Energy

19901 Germantown Road

Germantown, MD 20874-1290
No. of

Copies

J. J. Mocknick

Office of Business Management, EM-33

U.S. Department of Energy

19901 Germantown Road

Germantown, MD 20874-1290

J. L. Monhart

Contract Reform \& Privatization Office, PC-1

U.S. Department of Energy

1000 Independence Ave, S.W.

Washington, D.C. 20585

O. H. Paananen

Sandia National Laboratories,

P.O. Box 5800

Albuquerque, NM 87185-0749

G. M. Plummer

Contract Reform \& Privatization Office, PC-1

U.S. Department of Energy

1000 Independence Ave, S.W.

Washington, D.C. 20585

D. Robinson

Office of Management and Budget

725 17th Street, NW

Room 8001

Washington, D.C. 20503

A. F. Tavares

Office of Project and Fixed Asset

Management, FM-20

U.S. Department of Energy

1000 Independence Ave, S.W.

Washington, D.C. 20585

Distr.1 
No. of

Copies

Carlos Ulibarri

School of Business

New Mexico Highlands University

Las Vegas, NV 87701

\section{DOE Richland Operations Office}

P. T. Furlong

W. J. Taylor

A0-21

A0-21
No. of

Copies

26 Pacific Northwest National Laboratory

$\begin{array}{ll}\text { J. Holbrook } & \text { A0-21 } \\ \text { P. Kearns } & \text { A0-21 } \\ \text { G. Mellinger } & \text { A0-21 } \\ \text { M. Scott (2) } & \text { K8-17 } \\ \text { D. Seaver } & \text { K8-03 } \\ \text { M. Triplett } & \text { K9-70 } \\ \text { M. Weimar (12) } & \text { A0-21 } \\ \text { Information Release Office (7) } & \text { K1-06 }\end{array}$

Distr.2 